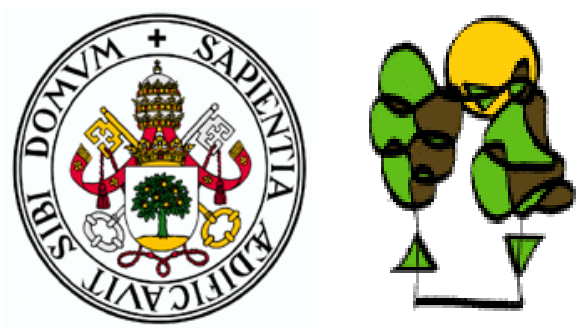

SUSTAINABLE FOREST MANAGEMENT RESEARCH INSTITUTE

\title{
ASSESSMENT OF BIOMASS AND CARBON DYNAMICS IN PINE FORESTS OF THE SPANISH CENTRAL RANGE: A REMOTE SENSING APPROACH
}

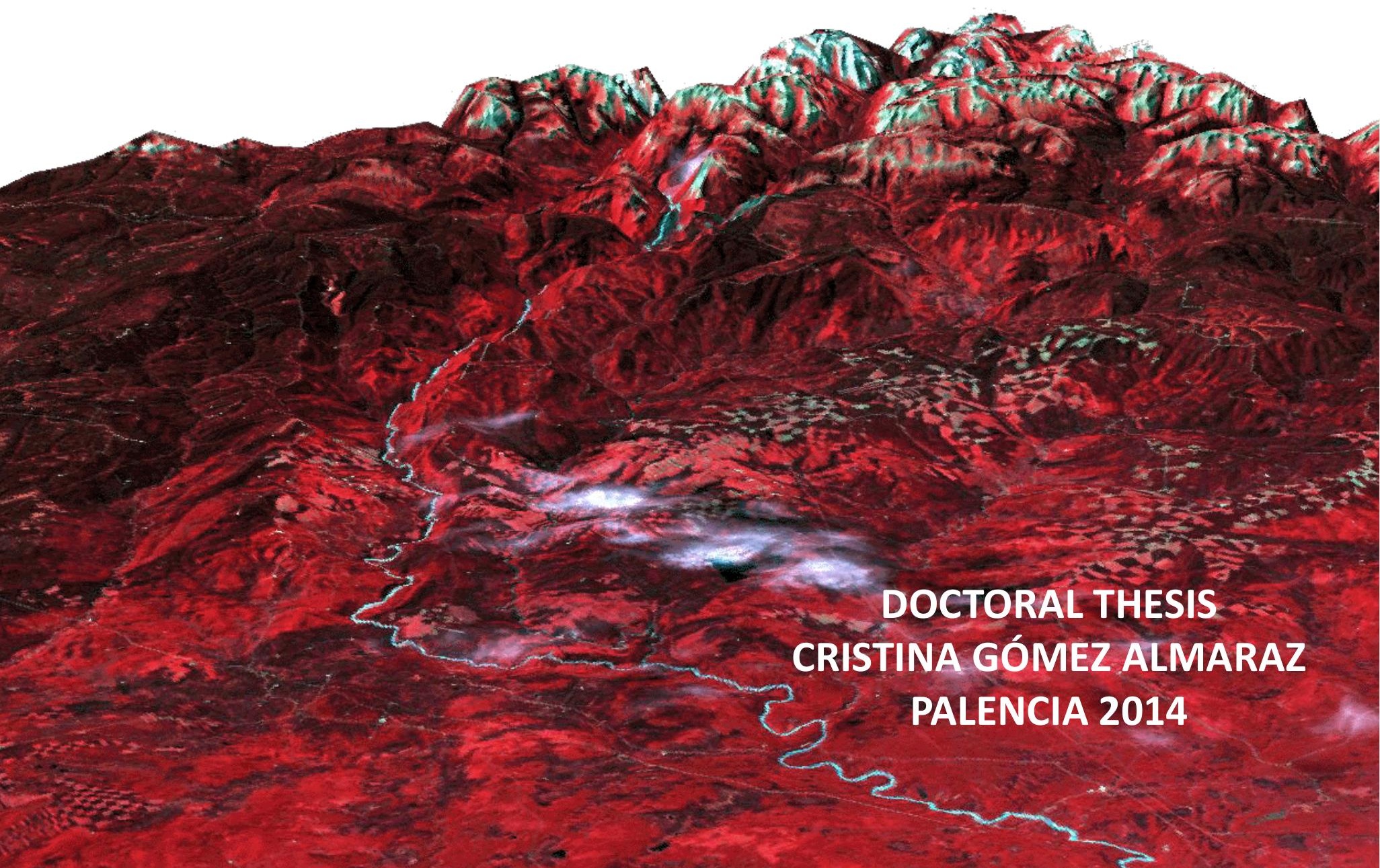





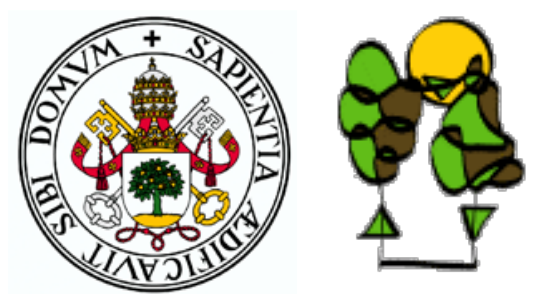

\title{
ASSESSMENT OF BIOMASS AND CARBON DYNAMICS IN PINE FORESTS OF THE SPANISH CENTRAL RANGE: A REMOTE SENSING APPROACH
}

\author{
Doctorate programme on "Conservation and Sustainable \\ Management of Forest Systems"
}

The present thesis fulfils the necessary requisites to obtain the International Doctorate Mention through the University of Valladolid

\section{Cristina Gómez Almaraz}

PhD Supervisor: Dr. José Antonio Delgado de la Mata (UVA-ETSIIAA, Spain)

PhD Co-Supervisor: Dr. Fernando Montes Pita (CIFOR-INIA, Spain) 



\section{TABLE OF CONTENTS}

FOREWORD

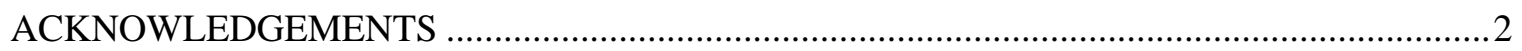

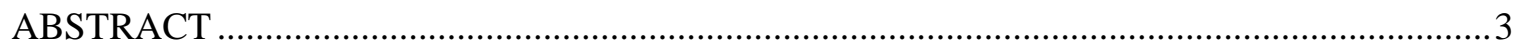

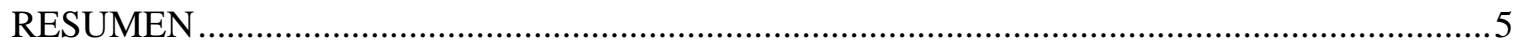

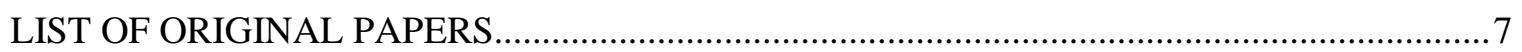

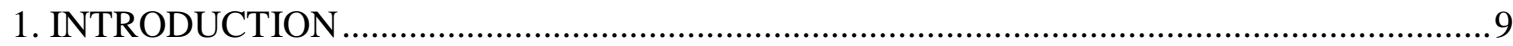

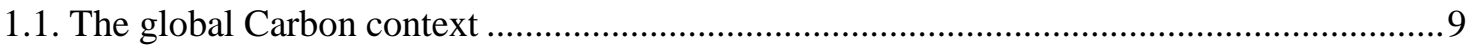

1.2. Spanish forests role in the Carbon context ...................................................................... 11

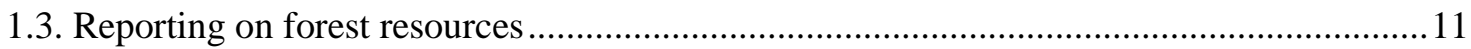

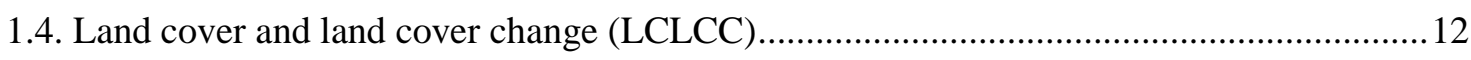

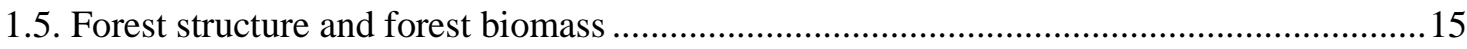

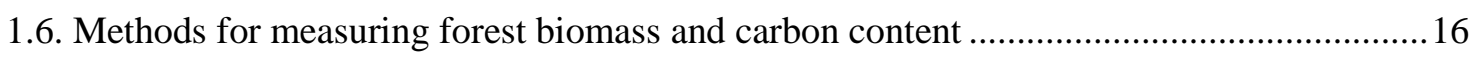

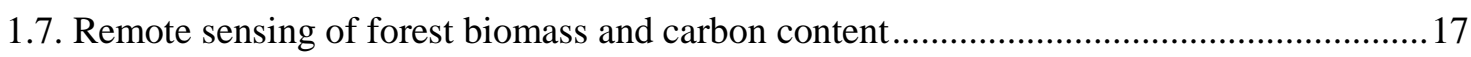

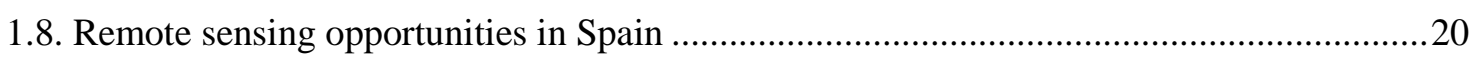

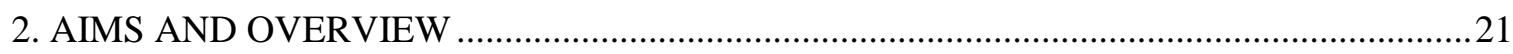

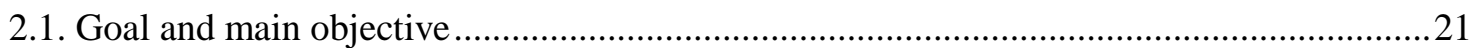

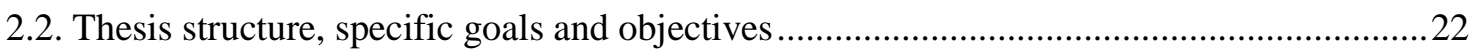

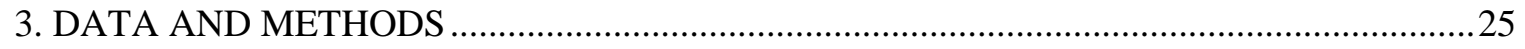

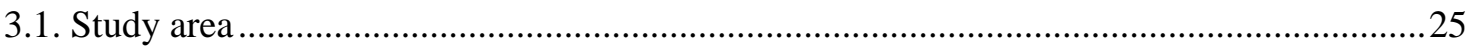

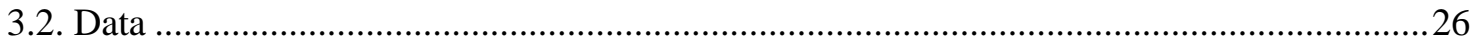

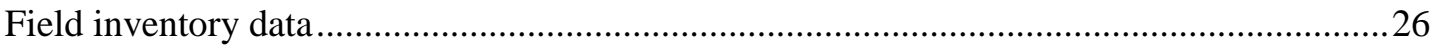

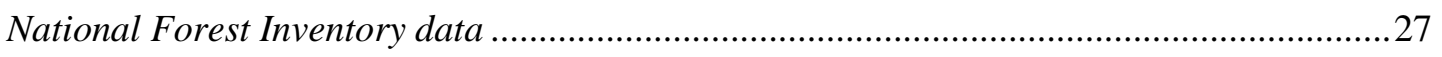

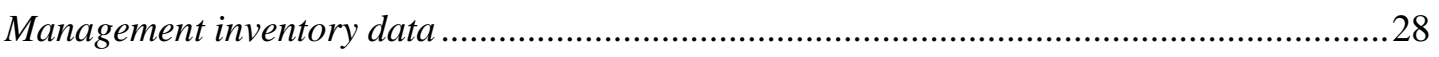

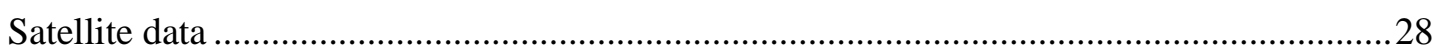

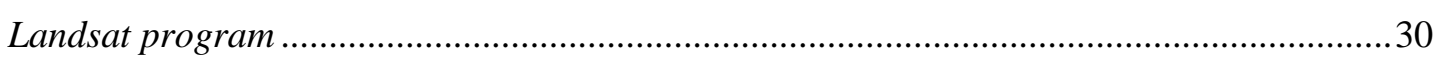

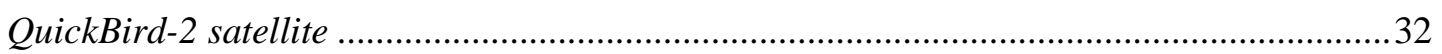

Ancillary data: cartography, aerial photography, digital elevation model .............................33

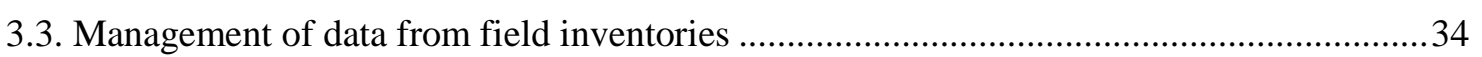

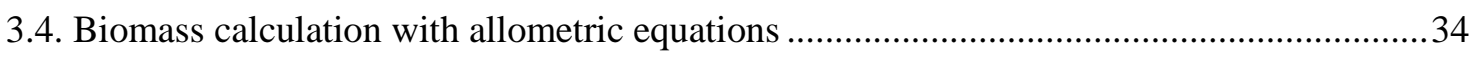

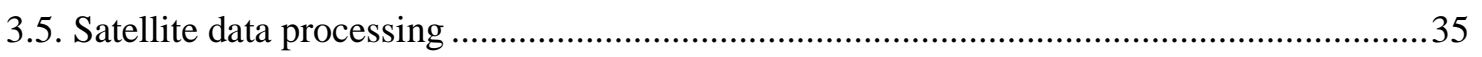

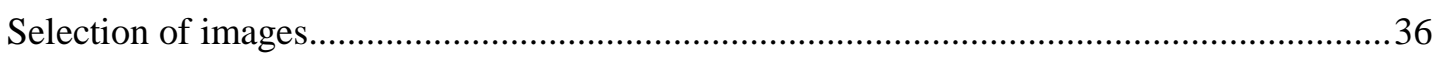

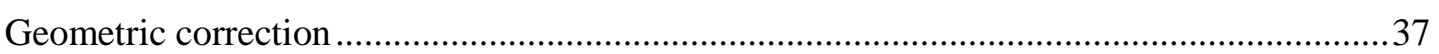




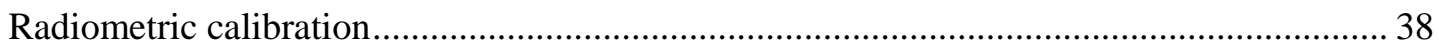

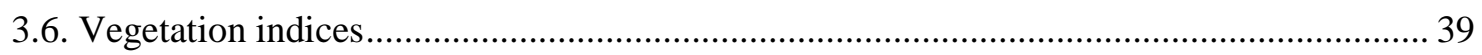

Normalized Difference Vegetation Index ........................................................................ 40

Tasseled Cap Transformation and derived indices ................................................................. 41

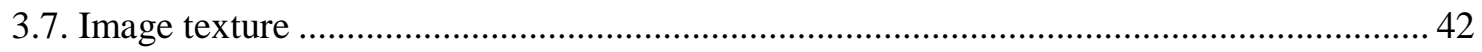

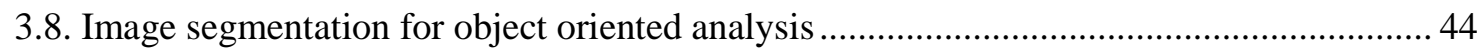

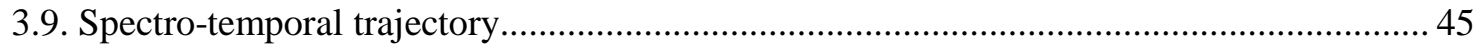

3.10. Data analysis techniques for exploration, characterization, and modelling ...................... 46

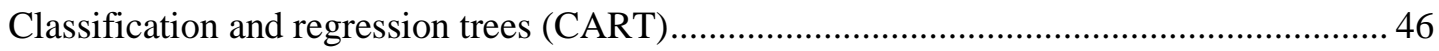

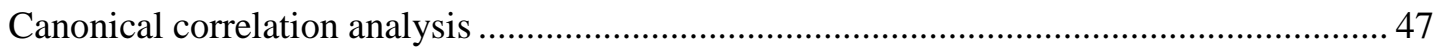

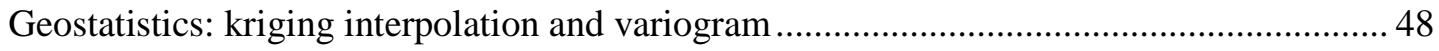

Moran Index for analysis of spatio-temporal correlation.......................................................... 49

Wavelet transformations for analysis of remotely sensed data ............................................. 51

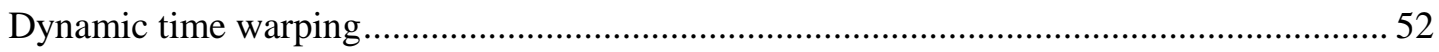

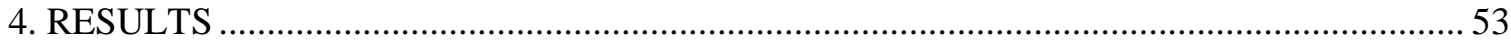

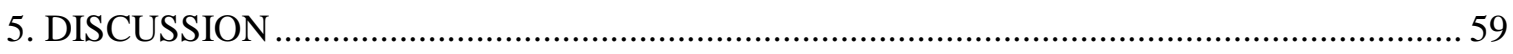

5.1. Location, extent, distribution, and change of pine forests .................................................. 62

5.2. Landscape processes and spatio-temporal associations ....................................................... 63

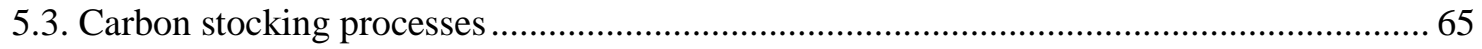

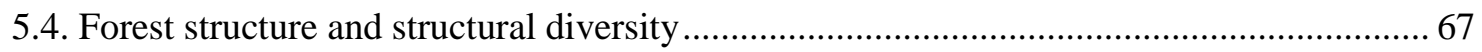

5.5. Historical biomass modelling, mapping, and dynamics..................................................... 71

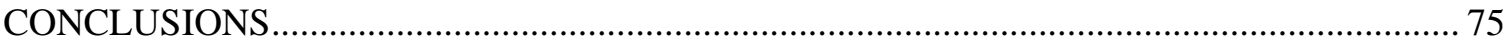

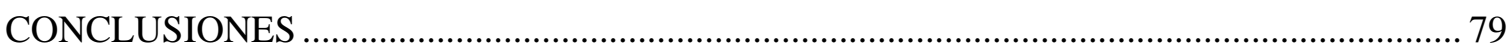

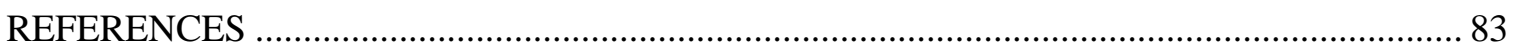

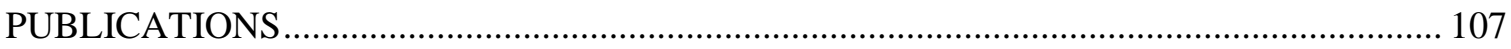

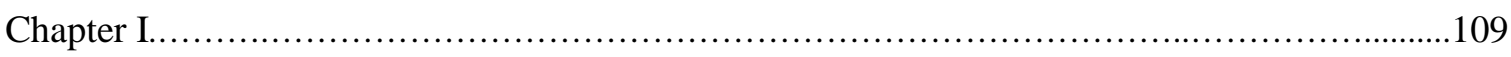

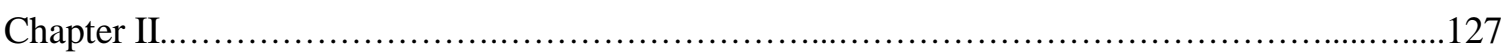

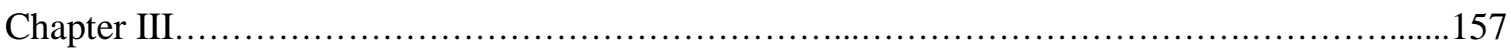

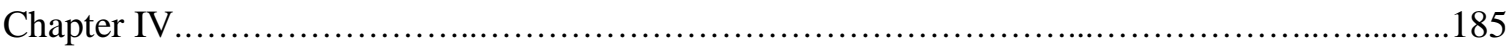

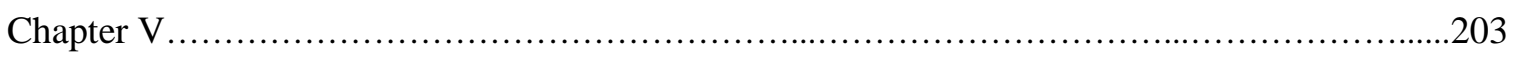




\section{FOREWORD}

According to the Spanish national (R.D. 99/2011, BOE 35/2011) and regional (BOCYL 243/2012) regulations, this doctoral thesis consists of a series of original research papers. Details for identification of these publications are listed below.

An extended introduction is included in this dissertation for contextualization and linkage of the original research publications, and to help understanding the relevance of the findings. A brief description of the main methods provides an overview of the range of techniques applied, and it is not intended to give exhaustive details of the work done, which is properly related in specific chapters (publications). Likewise, the compilation of specific objectives, summary of results and discussion, provide just a synthesized version of the entire work related in the publications. 


\section{ACKNOWLEDGEMENTS}

This work was in part done under the project: 'Estructura, dinámica y selvicultura para la conservación y el uso sostenible de los bosques en el Sistema Central' (VA-096-A05), with funding from Consejería de Educación, Junta de Castilla y León, Plan Regional I+D+I. The Government Related Initiatives Program (GRIP) of the Canadian Space Agency supported the project: "Ecomonitor: Northern Ecosystem Climate Change Monitoring From Space" that enabled implementation of part of this research. Landsat images are available online, provided by the USGS. Field inventory data were kindly provided by Centro de Montes de Valsaín, Consejería de Medio Ambiente y Ordenación Territorial de Castilla y León, and Ministerio de Medio Ambiente (España). 


\section{ABSTRACT}

Forests play a dynamic role in the terrestrial carbon (C) budget, by means of the biomass stock and $\mathrm{C}$ fluxes involved in photosynthesis and respiration. Remote sensing in combination with data analysis constitute a practical means for evaluation of forest implications in the carbon cycle, providing spatially explicit estimations of the amount, quality, and spatio-temporal dynamics of biomass and C stocks. Medium and high spatial resolution optical data from satellite-borne sensors were employed, supported by field measures, to investigate the carbon role of Mediterranean pines in the Central Range of Spain during a 25 year period (1984-2009). The location, extent, and distribution of pine forests were characterized, and spatial changes occurred in three sub-periods were evaluated. Capitalizing on temporal series of spectral data from Landsat sensors, novel techniques for processing and data analysis were developed to identify successional processes at the landscape level, and to characterize carbon stocking condition locally, enabling simultaneous characterization of trends and patterns of change. High spatial resolution data captured by the commercial satellite QuickBird-2 were employed to model structural attributes at the stand level, and to explore forest structural diversity. Aboveground biomass (AGB) was calculated retrospectively at specific dates (1990 and 2000) with modelled temporal trajectories of spectral indices, and maps were produced with $30 \mathrm{~m}$ spatial resolution depicting biomass, biomass change, and measures of uncertainty, from which carbon budgets were calculated.

Results indicate that the area occupied by pines in the Central Range of Spain fluctuated during period 1984-2009, with a final net increase of 40\%. A global activation of carbon pools was observed, being the area intermittently covered by pines strongly involved in processes of $\mathrm{C}$ exchange, while the permanent pines had a near to neutral net $\mathrm{C}$ character. The temporal character of local carbon fluxes was identified and summarized by date, showing that in 2000 there was a maximum of $33 \%$ of the area in a process of net $\mathrm{C}$ accumulation. A widespread trend to accumulate biomass was confirmed, with $18 \%$ of initial biomass accrued by the pine stable area between 1990 and 2000. On average, these pines accumulated $0.65 \mathrm{t} \mathrm{ha}^{-1} \mathrm{y}^{-1}$ of carbon in the form of AGB between 1990 and 2000, equivalent to $2.38 \mathrm{tha}^{-1} \mathrm{y}^{-1}$ fixation of $\mathrm{CO}_{2}$.

Remote sensing supports and enhances the value of forest inventories based on sample plots for assessment of biomass and $\mathrm{C}$ budgets, complementing rather than substituting 
essential field work. Access to archived historical and contemporary images of high and consistent quality provides opportunities to develop methods for unveiling information related to the development of forest ecosystems that would otherwise remain incomplete or unknown. In addition to international archives of medium spatial resolution images providing data free of cost, like the US Geological Survey and the European Space Agency, the Spanish Plan Nacional de Observación del Territorio acquires national coverage of high spatial resolution imagery annually, that constitutes an opportunity to support the evaluation of the national forest resources for planning and decision making.

Keywords: aboveground biomass, carbon dynamics, remote sensing, forest structure, structural diversity, spectro-temporal trajectory, successional process, modelling, Mediterranean pines, Spain. 


\section{RESUMEN}

Los bosques realizan una función dinámica en el balance de carbono (C) terrestre, a través de las reservas de biomasa y los flujos de C asociados a la respiración y fotosíntesis. La teledetección, combinada con técnicas de análisis de datos, constituye un medio práctico para evaluar el papel de los bosques en el ciclo de carbono, proporcionando estimaciones de la cantidad, calidad, y evolución de la biomasa y reservas de carbono. El objetivo de este trabajo fue el desarrollo y aplicación de técnicas para valorar la función de los pinares del Sistema Central español durante 25 años (1984-2009) en el contexto del carbono. Para ello se utilizaron datos ópticos de media y alta resolución espacial obtenidos con sensores remotos, junto con datos de inventario medidos en campo. Se identificó la localización, extensión, y distribución de los pinares, evaluando los cambios ocurridos en tres subperiodos. Gracias a las series temporales de datos Landsat se desarrollaron técnicas novedosas de procesamiento y análisis de datos para identificar procesos de sucesión forestal a escala de paisaje y para describir el carácter local de los almacenes de carbono, facilitando la caracterización simultánea de los patrones y las tendencias de cambio. Utilizando imágenes de alta resolución espacial obtenidas por el satélite QuickBird-2 se desarrollaron modelos de estructura forestal a escala de rodal y se exploró la diversidad estructural. Se calculó la biomasa aérea de forma retrospectiva para los años 1990 y 2000, incorporando trayectorias espectrales como variables dinámicas en los modelos de estimación. Finalmente se desarrolló cartografía ráster (resolución 30 m) de biomasa aérea y cambio de biomasa, junto a valores de la incertidumbre asociada. A partir de estos mapas se calcularon valores totales de acumulación y flujo de carbono.

Los resultados indican que el área ocupada por pinares en el Sistema Central español fluctuó durante el periodo 1984-2009, con un incremento final neto del 40\%. Se observó una activación generalizada de los almacenes de carbono, estando el área con cobertura intermitente de pinar fuertemente involucrada en procesos de intercambio de $\mathrm{C}$, mientras el área con cobertura estable tuvo un comportamiento neto casi neutro. El carácter de los flujos locales de carbono resumido por fechas demostró que en 2000 más de un tercio de la superficie considerada estaba acumulando carbono de forma neta. Se confirmó una tendencia global de acumulación de biomasa: entre 1990 y 2000 el área de pinar permanente acumuló el equivalente al 18\% de su biomasa inicial. Como media, la biomasa 
aérea de estos pinares almacenó $0.65 \mathrm{t} \mathrm{ha}^{-1} \mathrm{a}^{-1}$ de carbono entre 1990 y 2000, equivalente a la fijación de $2.38 \mathrm{t} \mathrm{ha}^{-1} \mathrm{a}^{-1}$ de $\mathrm{CO}_{2}$.

La teledetección complementa y realza el valor de los inventarios forestales basados en el muestreo de parcelas para la estimación de biomasa forestal y reservas de C. El acceso a archivos de imágenes históricas y contemporáneas ofrece la oportunidad de utilizar cuantiosos datos y desarrollar métodos que ayudan a generar información relacionada con el desarrollo forestal, de otra manera inexistente o incompleta. Además de los archivos de imágenes de media resolución espacial del US Geological Survey (USGS) y la Agencia Espacial Europea (ESA), libres de coste económico, la adquisición por parte del Plan Nacional de Observación del Territorio (PNOT) de una cobertura anual con imágenes de alta resolución espacial, constituye una oportunidad de respaldar la estimación de los recursos forestales nacionales para la planificación y los procesos de decisión.

Palabras clave: biomasa forestal aérea, carbono, teledetección, estructura forestal, diversidad estructural, trayectoria espectro temporal, proceso evolutivo, modelización, pinares mediterráneos, España. 


\section{LIST OF ORIGINAL PAPERS}

- Gómez, C., White, J.C., Wulder, M.A. 2011. Characterizing the state and processes of change in a dynamic forest environment using hierarchical spatiotemporal segmentation. Remote Sensing of Environment, 115 (7), 1665-1679. (DOI: http://dx.doi.org/10.1016/j.rse.2011.02.025)

- Gómez, C., Wulder, M.A., White, J.C., Montes, F., Delgado, J.A. 2012. Characterizing 25 years of change in the area, distribution, and carbon stock of Mediterranean pines in Central Spain. International Journal of Remote $\begin{array}{llll}\text { Sensing. } & 33 & \text { (17), } & \text { 5546-5573. }\end{array}$ http://dx.doi.org/10.1080/01431161.2012.663115)

- Gómez, C., Wulder, M.A., Montes, F., Delgado, J.A. 2012. Modeling Forest Structural Parameters in the Mediterranean Pines of Central Spain using QuickBird-2 Imagery and Classification and Regression Tree Analysis (CART). Remote Sensing. 4 (1), 135-159. (DOI: http://dx.doi.org/10.3390/rs4010135)

- Gómez, C., Wulder, M.A., Montes, F., Delgado, J.A. 2011. Forest structural diversity characterization in Mediterranean pines of Central Spain with QuickBird-2 imagery and canonical correlation analysis. Canadian Journal of Remote Sensing, 37 (6), 628-642. (DOI: http://dx.doi.org/10.5589/m12-005)

- Gómez, C., White, J.C., Wulder, M.A., Alejandro, P. Historical forest biomass dynamics modelled with Landsat spectral trajectories. ISPRS Journal of Photogrammetry and Remote Sensing (accepted January, 2014) 
Assessment of biomass and carbon dynamics in pine forests of the Spanish Central Range: a remote sensing approach 


\section{INTRODUCTION}

\subsection{The global Carbon context}

Concern about widespread instability of ecosystems, presumably affected by changes in atmospheric composition and gas circulation, has increased since the last decades of the $20^{\text {th }}$ century. Common distress has triggered the advance of a large-scale scientific framework, aiming to understand climate oscillations and to identify the factors involved. The cyclic flow and the balance of atmospheric gases, carbon dioxide, nitrous oxide, ozone, and methane, have been recognized of particular relevance.

Forests play an important role in the terrestrial carbon budget (FAO, 2010; IPCC, 2007), with an estimated annual net carbon uptake equivalent to $26 \%$ of the current human fossil emissions (Pan et al., 2011). As part of the photosynthesis, trees and shrubs absorb carbon dioxide $\left(\mathrm{CO}_{2}\right)$ from the atmosphere and fix carbon by accumulation in the form of biomass. A fraction of the in-taken carbon is outsourced in the continuous respiratory process, and all can be released in the processes of combustion (Körner et al., 2003) or decomposition (Krankina and Harmon, 1995). The net balance of respiration and primary production determines the overall quality of a forest as a carbon sink or carbon source (Law et al., 1999) and it is intimately related to age and development stage, health condition, and structural characteristics (Brown, 2002; Goward et al., 2008).

The uptake of $\mathrm{CO}_{2}$ by land sinks is not currently quantified with adequate accuracy (LeQuéré et al., 2009). Significant uncertainties in carbon (C) budgets exist related to imprecise estimates of biomass location and biomass change (Houghton, 2005). Furthermore, for prediction of future carbon scenarios, the gap of knowledge about prospective efficiency of natural sinks constitutes an important hitch (LeQuéré et al., 2012). The subsistence of uncertainties in $C$ budgets motivates international collaboration and establishment of multidisciplinary working programs, which aim to obtain harmonized assessments of the global C balance. The Global Carbon Project (GCP) was established in 2001 to set up a framework for international coordinated research and observation, aiming to develop a complete picture of the global C cycle, including biophysical and human interactions. Additionally, and complementary to the GCP, the Integrated Global Carbon Observations (IGCO) system coordinates networks of systematic in situ and remote measurements of C fluxes, pools, and processes. IGCO's goals are: to provide long-term 
observations required to improve understanding of the present state and future performance of the global $\mathrm{C}$ cycle, and to monitor and assess the effectiveness of carbon sequestration and/or emission reduction activities on global atmospheric $\mathrm{CO}_{2}$ levels, including attribution of sources and sinks by region and sector. Collaborators of the GCP such as CarboEurope, the North American Carbon Plan, or the Australian National Carbon Accounting Project, provide regional contributions with scientific understanding of sources, sinks, and changes in carbon stocks.

At regional and local scales, knowledge of forest $\mathrm{C}$ dynamics is relevant for marketing and management decisions, and for calibration of larger scale estimations. Modelling and estimation of forest carbon dynamics at medium scale is in continuous development, with work done in all terrestrial forested biomes (Table 1). Field data from national forest inventories constitute a main source of information for regional reports (e.g. Mäkipää et al., 2008; Liski et al., 2006) and remotely sensed data sources have become irreplaceable for this purpose (Lu, 2006).

Table 1. Examples of estimation and mapping of $\mathrm{C}$ dynamics and stocks at regional scale in different biomes.

\begin{tabular}{llll}
\hline Biome & Work & Area location & Goal \\
\hline \multirow{2}{*}{ Boreal } & Chen et al., 2000 & Canada & C dynamics \\
\cline { 2 - 4 } & Liski et al., 2003 & Eurasia, America & C stocks \\
\hline \multirow{2}{*}{ Temperate } & Fang et al., 2001 & China & C dynamics \\
\cline { 2 - 4 } & Goward et al., 2008 & USA & C stocks \\
\hline \multirow{2}{*}{ Tropical } & Asner, 2009 & Brazil & C dynamics \\
\cline { 2 - 4 } & Baccini et al., 2008 & Africa & C stocks \\
\hline
\end{tabular}

At the landscape level, the net exchange of carbon in a forest ecosystem is strongly controlled by the spatial distribution of stand age, structure, and condition (Goward et al., 2008). Integrating the dynamics of all stands with spatial data reporting on structure, age, and their distribution is necessary for the assessment of carbon budgets (Song and Woodcock, 2003). Unfortunately, the general lack of accurate spatial data regarding forest biomass is one of the most persistent uncertainties concerning $\mathrm{C}$ budgets (Harrel et al., 1995). Intense research is currently ongoing to mitigate this lack of information (e.g. Powell et al., 2010; Sales et al., 2007). 


\subsection{Spanish forests role in the Carbon context}

The Spanish forests currently cover 18.5 million ha, and perform an annual C uptake equivalent to $24 \%$ of the country fossil emissions (Montero and Serrada, 2013). As signatory country of the Kyoto Protocol, Spain is committed to provide data to establish the level of C stocks in 1990 and to enable an estimation of changes in carbon stocks in subsequent years (UNFCCC, 1997). For the post-Kyoto era, advanced carbon estimation methodologies are recommended to provide accurate, transparent, and reliable data to serve as a basis for market tools and international carbon policymaking (Zhang et al., 2012).

Variations in the Spanish forests $\mathrm{C}$ pools in relation to land use change are typically associated with reforestation of agricultural land. Carbon stocks in stable forest areas are modified by fire events, harvesting, recruitment, natural growth, and improvement of forest quality (MMA, 2002). Measurements acquired by the Spanish National Forest Inventory are currently the main source of data for calculation and evaluation of forest $\mathrm{C}$ balances at national level (MMA, 2002; González-Alonso, 2006) and regionally (e.g. Herrero and Bravo, 2012).

\subsection{Reporting on forest resources}

Forest stakeholders are obliged to report locally, nationally, and internationally about the state and condition of ecosystem resources, in order to meet management requirements and conservation commitments (Wulder et al., 2008a). The extent and distribution of forest stands, the biomass content, carbon sources, sinks and balances, species diversity, and changing dynamics, are typical features requiring characterization (Tomppo et al., 2010). Sustainable management is based on informed decisions about assets, and requires periodic evaluation for updating of the coverage, structure, and condition of forests resources (McDonald and Lane, 2004; Siry et al., 2005).

As regards to conservation, signatory countries of the United Nations Framework Convention on Climate Change (UNFCCC) are committed to regularly update an inventory of $\mathrm{CO}_{2}$ and other greenhouse gas emissions using comparable methods (Houghton et al., 1997). Party countries ratifying the Kyoto Protocol (1997), Spain amongst them, are required to reduce their 1990 level of human induced carbon emissions, 
with an option to trade part of this reduction with the conservation and enhancement of forestry resources through activities such as afforestation and reforestation (Patenaude et al., 2005). Forests have therefore to be monitored to account for any gains and losses in extent, and for changes in structure and condition that might impact carbon accounting. Additionally, international carbon credit trading schemes are in development, (Gibbs et al., 2007) and require accurate carbon stock estimation. Other international treaties, like the Biodiversity Convention or the World Heritage Convention, oblige countries to report regularly on changes in forest characteristics such as total forest area, woody biomass, or diversity of tree species (Andersson et al., 2009). Assessment of these changes for reporting at the national or regional level necessitates reliable and cost effective methods for spatially explicit monitoring over large areas (Krankina et al., 2004).

\subsection{Land cover and land cover change (LCLCC)}

Land cover is fundamental information for management of resources at medium to large scale (Smith, 2008). Identification of land cover type is the first step in any C assessment program (Andersson et al., 2009). The extent and spatial distribution of forests are naturally modified by disturbance agents such as fire, windstorm, or flood (Foster et al., 1998), and also by human-induced activities such as harvesting or plantation (Hannah et al., 1994). Land cover changes derived from afforestation or deforestation may turn the character of an area from net carbon source to net carbon sink or vice versa, and therefore they are significant events in the C budget (Houghton, 1999; Houghton et al., 2012).

To assess changes of land cover at medium and large scale, satellite remotely sensed data is a long-standing source of information with demonstrated capability (Coppin et al., 2004). When used synergistically with other sources of data, remote sensing technology is adequate to evaluate changes in land cover use, as required by the Kyoto Protocol (KP) (Patenaude et al., 2005). Since only the human induced land cover change episodes report to the KP, these changes require verification with contemporary data (Rosenqvist et al., 2003). A host of sensors onboard satellite platforms are well suited for detection of land cover types, providing consistent and repeatable measurements at an appropriate scale (Verbesselt et al., 2010). Optical sensors like SPOT VEGETATION and MODIS have been widely used for this purpose (Homer et al., 2001; Guindon and Edmonds, 2002; Potapov et al., 2008; Wulder et al., 2008b). The Landsat program has been during decades 
the gold-standard for land cover classification (Cohen and Goward, 2004) and change detection (Wulder et al., 2008c), thanks to a suitable combination of spatial resolution (30 $\mathrm{m})$, revisit period (16 days), and wide spatial coverage (185 km by $185 \mathrm{~km}$ ). With a long history of near continuous imagery acquisition of the Earth's surface starting in 1972 (Leimgruber et al., 2005), Landsat archival imagery is adequate for the establishment of a 1990 baseline as required by the KP, and for monitoring change with calibrated imagery.

Ongoing operational land cover change detection programs at national level have a main focus on forest change, and rely on Landsat imagery with support of data from other programs (Hansen and Loveland, 2012). Table 2 offers an overview of relevant international programs dedicated to LCLCC detection. 
Table 2. Overview of international programs dedicated to land cover and land cover change detection.

\begin{tabular}{|c|c|c|}
\hline \multirow{2}{*}{ Product } & \multicolumn{2}{|l|}{ Description } \\
\hline & Producer & Images \\
\hline \multirow{3}{*}{$\begin{array}{l}\text { CLC2000 } \\
\text { CLC90-2000 } \\
\text { (CORINE Land Cover) }\end{array}$} & \multirow{2}{*}{\multicolumn{2}{|c|}{$\begin{array}{l}\text { Map of land cover in } 29 \text { countries and changes (at least } 5 \text { ha) } \\
\text { between } 1990 \text { and } 2000\end{array}$}} \\
\hline & & \\
\hline & $\begin{array}{ll}\text { Europe } & \text { EEA and JRC }\end{array}$ & Landsat \\
\hline \multirow{2}{*}{$\begin{array}{l}\text { PRODES } \\
\text { (Program for Deforestation } \\
\text { Assessment in the Brazilian Legal } \\
\text { Amazonia) }\end{array}$} & \multicolumn{2}{|c|}{ Deforestation maps and annual statistics of the Legal Amazon } \\
\hline & Brazil & Landsat \\
\hline \multirow{2}{*}{$\begin{array}{l}\text { LCCP } \\
\text { (Land Cover Change Project) }\end{array}$} & \multicolumn{2}{|c|}{$\begin{array}{l}\text { Monitors vegetation with a backdating strategy to initial date } \\
1972\end{array}$} \\
\hline & Australia $\quad$ NCAS & Landsat \\
\hline \multirow{2}{*}{$\begin{array}{l}\text { NLCD } 2006 \\
\text { (National Land Cover Database) }\end{array}$} & \multicolumn{2}{|c|}{$\begin{array}{l}\text { Land cover map and map of change at national scale with high } \\
\text { temporal ( } 5 \text { years) resolution representing change since } 2001\end{array}$} \\
\hline & USGS & Landsat \\
\hline \multirow{2}{*}{$\begin{array}{l}\text { EOSD } \\
\text { (Earth Observation for Sustainable } \\
\text { Development of Forests) }\end{array}$} & \multicolumn{2}{|l|}{ Forest land cover map } \\
\hline & NRCAN & Landsat \\
\hline \multirow{2}{*}{$\begin{array}{l}\text { GLC2000 } \\
\text { (Global Land Cover) }\end{array}$} & \multicolumn{2}{|c|}{$\begin{array}{l}\text { Global land cover database produced by coordinating } 30 \\
\text { research partners }\end{array}$} \\
\hline & Global & $\begin{array}{l}\text { SPOT } \\
\text { VEGETATION }\end{array}$ \\
\hline \multirow{2}{*}{ FAO Africover } & \multicolumn{2}{|l|}{ Regional land cover map } \\
\hline & Africa $\quad$ GOFC-GOLD & Landsat \\
\hline \multirow{2}{*}{ FAO Asiacover } & \multicolumn{2}{|l|}{ Regional land cover map } \\
\hline & $\begin{array}{ll}\text { Asia } & \text { GOFC-GOLD }\end{array}$ & ALOS-AVNIR \\
\hline
\end{tabular}

Note. CORINE: Coordination of Information on the Environment; EEA: European Environment Agency; JRC: Joint Research Centre; INPE: National Institute for Space Research; NCAS: National Carbon Accounting System; USGS (United States Geological Survey); NRCAN: Natural Resources Canada; SPOT: Satellite Pour l'Observation de la Terre; GOFC-GOLD: Global Observation of Forest and Land Cover Dynamics; ALOS-AVNIR: Advanced Land Observation Satellite-Advanced Visible and Near Infrared

Regional maps produced with independent classification schemes are difficult to compare. To enable objective international comparison of land cover state and changes, FAO developed a standard classification scheme, the Land Cover Classification System (LCCS) (Di Gregorio and Jansen, 2000) that is being used by a growing number of international projects (e.g. GLC, 2000) (Bartholomé and Belward, 2005). Moreover, a number of 
countries have translated their existing land cover legends to align with the LCCS system (Latham, 2008).

For assessment of land cover change with digital image processing, a variety of techniques have been developed (Singh, 1989; Coops et al., 2006) and classified in scientific literature reviews according to different criteria (Coppin, 2004; Lu et al., 2004; Hussain et al., 2013). Common approaches for assessment of land cover change include: image algebra (Jensen and Toll, 1982), regression or correlation (Jha and Unni, 1994), statistical techniques (White et al., 2011), post classification comparison (Lyons et al., 2012), and the combined analysis of data in a GIS (Petit and Lambin, 2001). Change can be spatially evaluated with pixel or object based approaches, either kind of methods with particular strengths (Hussain et al., 2013). Successful implementation of any of these techniques requires identification of real change and discrimination of change artefacts due to seasonality, sun illumination, sensor orientation, and other confounding circumstances (Lu et al., 2004).

\subsection{Forest structure and forest biomass}

Forest structure refers to the vertical and horizontal arrangement of canopies (Coops et al., 2007), that is, the distribution of heights and spacing of trees. Several variables are useful to characterize forest structure: individual tree measures of height, diameter, and crown size, collective attributes like number of trees and spacing, and statistical averages or indicators of variability. Some structural parameters can be directly measured in ground plots (e.g. diameter) for inventory, other parameters can be modelled from direct measurements (e.g. volume). By means of wall-to-wall remotely sensed observations and statistical methods, structural parameters may be estimated over large areas (Tomppo et al., 2002; McRoberts and Tomppo, 2007).

Forest biomass is the organic matter weight of the above ground (i.e. stem, branches, and leaves) and below ground (i.e. radical system) portions of trees and shrubs (Montero et al., 2005). Structure and above ground biomass (AGB) are essential features for the assessment of forest productivity (Soenen et al., 2010), for modelling fire risks (Narayan et al., 2007), determining carbon budgets (Kurz and Apps, 1999), and selecting management options (Zianis et al., 2005).

Monitoring changes in the amount and spatial distribution of forest biomass and carbon stocks is required for the sustainable management of forest resources (Tan et al., 2007; 
Herrero and Bravo, 2012) and necessary to get some understanding of the forest carbon budget. Measures of biomass can be readily transformed into values of $\mathrm{C}$ content through species-specific or general conversion factors, being the relation of 0.5 carbon to biomass (Kollmann, 1959; Penman et al., 2003) widely used. Consequently, maps of forest biomass and biomass change enable spatially explicit estimates of forest carbon storage and fluxes (Blackard et al., 2008).

Biomass and carbon temporal dynamics in forests are naturally ruled by successional processes (Pregitzer and Euskirchen, 2004) and structural stage (Harmon et al., 1990). Forest regeneration results in sequestration of $\mathrm{C}$ into the ecosystem, with young and vigorously growing trees incorporating biomass in above and below ground fractions. As regenerating stands approach maturity, the size of the vegetation $C$ pool may eventually reach its maximum stock level, with the age at which a forest becomes a net carbon sink varying according to forest type, site productivity, and other factors (Birdsey et al., 2006; Goward et al., 2008). Management systems organizing the structure and age distribution of forest stands through space and time, and disturbances that modify the natural forest successional course are crucial factors affecting forest biomass and carbon dynamics. Quantifying the variability of forest biomass over large spatial extents and long periods of time is essential for accurate carbon accounting (Goetz et al., 2009; Houghton, 2005).

\subsection{Methods for measuring forest biomass and carbon content}

Currently the main existent methods for accurate assessment of wood volume, biomass, and carbon content in forests rely on sample plots measurements (Brown, 2002). Basic attributes measured directly on trees, such as height and diameter at breast height, can be readily converted to AGB through allometric regression equations (for individual trees), or through biomass expansion factors (for stand-like areas). As many other countries, the Spanish National Forest Inventory (NFI) has an established systematic network of permanent plots re-measured periodically (Bravo et al., 2002). The NFI provides reliable information on stocks, and also on growing rates, gains and losses, to estimate stock changes at national level as recommended by the IPCC (2003) (Mäkipää et al., 2010). Species specific allometric equations for coniferous and broadleaved native species have been developed by Montero et al. (2005) and by Ruiz-Peinado et al. (2011). These equations were derived with data measured in local forests, facilitate assessment of 
most Spanish tree species, and represent a base for extending plot measures to larger spatial units.

Forest inventories are typically designed based on statistical sampling to enable large area knowledge of the variables of interest, in particular to facilitate assessment of biomass and $\mathrm{C}$ resources. However, spatially explicit estimates of AGB over large areas that are derived from traditional field based forest inventories may be incomplete (Du et al., 2011) and limited by the sampling intensity (Wulder et al., 2008b). Carbon accounting approaches requiring periodical reporting might also be limited by the temporal frequency of measurements (Powell et al., 2010).

\subsection{Remote sensing of forest biomass and carbon content}

Remote sensing technologies constitute an effective instrument to evaluate biophysical properties of terrestrial ecosystems, in particular forest structure and biomass. Remote sensing has become the primary data source for biomass estimation ( $\mathrm{Lu}, 2006)$, providing repeat measurements with synoptic view of extensive areas, in digital format and with affordable costs (Bettinger and Hayashi, 2006). Satellite observations contribute to measuring and monitoring carbon stocks by routinely classifying land cover types, extending in situ measurements over larger areas, informing ecosystem models, and through direct relationships between biophysical attributes of vegetation and remotely sensed observations (Goetz and Dubayah, 2011).

Medium spatial resolution (MSR) imagery (10 - $100 \mathrm{~m}$ pixel size) is well suited for characterization of regional ecosystems. The Landsat series of satellites have provided profuse base data in support of ecological assessments, for mapping forested areas, and for estimating wood volume (Trotter et al., 1997; Kajisa et al., 2007), biomass (Zheng et al., 2004; Luther et al., 2006) and carbon stocks (Foody et al., 1996; Turner et al., 2004). Other satellites with similar spectral, spatial, and revisiting characteristics exist (Stoney, 2008) or are expected to be soon in operation (e.g. Sentinel-2) that may provide data to cover potential gaps in the Landsat acquisition (Wulder et al., 2011). High spatial resolution (HSR) imagery ( $<5 \mathrm{~m}$ pixel size) is increasingly available to public use, following the launch of commercial satellites: IKONOS (1999), QuickBird-2 (2001), and GeoEye-1 (2008). The range of applications utilizing HSR imagery grows constantly and 
includes estimation of forest structural parameters (Hirata, 2008; Mora et al., 2010, 2013) and biomass assessment (Greenberg et al., 2005; Proisy et al., 2007).

For estimation of biomass, remotely sensed data can be used with different approaches (Wulder et al., 2008b), based on the assumption of a strong statistical relationship between above ground biomass and the spectral response as captured by the sensor ( $\mathrm{Lu}, 2006)$. Relations can be established directly between ground biomass and spectral response, or indirectly through other estimated attributes such as Leaf Area Index or crown closure. Statistical strategies for establishment of the most reliable relationships include multiple regression, imputation, neural networks, or decision trees. The adequacy of a particular model depends on data availability, desired precision, transparency, and site-specific characteristics (Labrecque et al., 2006). Plot based National Forest Inventories are frequently the source of data for calibration of models (Gallaun et al., 2010), meeting the requirements recommended for modelling: data are representative of all conditions present, and are acquired according to consistent specifications (Duane et al., 2010).

Optical sensors have a recognized and extensively reported limitation in the estimation of some forest biophysical parameters, namely the saturation of measured reflectance at high values of biomass or other estimated variables (Turner et al., 1999; Duncanson et al., 2010). Expected to alleviate to some extent the saturation problem of previous sensors (Wulder et al., 2011), the radiometry of the optical sensor onboard Landsat 8 (launched $11^{\text {th }}$ February 2013), has been improved (data quantized to 12 bit instead of 8 bit) (Irons et al., 2012). Landsat provides a favourable spatial resolution, revisit period, radiometric resolution, and four decades of continuous Earth Observation (EO). Until more promising techniques become operational, Landsat sensors and others alike remain the most useful means for regional estimations of forest attributes.

The development of new technologies to map forest structure and biomass is a priority for remote sensing agencies (Hese et al., 2005; Lefsky, 2010). A range of satellite missions have been planned in the last decades with main goal estimation of biomass and biomass change. NASA's projected mission DESDynI (Deformation Ecosystem Structure and Dynamics of the Ice) (Hall et al., 2011) was intended to include InSAR (Interferometric Synthetic Aperture Radar) and LiDAR (Light detection and ranging) equipment. Unfortunately, this promising mission was cancelled before birth (Goetz, 2011) due to redistribution of funding. BIOMASS is an ESA projected mission conceived to include P- 
band polarimetric SAR equipment with interferometric capability (Le Toan et al., 2011). The advantage of radar technology is the transparency to atmospheric moisture, particularly important in tropical and boreal systems, whereas LiDAR has demonstrated to be highly sensitive to biomass change (Lefsky et al., 2002).

As part of the Global Monitoring for Environment and Security (GMES) programme, a series of Sentinel satellites will commence operational phase in 2014 (Aschbacher and Milagro-Pérez, 2012) providing continuity to SPOT and Landsat-type data. The Sentinel-2 is the optical high-resolution mission for GMES operational services (Drusch et al., 2012). With global coverage, high revisit period (5 days) enabled by dual satellite constellation and a set of narrow bands (12 bit quantization) dedicated to characterization of vegetation, Sentinel-2 will be a good source of data for forestry characterization and monitoring of change. Sentinel data policy is still undefined, but expected to be to allow anybody (individuals and institutions from any part of the World) access to data of some processing level (Aschbacher and Milagro-Pérez, 2012).

Synergistic use of data from passive and active sensors (e.g. LiDAR, radar) has shown promising for improvement of biomass estimations. Combining Landsat with GLAS (Geospatial Laser Altimeter System) data has shown successful to calculate biomass in British Columbia (Duncanson et al., 2010) and forest height in Mississippi (Li et al., 2011) while extending LiDAR estimates of forest parameters with Landsat imagery is becoming frequent at the regional level (Maselli et al., 2011). In spite of the remarkable opportunities offered by remote sensing technology and a continuous improvement of the space (i.e. satellite, sensor) and ground (i.e. processing, distribution) segments, the estimation of AGB is also restricted by uncertainties in the models, requiring further development and refinement (Zhang et al., 2012). Nevertheless, remote sensing is the only feasible means for national level assessments of AGB and carbon, and a growing number of countries are incorporating remote sensing technologies in their National Carbon Accounting Systems (e.g. Indonesia, Australia, USA). 


\subsection{Remote sensing opportunities in Spain}

As part of the Spanish Plan Nacional de Observación Terrestre (PNOT), the Plan Nacional de Teledetección (PNT) is committed to acquiring complete national coverage of high spatial resolution satellite imagery annually (Arozarena, 2008). The acquisition phase started in 2008 (Villa et al., 2009), capitalizing on archival data to backdate the database to 2005 coverage. Initial coverage consists of SPOT 5 HRG XS + P 2.5 m data, and other sensors are being considered for future acquisitions (IGN, 2009). Access to this data source represents a unique opportunity to incorporate HSR into Spanish forest inventories as an operational and low cost data source to meet a range of information needs. The data is to be collected with a primary focus on land-use land-cover change assessment (Villa et al., 2009), but has capacity to generate information for forest monitoring and reporting. Additionally, the PNOT acquires and pre-process abundant medium spatial resolution imagery from the historical Landsat archive, making them available for research, and low spatial resolution data from the AQUA/TERRA MODIS and ENVISAT MERIS sensors. Furthermore, the Plan Nacional de Ortofotografía Aérea (PNOA) compiles LiDAR data (0.5 pulses per square meter) over the entire national territory since 2009 , from which digital elevation products of high resolution are derived. LiDAR and aerial photography are very supportive material for forestry applications (Suárez et al., 2005; Wulder et al., 2008d). The PNT provides opportunities for future work that might be informed by the methods and results of the work developed in this doctoral thesis. 


\section{AIMS AND OVERVIEW}

This thesis focuses on the employment of satellite optical remotely sensed data of medium and high spatial resolution, in combination with field measures, to estimate the content and to assess changes of forest biomass and carbon fluxes over two and a half decades (1984-2009) in pines of the Central Range of Spain. Novel techniques for data processing and analysis are developed and tested in a dynamic forest area in Canada prior to application in the target area. The location, extent, and distribution of pine forests are characterized, and changes occurred during 25 years are evaluated. Capitalizing on temporal series of spectral data, techniques are developed to identify forest successional processes at the landscape level, and to characterize carbon stocking condition locally. In addition to the characterization of trends and patterns of change through temporal derivatives of medium spatial resolution spectral trajectories, an original application of spatial statistics enables explanation of the spatial and temporal association of successional processes. Forest structure is characterized at the stand level, and structural diversity explored with high spatial resolution data captured by the QuickBird-2 satellite. Aboveground biomass (AGB) is calculated retrospectively at specific dates (1990 and 2000) with modelled temporal trajectories of spectral vegetation indices. Maps are produced at $30 \mathrm{~m}$ spatial resolution depicting AGB and change of AGB, providing spatially detailed information and measures of the uncertainty associated, from which carbon budgets are calculated.

\subsection{Goal and main objective}

The goal is to develop and test novel methods for estimation and monitoring of forest biomass and carbon stock dynamics in pines of the Central Range of Spain, combining optical remotely sensed data with field inventory data.

A specific objective is to obtain estimated values of above ground biomass and carbon stored in pine areas of the Central Range of Spain, assessing changes that have occurred in a twenty-five year period (1984-2009). 


\subsection{Thesis structure, specific goals and objectives}

This doctoral thesis is structured into five chapters, each one holding a self-contained investigation published or under review in peer reviewed international journals. Each chapter focuses on different aspects of remote sensing technologies dedicated to the assessment of forest AGB and AGB dynamics: land-cover and land-cover change, distribution and association of state and processes of change over the landscape, forest structure, structural diversity, biomass modelling and mapping. A schematic overview of the main topics covered by each chapter is shown in Figure 1. Table 3 synthesizes the goals and objectives of each chapter.

The main methods applied in this work, main results, some discussion, and conclusions (in English and Spanish) are synthesized and presented prior to the main five chapters that correspond with peer reviewed publications. Each publication is preceded by a summary in Spanish.

\section{FOREST CONDITION}

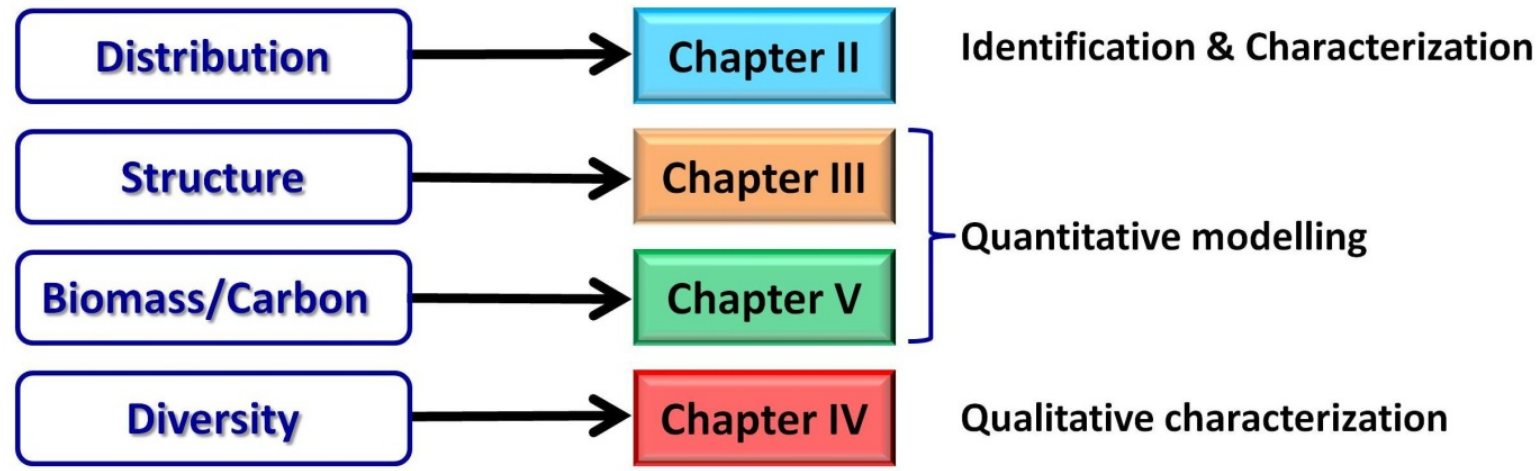

\section{FOREST CHANGE}

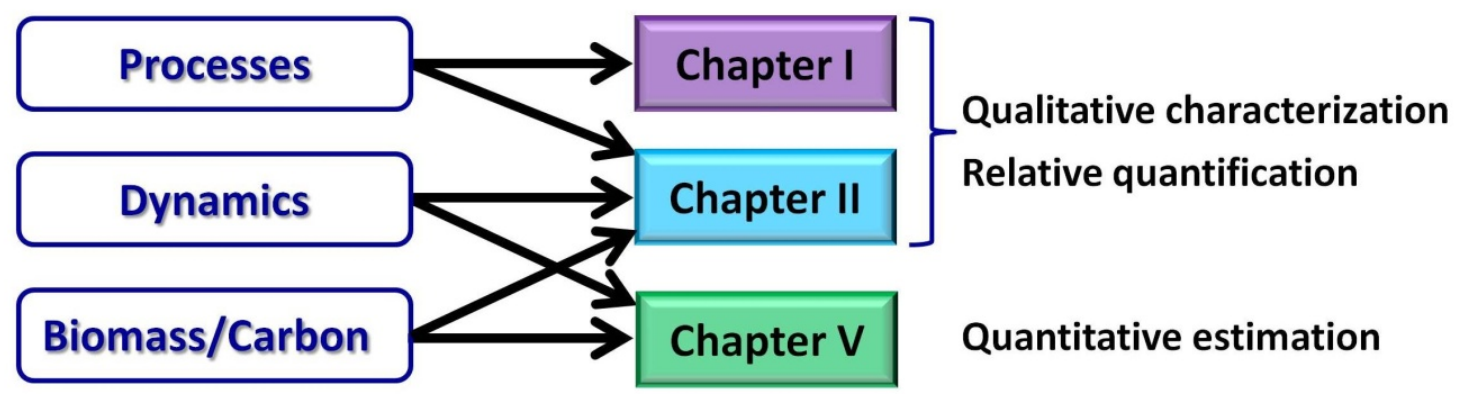

Figure 1. Schematic overview of topics covered in the thesis. 
Table 3. Summary of the goals, specific objectives, and outline of each chapter.

\begin{tabular}{|c|c|c|}
\hline & Goal & Specific objectives \\
\hline & \multicolumn{2}{|c|}{ Overview } \\
\hline \multirow{2}{*}{ 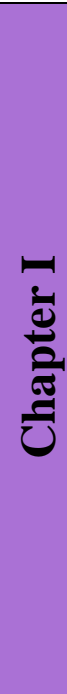 } & $\begin{array}{l}\text { To investigate the capacity of spectral } \\
\text { trajectories generated from a } 35 \text {-year } \\
\text { time-series of Landsat images for } \\
\text { description and analysis of spatially and } \\
\text { temporally diffuse change in a dynamic } \\
\text { forest environment }\end{array}$ & $\begin{array}{l}\text { - To characterize forest landscape change using } \\
\text { Tasseled Cap Transformation derived indices } \\
\text { - To incorporate spatial and temporal properties } \\
\text { into a hierarchical segmentation process to } \\
\text { capture forest landscape-level change } \\
\text { - To analyze the spatial and temporal correlation } \\
\text { of landscape change and processes through } \\
\text { time }\end{array}$ \\
\hline & \multicolumn{2}{|c|}{$\begin{array}{l}\text { A temporal series (35 years) of calibrated and radiometrically normalized Landsat images helps } \\
\text { charactering landscape changes in a very dynamic forest region of Alberta, Canada. Drastic and } \\
\text { subtle processes are described through a new metric originated from the Tasseled Cap } \\
\text { Transformation (TCT) Greenness and Brightness components, the Tasseled Cap Angle (TCA) } \\
\text { and its derivative, the Process Indicator (PI). Simultaneous description of landscape process } \\
\text { and pattern is enabled }\end{array}$} \\
\hline \multirow{2}{*}{ } & $\begin{array}{l}\text { To characterize changes in area, } \\
\text { distribution, and carbon stocking } \\
\text { processes of pines in the Central Range of } \\
\text { Spain during a period of twenty-five years } \\
(1984-2009) \text { with a medium spatial } \\
\text { resolution time series of images from the } \\
\text { Landsat program }\end{array}$ & $\begin{array}{l}\text { - To assess changes in extent of a Mediterranean } \\
\text { forest with a multilevel object oriented } \\
\text { methodology } \\
\text { - To identify with spatial precision the } \\
\text { distribution of pines in the Central Range of } \\
\text { Spain and variations occurring in three sub- } \\
\text { periods } \\
\text { - To characterize carbon stocking areas with the } \\
\text { TCA, assessing trends of change over the } \\
\text { period 1984-2009 }\end{array}$ \\
\hline & \multicolumn{2}{|c|}{$\begin{array}{l}\text { Evaluates the distribution of pine forests in the Central Range of Spain during two and a half } \\
\text { decades (1984-2009), mapping areas permanently covered by pines and areas of change. The } \\
\text { state of development, that is, the closure or density condition is characterized and evaluated at } \\
\text { various key times with the Tasseled Cap Angle (TCA) and changes are assessed with the TCA } \\
\text { derivative, the Process Indicator (PI). The use of these newly derived indices, (TCA and PI) } \\
\text { enables a combined analysis of forest state and stocking process }\end{array}$} \\
\hline 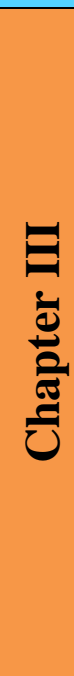 & $\begin{array}{l}\text { To explore the potential of high spatial } \\
\text { resolution (HSR) imagery to characterize } \\
\text { forest structure in Mediterranean pines in } \\
\text { the Central Range of Spain. Motivated by } \\
\text { this purpose the capacity of QuickBird-2 } \\
\text { imagery to model the quadratic mean } \\
\text { diameter, basal area, and number of trees } \\
\text { per unit area at the stand level (as direct } \\
\text { estimators of volume and biomass) is } \\
\text { evaluated }\end{array}$ & $\begin{array}{l}\text { - To model the relation between structural } \\
\text { parameters (quadratic mean diameter, basal } \\
\text { area, and number of stems per hectare) } \\
\text { measured via field sampling and a set of } \\
\text { spectral and spatial variables derived from } \\
\text { QuickBird-2 multispectral and panchromatic } \\
\text { imagery } \\
\text { - To test and verify the ability of Classification } \\
\text { and Regression Trees (CART) as the statistical } \\
\text { technique for modelling structural parameters } \\
\text { - To identify the image derived variables with } \\
\text { the greatest informative capacity in the } \\
\text { modelling of structural parameters, assessing in } \\
\text { particular the inclusion of image textural } \\
\text { metrics in the models }\end{array}$ \\
\hline
\end{tabular}


Investigates the local relationships of variables derived from HSR images with forest structural parameters such as quadratic mean diameter, basal area, and number of trees per unit area, as descriptors of stand density and direct estimators of volume and biomass. Statistical models based on dichotomous relations of images' spectral and spatial features predict forest structural attributes

To assess the potential of high spatial resolution (HSR) imagery to characterize forest structural diversity in Mediterranean pines of the Spanish Central Range
- To determine and quantify the relationships between forest structural diversity measured at the plot level and data captured by a satelliteborne sensor in the form of visible and NIR spectral reflectance as well as spatial combinations of panchromatic reflectance values, as related by texture metrics

- To identify the relative relevance of reflectance measures versus texture metrics in characterizing the forest structural diversity

- To assess how the spectral diversity-structural diversity relationship varies under different conditions of forest density, that is, determine if different relations occur in open versus closed forest conditions

Explores the capacity of HSR data to assess the structural diversity in forest stands of various crown closure conditions. The structural diversity is characterized at the plot level with a linear combination of internal variability of height, bole diameter, and crown diameter measured on the field. At similar spatial level the spectral and textural variability of multispectral and panchromatic imagery are evaluated. The strongest relations between a combination of image variables and a combination of field variables are identified with canonical correlation analysis. The relative importance of spectral and textural attributes in these relations is assessed as a function of stand density

To estimate and map historical AGB (at specific dates in time), as well as a decade of change in AGB, by combining the precision of field measures from a network of NFI plots with the wall-to-wall spatial coverage provided by remotely sensed data
- To explore the relationship between live AGB derived from NFI ground plot measurements and vegetation spectral indices derived from Landsat data

- To model past AGB with historical spectral data, including single-date data and multitemporal trajectories, providing a baseline for comparison with more recent estimations

- To map historical AGB at two dates coincident with NFI rotations (1990 and 2000) and evaluate the distribution of change in view of the uncertainties associated with the process of modelling and mapping

Develops novel methods for spatially explicit assessment of historical biomass and biomass change, based on the linkage between NFI data and archival Landsat imagery. Mathematical transformations of the data system formed by spectral indices and two rounds of NFI data enable derivation of dynamic variables associated to successional processes that happen to be good predictors of biomass. A baseline AGB $_{1990}$ is produced 


\section{DATA AND METHODS}

\subsection{Study area}

The Central Range of Spain is a mountain chain located in the middle of the Iberian Peninsula, separating the North and South plateaus, and with a main SW to NE direction (Figure 2). Its maximum height is reached at Pico Almanzor (Ávila) with $2592 \mathrm{~m}$. As the Spanish plateaus lay at very different elevation, the Central Range base height is $900 \mathrm{~m}$ on the north face and $400 \mathrm{~m}$ on the south face. This height difference has direct weather implications, with generalized milder conditions on southern locations. Rainfall and temperature are very variable: many places on northern expositions receive $1000 \mathrm{~mm} \mathrm{y}^{-1}$ of water, frequently in the form of snow, and average temperatures in some places remain below zero. Soils are predominantly acidic, with abundant granites, gneiss, and shales (Gandullo, 1976; Aparicio and García Cacho, 1984).

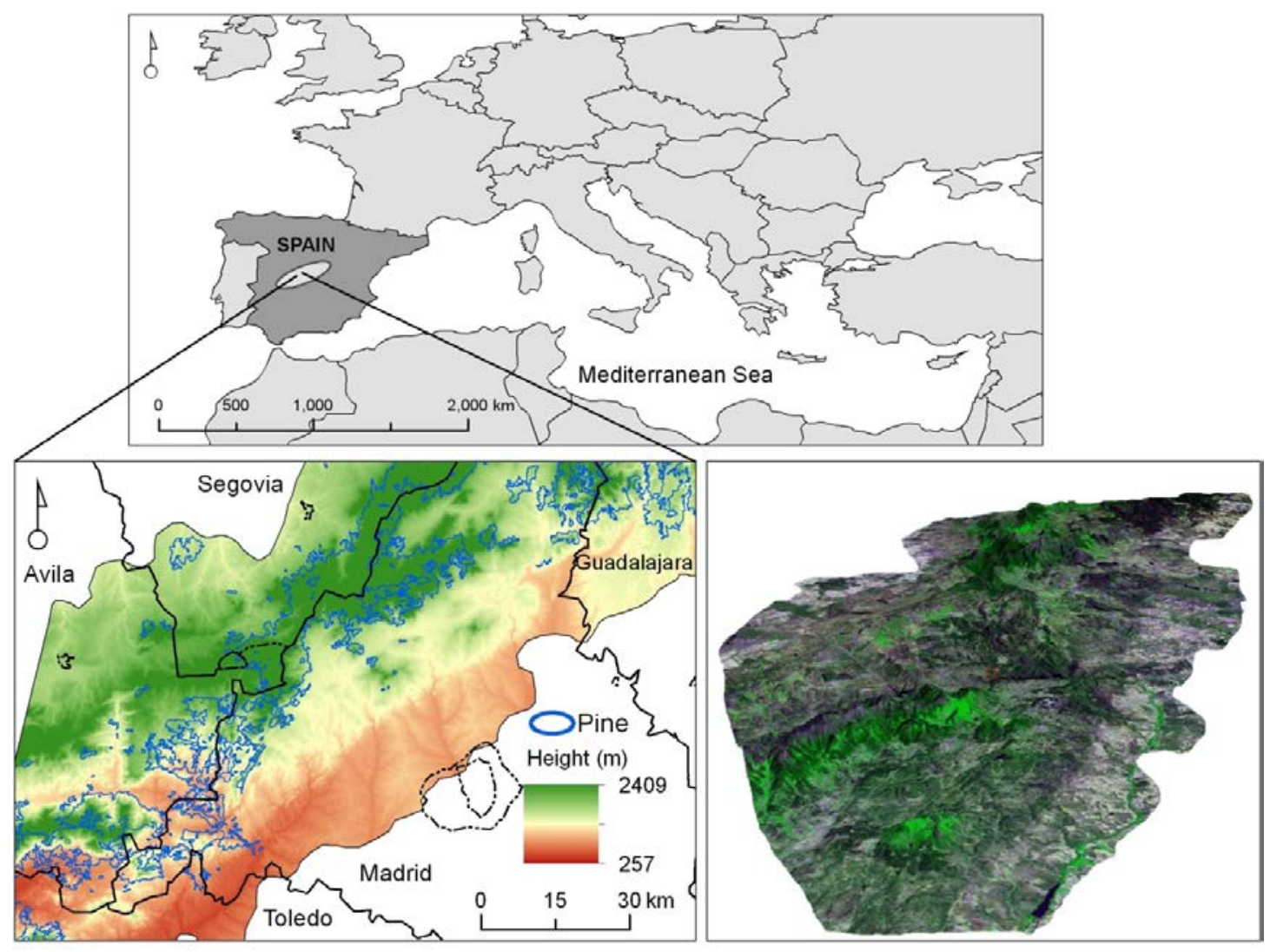

Figure 2. Location of the area of interest in the middle of the Iberian Peninsula. 
Dominant vegetation communities are distributed mainly as a function of altitude. On the lower heights evergreen Holm oaks (Quercus ilex L.), sometimes combined with pines and juniperus, dominate the landscape. Marcescent Pyrenean oaks (Quercus pyrenaica Willd.) occupy areas in the mid heights, and mountain pines are the dominant tree species over 1600 m. Natural and planted pines (P. sylvestris L., P. pinaster Ait., P. nigra Arnold) are the most extended tree species, climbing to elevations of $2000 \mathrm{~m}$, beyond which shrubs (Cytisus sp., Genista sp., Erica sp., Echinospartum sp.) and high altitude meadows are the prevalent vegetation (Rivas-Martínez, 1963).

The area of interest for the work reported in this dissertation covers approximately one million hectares in the Central Range of Spain, occupying part of the Ávila, Segovia, Madrid, Guadalajara and Toledo provinces. It is centred at latitude $40^{\circ} 37^{\prime} 56^{\prime \prime}$ N and longitude $-4^{\circ} 6^{\prime} 47^{\prime}$ ' $E$. Some forests in this region have been subject to a management plan for more than a century, and although punctual socioeconomic circumstances sometimes precluded perfect application (Bravo et al., 2010) forest structure has been modified by silvicultural treatments.

\subsection{Data}

The work reported in this doctoral thesis was supported by data measured on the ground and data sensed remotely. Measures from plot based field inventories served as reference for derivation of statistical models of structure, diversity, and biomass, and in the stages that required accuracy assessment of estimated values. Satellite remotely sensed data was the base for identification and characterization of areas of interest (extent and distribution), for up-scaling modelled parameters to the entire area, and to evaluate trends and patterns of change, as well as absolute values of biomass and carbon content. Ancillary data used include aerial photography at various dates and vector cartography.

\section{Field inventory data}

Field data from plot-based inventories such as the NFI and local management plans were used at various stages of this research, being of particular value in the accuracy assessment during the confidence building stages. Standard forest variables like tree species, number of trees per plot, and diameter at breast height are measured in field inventories, which are typically updated on a decadal basis. 


\section{National Forest Inventory data}

National Forest Inventories are meant to provide information on forest resources at the national level. At the beginning of the $20^{\text {th }}$ century some NFIs introduced statistical sampling as a means for basing their assessments (Tomppo et al., 2010), improving calculations of volume stocks and forest growth. In Spain, the first global inventory was motivated by the need of statistical data at the regional and national levels for policy making, and by the requirement of estimates of forest areas and forest growing stock to guide the establishment of new enterprises (Alberdi Asensio et al., 2010). The NFI1 was conducted between 1965 and 1974, covered the entire national area, and employed provinces (with $\sim 10^{6}$ ha on average) as the assessment units. The methods applied were supported by aerial photography to determine forest/non-forest areas, and a sample of spatially stratified non-permanent ground plots in which tree variables were measured.

Subsequent NFI rotations established a network of permanent plots over a systematic 1x1 $\mathrm{km}$ grid, with four concentric circular subplots of radius $5,10,15$, and $25 \mathrm{~m}$ where trees of different diameter at breast height (dbh) are measured (Bravo et al., 2002). NFI2 was performed between 1986 and 1995, with spatial stratification of plots based on land-use cartography, which had been created for agricultural use. To support NFI3 (1997-2007) digital cartography was generated (Vallejo, 2005), and starting 2005 this NFI rotation incorporated new measures for estimation of biodiversity (e.g. presence of threatened species, volume of dead wood, soil parameters). Currently the fourth rotation of the NFI is in course and expected to conclude in 2018. The NFI4 uses forest dedicated cartography of scale 1:25000 and has consolidated the measurement of biodiversity variables. Application of improved volume and growth equations is under investigation. To control the quality of the inventory measurements, $5 \%$ of the plots are completely re-measured by a checking crew soon after the regular measurement campaign.

Data from five provincial databases (Madrid, Segovia, Toledo, Guadalajara, and Ávila) acquired by NFI2 and NFI3 were used in this work. 
Management inventory data

In forest sites dedicated to production of timber, resin, pine nut or other extractive resources, surveys or inventories are conducted periodically, for evaluation of forest condition and assessment of resources. These inventories are based on interpretation of aerial photography or on ground sample plots, systematically distributed over a stratified grid of variable size that depends on forest condition. Plots are typically smaller than NFI plots but located in a denser network. Attributes measured on the ground include diameter at breast height (dbh), tree height, number of trees, and other features to characterize the forest locally. Advanced technologies providing 3D data from ground measures, like hemispheric photography with the ForeStereo (Montes et al., 2008) and Terrestrial Laser Scanner (Maas et al., 2008) offer a range of opportunities to obtain comprehensive information with some data processing back in the office. From aerial platforms, LiDAR technology is progressively being incorporated into operational inventories (Hyppa et al., 2012) as it is efficient in estimation of forest parameters at the stand level (Næsset, 1997), for delineation of stands (Eysn et al., 2012), and for extraction of accurate elevation models (Fricker et al., 2012). Lately, a number of management instructions in Spanish forests require using these technologies for inventory. Data from two managed sites, Valle de Iruelas (Ávila) and Pinar de Valsaín (Segovia), were used in the work presented in this dissertation, as reference data for modelling structural parameters and structural diversity.

\section{Satellite data}

Satellite Earth Observation (EO) programs dedicated to observe the Earth landscape started in 1960 with the launch of meteorological satellite TIROS-1 (Lauer et al., 1997). A host of satellites have been launched and have orbited the Earth ever since, and forecast is to see more in the future. Sensors onboard satellite platforms are identified as passive, if they capture objects' reflectance of the sun radiation (e.g. optical sensor), or active, when the sensor captures its own radiation as reflected by other object (e.g. LiDAR and radar). According to the pixel size or spatial resolution, (i.e. the minimum spatial unit on the ground for which distinctive data acquisition is possible) (Jensen, 2005), sensors are grouped into low- to very high- spatial resolution (Wulder et al., 2008d) (Table 4). Tradeoffs between sensor resolutions (spatial, temporal, spectral, and radiometric) are key for adequacy to applications (Lefsky and Cohen, 2003). 
Table 4. Examples of EO satellites and sensors of low-, medium-, high- and very high- spatial resolution

\begin{tabular}{|c|c|c|c|c|}
\hline Group & \multicolumn{2}{|c|}{ Satellite (Sensor) } & Spatial resolution (m) & Swath (km) \\
\hline Very high $(<1 \mathrm{~m})$ & \multicolumn{2}{|c|}{ GeoEye-1 } & 1.65 (MS) 0.41 (Pan) & 15.2 \\
\hline \multirow{3}{*}{ High (1-10 m) } & \multicolumn{2}{|c|}{ QuickBird-2 } & 2.44 (MS) 0.68 (Pan) & 16.5 \\
\hline & \multicolumn{2}{|c|}{ Orbview-3 } & $4(\mathrm{MS}) 1(\mathrm{Pan})$ & 8 \\
\hline & \multicolumn{2}{|c|}{ IKONOS-2 } & 4 (MS) 1(Pan) & 13.8 \\
\hline \multirow{11}{*}{ Medium (10-100 m) } & \multirow{4}{*}{ Landsat } & MSS & 30-60 (MS/SWIR) & \multirow{4}{*}{185} \\
\hline & & TM & 30 (MS, SWIR) & \\
\hline & & ETM+ & $\begin{array}{c}30 \text { (MS, SWIR) } 30 \\
\text { (Pan) }\end{array}$ & \\
\hline & & OLI & $\begin{array}{c}30 \text { (MS, SWIR) } \\
\text { 15(Pan) }\end{array}$ & \\
\hline & \multirow{3}{*}{ SPOT } & 2 (HVR) & 20 (MS) 10 (Pan) & \multirow{3}{*}{60} \\
\hline & & 4 (HVIR) & 20 & \\
\hline & & 5 (HRG) & 10 (MS) 20 (SWIR) & \\
\hline & \multicolumn{2}{|c|}{ IRS (ResourceSat-1) } & 23.5 & 140 \\
\hline & \multicolumn{2}{|c|}{ Terra (ASTER) } & 15 (MS) 30 (SWIR) & 60 \\
\hline & \multicolumn{2}{|c|}{ EO-1 (Hyperion) } & $30(\mathrm{MS})$ & 7.5 \\
\hline & \multicolumn{2}{|c|}{ CBERS-1 and -2} & 20 & 113 \\
\hline \multirow{3}{*}{ Low $(>100 \mathrm{~m})$} & \multicolumn{2}{|c|}{ Terra (MODIS) } & $250-1000$ & 2300 \\
\hline & \multicolumn{2}{|c|}{ SPOT $5(\mathrm{VGT})$} & 1000 & 2250 \\
\hline & \multicolumn{2}{|c|}{ NOAA-19 (AVHRR/3) } & 1100 & 2600 \\
\hline
\end{tabular}

Note. MS: Multispectral; Pan: panchromatic; SWIR: shortwave infrared

The high temporal frequency and large image swaths of the Moderate Resolution Imaging Spectroradiometer (MODIS) and Advanced Very High Resolution Radiometer (AVHRR) make them adequate data sources for regional to global monitoring and mapping of broad land cover patterns (Potter et al., 2005), for monitoring change over large areas (Potter et al., 2003), and for rapid response action. Free economic cost and easy access to high quality processed data support operational programs like Active Fire Mapping Project (AFMP), which reports daily on fire activity in the USA and Canada, or DEFER project, which offers monthly reports of tropical deforestation. AVHRR and MODIS programs have provided daily records since 1981 and 2000, respectively, making them suitable for medium term assessment of global transformations. High and very high spatial resolution images (<1-10 m pixel size) permit identification of small objects on the ground, like large individual trees, and even related dimensions for estimation of forest structure (Wulder et al., 2004a). Some commercial satellites offering this kind of data are steerable, enabling a 
short return period of 1-5 days. Small image footprints (image size per acquisition) and high data costs preclude more regular use in the civilian world.

Medium spatial resolution (MSR) images are adequate for characterization of landscapes, and to monitor change events at the scale of human impacts. MSR is well suited for characterization of forest condition (Cohen and Goward, 2004), and to monitor forest change at the stand level (Wulder et al., 2008d). Typical MSR images are captured with a wide swath, providing synoptic views for regional studies, and with an adequate range of visible and infrared wavelengths for accurate characterization of land covers. Recent policies making imagery easily accessible (e.g. Brazilian INPE, USGS, ESA) positions this type of data as the most used and reliable for regional works.

\section{Landsat program}

The Landsat program was the first to launch an Earth-observing satellite with the express intent to study and monitor our planet's landmasses (Lauer et al., 1997). Back in 1972 when Landsat 1 was launched, it was called Earth Resources Technology Satellite (ERTS). With seven satellites successfully launched (Figure 3), the program has acquired imagery covering all but the highest polar latitudes during more than forty years, contributing to the longest and most geographically comprehensive record of the Earth's surface ever assembled (Wulder et al., 2012a). Technical characteristics of all segments (spacecraft, sensors, ground station, and data transfer) have evolved over the years, improving the spectral, spatial, temporal, and radiometric resolution of the data, refining the instruments' calibration (Irons and Masek, 2006), and establishing an optimized plan called Long Term Acquisition Plan for acquisition of global imagery (Arvidson et al., 2006). Landsat 8 was launched in February 2013, assuring the continuity of monitoring programs. Further operational missions (Landsat 9 and 10) are intended to follow (Loveland and Dwyer, 2012) and will provide continuity of comparable measures.

The sequence of Landsat satellites, operational period and the office in charge of management are presented in Figure 3. The spectral, radiometric, and spatial characteristics of the optical components of sensors onboard all Landsat satellites (Multi Spectral Scanner, Thematic Mapper, Enhanced Thematic Mapper Plus, and Operational Land Imager) are presented in Table 5. 
Table 5. Spectral, spatial, and radiometric characteristics of Landsat sensors (thermal components of TM and ETM+ are not included). MSS: Multispectral Scanner; TM: Thematic Mapper; ETM+: Enhanced Thematic Mapper Plus. OLI: Operational Land Imager.

\begin{tabular}{|c|c|c|c|c|c|c|c|c|c|c|c|c|}
\hline & & MSS & & & TM & & & ETM+ & & & OLI & \\
\hline & \#Band & $\begin{array}{l}\text { Width } \\
(\mu \mathrm{m})\end{array}$ & $\begin{array}{c}\text { GSD } \\
(\mathrm{m})\end{array}$ & \#Band & $\begin{array}{c}\text { Width } \\
(\mu \mathrm{m})\end{array}$ & $\begin{array}{l}\text { GSD } \\
\text { (m) }\end{array}$ & \#Band & $\begin{array}{c}\text { Width } \\
(\mu \mathrm{m})\end{array}$ & $\begin{array}{l}\text { GSD } \\
\text { (m) }\end{array}$ & \#Band & $\begin{array}{c}\text { Width } \\
(\mu \mathrm{m})\end{array}$ & $\begin{array}{l}\text { GSD } \\
\text { (m) }\end{array}$ \\
\hline \multirow{4}{*}{ Visible } & & & & & & & & & & 1 & $0.43-0.45$ & 30 \\
\hline & & & & 1 & $0.45-0.52$ & 30 & 1 & $0.45-0.52$ & 30 & 2 & $0.45-0.51$ & 30 \\
\hline & $4(1)$ & $0.5-0.6$ & $68 \times 83$ & 2 & $0.52-0.60$ & 30 & 2 & $0.52-0.60$ & 30 & 3 & $0.52-0.60$ & 30 \\
\hline & $5(2)$ & $0.6-0.7$ & $68 \times 83$ & 3 & $0.63-0.69$ & 30 & 3 & $0.63-0.69$ & 30 & 4 & $0.63-0.68$ & 30 \\
\hline \multirow{2}{*}{ NIR } & $6(3)$ & $0.7-0.8$ & $68 \times 83$ & 4 & $0.76-0.90$ & 30 & 4 & $0.76-0.90$ & 30 & 5 & $0.84-0.88$ & 30 \\
\hline & $7(4)$ & $0.8-1.1$ & $68 \times 83$ & & & & & & & & & \\
\hline \multirow{2}{*}{ SWIR } & & & & 5 & $1.55-1.75$ & 30 & 5 & $1.55-1.75$ & 30 & 6 & $1.56-1.66$ & 30 \\
\hline & & & & 7 & $2.08-2.35$ & 30 & 7 & $2.09-2.35$ & 30 & 7 & $2.10-2.30$ & 30 \\
\hline Pan & & & & & & & 8 & $0.50-0.68$ & 30 & 8 & $0.50-0.68$ & 15 \\
\hline SWIR & & & & & & & & & & 9 & $1.36-1.39$ & 30 \\
\hline
\end{tabular}

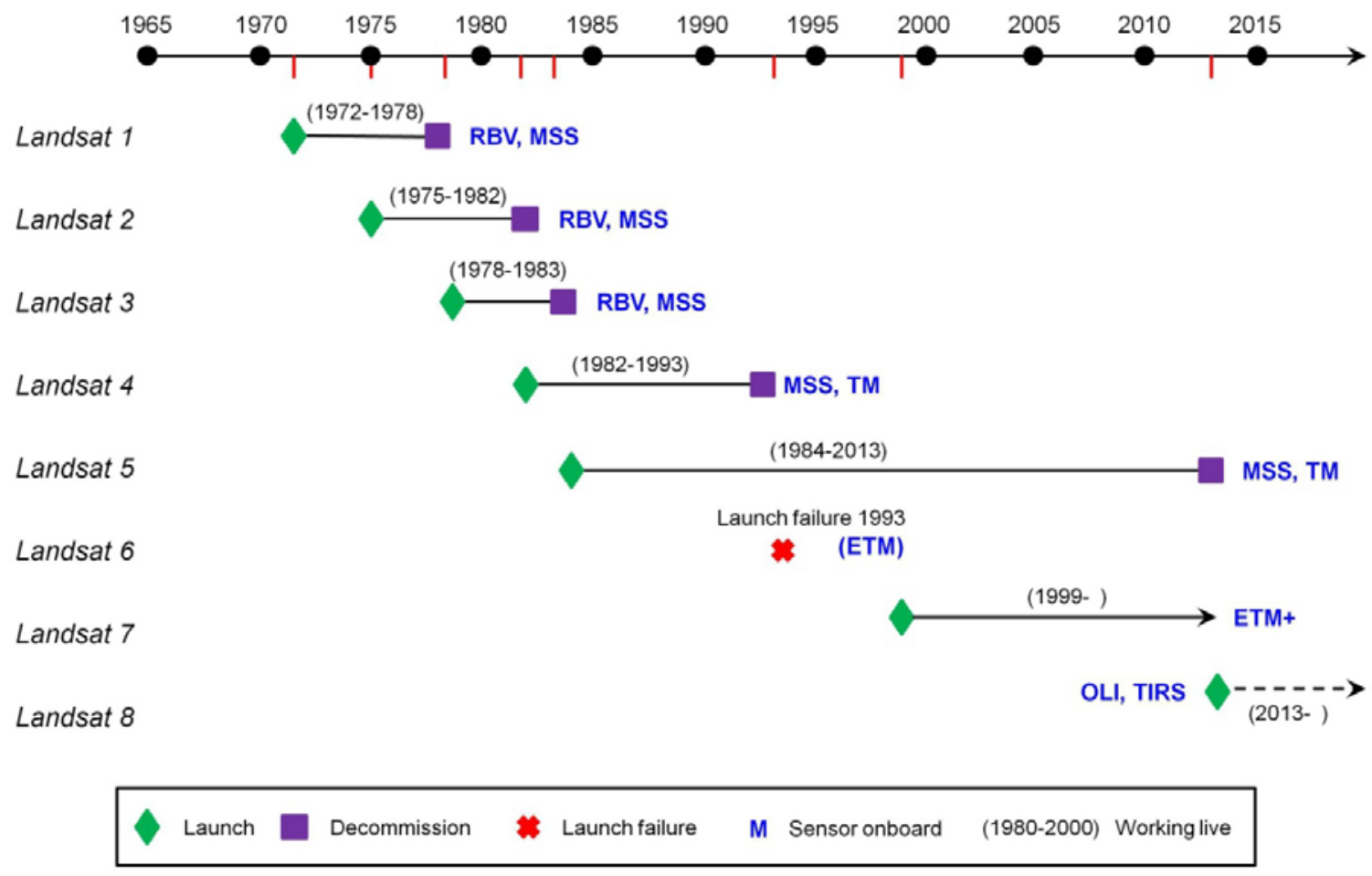

Figure 3. History of Landsat satellites and sensors. Adapted from:

http://landsat.gsfc.nasa.gov/about/landsat7.html. RBV: Return Beam Vidicon, MSS: Multispectral Scanner; TM: Thematic Mapper; ETM+: Enhanced Thematic Mapper Plus. 
Currently managed by the US Geological Survey (USGS) and the National Aeronautics and Space Administration (NASA), the Landsat program has a network of international cooperators well distributed over all continents. These co-operators, with established ground stations, contribute to the downlink services and enable scientific and technical collaboration. The European Space Agency (ESA), one of the Landsat international cooperators, holds two million Landsat images, presently available for research under licence, but expected to be transferred to the USGS archive and made available to the public with the USGS standard level of processing. The USGS Landsat archive has more than four million images ${ }^{1}$ freely available through a website portal since 2008 (Woodcock et al., 2008). Images of any part of the Globe are subject to a standard high level of processing, including radiometric calibration, geometrically precise location and registration (better than 0.44 pixels root mean square error in $\mathrm{x}$ and $\mathrm{y}$ directions), and surface reflectance products that facilitate applications' use.

Landsat images are identified by the Worldwide Reference System (WRS) that parcels the Globe into 185 x 185 km scenes indexed by paths (north-south) and rows (east-west). This research is focused on a single Landsat scene (WRS-2 Path 201, Row 032) as it encompasses the most extensive continuous pine stands of the Spanish Central Range.

\section{QuickBird-2 satellite}

Some commercial satellites carrying high spatial resolution sensors have been launched in the last fifteen years - IKONOS in 1999, QuickBird-2 in 2001, Orbview-3 in 2003, RapidEye in 2008- and are currently orbiting the Earth. QuickBird-2 is operated by Digital Globe and provides data in five spectral bands (Table 6). It has the capacity to be oriented and to capture images off nadir, enabling a temporal revisit of 2-6 days depending on latitude. The pixel size of QuickBird-2 images is $\sim 2.4 \mathrm{~m}$ for the multispectral bands and $\sim 0.68 \mathrm{~m}$ for the panchromatic band (Table 6). QuickBird-2 is unique among other satellites in this class as it has the largest image footprint and most on-board storage capacity.

Table 6. Characteristics of the QuickBird-2 imagery. Adapted from www.satimagingcorp.com

\footnotetext{
${ }^{1}$ http://www.landsat.usgs.gov
} 


\begin{tabular}{l|l}
\hline Launch & 18 October 2001 \\
\hline Altitude & $450 \mathrm{~km}$ \\
\hline Speed & $25560 \mathrm{~km} / \mathrm{h}$ \\
\hline Period & $93.5 \mathrm{~min}$ \\
\hline Return period & $1-3.5$ days \\
\hline Equator & $10: 30$ a.m. \\
\hline Radiometric resolution & 11 bits \\
\hline
\end{tabular}

\begin{tabular}{l|l|l}
\hline \multirow{4}{*}{ Bands $(\mu \mathrm{m})$} & Pan & $0.45-0.90$ \\
\cline { 2 - 3 } & Blue & $0.45-0.52$ \\
\cline { 2 - 3 } & Green & $0.52-0.60$ \\
\cline { 2 - 3 } & Red & $0.63-0.69$ \\
\cline { 2 - 3 } & NIR & $0.76-0.90$ \\
\hline
\end{tabular}

HSR imagery provides the opportunity for precise exploration of forest parameters, reducing estimation errors to an acceptable level for operational applications (Kayitakire et al., 2006). Very high spatial resolution imagery facilitates for instance the detection of individual tree characteristics, providing improved estimates of forest attributes (Wulder, 1998). Nevertheless, dearth of established methods for processing and the complex interactions between sun-sensor-surface geometry and forest structural characteristics (Wulder et al., 2008d), particularly in complex topographies, make the use of these data challenging (Falkowski et al., 2009a).

\section{Ancillary data: cartography, aerial photography, digital elevation model}

The Mapa Forestal Español (MFE50) is the digital version of Ruiz de la Torre forest map of Spain for the year 2000. In the construction of this map the source of data consisted of aerial photography and field notes. Polygons interpreted on photography were transferred to the 1:50000 National Topographic Map and the paper map version was later digitized. This GIS database encompasses 68 attributes to characterize vegetation units. Among relevant attributes for identification of pine forest areas are dominant species and crown cover (that is, the proportion of area covered by the horizontal projection of the canopy, in percentage). The MFE50 is used in this work for assessment of accuracy during confidence building stages.

Aerial photography scale 1:10000 provided by Castile and Leon government was used in support of accuracy assessment and checking stages. Historical and online aerial photography was supportive in visual evaluation of the accuracy of changing trends derived from satellite spectral series.

Digital elevation models (DEM) were used to support spatial registration of satellite imagery: a 25 m DEM was used for orthocorrection of Landsat images, and a DEM 
derived from 1:10000 cartography (www.sitcyl.org) was used in processing stages of HSR satellite imagery.

\subsection{Management of data from field inventories}

Plots from the National Forest Inventory (NFI) were selected with BasIFor 2.0 (Bravo et al., 2005), software dedicated to handle the NFI provincial databases for research, management, and planning (Bravo et al., 2002). BasIFor 2.0 enables selection of data based on location, species, or structural parameters, calculates volumes and growth, and facilitates NFI2 and NFI3 data comparison. BasIFor 2.0 has an option to export results in standard format, compatible for numerical analysis in common software. Spatial location of data is facilitated by identification of plot coordinates.

Plots measured in the most recent inventories for planning of two pilot sites were considered. To synchronize field measures with HSR satellite imagery, some data measured on the ground were updated with species specific growth models as proposed in the NFI methodology. Geographical Information System (GIS) tools assisted in location and geo-processing for analysis of inventory data.

Forest structural variables were derived by application of standard formulas to field measurements. Structural diversity attributes were evaluated at the plot level as the median absolute deviation (MAD) of diameter, height, and crown diameter from regional average values. The MAD metrics are always positive and their values are directly related with structural diversity, i.e. plots with higher values of MAD are structurally more diverse.

\subsection{Biomass calculation with allometric equations}

Live AGB was calculated with the species specific allometric equations of Montero et al. (2005) and Ruiz-Peinado et al. (2011) for trees with $\mathrm{dbh} \geq 7.5 \mathrm{~cm}$. These equations account the dry biomass fraction of stem, roots, and branches of various dimensions, but we did not consider the root portion in our analysis. Expansion factors accounting for the size of concentric NFI plots were applied, to scale measured attributes to standard spatial units. Absolute and relative change of AGB between the NFI2 and NFI3 was calculated at the plot level. 
Equations developed by Montero et al. (2005) require just measures of tree diameter as inputs, and are available for a large number of species. Models by Ruiz-Peinado et al. (2011) incorporate measures of tree diameter and height. These equations were derived subject to an additive property: the sum of all biomass fractions (i.e. stem, branches, and roots) equals the total biomass of the tree.

\subsection{Satellite data processing}

Remotely sensed data from satellite platforms are usually delivered by data providers after basic processing, and require further treatment for incorporation into project flows to generate information. However, recent technological improvements facilitate standard processing and enable providers to offer data in high quality processing stage, sometimes ready for user applications. Typical image preparation techniques include geometric and radiometric adjustments. Figure 4 provides an overview of the main processing stages applied in this work, and a brief description of the processes performed follows. Specific processing applied at each stage is reported in individual chapters.

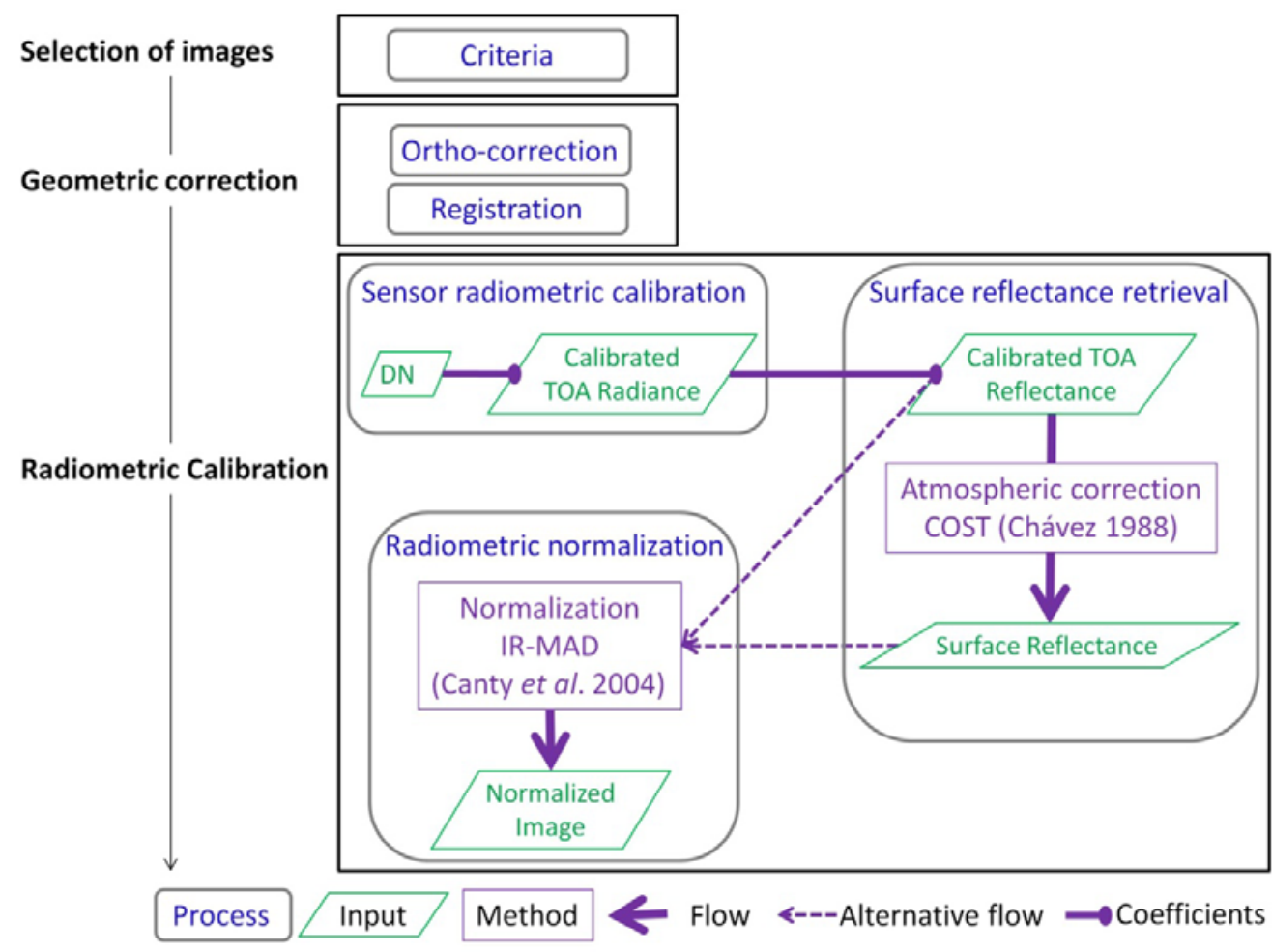

Figure 4. Overview of image processing flow with some specific methods applied in this work. DN: Digital Number; TOA: Top of Atmosphere; COST: Cosine Theta; IR-MAD: Iterative Re-Weighted Multivariate Alteration Detection. 


\section{Selection of images}

For monitoring and analysis of change a number of acquisitions of each scene covering the area of interest are necessary, although the exact number, assuming availability, is a trade-off between processing effort and detail of results. Trends of change become reliable when examining frequent images with comparable characteristics: atmospheric condition, sun elevation, sensor orientation, and vegetation phenology. Anniversary images are desirable for monitoring forest ecosystems (Wulder and Franklin, 2002) and the acquisition of a historical time series of multiple Landsat images relatively cloud-free can be a complicated task (Homer et al., 2004). In the study area, in order to capture stable phenological conditions and to avoid the presence of snow in high altitudes, summer images were preferred. The spectral suitability of images on the edge of season (early or late summer images) required thorough checking through the processing stages to detect and avoid possible phenology artefacts. The selection of MSR images consisted of nine Landsat TM and two ETM+ (Scan Line Corrector on) images. To ensure a more complete time series, the tolerance for a small amount of cloud cover in the images was increased, but still, a yearly time series of images was not possible to obtain, and the time step was not constant. There is a gap in images in the 1990s corresponding to the private sector distribution era (Tolomeo et al., 2009) that had to be considered in interpretation of results, as longer intervals between images may reduce detection accuracy for subtle changes (Wilson and Sader, 2002; Jin and Sader, 2005).

In the near future, the Sentinel-2 satellites of the European Space Agency (ESA) will collect data similar to the Landsat series of satellites, augmented by refinements to spatial, spectral, radiometric, and temporal resolutions (Drusch et al., 2012). Notably, Sentinel-2 is planned to be a two sensor constellation, off-setting two satellites in the same orbit to shorten the revisit and increase the opportunity to obtain cloud free imagery. A large imaging footprint will also aid the collection of data for desired time periods and free of clouds, complementing Landsat acquisitions for monitoring projects.

Archived HSR images from QuickBird-2, covering the pilot areas for the study of forest structure and diversity, and acquired during the summer with adequate technical characteristics, were available from the supplier at standard price. 
Fourteen Landsat images (MSS, TM and ETM+) were employed for our study in Alberta (Canada) (Chapter I) in which novel techniques were developed and changes on the forest landscape were analysed and described (Gómez et al., 2011a).

\section{Geometric correction}

Remotely sensed raw images contain geometric distortions specific to the acquisition system, mainly related to sensor orientation and viewing angle, sun elevation, and atmospheric effects. Every system geometric distortions require a particular correction approach prior to analysis or integration with other spatial data. Systematic distortions introduced by the instrumentation (e.g. skew caused by Earth rotation effects, variation in ground resolution cell size due to the scanning system) are corrected at ground receiving stations or image distributors, but distortions related to specific acquisition time and location (e.g. topographic relief) require correction by the user.

Geometric correction with 3D parametric mathematical models supported by a DEM is superior to other methods (Toutin, 2004). In this work Landsat and QuickBird-2 images were orthocorrected with DEMs of $25 \mathrm{~m}$ and $2 \mathrm{~m}$ resolution respectively, and adjusted with ground control points manually identified over the images. To integrate all images into a geospatial database enabling simultaneous use, geometric registration to reference cartography is necessary. All images were co-registered to the UTM 30N (datum WGS84) coordinate system.

Image rectification involves a geometric operation to compute the cell coordinates in the original image, and a radiometric operation to compute the intensity value on the "map image” cell (geometrically corrected) as a function of the intensity values of original image cells (Toutin, 2004). This operation is performed by a resampling kernel applied to the original image cells. Nearest neighbour resampling does not alter the radiometry of the original image but introduces some geometric error and the visual quality is altered. As an alternative a specific interpolation or deconvolution algorithm using the digital numbers of the surrounding cells can be applied: bilinear interpolation does not alter the geometry but produces a smoothing effect, while cubic convolution does not smooth but enhances and generates some contrast in the image. Trade-offs of these options requires consideration in deciding processing alternatives. 


\section{Radiometric calibration}

Radiometric image processing is aimed to transform raw data (i.e. radiant energy coded by intensity and spectral character) as captured by the sensor into at surface reflectance suitable for applications (Figure 4). Radiometric processing includes sensor radiometric calibration, surface reflectance retrieval based on atmospheric corrections, image normalization to provide radiometric consistency across multiple scenes and/or dates, and specialized corrections for surface terrain induced variations (Peddle et al., 2003). A robust radiometric calibration of images is essential in change detection applications (Lu et al., 2004; Coppin et al., 2004), and it is crucial if images are to be related with biophysical phenomena (Gong and $\mathrm{Xu}$, 2003) like forest structure, health, biomass, or successional development. This task becomes especially challenging when various sensors are included in the analysis (Roder et al., 2005).

The radiometry of satellite sensors is evaluated periodically to account for changes produced after pre-launch calibration. Onboard systems, pseudo-invariant targets and cross-sensor approaches are used for calibration, and coefficients to transform digital numbers into radiance and at sensor (top of atmosphere-TOA) reflectance are provided in user manuals (Chander et al., 2009). The reduction in scene-to-scene variability is an advantage of reflectance over radiance, due to the removal of the cosine effect of different solar zenith angles, the compensation for different values of the exoatmospheric solar irradiance, and the correction for variation in the Earth-Sun distance between different data acquisition dates.

To account for atmospheric effects (i.e. haze) when transforming at sensor reflectance to surface reflectance, absolute correction with models based on radiative transfer theory (e.g. 6S-second simulation of a satellite signal in the solar spectrum) require frequently unavailable atmospheric data. Image-based correction approaches based on the dark-object theory provide a reliable alternative solution. Assuming the radiance of a dark object (e.g. water body, shadow) is near to zero, its value of reflectance as captured by the sensor is credited to atmospheric effects and subtracted from all pixels in each spectral band. The cosine-Theta (COST) model (Chávez, 1988) is an improved dark-object subtraction technique that, based on a relative scattering model, identifies wavelength dependent haze values correlated with each other, and maintains a correct relationship between spectral 
bands. We applied the COST model for correction of atmospheric effects in Landsat and QuickBird-2 images, obtaining the minimum value of reflectance from imaged water bodies.

Image normalization is the adjustment of the radiometric properties of one image to match that of another. Normalization is important in forest applications that involve multiple images acquired over large areas or at different times (e.g. inventory, change detection). For analysis of spectral trajectories, a relative calibration or radiometric normalization of a sequence of images with the Iterative Re-Weighted Multivariate Alteration Detection (IRMAD) process (Canty et al., 2004) had been recommended (Schroeder et al., 2006) and was used in this work. Image normalization transforms images to a common radiometric scale, minimizing sun and sensor view angles, as well as atmospheric differences among images. The process of normalization reduces the amount of artefacts due to illumination or atmospheric variations, enabling more reliable detection of true change (Song et al., 2001).

\subsection{Vegetation indices}

A vegetation index is a dimensionless, radiation based measurement that indicates relative abundance and activity of green vegetation (Jensen, 2005) by isolating its contribution from other materials (Asner et al., 2003). Vegetation indices are simple, reduce data dimensionality, and can easily be applied to different scenes. Vegetation indices take advantage of the unique spectral signature of vegetation, characterized by a large difference in reflectance between the visible (high absorption) and near-infrared (reflectance). Typical indices use the ratio or difference of NIR (near infrared) and VIS (visible) reflectance, and most commonly are defined with VIS in the red region of the visible spectrum (630-690 nm).

Vegetation indices are frequently used in forestry applications, capitalizing on a strong relationship with structural attributes like Leaf Area Index (LAI) and canopy cover, to estimate, map, and monitor forest health, biomass content, and landscape disturbances (i.e. fire, windstorms). When used for discrimination of land cover and characterization of vegetative condition, vegetation indices must normalize effects such as sun angle or atmospheric effects for consistent comparisons in time and space. 


\section{Normalized Difference Vegetation Index}

One of the most widely used vegetation indices is the Normalized Difference Vegetation Index (NDVI) developed by Rouse et al. (1973). NDVI is defined as (eq. 1)

$$
N D V I=\frac{\rho_{\text {nir }}-\rho_{\text {red }}}{\rho_{\text {nir }}+\rho_{\text {red }}}
$$

where $\rho_{\text {nir }}$ and $\rho_{\text {red }}$ are the reflective values in the NIR and red bands for each pixel. NDVI values vary between 0 and 1 and are directly related to the vigour of vegetation. NDVI is extensively used to monitor seasonal and annual global changes in vegetation communities, and as a component of particular models. NDVI has demonstrated useful for evaluation of forest biomass and structure (Piao et al., 2005; Dong et al., 2003). Chuvieco (2002) noted as a weakness of the NDVI its inability to discriminate between areas with different proportion of vegetation/soil: an area with vigorous canopy and scarce density can show the same NDVI value as other area with higher density but less vitality.

NDVI values were calculated on the series of Landsat images and on QuickBird-2 images. Figure 5 illustrates the usefulness of this index to discriminate vegetation from other land cover classes.
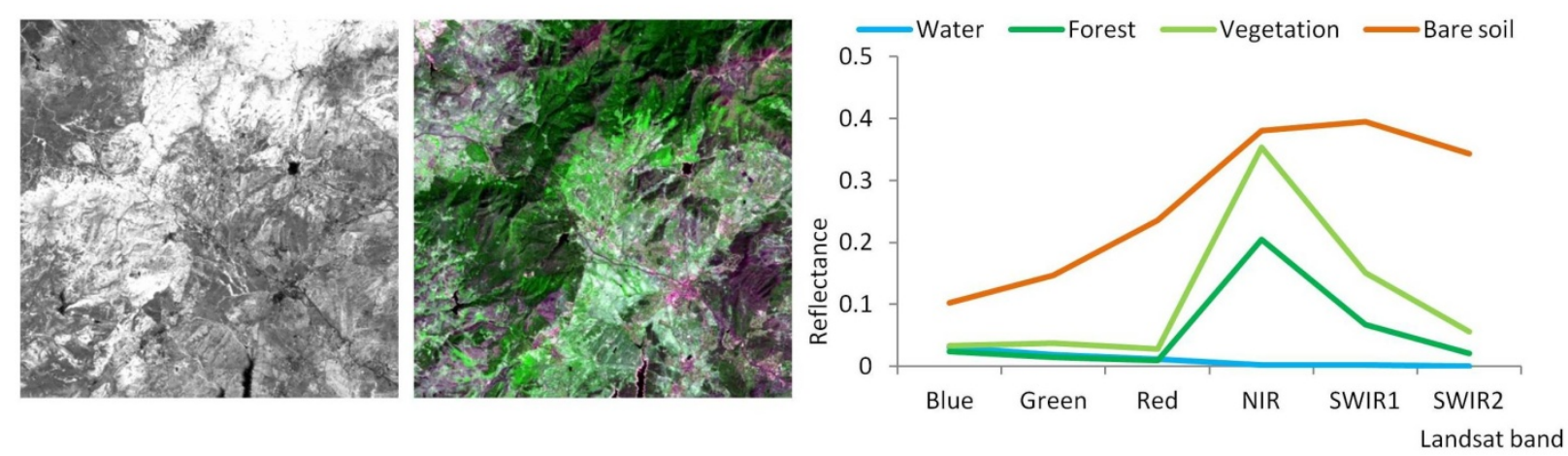

Figure 5. Left: Landsat NDVI image of part of the study area. Dark regions are water bodies, roads and bare soil; bright regions are forest. Middle: same region, visualization R/G/B: 3/4/1; Right: Spectral signatures of some cover classes. 


\section{Tasseled Cap Transformation and derived indices}

The Tasseled Cap Transformation (TCT) (Kauth and Thomas, 1976; Crist and Cicone, 1984; Crist, 1985; Huang et al., 2002) is a linear transform for reduction of the Landsat spectral space that was initially developed by Kauth and Thomas (1976) for understanding of crop spectral behaviour. The TCT has been broadly employed in forestry studies of structure (Hansen et al., 2001; Cohen et al., 2001), condition (Wulder et al., 2006, Healey et al., 2006), successional state (Peterson and Nilson, 1993; Helmer et al., 2000) and change detection (Lea et al., 2004; Jin and Sader, 2005) in a range of forest environments.

The first three components of the TCT were named Wetness, Greenness, and Brightness, in relation with their physical interpretation, and have received special attention for forest applications. The Tasseled Cap Brightness (TCB) and Tasseled Cap Greenness (TCG) components form the vegetation plane (Crist and Cicone, 1984), where the spectral behaviour of forest stands provides insights into forest cover densities and forest development stages. By combination of TCG and TCB values in the vegetation plane, the Tasseled Cap Angle (TCA) and Tasseled Cap Distance (TCD) condense in single values information related to forest structure and successional stages that can be related to biomass and diversity. The TCA is defined as the angle formed by TCG and TCB (eq. 2), whereas the Tasseled Cap Distance is the distance to the origin of the vegetation plane (eq. 3) (Figure 6). TCA and TCD were tested for the first time in temperate forests of Oregon (USA): Powell et al. (2010) related these indices with AGB and Duane et al. (2010) with forest structure. TCA was used by Gómez et al. (2011a) for analysis of temperate forests of Canada (this dissertation), and combined with TCD by Gómez et al. (2012a) in Mediterranean pines of Spain (this dissertation) in relation with structure and biomass. 


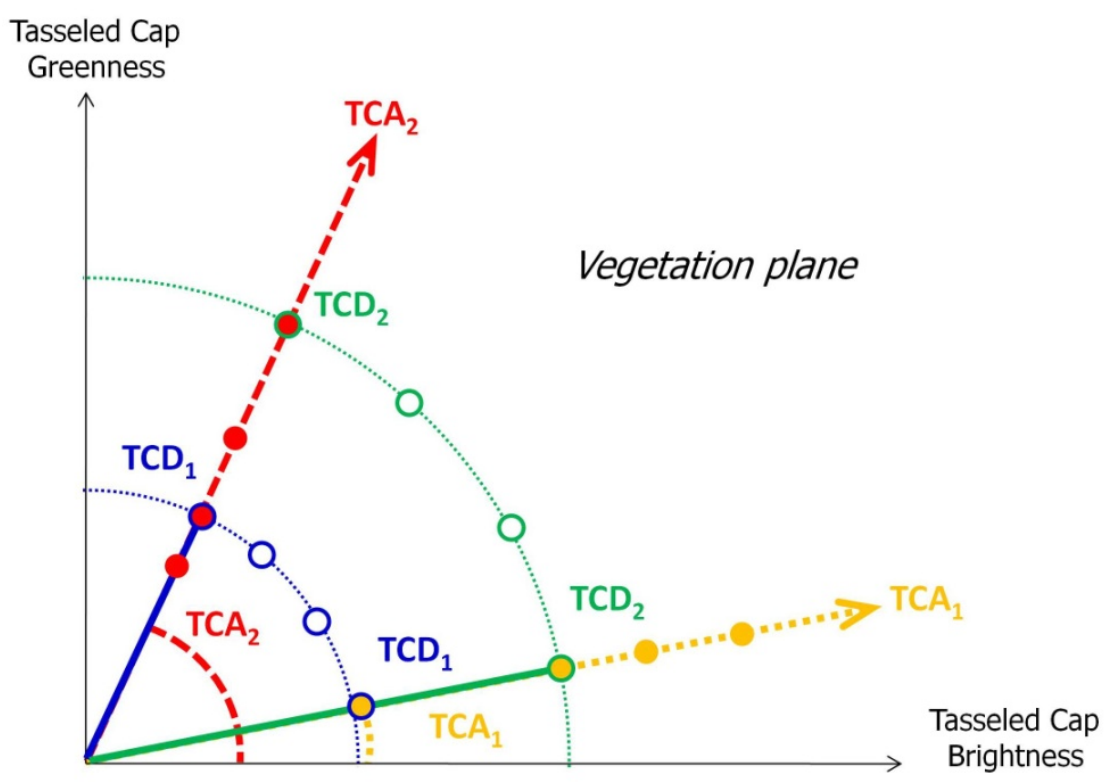

Figure 6. Vegetation plane of the Tasseled Cap Transformation. Tasseled Cap Angle (TCA) and Tasseled Cap Distance (TCD) are represented.

$$
\begin{aligned}
& T C A=\arctan (T C G / T C B) \\
& T C D=\sqrt{T C G^{2}+T C B^{2}}
\end{aligned}
$$

\subsection{Image texture}

Image texture was defined by Haralick and Bryant (1976) as "the pattern of spatial distributions of grey-tone”, and describes the relationship between elements of surface cover (Wulder et al., 1998). Image texture is one of the most valuable criteria in visual interpretation. The estimation of forest stand parameters with digital data is sometimes improved with a combination of spectral and spatial information ( $\mathrm{Lu}, 2006)$ such as texture. Consequently a host of texture measures have been utilized to predict structural parameters in various environments (Franklin et al., 2001; Devereux et al., 2004; Couteron et al., 2005) and has shown particular utility in complex structures such as tropical forests for above ground biomass estimation (Lu et al., 2002; Lu and Batistella, 2005).

For evaluation of image texture various methods (e.g. variograms, Fourier transform, fractal dimension) have become relatively fast and simple with computer algorithms (Han 
Bell, 2007). One approach for texture analysis (used in this work) can be based on measures derived from the Grey Level Coocurrence Matrix (GLCM) (Haralick et al., 1973; Caridade et al., 2008). The GLCM is a tabulation of how often different combinations of pixel grey levels occur in an image (Hall-Beyer, 2007) at a specific distance and orientation (within a particular processing kernel, or analysis window). Texture measures calculated from the GLCM (e.g. homogeneity, entropy) consider the relationship between neighbouring pixels, and are known as second order or coocurrence texture measures, as opposed to first order texture measures simply calculated from the original image values (e.g. variance, standard deviation). Since texture analysis is a multi-scale phenomenon (Ahearn, 1988), choosing the right window size to capture meaningful local variance without generalizing unrelated features (Kayitakire et al., 2006) is one of its key challenges (Ferro and Warner, 2002). Among the range of texture variables that can be derived from the GLCM, Homogeneity, Contrast, and Entropy (eq. 4-6) showed high values of correlation with structural parameters in pre-analysis investigations in the study area. Some examples of forest areas with different visual texture are depicted in Figure 7.

$$
\begin{aligned}
& \text { Homogeneity }=\sum_{i, j=0}^{N-1} \frac{P_{i, j}}{1+(i-j)^{2}} \\
& \text { Contrast }=\sum_{i, j=0}^{N-1} P_{i, j}(i-j)^{2} \\
& \text { Entropy }=\sum_{i, j=0}^{N-1} P_{i, j}\left(-\ln P_{i, j}\right)
\end{aligned}
$$

where $P_{i, j}$ is the $(i, j)$ th entry of the normalized GLCM matrix, $\mathrm{N}$ is the number of rows and columns in the image. 

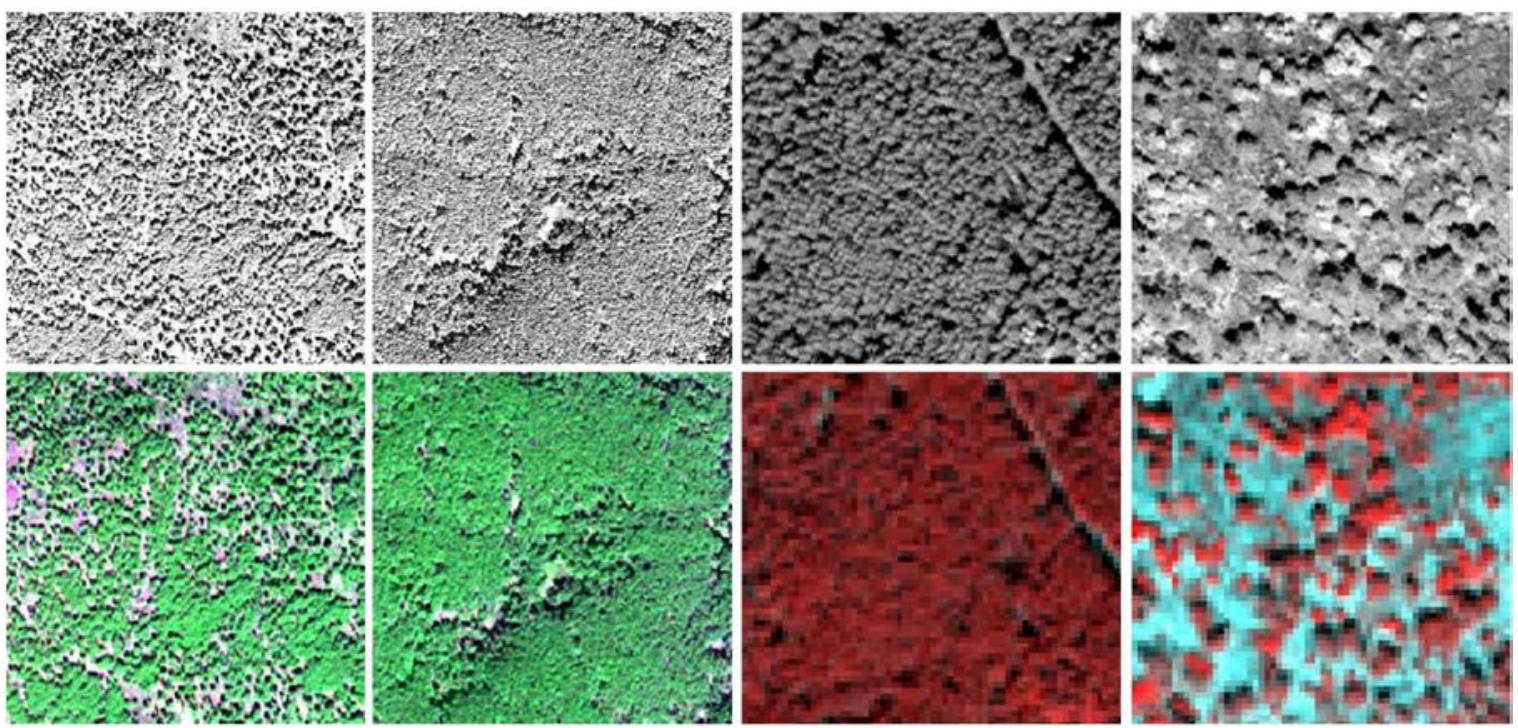

Figure 7. Examples of forest areas with different visual texture, associated with forest structure, as depicted in HSR images. Top: panchromatic visualization; bottom: multispectral visualization.

\subsection{Image segmentation for object oriented analysis}

Digital images provide data coded into square picture elements (pixels) which seldom correspond with objects of interest on the ground. Target objects larger than one pixel can be identified on the image by a process of aggregation based on a rule of similarity. Following this rationale, image segmentation consists in the partition of the image into homogeneous spatial units (Devereux et al., 2004) based on one or more attributes. With the image segmented into meaningful objects with distinctive attributes, visualization and analysis of spatially correlated properties is facilitated.

There is no unique way of partitioning the landscape (Burnett and Blaschke, 2003) for ecological analysis and no single spatial scale is optimal for characterizing the multiple options in which the image can be divided (Hay et al., 2005). Defining semantic rules to relate multi-level landscape divisions of organization is a big challenge (Burnett and Blaschke, 2003) and three is the minimum number of levels recommended for analytical studies of landscape (O’Neill, 1986).

Through the application of automated algorithms, the criteria for homogeneity can be defined by the user, based on parameters such as tone or spatial pattern. Image objects or segments composed of various pixels provide supplementary features for image analysis, 
not available in pixel based analysis, such as local statistical relations of digital numbers (Chubey et al., 2006), shape, size or context. That is, once segments are produced, objects (e.g., trees or groups of trees) or spatially constrained summaries of the digital numbers within the segment may be used to provide representative segment-level information (Palace et al., 2008). In forest environments, the segments can often be considered as analogous to the manually delineated stands found in forest inventories (Hay et al., 2005).

Definiens Cognition Network Technology ${ }^{\circledR}$ is software dedicated to image segmentation, with strong capacity to incorporate contextual information. In the process of image segmentation the size of resulting objects is determined by the scale parameter and by the landscape characteristics; for instance, a given scale value would produce larger objects in a homogeneous landscape and smaller objects in irregular areas. Other settings guiding the segmentation routine include complementary criteria of colour-shape and smoothnesscompactness. The homogeneity criterion is based on weighted selected bands, which can include spectral or thematic layers. Definiens Cognition Network Technology ${ }^{\circledR}$ was employed for segmentation of Landsat and QuickBird-2 images at various stages of processing and analysis in this work. Specific segmentation parameters are reported in corresponding chapters.

\subsection{Spectro-temporal trajectory}

A spectro-temporal trajectory is the sequence of spectral values corresponding to a single pixel (or object when averaged) on temporally consecutive co-located images. The preferred time step of values (i.e. the time lapse between image repetitions) depends on applications: while frequent data would benefit the monitoring of a fast changing phenomenon, it could be a source of noise in identification of slow changing processes. However, the frequency of image captures is limited by the sensor and platform operational characteristics. When the spectral attribute is associated with a biophysical property, the temporal trajectory may provide information of that property evolution through time. Spectro-temporal trajectories of low spatial resolution have been used for some time, but the use of medium spatial resolution temporal trajectories has only recently become doable, as result of the open access data policies (Wulder et al., 2012a). 
Spectral trajectories of calibrated and normalized imagery inform at least on trends of change (Powell et al., 2010), and when analyzed thoroughly they can provide information of the target object physical changes (Pflugmacher et al., 2012). Methods for extraction of information from spectral trajectories of medium spatial resolution, like polynomial characterization of spectral curves (Goodwin et al., 2010) or identification of distinctive trajectory segments (Kennedy et al., 2010) are still on the infancy of development, and are a promising field of research.

\subsection{Data analysis techniques for exploration, characterization, and modelling}

Statistics and techniques for data analysis were fundamental tools in most stages of this work, for exploration and description of datasets, in determining relations among data, and for modelling. A brief description of the main statistical and data analysis methods employed follows, oriented to the specific application made in this work.

\section{Classification and regression trees (CART)}

One option to identify relations between variables in multivariate data sets is the use of decision tree data analysis (Chubey et al., 2006) also known as Classification And Regression Trees (CART). Regression trees identify relationships between a single continuous response (dependent variable) and multiple, continuous and/or discrete, explanatory (independent) variables, through a binary recursive partitioning process, where the data are split repeatedly into increasingly homogeneous groups (nodes), using combinations of variables (rules) that best distinguish the variation of the response variable. Tree models do not make assumptions regarding the distribution of the input data (Pal and Mather, 2003; Baccini et al., 2008); plus, they are able to capture non-linear relationships between variables and are robust to errors in the input and results. Tree modelling is a nonparametric method which basic theory is reported in Breiman et al. (1984).

CART approaches have frequently been used in the environmental remote sensing community for classification and mapping (Brown de Colstoun et al., 2003; McDermid and Smith, 2008; Ke et al., 2010) for modelling (Andrew and Ustin, 2009; Im and Jensen, 2005; Lozano et al., 2008), for forest characterization (Falkowski et al., 2009b) and in 
particular in the estimation of forest structural parameters with HSR satellite imagery (Chubey et al., 2006; Goetz et al., 2003; Mora et al., 2010).

CART was employed in Chapter III to model structural parameters and in Chapter V to model biomass retrospectively.

\section{Canonical correlation analysis}

Canonical correlation analysis (CCA) is defined as "a multivariate statistical model that facilitates the study of interrelationships among sets of multiple dependent and multiple independent variables" (Hair et al., 1998). Forest structure is difficult to characterize using a single variable (Lefsky et al., 2005) requiring multiple attributes for description (e.g. height, canopy cover). Hence, CCA is particularly suited to explore relationships between forest structure and multiple spectral variables.

CCA generates the canonical variates, representing the optimal linear combinations of dependent and independent variables, and the canonical correlation, representing the relationship between canonical variates. During the analysis each group of variables is linearly combined into a variate; one is identified as the dependent variate, the other as the independent. The dependency roles are interchangeable and thereby are easier to interpret.

The strength of the relationship between the dependent and independent variables is quantified by the canonical correlation coefficient. Canonical functions maximize the correlation between the linear composites (variates), and canonical weights, the coefficients of each variable in the canonical functions, represent the partial correlations of the variables with the respective canonical function. Although the canonical weights enable an understanding of the composition of each canonical function, they can be unstable and are therefore not typically used to interpret the canonical variates (Hair et al., 1998). To facilitate comparison between canonical weights, they are transformed into standardized variables (i.e., with a mean of 0 and a standard deviation of 1 ) and are used to calculate canonical scores for the canonical variates. Canonical loadings measure the simple linear correlation between an original observed variable in the dependent or independent set and the set's canonical variate: canonical loadings indicate the variance that the variable shares with its canonical variate. Variables that are highly correlated with a canonical variate have more in common with the variate and should therefore be given more importance in the variate's interpretation. Finally, a measure of redundancy may be calculated that informs on 
the amount of variance in a set of input variables (dependent or independent) that is explained by the other canonical variate. For example, a measure of redundancy for the dependent variate represents the amount of variance in the dependent variables that is explained by the independent variate. As canonical functions may have statistical significance even though they lack practical significance (Hair et al., 1998), the canonical functions to be interpreted require being determined with criteria such as the level of statistical significance of the canonical function, the practical significance of the canonical correlation, and the redundancy measures for each variate.

For assessment of the CCA validity, a reliable option is to run the analysis repeatedly, by removing individual independent variables, and assess the stability of the canonical loadings, the overall canonical correlations, and the redundancy measures. The applicability of CCA in remote sensing is demonstrated and described in detail by Cohen et al. (2003). CCA has been successfully applied by Lefsky et al. (2005) to compare the relationships between LiDAR-measured canopy structure and coincident field measurements of forest structure, and by White et al. (2010) to explore the relationship between spectral diversity and forest canopy structural diversity.

CCA was employed in Chapter IV for characterization of the strength and quality of the relationship between structural diversity measures and image diversity measures.

\section{Geostatistics: kriging interpolation and variogram}

Geostatistics focus on spatial and spatio-temporal datasets, and provides means for extrapolation of measured values to unmeasured points and areas, facilitating the derivation of thematic layers for integration with other data (Chica-Olmo, 2005). Geostatistical methods are more appropriate for generating estimates of the distribution of forest properties than the use of simple average or statistical models that ignore spatial correlation (Sales et al., 2007).

Kriging is a spatial interpolation method that yields the best possible estimation of the spatial variable of interest at every unmeasured point (Curran and Atkinson, 1998). The error committed at each point in the estimation is minimized and known (Clark, 2001). Kriging facilitates mapping of forest variables of interest measured in ground plots (e.g. inventory attributes) into raster layers. Moreover, block kriging enables estimation of the relative standard error (i.e., the standard error of the kriged surface relative to the mean 
attribute value at the polygon level). Since sampling is complete and the spatial correlation of plot values is accounted for, inside polygon average values are more accurate than standard means.

Variogram is by definition the expected squared difference between two data values separated by a given distance vector. The variogram calculated with digital image values is a useful tool to characterize forest structure, relating range and sill with forest stands characteristics (e.g. Cohen and Spies, 1990; Merino de Miguel et al., 2010). The range of the variogram indicates the distance beyond which sample values (e.g. pixel values) are no longer correlated (Johansen et al., 2007) and it is indicative of the elements forming the texture present within the scene. The range is frequently associated with the most dominant elements in the scene, be it single tree crowns in open forests, or the canopy of groups of trees in close environments. It is a measure of variability and increases as samples become more dissimilar (Gringarten and Deutsch, 2001). The semivariogram approach (Johansen et al., 2007; Nijland et al., 2009) is used in image analysis to identify the size of the relevant scene objects, and to determine an adequate window size for texture analysis (Franklin et al., 1996). Homogeneous forests require smaller windows for analysis and characterization than heterogeneous ones, which might also benefit from a series of different size windows.

The variogram approach was employed in Chapter III and Chapter IV for identification of the most adequate textural window sizes. Kriging was applied in Chapter III for interpolation of field measured plot data.

\section{Moran Index for analysis of spatio-temporal correlation}

Moran's Index (Moran, 1948) is one of the most commonly used statistical measures for spatial autocorrelation (Anselin, 1992), and it can be expressed as (eq. 7):

$$
I=\frac{N}{\sum_{i} \sum_{j} w_{i j}} * \frac{\sum_{i} \sum_{j} w_{i j}\left(x_{i}-\mu\right)\left(x_{j}-\mu\right)}{\sum_{i}\left(x_{i}-\mu\right)^{2}}
$$

Where $x_{i}$ is the variable of interest $x$ measured at location $i, N$ the number of observations, $\mu$ the mean of the variable, and $w_{i j}$ are the elements of the spatial weights matrix, which expresses the membership of observations in the neighbourhood set for each location (Anselin, 1992). For easiness of interpretation, a standardized z-value is reported instead of 
the index itself; z-value is calculated by subtracting the expected value for the statistic, and dividing the result by the standard deviation (eq. 8). When interpreted as a global measure, positive $\mathrm{z}$-values point to positive spatial correlation and negative $\mathrm{z}$-values point to negative spatial correlation; a zero value indicates there is no spatial association in the dataset. Moran's I can be interpreted as a spatially weighted form of Pearson's correlation coefficient (Goovaerts et al., 2005) and its significance is assessed against a null hypothesis of no correlation with a permutation procedure (Anselin, 2003).

$$
Z_{i}=\frac{I_{i}-E\left(I_{i}\right)}{\sqrt{V\left(I_{i}\right)}}
$$

For visual exploration and interpretation of the global Moran's I, the Moran scatterplot is a useful tool (Anselin, 1993). All observations are plotted on the horizontal axis versus corresponding spatial lags (neighbours' weighted averaged values) (Anselin, 1992) on the vertical axis. The slope of the regressive line is an estimate of the index, and points in each quadrant of the scatterplot can readily be interpreted: values in the upper right and lower left quadrants represent positive spatial association (Anselin, 1993). For the upper right the association is between values above the mean, for the lower left quadrant the association is between values below the mean. The relative density of these quadrants provides an indication of the extent to which the global measure of spatial association is determined by patterns of association between high or low values. The lower right and upper left quadrants identify spatial outliers.

For analysis of local associations or clusters, and for identification of local outliers, i.e., observations out of the local pattern, a Local Indicator of Spatial Analysis (LISA) (Anselin, 1995) is more adequate. A LISA is any statistical measure (e.g. local Moran’s I) that gives an indication of the significant spatial clustering of similar values around each observation, conditioned to sum proportionally to a global indicator of spatial association when all observations are added (Anselin, 1995). Maps of clusters (LISA cluster map) identifying and classifying (high-high, low-low, high-low and low-high) locations with significant association and significance maps can be visualized together, with the option to assess the sensitivity of results to multiple comparisons (Anselin et al., 2006).

LISA analysis of univariate data permits detection of spatial patterns of correlation at a single date. Furthermore, the option of bivariate LISA analysis facilitates temporal analysis 
of the spatial correlation, detecting if there is any association between the variable measured at a reference time and the same variable measured in the neighbourhood at a different time (Anselin, 2003).

Moran Index was applied in Chapter I for characterization of the spatial correlation of state and process of change over the landscape, and for temporal analysis of spatial associations of state and processes of change.

\section{Wavelet transformations for analysis of remotely sensed data}

Wavelet is a function that oscillates around zero, and that is localized in a finite width interval (Meyers et al., 1993). As a tool for analysis of data, Wavelet Transform (WT) techniques facilitate the characterization of non-stationary processes (Meyers et al., 1993), that is, processes of change dependent on the scale of variation. The most distinctive property of WT is the capacity to provide local information of the target series $\mathrm{F}(\mathrm{x})$ and at a range of selected scales (Lindsay et al., 1996). Basically, a WT decomposes an original series of data $\mathrm{F}(\mathrm{x})$ into a set of functions by convolving $\mathrm{F}(\mathrm{x})$ with a family of wavelets, which are derived by scaling and translation of a mother or basis function $\mathrm{G}(\mathrm{x})$. As result of the WT a number of functions are produced, one approximation (Ai) and one detail (Di) function per scale or level. The original series can always be reconstructed from its decomposed elements: at any level of decomposition (i) the original series $\mathrm{F}(\mathrm{x})$ equals that level approximation Ai plus the sum of all lower level details $\left(\Sigma D_{j}\right)(j=1 \ldots i-1)$.

For interpretation approximation functions inform trends of change whilst detail functions account for high frequency related with noise (Percival et al., 2004) and are associated with changes in averages at each given scale. A measure of variance or energy associated with each function helps identifying which are the most relevant levels of the WT decomposition (Lindsay et al., 1996).

Wavelet transforms have been used in the remote sensing community for image blending (Garguet-Duport et al., 1996; Zhou et al., 1998), for detection of haze (Du et al., 2002), spectral unmixing of hyperspectral data ( $\mathrm{Li}, 2004)$, post-classification change detection (Raja et al., 2013) and feature extraction (Simhadri et al., 1998; Fukuda and Hirosawa, 1999; Niedermeier et al., 2000). In relation to vegetation dynamics Sakamoto et al. (2005) developed a method for detection of crop phenology. Percival et al. (2004) proposed the usefulness of the multi-resolution analysis (MRA) applied to vegetation time series, with 
which Martínez and Gilabert (2009) identified seasonal and long term trend changes of various land covers in Spain. Freitas and Shimabukuro (2008) applied MRA to spectral fractions of MODIS bands for analysis of land cover change in Brazil, identifying the location and time of disturbance events.

Wavelet transforms were applied in Chapter $\mathbf{V}$ for identification of the relationship between vegetation spectral indices and aboveground biomass values as calculated from field measures, and to help identification of modelled local patterns of spectral trajectories.

\section{Dynamic time warping}

Dynamic Time Warping (DTW) is a flexible algorithm for alignment of vectors (e.g., time series) (Giorgino, 2009) that compares and evaluates the difference between series of values. DTW is more sensitive than the Euclidean distance to distortion in the time axis (Ratanamahatana and Keogh, 2005) allowing certain stretch or compression defined by user criteria, such as delays in a curve maxima or minima, and has ability to handle sequences of different lengths (Ratanamahatana and Keogh, 2005). DTW has been applied in a variety of fields, including word recognition (Velichko and Zagoruiko, 1970), biometrics (Faundez-Zanuy, 2007) and gene expression profiles (Aach and Church, 2001).

The rationale supporting DTW is that given two series of data, local stretching or compressing makes one resemble the other as much as possible, and the optimal alignment is obtained by minimization of a dissimilarity function. DTW provides a distance measure and the warping function which optimally deforms one of the two input series onto the other (Giorgino, 2009). A variety of DTW algorithms differ in the input feature space, the local distance assumed (e.g. Euclidean, Manhattan), and the presence of local and global constraints on the alignment (e.g. monotonicity) to ensure reasonable warps.

Dynamic Time Warping was used in Chapter $\mathbf{V}$ to identify similarities in time series of spectral values. 


\section{RESULTS}

Technical approaches were specifically designed and implemented for the first time in this research. The performance and main outcomes of those novel techniques are mentioned here, and the most important results are summarized. Detailed results are described in each chapter.

\section{CHAPTER I: Characterizing the state and processes of change in a dynamic forest environment using hierarchical spatio-temporal segmentation.}

- The Tasseled Cap Angle (TCA) spectral index was related with the vegetation-non vegetation proportion in a forest ecosystem, and showed proficient to describe the landscape state over time. TCA provides a bridge to link information from the entire series of Landsat sensors. The temporal derivative of the TCA trajectory, the Process Indicator (PI), managed to describe processes of forest change, including rate and directionality, of drastic and of subtle character.

- The TCA and PI condense information from the visible and near-infrared wavelengths, and constitute an instrument for characterizing the state and processes of change from lengthy time series of medium spatial resolution imagery. The Lagrange polynomial interpolation and its derivative provided a mechanism to deal with the irregular and incomplete character of the temporal series of imagery available.

- Spatial and temporal distribution of state condition and processes of change were characterized with the Moran Index, identifying patterns and local associations of state and processes at the landscape level. Thirty five years of spectral trajectories summarized by homogeneous image objects facilitated the analysis of the landscape change.

- The area chosen to test these novel tools, located in Alberta, Canada, was in a constant state of change, and maintained a high average proportion of vegetation to nonvegetation during period 1973-2008. The amount of total landscape modified per decade increased from $18 \%$ and $14 \%$ in the 1970 s and 1980 s respectively, to more than $30 \%$ and $33 \%$ in the 1990s and 2000s. On average, the proportion of vegetation to nonvegetation was increasing prior to 1981, decreasing between 1981 and 1997, and 
increasing post-1997. There was a high degree of spatial correlation amongst processes of change, with a maximum Moran’s I of 0.79 in 1973; landscape change became more spatially disperse and widespread after 1981. Temporal correlation of processes of change was observed locally, with the period 1990-1995 having the most persistent change.

CHAPTER II: Characterizing 25 years of change in the area, distribution, and carbon stock of Mediterranean pines in Central Spain.

- The location and area covered by Mediterranean pines in the Spanish Central Range fluctuated between 1984 and 2009. The analysis of the area considered revealed a net increase of $40 \%$, from 1211 to 1698 square kilometres, and a variable rate of change over the twenty five year period.

- The distribution of pine dominated areas indicates an intermittent coverage of $945 \mathrm{~km}^{2}$ actively implicated in processes of carbon exchange and a more stable carbon stock in the $765 \mathrm{~km}^{2}$ area permanently covered with pines.

- A strong relation between TCA values and density variables measured in plots dominated by pine species, (Pearson's correlation of 0.89), supported the rationale of the carbon stocking processes: in the absence of disturbance or evident removals, biomass accrual or depletions occurring naturally can be related to the carbon stock existent.

- Spectral variations detected in a series of calibrated and normalized Landsat images served to describe trends of change in carbon stocks, identifying sources and sinks. Between 1984 and 2009, there has been a clear trend of activation of the carbon pools, with a variable rate of change.

- In 2000 more than 33\% of the entire area, a maximum during the 1984-2009 period, was in a process of net carbon stocking, but there was an apparent posterior decline in the global stocking. At the end of the analysis period, $20 \%$ of the potential pine area is increasing its carbon stock and $40 \%$ of this area is experiencing a decrease. 
CHAPTER III: Modeling forest structural parameters in the Mediterranean pines of central Spain using QuickBird-2 imagery and classification and regression tree analysis (CART).

- Models of quadratic mean diameter (QMD) created with spectral and textural variables derived from the commercial satellite QuickBird-2 images (pixel sized $2.4 \mathrm{~m}$ multispectral, $0.68 \mathrm{~m}$ panchromatic) were accurate $\left(\mathrm{R}^{2}=0.8\right.$; $\left.\mathrm{RMSE}=0.13 \mathrm{~m}\right)$ and with an average error of 17\%. Average error of basal area (BA) models was 22\% (RMSE = $5.79 \mathrm{~m}^{2} \mathrm{ha}^{-1}$ ). When the measured number of trees per unit area $(\mathrm{N})$ was categorized, as per frequent forest management practices, CART models correctly classified $70 \%$ of the stands, with all other stands classified in an adjacent class.

- The pattern of residuals generated in models indicates that the accuracy of the attributes estimated is expected to be better when canopy cover is more open and attribute values are at the lower end of the range present.

- The outcomes of this work indicated that attributes derived from HSR imagery captured from space-borne platforms have capacity to inform on local structural parameters of Mediterranean pines.

\section{CHAPTER IV: Forest structural diversity characterization in Mediterranean pines of central Spain with QuickBird-2 imagery and canonical correlation analysis.}

- Combining multiple aspects of tree conditions at a stand level, forest structural diversity was characterized at the plot level $(\mathrm{N}=1022)$ as a linear combination of the median of absolute differences (MAD) of individual trees' bole diameter, height, and crown diameter, from the local median equivalents. Ground measured forest diversity showed robust relations with multispectral reflectance variations in the visible and NIR wavelengths (2.4 m spatial resolution), as well as image co-ocurrence texture metrics from the panchromatic imagery (0.68 $\mathrm{m}$ spatial resolution), generated at various window sizes. 
- Canonical correlation analysis aided identifying combinations of reflectance and texture metrics generated from circular 0.3 ha areas most highly related with forest structural diversity ( $\mathrm{R} \sim 0.89)$.

- Reflectance diversity was found to be more important than co-occurrence texture features in describing forest structural diversity when forest structure was limited ( $R \sim 0.47$ versus $R \sim 0.39$ ), whereas texture was more informative to the model when the forest structural diversity was high $(\mathrm{R} \sim 0.88$ versus $\mathrm{R} \sim 0.63)$ - relating more complex forest conditions.

- While diameter variability was the most relevant parameter in building the forest structure diversity variate, contrast and homogeneity were the image variables most strongly correlated with forest structural diversity.

\section{CHAPTER V: Historical forest biomass dynamics modelled with Landsat spectral trajectories.}

- Spectral trajectories modelled from a 25-year period of Landsat images and supported with ground data from the National Forest Inventory, successfully predicted aboveground biomass retrospectively at specific dates (1990 and 2000).

- Patterns of change found in Normalized Difference Vegetation Index values were associated and related well to classes of past AGB. The Tasseled Cap Angle index was found to be strongly related with forest density, although the related patterns of change had little relation with variability in historic AGB. 25-year patterns provided more accurate information than 15-year patterns, but a combination of both explained better the historical AGB variability.

- Binary models (CART) of biomass built at the pixel level were successfully scaled to the object level, with 95\% of objects characterized by dynamic variables (temporal spectral trajectories) fitting rules to the final nodes of the decision tree.

- Maps of biomass dynamics in the period 1990-2000 were produced with 70\% accuracy, providing a reliable source of historical spatial information. 
- In an area permanently covered with pines during period 1984-2009, the aboveground biomass increased 18\% between 1990 and 2000 with an irregular spatial distribution of the change. On average, the AGB of these pines accumulated $0.65 \mathrm{t} \mathrm{ha}^{-1} \mathrm{y}^{-1}$ of $\mathrm{C}$ in the decade 1990-2000, equivalent to a $2.38 \mathrm{t} \mathrm{ha}^{-1} \mathrm{y}^{-1}$ fixation of $\mathrm{CO}_{2}$. 
Assessment of biomass and carbon dynamics in pine forests of the Spanish Central Range: a remote sensing approach 


\section{DISCUSSION}

Assessment of forest aboveground biomass and its dynamics over time at the landscape level involves evaluation of diverse and related aspects. The location, extent and distribution of the forest area, as well as any changes over time require identification; the forest quality, that is, its structure and diversity, has to be described; ongoing successional processes and trends of change characterized; models derived from available data and extended to the entire area, and maps accounting uncertainties created for informed interpretation by users. Remote sensing technology is well suited to support these activities and has become the primary data source for biomass estimation ( $\mathrm{Lu}, 2006)$ in medium to large areas. Synoptic, repetitive and consistent observations of the landscape provide information in a range of electromagnetic wavelengths associated with forest traits at affordable cost (Bettinger and Hayashi, 2006) to assist in the process of regional and global forest biomass assessment and monitoring.

The work performed in this doctoral thesis covered a range of topics necessary for the assessment of forest biomass at the landscape level. Novel methods were developed building on the most recent research literature, which in turn contributed to the advance of scientific knowledge on the field. Remarkably, analysis and interpretation of medium spatial resolution temporal spectral trajectories and associated temporal derivatives for description of landscape change and forest carbon dynamics, application of hierarchical spectro-temporal segmentation for combined interpretation of the state and processes of change across the landscape, and modelling patterns of spectral trajectories associated with past biomass values are original techniques designed and applied here for the first time.

Interpretation of temporal spectral trajectories for assessment of landscape processes has only recently become possible. Methods for analysis of spectral time series are being developed, leveraged by the free access to high quality archived imagery and by improved computing capacity (Wulder et al., 2012a). Pixel level processing is intuitive and prevalent, but ecological processes rarely conform to single pixels. The extension of processing methods developed in the temporal realm at the pixel level into patch aggregation methods remains a conceptual difficulty (Kennedy et al., 2014). In particular, defining objects that remain meaningful over time is a fundamental challenge (Chen et al., 2012): a homogenous entity identified at initial stages of the period of analysis might be 
only partially changed over time, losing its initial integrity for interpretation. Methods considering temporal linkages (Hofmann and Blaschke, 2012) are being developed to cope with this kind of limitations in object-based analysis of change. In this context, the nested hierarchy of spatial units (Gómez et al., 2011a) constitutes an optional framework for analysis and interpretation of landscape dynamics. The approach is based on a double way (top-down and bottom-up) (Hay et al., 2001) transfer of contextual information between various spatial levels, where the larger spatial objects encompass the smaller ones and each level is defined with a different similarity condition. The criteria and order for definition of meaningful units in a hierarchical multi-scale segmentation is important for interpretation and analysis (Gómez et al., 2011a).

Temporal segmentation was coined and applied for the first time by Desclée et al. (2006), partitioning a two-date image stack into spatial objects. These objects incorporated temporal information that facilitated identification of change or no-change by statistical comparison of averaged spectral signatures. This temporal segmentation technique has been enhanced by inclusion of more imagery into the stack (Bontemps et al., 2008, 2012) and has been applied followed by other types of analysis (Conchedda et al., 2008; Duveiller et al., 2008) for evaluation of landscape change. The hierarchical spectrotemporal segmentation approach developed in this thesis capitalizes on the compilation of temporal series of spectral values related with forest condition (state) and processes of change, to define homogeneous forest units. Rather than single date spectral or textural image values, the criteria of similarity for definition of three nested levels of spatial units were forest state and process of change (as related by spectral vegetation indices) at specific dates, facilitating the analysis of the landscape at various spatial scales. The hierarchical spectro-temporal segmentation is a flexible approach that allows diverse criteria of similarity in relation with the analysis perspective.

Inference of forest condition from traits of past spectral trajectories is a current and promising field of research (e.g. Pflugmacher et al., 2012; Ahmed et al., 2013). A new temporal segmentation concept has emerged (Kennedy et al., 2010) with methods designed for application to dense time series of images (one image per year), whereby pixel-level temporal trajectories are segmented into fragments representative of processes of forest change. Some features of these temporal spectral fragments (e.g. onset, duration) have demonstrated powerful for prediction of current forest structural attributes (Pflugmacher et 
al., 2012). In areas where annual data of enough quality are not available, data modelling contributes to overcome difficulties related with the incompleteness and irregularity of the spectral series, and to enable interpretation of continuous change. Our approach shows that under certain conditions, an entire spectral trajectory (of certain duration) enables the inference of forest past attributes. Patterns of temporal spectral trajectories of medium spatial resolution were considered as dynamic variables to model values of past biomass (at specific dates) in a Mediterranean environment. In this area, sudden perturbations had not been the rule during the period of analysis, and semi-natural succession could be assumed. Past values of biomass constitute a valuable baseline, necessary as reference in scenarios of change (Krankina et al., 2004).

Non-parametric techniques (e.g. neural networks, decision trees) improve the accuracy and precision of more traditional methods (e.g. multivariate regression) in models of forest structural attributes based on optical imagery, particularly when the linear relationship between field and spectral data is relatively weak (Chirici et al., 2008). Non-parametric methods facilitate identification of non-linear relations and inclusion of numerous predictors into the models (Aertsen et al., 2010). Furthermore, decision trees are easily applied and interpreted. Notwithstanding notable improvements in modelling algorithms, optical data is a limited source to inform forest condition, constrained by the inability to provide below canopy structural information. Although Lidar technology has lately bloomed in forestry research and operational applications (Wulder et al., 2013), with direct measures of the canopy height enabling derivation of other variables of interest (e.g. volume, biomass), its use is unfeasible or economically unaffordable for large area wall-towall applications. Optical data is supportive in combined modelling approaches (Ke et al., 2010; Chen and Hay, 2011), providing complete coverage complemented by a sample based Lidar dataset (Wulder et al., 2012b). Lidar data captured over the study area (Villa et al., 2009), not available at the time of the study, might complement and improve some of the results obtained in this work. For applications based on historical data, Landsat is definitely the only reliable data source. 


\subsection{Location, extent, distribution, and change of pine forests}

The area and distribution of pines in the Central Range of Spain varied during the twenty-five year period studied (1984-2009). The characteristic spectral signature shown by pines and a multilevel object-based classification of geometrically coincident and radiometrically calibrated historical images acquired at regular intervals, enabled reliable identification of changes over time. Land use in the Central Range of Spain is governed by national and regional administrations, and land use changes do not proliferate. Moreover, pines have been managed in a sustainable manner for several decades (Bravo et al., 2010), with extractions of light intensity and assurance of regeneration by natural methods or plantation; clear cutting is not a local forest practice. To detect the expected small variations of the pine dominated area, the approach applied was based on objects with contextual information (Johansen et al., 2010) and included the Tasseled Cap Angle (TCA) among the input features to aid in sorting stand density. Thanks to the multilevel character of the land cover classification approach implemented (Gómez et al., 2012a), simultaneous detection of larger stands with the required characteristics (species and density) and smaller objects in patchy areas was possible. This technique is of particular interest to distinguish small changes in distribution that would otherwise blur into larger objects or be rejected as a speckle effect in a pixel-based classification. Results indicate that the pine dominated area in the Central Range increased $40 \%$ from initial to final date; there was an area permanently covered with pines and a large extent only temporarily occupied during these decades.

One of the difficulties when comparing the Spanish National Forest Inventory (NFI) data for assessment of change is the declared disparity of base cartography used in each NFI repetition (Vallejo, 2005). With a historical series of good quality images available, retrospective studies of change become feasible and offer increased precision. In this work images acquired at time intervals similar to NFI repetitions (10 years) were classified, and results are in agreement with other works based on field data comparison (i.e. indicating a trend of increment in forest area). The spatially detailed information provided and the capacity to readily incorporate data at intermediate dates for more detailed reports are key strengths of methods based on remotely sensed data. The classification accuracy, assessed with independent reference information (Congalton and Green, 1999), was $>90 \%$ in the 
present work. The accuracy of the multiple dates' classifications relied on the exhaustive process of radiometric normalization, since class signatures were transferred from samples acquired in reference image.

Further discussion and deeper insights can be found in Chapter II.

\subsection{Landscape processes and spatio-temporal associations}

Forest landscapes are dynamic ecosystems with different processes of change ongoing at any given time, which affect the quality and quantity of biomass and carbon stocks. Although a variety of remote sensing techniques have the capacity to detect stand replacing events, the detection of subtle alterations that result in only minor spectral changes remains a challenge (Goodwin et al., 2010) as different phenology and illumination of images induce detection of false change. To detect and assess forest cover condition the Tasseled Cap Angle (TCA) is a valuable tool, reporting the proportion of vegetation to non-vegetation (occupation state) in a defined area. A temporal series of spatially coincident and radiometrically normalized images providing TCA temporal trajectories for individual locations (pixel or object) enables the assessment of change in the proportion of vegetation to non-vegetation. The temporal derivative of the TCA series, the Process Indicator (PI), informs rate and directionality of ongoing processes, providing informative values at individual dates. These coupled indices, TCA and PI, condense information from the visible and NIR wavelengths, and facilitate comparison of data from all Landsat sensors, enabling the study of forest landscape change with a lengthy series of historical satellite images dating from 1972 to present. Temporal derivatives had been used in temporally dense series of low spatial resolution images, and were implemented in our study for the first time on a series of Landsat images, encouraged by a long series of images subject to robust radiometric normalization and the flexible polynomial approximation of Lagrange (Gómez et al., 2011a).

With disrupting artefacts suppressed, the PI would be able to account for a wide variety of change types, providing information of slight or substantial modifications that is made available by a temporal series of three or more normalized images: low positive values of PI indicate a slow increment in the occupation state due to natural growth, while low negative values of PI point to natural processes of decay, such as aging or disease, or human induced modifications such as partial harvest or thinning. More notable and fast 
changes in the occupation state, like a disturbance with reduction of vegetation or a process of vegetation emergence are indicated with high negative or positive PI values, respectively. The capacity to relate both positive and negative changes is a powerful aspect of the PI, unveiling insights relating both forest (vegetation) gain and loss.

Analyzing a temporal series of images supports the assessment of trends and rates of change that otherwise might be missed with only a bi-temporal change detection approach (Lunetta et al., 2004). The adequate interpretation of tendencies is conditioned by the time interval between consecutive images, and the scarcity of data for any one period may preclude a complete understanding of the landscape change. A decadal interval might be sufficient for preparing a summary of conditions and for planning silvicultural treatments and wood extractions, but more frequent information is required for monitoring of forest health and biomass. Jin and Sader (2005) recommend a period of three to five years for interpretation of condition and change in a forest area, but the ideal number of images and acquisition timing is site dependent (Wilson and Sader, 2002) and often restricted by image availability. In a very dynamic forest landscape in Canada, where we tested this technique of analysis for the first time, a quasi-quinquennial interval was considered for evaluation of change processes (PI) and a decadal interval for summary of change in the landscape state (TCA) obtaining sound and useful outcomes.

As long as temporal factors are considered, the interpretation of TCA and PI may be combined to provide insights on the processes of change that are active in a forest landscape: varying rates of cover change could have different effects on dense or open forests and could trigger different phenomena. A simultaneous view of occupation states defining the landscape pattern and current processes of change could help understanding the relation between pattern and process, a recursive question difficult to solve in landscape ecology (Turner, 1989; Walsh et al., 2009). The combined interpretation acts to facilitate analysis of successional patterns, and the contextual temporal information given by the TCA enables proper interpretation of change that may be confounded with traditional techniques (Masek et al., 2008). The TCA provides information of vegetation proportion and the PI gives an instantaneous picture of the process of change; together with some ecological knowledge, forest seral stages may be identified (i.e., young stand growing, young stand with disease, mature stand in decay, recovery from disturbance, or 
other situation). It must be noted that in order to enable accurate understanding of a trajectory of change, some knowledge of the local ecology is always required.

The spatial scale is a key parameter for assessment of ecological processes. To provide meaningful reporting units and to investigate the spatial and temporal correlation of occupation state and ongoing processes, we defined objects analogous to forest stands, implementing an object oriented approach. A data driven method was implemented in the definition of spatial units, based on homogeneity of areas at the initial and final dates of the period under investigation (1973-2008). The transmission of significant contextual information was assured by the establishment of a hierarchy of spatial levels: larger objects defined by initial state (TCA) similarity and smaller objects defined by final state similarity are connected through an intermediate spatial level defined by similar processes of change, as depicted by the entire trajectory of PI.

Spatial and temporal correlation is a complex and scale dependent phenomenon that is expected in natural environments. In the time period analyzed, some relations and patterns were unveiled for occupation state and change processes in the target area. The spatial correlation of occupation state was always positive, with objects of similar state clustering together; change processes were positively correlated at the global spatial level, but the tendency was towards lower association over time, creating a mosaic of ongoing processes.

Further discussion and deeper insights can be found in Chapter I and Chapter II

\subsection{Carbon stocking processes}

The rationale of the combined TCA and PI, obtained from a time series of Landsat images, to describe state and processes of change was applied in pines of the Spanish Central Range, capitalizing on the local relation of these spectral indices with forest variables. The TCA is strongly correlated with stand density in the study area, and its temporal derivative, the PI, characterizes rates and directionality of change, enabling description of processes. Biomass accrual occurs naturally in the absence of disturbance, unless there is depletion in cases where removals are evident, and carbon equivalents generally follow the same logic. Analyzing and interpreting the spectral dynamics of pines, results show that the carbon stocking pools of the study area have been activated in the 
second half of the analysis period (1984-2009), when larger areas show faster rates of carbon stocking rise and carbon stocking fall.

The TCA index is relatively new, but the relation of Greenness to Brightness components of the TCT for characterizing forest density classes and successional stages has been used before in various forest environments. TCA and PI, as resulting from the TCT, are scene dependent (Crist and Cicone, 1984). Since the TCA is strongly related with forest density in the study area, with three or more consecutive images the PI enables characterization of relative rates of change in forest density and carbon stocks. Possible artefacts induced by annual phenology dissimilarities are minimized by a rigorous process of image normalization. Trends in carbon stocking were analyzed for the area potentially covered by pine during the entire period, and rates of change were assessed, comparing outcomes from the areas permanently or intermittently covered with pines. There was a global trend towards activation of carbon pools, and the intermittent area showed higher variability of processes, whereas the area of permanent pine had a near to neutral carbon pooling character. A combined interpretation of the TCA and the PI can provide simultaneous view of forest density and ongoing relative carbon stocking processes.

The PI continuous scale of values provides versatility in change detection capacity and enables the characterization of rapid (high PI values) and slow (low PI values) rates of change. Subtle changes in forest density can be detected, which is of particular interest in the Mediterranean area, where the majority of forests are subject to some drought and consequently are relatively slow growing when compared with other temperate areas (Merlo and Croitoru, 2005). In managed forests, partial harvest or thinning operations might be detected (low negative PI value) and later recovery of density tracked (positive PI value). If the silvicultural goal is to maintain a constant value of basal area, a time series of PI values would remain close to zero. Historic trends of relative carbon stocking can be assessed, and the effect of management practices monitored with detailed spatial information. A PI based approach is especially informative for locations characterized by subtle, non stand-replacing disturbances.

Further discussion and deeper insights can be found in Chapter II. 


\subsection{Forest structure and structural diversity}

Forest structure and variability provide information of standing biomass and carbon content. Structural parameters such as quadratic mean diameter (QMD), basal area (BA), and number of trees per unit area $(\mathrm{N})$ are crucial data for estimation of biomass and for carbon account. These parameters are typically measured on the ground in a limited sample of plots, frequently restricted to managed forests. Estimation of structural parameters and variability over large areas for comprehensive assessment of biomass can only be achieved by modelling, and requires adequate input data. Furthermore, the necessity to account and evaluate forest biodiversity imposed by international commitments, obliges quantification of structural diversity (Gordillo et al., 2001) and makes appealing the exploration of remote sensing as an optional means for this purpose (e.g. Alberdi Asensio et al., 2009).

High spatial resolution QuickBird-2 imagery $(2.4 \mathrm{~m}$ multispectral and $0.68 \mathrm{~m}$ panchromatic) was tested as source of data for modelling structural parameters (Gómez et al., 2012b) and as potential surrogate of field measures for evaluation of forest structural diversity (Gómez et al., 2011b). Reflectance and texture metrics were considered in both efforts. In modelling structural parameters the results showed reasonable accuracy $\left(\mathrm{R}^{2}=\right.$ 0.8 ) and precision (estimation relative error $\sim 17 \%$ ) for the QMD model and robust models $(\mathrm{R}>0.7)$ for $\mathrm{BA}$ and $\mathrm{N}$ but with higher estimation relative error (22-31\%). A strong relationship between field-derived and image-derived diversity features was found at the plot level when an appropriate range of variation was considered, indicating the potential of remote sensing and image processing as an approach for characterization of forest structural diversity over wide areas.

Although management plans were initiated in Spanish forests more than a hundred years ago (Bernués, 2008), less than 20\% of the treed forest area in Spain is currently governed by a management plan under formal implementation (MMA, 2009). The high cost of field inventories is frequently noted as a reason for this unfavourable proportion, limiting surveys to forests with high potential to produce economic revenue. However, with the increasing concern over environmental issues, current forest inventories are aimed at informing a variety of long-term objectives including biodiversity, carbon accounting, habitat protection, and sustainable timber production (Wulder et al., 2004b). Remote sensing can contribute to the ability to produce timely, cost efficient inventory estimates 
via image segmentation for stand delineation (Leckie et al., 2003; Pascual et al., 2008) and statistical modelling for assessment of attributes with acceptable precision (McRoberts and Tomppo, 2007). If adequately trained, segmentation algorithms have the ability to semiautomatically divide images into structurally homogeneous areas only requiring human revision (Wulder et al., 2008e), that can be used as strata to optimize the field sampling design (Lamonaca et al., 2008) and allow the reduction of sample collection needs. In other words, the complete spatial coverage of remotely sensed images allows thinning the dense network of sample plots required for an adequate assessment of varying conditions (Maselli, 2004) typically found in Mediterranean environments. Remote sensing is not seen to fully supplant the need for field measures, but to spatially and temporally augment such measures, with regular and consistent data acquisitions; in particular, HSR satellite sensors emerged a few years ago as promising data sources for forest inventory (Culvenor, 2003; Falkowski et al., 2009a) providing consistent and frequent imagery. Our studies demonstrate that in Mediterranean pines of Spain, QuickBird-2 or similar imagery combined with modelling techniques would be useful and affordable for assisting in the assessment of structure and diversity of forest areas with a variety of objectives (e.g., recreation, carbon storage), though caution is required to deal with inherent modelling uncertainties.

Among the strengths of HSR imagery is the high geometric fidelity (Aguilar et al., 2008) and the possibility to identify individual elements such as trees or groups of trees. Textural and spectral signatures provide information that is complementary ( $\mathrm{Lu}$ et al., 2002), for estimation of forest parameters ( $\mathrm{Lu}$ and Batistella, 2005) and evaluation of structural diversity. Image texture is influenced by several biophysical parameters including crown diameter, distance between trees, tree positioning, Leaf Area Index (LAI), and tree height, and has demonstrated to improve structural models in a variety of environments (e.g. Wulder et al., 1998; Chubey et al., 2006) being particularly useful in complex structures ( $\mathrm{Lu}$ and Batistella, 2005). The importance of the window size for evaluation of texture measures has been stressed (Ferro and Warner, 2002; Kayitakire et al., 2006) and the variogram approach is recommended as an appropriate method to guide window size selection (Franklin et al., 1996). A common variogram range value was found in our two study sites (with open and closed canopy conditions), which is coincident with the median value of crown diameter present; additional range values were found, as a function of the 
local structural diversity. The absence of shadows in the imagery allowed identification of individual trees as dominant textural objects on the ground (Kayitakire et al., 2006). Alternately, for monitoring programs with various dates of imagery and more than one scene, off-nadir view angles and differing solar and atmospheric conditions should be considered (Wulder et al., 2008f) as they may pose analysis difficulties. The limited use of texture parameters previously indicated as due to a lack of software tools (Bruniquel-Pinel and Gastellu-Etchegorry, 1998) is progressively being overcome, but other considerations remain, such as viewing and illumination configurations, spectral domain, and spatial resolution. However, image texture analysis has demonstrated utility for characterizing habitat structure (St-Louis et al., 2006) and to identify areas of high diversity with conservation priority.

Combining complex data of different nature and origin requires a careful choice of tools for processing and analysis. Classification And Regression Trees (CART) models are easily interpreted and applied, with few statistical requirements imposed that make it an appropriate method of estimation in forest environments. Data employed in support of modelling efforts also require conscious use to allow consideration of all sources of uncertainty: for instance employing data from field inventories of managed stands has an intrinsic limitation related to the dearth of measurements of small trees, possibly related to a bias of the data considered as truth, and could lead to underestimation trends in models. Accurate spatial location of field plots and high quality geometric processing of the remotely sensed data are important factors to develop strong empirical models, particularly in Mediterranean forests with complex topography (Salvador and Pons, 1998) which often results in high spatial heterogeneity (Neumann and Starlinger, 2001). The amount of data used for calibration has an impact on the accuracy of models, tending to increase with increasing calibration sample size (Ferro and Warner, 2002). Mora et al. (2010) in Yukon (Canada) demonstrated that a smaller calibration dataset (30\% of the sample) could perform adequately if there were difficulties to obtain reference information, making CART methods even more appealing tools for inventory. With a simple structure, that is, low number of rules and final nodes, CART constitute a practical and parsimonious tool to classify stands for management or planning.

Diameter and basal area are the attributes most frequently used in studies of structural diversity (Solomon and Gove, 1999; Varga et al., 2005; Motz et al., 2010) and forest 
structure per se (Goodburn and Lorimer, 1998; Rouvinen and Kuuluvainen, 2005; Rubin et al., 2006). Field measured variables (dbh, height, and crown diameter) were included in characterization of structure diversity for ease of measurement (McElhinny et al., 2005) and as identified by Río et al. (2003) among the most important aspects of forest structure. Dbh was found to be the attribute indicating variation in forest structure at the plot level that had the highest relevance. Height showed slight importance but is still relevant to the model, as shown in the sensitivity analysis. Height variation is difficult to detect with optical sensors (Mora et al., 2010), which are better suited for mapping horizontal structure (Hyde et al., 2006). Although shadows and gap fraction are sometimes useful (Shettigara and Sumerling, 1998; Leboeuf et al., 2007), the images used in our investigation, captured with high elevation angles (> 60 degrees), did not include significant shadows. Including LiDAR measured heights in the modelling process may improve the study results, as fusion of high spatial resolution and LiDAR data is an approach yielding good results (StOnge et al., 2008; Ke et al., 2010; Chen and Hay, 2011).

Furthermore, the scale of analysis is an important factor when measuring or characterizing diversity (Lähde et al., 1999), and was determined in our case by the availability of field data. The detailed plot-level measures available made for a logical informational link between the field and image-based data sources with both of a comparable scale. At this scale of analysis (alpha diversity) the study showed there is potential for characterization of structural diversity from the space. Lamonaca et al. (2008) reached similar conclusions in a study that applied an object oriented approach for characterization of the structure diversity in Mediterranean environments at the stand level. Pasher and King (2010) modelled and mapped forest structural diversity in temperate hardwood forests of Quebec (Canada) with airborne derived data, highlighting the convenience of satellite derived data for mapping of larger areas.

Interestingly, we found that the relation between the variability in image derived variables and forest structural diversity was stronger when considering various crown closure conditions pooled together, that is, open and dense forest sites' data analyzed jointly, than when considering either individual scenario alone. In our scenarios of relatively low structural diversity, considering close or open canopy conditions individually, the variation in reflectance of the visible and NIR was more explicative of the structural diversity than variations in texture measures evaluated with finer spatial resolution panchromatic data. 
Similarly, Rocchini et al. (2010) highlight the relevance of spectral resolution versus spatial resolution for evaluation of species diversity, supported by a series of studies in different environments that buttress this idea.

As demonstrated in our studies, HSR imagery from optical sensors, integrated with field measures provides a useful approach to investigate and characterize forest structure and structural diversity in Mediterranean pine forests. The acquisition of periodic HSR coverage of the entire Spanish territory by the Plan Nacional de Teledetección (PNT) poses an unprecedented opportunity to use remote sensing for assessment of the structure and diversity of Spanish forests that managers should strongly consider.

Further discussion and deeper insights can be found in Chapter III and Chapter IV

\subsection{Historical biomass modelling, mapping, and dynamics}

As a baseline for comparison with more recent estimates, an assessment of past aboveground biomass (AGB) with spatial detail is of value to support monitoring and reporting commitments. Historical forest AGB was modelled, evaluated, and mapped, combining a set of NFI plots representative of the forest conditions present and spectral data captured by Landsat sensors over a period of 25 years (1984-2009). In this area, characterized by absence of major perturbations and moderate human intervention during succession stages, dynamic variables of change (i.e. predictors combining data captured at various dates), showed higher predictive capacity than static variables to explain the variability of AGB retrospectively.

Spectral response related to forest structure (Cohen et al., 1995) develops progressively with successional state (Peterson and Nilson, 1993). Under equal environmental conditions and absent disturbance, forest stands develop similarly and are expected to show similar temporal spectral trajectories, although slight deviations from a pattern may exist. However, although forest attributes have been modelled accurately with spectral variables, forest change remains elusive for direct modelling: spectral differences alone have demonstrated inadequate for the purpose (Healey et al., 2006), and trends of spectral trajectories do not necessarily have a direct relation with the increase or decrease of biomass (Campbell et al., 2012). 
Previous attempts to model biomass in the Central Range of Spain with single date optical data were limited, characterized by moderate fitting correlation $(\mathrm{R}=0.7)$ and mean error of 0.78 (Gómez, 2006). Also in the same area, Vázquez de la Cueva (2008) found structural parameters (canopy crown closure, stand height, stem density, and basal area) insufficiently explained by the multispectral predictors selected to derive empirical models; however, the Tasseled Cap Wetness had a stronger relation with forest density than NDVI or other TM/ETM+ bands. Interestingly, in the present work the TCA was found significant as static variable, while patterns associated with NDVI were relevant as process variables. The Tasseled Cap Distance (TCD), more related to age and associated structural complexity than other Tasseled Cap related indices in coniferous forests of Oregon, USA (Duane et al., 2010), was also found linked to forest diversity in these Mediterranean pines, despite a low correlation between AGB and parameters of structural diversity. In view of local difficulties to directly model forest attributes with Landsat data, mathematical transformations based on 2D wavelet algorithms were applied to a data-system created with information from two rounds of field measures and eight repetitions of calibrated spectral data. This technique helped filtering fundamental relations from environmental and endogenous noise. Dynamic variables (i.e. variables with an inherent temporal component) associated with patterns of change, including rate and shape, characterized ground plots, and together with static variables served to model AGB and calculate AGB dynamics. This approach significantly improved previous results, but no single predictor was able to accurately classify biomass.

Frequency and regularity of measurements can be critical in providing an accurate understanding of ecological processes. Gaps in a series of measures and irregular data frequencies leave intervals of uncertainty in explaining continuous processes that might be notable in ecosystems prone to rapid changes related to disturbance (Jin and Sader, 2005). Successional patterns are more predictable in undisturbed forests than in areas with unexpected perturbations (Schroeder et al., 2007; Vogelmann et al., 2009) and the rate of spectral variation is typically greater in immature stands when compared to more mature stands in similar environments. Wavelet transform analysis is particularly suited to detect anomalies in series of data (Mallat and Hwang, 1992) and does not require periodic sampling (Daubechies et al., 1999), conferring this approach versatility for analysis of data in a wide range of environments. The limited number of seasonally appropriate, cloud-free 
images available at the time of this study is not necessarily indicative of the full Landsat archive, which the USGS is currently consolidating with unique images held by International Cooperators (Loveland and Dwyer, 2012). As of writing, the European Space Agency has yet to provide Landsat data through the free and open access model demonstrated by the USGS. Reportedly there are plans to share these European images with the USGS, which when implemented, will improve the density of images available over Spain.

The temporal configuration (i.e. the duration, starting point, and position relative to the target date) of the dynamic variables presumably affects the capacity to predict structural and successional forest attributes, as suggest different results in modelling AGB in 1990 and 2000. $\mathrm{AGB}_{1990}$ corresponds with the initial stages of a trajectory to resemble one of a series of temporal patterns, with possible deviations or delays of key features. Deviation of forest stands from standard expectations of development is often related to site index differences, canopy cover and density, or species characteristics, factors requiring attention when deriving, applying, and interpreting model results. Alternatively, $\mathrm{AGB}_{2000}$ corresponds with an intermediate position of the available spectral trajectories, with which processes are not aligned. The duration of spectral trajectory necessary to identify significant temporal patterns in AGB is presumably variable and site dependent. Liu et al. (2008) demonstrated that a series of images covering a longer period predicts forest age more accurately, but in some cases a shorter time series of imagery may suffice. In our work, a combination of 25-year and 15-year trajectories was the best option for estimating retrospective AGB. Longer-term patterns may potentially explain the variability of AGB more precisely, but they may also introduce irregularities outside the time lapse between data used for calibration of the trajectory models; on the other hand, shorter-term patterns are more explicit and less prone to variations out of the reference period. Further work is necessary to clarify the distinctive effect that duration and relative location of spectral trajectories produce when employed as dynamic variables. Another set of ground plot measures (NFI4 ca. 2010) in the study area is expected to be released shortly, with available spectral data completing the temporal series to that date and beyond. Hence the duration, starting point, and temporal character (retrospective, prospective or inclusive) of the trajectory will be available for further exploration. 
The uncertainty remaining in maps of AGB dynamics originates from possible imprecision in modelling, but also from the various stages in the overall approach, including location of plots, field measures, allometric equations, image capture, and image processing (Lu et al., 2012). To minimize the impact of these factors, a representative sample acquired to consistent specifications, such as NFI plots, is recommended for modelling (Duane et al., 2010), and necessary to obtain a comprehensive domain of trajectory patterns for accurate identification by the similarity algorithm. Confusion was identified in the final map of change with an inclusive approach of all error sources, but from plot based model to final maps, some aspects could be subject to individual testing, such as the equivalence of pixel and object trajectory or the vector to raster transformation.

Our estimates of AGB dynamics between 1990 and 2000 are in agreement with complementary regional studies. For instance, pines in the Central Range were found to be more dense and mature in year 2000 than during the previous decade, and - as could be expected - accounted a net increment of biomass and carbon stock. On average, our estimation was that the AGB of these pines accumulated $0.65 \mathrm{tha}^{-1} \mathrm{y}^{-1}$ of $\mathrm{C}$ in the decade 1990-2000. Analyzing inputs and outputs recorded by NFI measures, Herrero and Bravo (2012) corroborated a net carbon sinking character between NFI2 and NFI3 rotations, with AGB allocated in pines of $85 \mathrm{t} \mathrm{ha}^{-1}$, while Montero et al. (2004) estimated an annual increment of $0.9 \mathrm{t} \mathrm{ha}^{-1}$ of pine biomass between 1993 and 2003.

Modelled spectral trajectories have been useful for characterizing mountain pine beetle infestations (Goodwin et al., 2010) and for prediction of forest change (Zhu et al., 2012). Directly linked to field derived measurements, the information provided by Landsat spectral trajectories has proven useful to improve estimation of current biomass and other structural attributes, particularly in ecosystems with stand replacing disturbances (Pflugmacher et al., 2012). The identification of temporal patterns in the trajectory of vegetation indices (i.e. dynamic variables) was found in this work to provide useful information to model and explain historical biomass variability.

Further discussion and deeper insights can be found in Chapter V. 


\section{CONCLUSIONS}

\section{Overall}

Pine forests in the Central Range of Spain constitute a spatially and temporally dynamic stock of biomass that plays a significant role in the regional carbon budget. For assessment of forest above ground biomass (AGB) and carbon (C) resources, remote sensing supports and enhances the value of the National Forest Inventory (NFI), complementing rather than substituting essential field work. Access to archived historical and contemporary images of high and consistent quality, provides the opportunity to build up methods for unveiling information related to the development of forest ecosystems that would otherwise remain incomplete or unknown.

\section{Particular}

1. The location, extent, and distribution of forest resources in central Spain can be effectively and accurately evaluated with optical images of medium spatial resolution obtained with sensors onboard satellite platforms. The historical Landsat archive enables the characterization of past conditions, and the assessment of four decades of change in forest resources. The area covered by Mediterranean pines in the Spanish Central Range fluctuated between 1984 and 2009, with a net increase of $40 \%$ and a variable rate of change over the period. The distribution of pine dominated areas indicates an area of intermittent coverage actively implicated in processes of carbon exchange and a more stable carbon stock in the area permanently covered with pines.

2. High spatial resolution data obtained remotely and available from commercial sources provide useful information for characterization of forest structural parameters, and for assessment of structural diversity. Spectral variables from the visible and near infrared spectrum range, and spatial variables in the form of image texture support this process, showing variable relevance as a function of canopy closure: homogeneous areas are better characterized by spectral measures while texture variables are more relevant in structurally complex areas. In Spain, the Plan Nacional de Observación del Territorio (PNOT) acquires national coverage of high spatial resolution (2.5 m) imagery annually, providing an opportunity to support the evaluation of forest resources for planning and decision making.

3. The forest area in the Spanish Central Range considered in this work was a net $\mathrm{C}$ sink over the period 1984-2009, with dynamic temporal and spatial distribution of sources and sinks. Between 1984 and 2009, there has been a clear trend of 
activation of carbon pools, with a variable rate of change. In 2000 more than a third (567 $\mathrm{km}^{2}$ ) of the entire area, a maximum in the 1984-2009 period, was in a net process of carbon stocking.

4. In the area permanently covered with pines during period 1984-2009, the AGB increased 18\% between 1990 and 2000, with an irregular spatial distribution of the change. On average, the AGB of these pines accumulated $0.65 \mathrm{t} \mathrm{ha}^{-1} \mathrm{y}^{-1}$ of $\mathrm{C}$ in the decade 1990-2000, equivalent to a $2.38 \mathrm{t} \mathrm{ha}^{-1} \mathrm{y}^{-1}$ fixation of $\mathrm{CO}_{2}$.

5. Temporal series of calibrated and co-registered medium spatial resolution imagery provide information associated with forest successional processes and, when supported with spatial statistics, enable identification of spatial and temporal relations between patterns and processes at the landscape level. Reliable comparisons of information along temporal series of data are based on accurate calibration of imagery and on the application of spectral measures that provide consistent information across sensors. Vegetation indices derived from the Greenness and Brightness components of the Tasseled Cap Transformation, the Tasseled Cap Angle and the Process Indicator, were shown to be good measures to bridge information between all Landsat sensors.

6. Information provided by series of temporal spectral data captured remotely can be related to patterns of forest succession. Spectral trajectories inform about stability or change, and about trends in structural and sanitary condition. Temporal traits of spectral trajectories showed capacity to inform on forest condition at a given point in time. Although the processing, modelling, and interpretation are in the early stages of development, spectral trajectories are a promising source of information for the study of ecological processes and the assessment of retrospective and present ecosystem attributes.

7. The results of this work corroborate that remote sensing supports and enhances the value of NFI data for the assessment of forest AGB and C balances. Remote sensing does not substitute field work, but rather highlights the importance of field data to support modelling and spatial extension of models to larger areas of interest.

8. The spatial identification of sources and sinks of carbon, as well as changing trends over time provided by the analysis of remotely sensed data, are valuable contributions for the global issue of carbon budgeting reports, and for evaluation of management strategies. However, remote observations are not the sole answer to 
resolving uncertainty in carbon budgets, and field measures are essential for calibration and validation of estimates.

9. Image processing combined with mathematical transformations showed capacity to unveil relationships between temporal spectral trajectories and forest properties. Dynamic spectral features related to successional processes, such as pattern and rate of change, had capacity to explain past and present biophysical conditions. Dynamic variables showed to be more relevant than static variables in the retrospective estimation of AGB in Mediterranean pines of central Spain, in order to establish a historical baseline that would enable reporting of change.

10. The applications demonstrated in this work show that for assistance in the fulfilment of the Kyoto Protocol commitments, remote sensing can effectively help assessing land cover and change; establishing a biomass and carbon baseline in 1990, and estimating carbon stocks and changes with acceptable uncertainty; and identifying the spatial distribution of successional processes. 
Assessment of biomass and carbon dynamics in pine forests of the Spanish Central Range: a remote sensing approach 


\section{CONCLUSIONES}

\section{Generales}

Los pinares del Sistema Central español constituyen un almacén permanente y dinámico de biomasa y juegan un papel relevante en el balance regional de emisión y fijación de carbono (C). La teledetección es una herramienta de apoyo que complementa el valor del Inventario Forestal Nacional (IFN) en la evaluación de las existencias de biomasa forestal y los sumideros de carbono asociados, pero no sustituye el trabajo de campo. El acceso a los archivos de imágenes contemporáneas e históricas de calidad coherente, ofrece la oportunidad de utilizar cuantiosos datos y desarrollar métodos que ayuden a obtener información relacionada con el desarrollo de los ecosistemas forestales, de otra forma incompleta o inexistente.

\section{Particulares}

1. La localización, extensión, y distribución de los recursos forestales en el centro de España se puede evaluar de forma precisa y efectiva mediante imágenes ópticas de resolución espacial media obtenidas mediante sensores remotos en órbita espacial. El archivo histórico de Landsat permite caracterizar situaciones pasadas y evaluar más de cuarenta años de evolución de los recursos forestales. La extensión de los pinares mediterráneos del Sistema Central español fluctuó entre 1984 y 2009, con un incremento neto del $40 \%$ y una tasa de cambio variable a lo largo de este tiempo. Al estudiar la distribución del área con predominio de pinar se observa una zona de cobertura permanente, con reserva estable de carbono, además de otras zonas con cobertura intermitente y responsables principales de los flujos de carbono.

2. Imágenes de alta resolución espacial proporcionan información útil para la caracterización de la estructura forestal y la evaluación de su diversidad estructural. Los valores espectrales de la zona visible e infrarroja del espectro electromagnético, y las variables espaciales en forma de textura local de la imagen, tienen distinta relevancia en esta caracterización, en función del tipo de cobertura: zonas homogéneas son caracterizadas mejor mediante variables espectrales, mientras las variables de textura aportan mayor información en regiones de estructura compleja. España, a través del Plan Nacional de Observación del Territorio (PNOT) adquiriere una cobertura anual de imágenes de alta resolución espacial $(2.5 \mathrm{~m})$ sobre todo el territorio nacional. La existencia de estos datos 
supone un apoyo para la evaluación periódica de existencias forestales, factor crítico en procesos de decisión y planificación territorial.

3. La superficie forestal objeto de este trabajo constituyó un sumidero neto de C durante el periodo 1984-2009. Localmente, las fuentes y sumideros de C alternaron su función dominante, ofreciendo en conjunto una distribución espacial y temporal dinámica. Entre 1984 y 2009 tuvo lugar una tendencia generalizada de activación de los flujos de C, con tasa de cambio variable en función del momento y localización. El año 2000 registró el máximo de superficie actuando como sumidero, con más de un tercio $\left(567 \mathrm{~km}^{2}\right)$ del área considerada fijando C de forma neta.

4. La zona con cobertura permanente de pinar durante el periodo 1984-2009, incrementó en un 18\% su biomasa aérea total entre 1990 y 2000. La distribución espacial de los cambios de biomasa se produjo de forma irregular. Como promedio, la biomasa aérea de estos pinares acumuló $0.65 \mathrm{t} \mathrm{ha}^{-1} \mathrm{a}^{-1}$ de $\mathrm{C}$ en el decenio 19902000, equivalente a la fijación de $2.38 \mathrm{tha}^{-1} \mathrm{a}^{-1}$ de $\mathrm{CO}_{2}$.

5. Series temporales de imágenes de media resolución espacial proporcionan información asociada a procesos de sucesión forestal. Mediante técnicas estadísticas, los datos espectrales permiten identificar la distribución, y las relaciones espaciales y temporales entre los procesos que ocurren a escala de paisaje, identificando patrones espaciales y tendencias temporales. La fiabilidad de esta información, que se obtiene por comparación de datos captados a lo largo del tiempo, se basa en técnicas rigurosas de calibrado de imágenes y en la utilización de medidas espectrales coherentes entre sensores. Los índices de vegetación derivados de las componentes Verdor y Brillo de la Transformación Tasseled Cap, TCA y PI, han demostrado ser buenas medidas para actuar de vínculo y enlace entre sensores de Landsat, y por tanto son indicadores fiables de la evolución de variables biofísicas que correlacionan con ellos.

6. La información proporcionada por secuencias temporales de datos espectrales es indicativa de procesos de estabilidad o cambio en las masas forestales. Esos procesos están ligados a estados evolutivos y a tendencias en el estado sanitario o estructural. Así mismo, como portadoras de información temporal, representan modelos de evolución que se pueden asociar a características biofísicas en momentos puntuales. Aunque el procesamiento e interpretación de las trayectorias espectrales de media resolución espacial está en fases iniciales de desarrollo, este campo promete ser una fuente valiosa de información para el estudio de procesos 
ecológicos y para la evaluación retrospectiva (y actual) de características de los ecosistemas.

7. Los resultados de este trabajo corroboran la utilidad de la teledetección como respaldo del IFN, realzando su utilidad para la evaluación de la biomasa forestal aérea y los balances de carbono. La teledetección no es sustitutiva del trabajo de campo, sino que pone de relevancia la importancia que este tiene como base de información y validación de los modelos estadísticos, y en la aplicación espacial de los modelos a toda el área de interés.

8. La identificación espacial de las fuentes y sumideros de C, así como de los cambios de tendencia en la fijación neta a lo largo del tiempo que proporciona el análisis de datos de teledetección, son una valiosa contribución para la generación de informes de emisiones de carbono, y para la evaluación de estrategias de planificación territorial. Los datos de satélite no son por si mismos una solución que permita despejar la incertidumbre asociada a los ciclos de carbono. Los datos de campo son esenciales para calibrar y validar las estimaciones de biomasa y carbono que se derivan de observaciones remotas.

9. Mediante procesamiento de imágenes y transformaciones matemáticas de datos se descubrieron relaciones subyacentes entre las trayectorias espectrales y ciertas propiedades forestales. Variables dinámicas derivadas de series espectrotemporales y asociadas a procesos de sucesión forestal, tales como el patrón y la tasa de cambio, han demostrado capacidad predictiva en modelos de parámetros forestales. Las variables dinámicas fueron más efectivas que las estáticas en la estimación retrospectiva de biomasa aérea en pinares mediterráneos del Sistema Central español, estableciendo una referencia histórica que permite hacer comparaciones con valores posteriores.

10. Las aplicaciones demostradas en este trabajo demuestran que la teledetección es una herramienta de ayuda al cumplimiento de los compromisos del Protocolo de Kioto. En concreto es útil para la evaluación de la cobertura del suelo, así como de su conversión; para el establecimiento de una referencia en las existencias de biomasa y carbono con grado de incertidumbre aceptable; y para la identificación espacial de procesos de sucesión forestal. 
Assessment of biomass and carbon dynamics in pine forests of the Spanish Central Range: a remote sensing approach 


\section{REFERENCES}

Aach, J., Church, G.M. 2001. Aligning gene expression time series with time warping algorithms. Bioinformatics, 17(6), 495-508.

Aertsen, W., Kint, V., van Orshoven, J., ad Özkan, K., Muy, B. 2010. Comparison and ranking of different modelling techniques for prediction of site index in Mediterranean mountain forests. Ecological Modelling, 221, 1119-1130.

Aguilar, M.A., Agüera, F., Aguilar, F.J., Carvajal, F. 2008. Geometric accuracy assessment of the orthorectification process from very high resolution satellite imagery for common agricultural policy purposes. International Journal of Remote Sensing, 29, 7181-7197.

Ahearn, S.C. 1988. Combining Laplacian images of different spatial frequencies (scales): Implications for remote sensing analysis. IEEE Transactions on Geosciences and Remote Sensing, 26, 826-831.

Ahmed, O.S., Franklin, S.E., Wulder, M.A., White, J.C. 2013. Characterizing forest structure using time series Landsat imagery, airborne LiDAR, and machine learning algorithms. In: Multitemp. 7th International Workshop on the analysis of multi-temporal remote sensing images. The Banff Centre, Banff, Alberta, (Canada), 26-28th June.

Alberdi Asensio, I., Condés Ruiz, S., García Robredo, F. 2009. Estimación de la biodiversidad forestal mediante toma de datos de campo e imágenes de teledetección. Aplicación a la sierra de Guadarrama. $5^{\circ}$ Congreso forestal español. Sociedad Española de Ciencias Forestales, Ávila.

Alberdi Asensio, I. et al., 2010. Chapter 34: Spain. In Tomppo, E., Gschwantner, Th., Lawrence, M., McRoberts, R.E. (eds.) 2010. National Forest Inventories - Pathways for common reporting. Springer, 612 pp.

Andersson, K., Evans, T.P., Richards, K.R. 2009. National forest carbon inventories: policy needs and assessment capacity. Climatic Change 93, 69-101.

Andrew, M.E., Ustin, S.L. 2009. Habitat Suitability Modeling of an invasive plant with advanced remote sensing data. Diversity Distributions, 15, 627-640.

Anselin, L. 1992. Spatial data analysis with GIS: An introduction to application in the social sciences. Technical Report 92-10. University of California, Santa Barbara: National Center for Geographic Information and Analysis.

Anselin, L. 1993. The Moran Scatterplot as an ESDA tool to assess local instability in spatial association. Research paper 9330. University of California, Santa Barbara: Regional Research Institute, West Virginia University and National Center for Geographic Information and Analysis.

Anselin, L. 1995. Local indicators of spatial association-LISA. Geographical Analysis, 27, 93115. 
Anselin, L. 2003. An introduction to spatial autocorrelation analysis with GeoDa. University of Illinois, Urbana-Champaign: Spatial Analysis Laboratory, Department of Agricultural and Consumer Economics.

Anselin, L., Syabri, I., Kho, Y. 2006. GeoDa: An introduction to spatial data analysis. Geographical Analysis, 38, 5-22.

Aparicio, A., García Cacho, L. 1984. Geología del Sistema Central español. Conserjería de Política territorial-Consejo Superior de Investigaciones Científicas.

Arozarena, A. 2008. El Plan Nacional de Observación del territorio en España como sistema básico de información Medio Ambiental. In Congreso Nacional del Medio Ambiente, Cumbre del Desarrollo Sostenible, Madrid, Spain, 1-5 December.

Arvidson, T., Goward, S., Gasch, J., Williams, D. 2006. Landsat-7 Long-Term Acquisition Plan: Development and Validation. Photogrammetric Engineering and Remote Sensing, 72(10), 11371146.

Aschbacher, J., Milagro-Pérez, M.P. 2012. The European Earth monitoring (GMES) programme: status and perspectives. Remote Sensing of Environment, 120, 3-8.

Asner, G.P., Hicke, J.A., Lobell, D.B. 2003. Per-pixel analysis of forest structure. In: Wulder, M.A., Franklin, S.E. (eds.) Remote sensing of forest environments: Concepts and case studies. Kluwer Academic Publishers, Boston, USA.

Asner, G.P. 2009. Tropical forest carbon assessment: integrating satellite and airborne mapping approaches. Environmental Research Letters, 4, 034009. DOI: http://dx.doi.org/10.1088/17489326/4/3/034009

Baccini, A., Laporte, N., Goetz, S.J., Sun, M., Dong, H. 2008. A first map of tropical Africa's above-ground biomass derived from satellite imagery. Environmental Research Letters, 3, 045011. DOI: http://dx.doi.org/:10.1088/1748-9326/3/4/045011

Bartholomé, E., Belward, A.S. 2005. GLC2000: a new approach to global land cover mapping from earth observation data. International Journal of Remote Sensing, 26, 1959-1977.

Bernués, D. 2008. La gestión forestal sostenible en Aragón. Foresta, 43, 104-107.

Bettinger, P., Hayashi, R. 2006. Estimation of above-ground biomass with remotely sensed imager: a brief literature review. University of Georgia, Center for Forest Business. Research note 25.

Birdsey, R., Pregitzer, K., Lucier, A. 2006. Forest carbon management in the United States: 16002100. Journal of Environmental Quality, 35, 1461-1469.

Blackard, J.A., Finco M.V., Helmer E.H., Holden G.R., Hoppus M.L., Jacobs D.M., Lister A.J., Moisen G.G., Nelson M.D., Riemann R., Ruefenacht B., Slajanu D., Weyermann D.L., Winterberger K.C., Brandeis T.J., Czaplewski R.L., McRoberts R.E., Patterson P.L., Tymcio R.P. 2008. Mapping US forest biomass using nationwide forest inventory data and moderate resolution information. Remote Sensing of Environment, 112, 1658-1677. 
Bravo, F., Río, M., Pando, V., San Martín, R., Montero, G., Ordoñez, C., Cañellas, I. 2002. El diseño de las parcelas del inventario forestal nacional y la estimación de variables dasómetricas. In: El Inventario Forestal Nacional, Elemento Clave para la Gestión Forestal Sostenible; Bravo, F., Rio, M., Peso, C., (eds.). Fundación General de la Universidad de Valladolid: Valladolid, Spain, pp. 19-35.

Bravo, F., Ordóñez, A.C., Del Río, M. 2005. BASIFOR 2.0: Aplicación informática para el manejo de bases de datos del Segundo y del Tercer Inventario Forestal Nacional. Disponible en www.basifor.es (Accessed 6 August 2013).

Bravo, F., Osorio, L.F., Pando, V. and Del Peso, C. 2010. Long-term implications of traditional forest regulation methods applied to Maritime pine (Pinus pinaster Ait.) forests in central Spain: a century of management plans. iForest, 3, 33-38.

Breiman, L., Friedman, J.H., Olshen, R.A., Stone, C.J. 1984, Classification and Regression Trees. Chapman and Hall/CRC: Boca Raton, FL, USA, pp. 358.

Brown, S. 2002. Measuring carbon in forests: current status and future challenges. Environmental Pollution, 116, 363-372.

Brown de Colstoun, E.C., Story, M.H., Thompson, C., Commisso, K., Smith, T.G., Irons, J.R. 2003. National Park vegetation mapping using multitemporal Landsat 7 data and a decision tree classifier. Remote Sensing of Environment, 85, 316-327.

Bruniquel-Pinel, V., Gastellu-Etchegorry, J.P. 1998. Sensitivity of texture of high resolution images of forest to biophysical and acquisition parameters. Remote Sensing of Environment, 65, 61-85.

Burnett, C., Blaschke, T. 2003. A multiscale segmentation object relationship modelling methodology for landscape analysis. Ecological Modelling, 168, 233-249.

Campbell, J.L., Kennedy, R.E., Cohen, W.B., Miller, R.F., 2012. Assessing the carbon consequences of western juniper (Juniperus occidentalis) encroachment across Oregon, USA, Rangeland Ecology Management, 5, 223-231.

Chander, G., Markham, B.L., Helder, D.L. 2009. Summary of current radiometric calibration coefficients for Landsat MSS, TM, ETM+, and EO-1 ALI sensors. Remote Sensing of Environment, 113, 893-903.

Chávez, P.S. 1988. An improved dark-object subtraction technique for atmospheric scattering correction of multispectral data. Remote Sensing of Environment, 24, 459-479.

Chen, J.M., Ju, W., Cihlar, J., Price, D., Liu, J., Chen, W., Pan, J., Black, A., Barr, A. 2000. Spatial distribution of carbon sources and sinks in Canada's forests. Tellus, 55B, 622-641

Chen, G., Hay, G. 2011. An airborne lidar sampling strategy to model forest canopy height from Quickbird. Remote Sensing of Environment, 115(6), 1532-1542. 
Chen, G., Hay, G.H., Carvalho, L.M.T., Wulder, M.A. 2012. Object-based change detection. International Journal of Remote Sensing, 33(14), 4434-4457.

Chica-Olmo, M. 2005. La geoestadística como herramienta de análisis en la gestión forestal. Cuadernos de la Sociedad Española de Ciencias Forestales, 19, 47-55.

Chirici, G., Barbati, A., Corona, P., Marchetti, M., Travaglini, D., Maselli, F., Bertini, R. 2008. Non-parametric and parametric methods using satellite images for estimating growing stock volume in alpine and Mediterranean forest ecosystems. Remote Sensing of Environment, 112, 2686-2700

Chubey, M.S., Franklin, S.E., Wulder, M.A. 2006. Object-based analysis of IKONOS-2 imagery for extraction of forest inventory parameters. Photogrammetric Engineering and Remote Sensing, 72, 383-394.

Clark, I. Practical Geostatistics; Geostokos Limited: Scotland, UK, 2001. Available online: http://w3eos.whoi.edu/12.747/resources/pract_geostat/pg1979_latex.pdf (accessed on 17 May 2011).

Cohen, W.B., Spies, T.A., Bradshaw, G.A. 1990. Semivariograms of digital imagery for analysis of conifer canopy structure. Remote Sensing of Environment, 34(3), 167-178.

Cohen, W.B., Spies, T.A. Fiorella, M. 1995, Estimating the age and structure of forests in a multiownership landscape of western Oregon, U.S.A. International Journal of Remote Sensing, 16, 721-746.

Cohen, W.B., Maiersperger, T.K., Spies, T.A., Oetter, D.R. 2001. Modelling forest cover attributes as continuous variables in a regional context with thematic mapper data. International Journal of Remote Sensing, 22, 2279-2310.

Cohen, W.B., Maiersperger, T.K., Gower, S.T., Turner, D.P. 2003. An improved strategy for regression of biophysical variables and Landsat ETM+ data. Remote Sensing of Environment, 84, 561-571.

Cohen, W., Goward, S. 2004. Landsat's role in ecological applications of remote sensing, BioScience, 54, 535-545.

Coppin, P., Jonckheere, I., Nackaerts, K., Muys, B. 2004. Digital change detection methods in ecosystem monitoring: a review. International Journal of Remote Sensing, 25 (9), 1565-1596.

Coops, N.C., Wulder, M.A., White, J.C. 2006. Identifying and describing forest disturbance and spatial pattern: data selection issues and methodological implications. In: Wulder, M.A., Franklin, S.E. (eds.) Understanding forest disturbance and spatial pattern. Taylor and Francis, Boca Raton, Florida, USA.

Coops, N.C., Hilker, T., Wulder, M.A., St-Onge, B., Newnham, G., Siggins, A., Trofymow, J.A. 2007. Estimating canopy structure of Douglas fir forest stands from discrete-return LiDAR. Trees, 21, 295-310. 
Couteron, P., Pelissier, R., Nicolini, E.A., Paget, D. 2005. Predicting tropical forest stand structure parameters from Fourier transform of very high-resolution remotely sensed canopy images. Journal of Applied Ecology, 42, 1121-1128.

Crist, E. P., Cicone, R. C. 1984. A physically based transformation of Thematic Mapper data- the TM tasseled Cap. IEEE Transactions on Geoscience and Remote Sensing, 22, 256-263.

Crist, E. P. 1985. A TM Tasseled Cap equivalent transformation for reflectance factor data. Remote Sensing of Environment, 17, 301-306.

Curran, P.J., Atkinson, P.M. 1998. Geostatistics and remote sensing. Progress in Physical Geography, 22, 61-78.

Daubechies, I., Guskov, I., Schröder, P., Sweldens, W. 1999. Wavelets on Irregular Point Sets, Philosophical Transactions of the Royal Society A: Mathematical Physical and Engineering Sciences, 357 (1760), 2397-2413.

Devereux, B.J., Amable, G.S., Costa Posada, C. 2004. An efficient image segmentation algorithm for landscape analysis. International Journal of Applied Earth Observation and Geoinformation, 6, 47-61.

Di Gregorio, A., Jansen, L.J.M. 2000. Land Cover Classification System, Concepts and User Manual. GCP/RAF/287/ITA Africover, Food and Agriculture Organization of the United Nations Publishing Service, Rome.

Drusch, M., Del Bello, U., Carlier, S., Colin, O., Fernandez, V., Gascon, F., Hoersch, B., Isola, C., Laberinti, P., Marimort, P., Meygret, A., Spoto, F., Sy, O., Marchese, F., Bargellini, P. 2012. Sentinel-2: ESA's optical high-resolution mission for GMES operational services. Remote Sensing of Environment, 120, 25-36.

Du, Y., Guindon, B., Cihlar, J. 2002. Haze detection and removal in high resolution satellite image with wavelet analysis. IEEE Transactions on Geosciences and Remote Sensing, 40(1), 210-217.

Du, H., Zhou, G., Ge, H., Fan, W., Xu, X., Fan, W., Shi, Y. 2011. Satellite-based carbon stock estimation for bamboo forest with a non-linear partial least square regression technique. International Journal of Remote Sensing, iFirst, 1-17, DOI: http://dx.doi.org/10.1080/01431161.2011.603379

Duncanson, L.I., Neimann, K.O., Wulder, M.A. 2010. Integration of GLAS and Landsat TM data for aboveground biomass estimation. Canadian Journal of Remote Sensing, 36 (2), 129-141.

Eysn, L., Hollaus, M., Schadauer, K., Pfeifer, N. 2012. Forest delineation based on airborne lidar data. Remote Sensing, 4, 762-783.

Falkowski, M.J., Wulder, M.A., White, J.C., and Gillis, M.D. 2009a. Supporting large-area, sample-based forest inventories with very high spatial resolution satellite imagery. Progress in Physical Geography, 33(3), 403-423. DOI: http://dx.doi.org/10.1177/03091333093 42643 
Falkowski, M.J., Evans, J., Martinuzzi, S., Gessler. P.E., Hudak, A.T. 2009b. Characterizing forest succession with lidar data: an evaluation for the Inland Northwest, USA. Remote Sensing of Environment, 113, 946-956.

FAO, 2010. Global Forest Resources Assessment. Rome, Italy. Available at www.fao.org/forestry/fra/fra2010/en/

Faundez-Zanuy, M. 2007. On-Line Signature Recognition Based on VQ-DTW. Pattern Recognition, 40(3), 981-992.

Ferro, C., Warner, T. 2002. Scale and texture in digital image classification. Photogrammetric Engineering and Remote Sensing, 68, 51-63.

Foster, D.R., Knight, D.H., Franklin, J.F. 1998. Landscape patterns and legacies resulting from large, infrequent forest disturbances. Ecosystems, 1, 497-510.

Foody, G.M., Palubinskas, G., Lucas, R.M., Curran, P., Honzak, M. 1996. Identifying terrestrial carbon sinks: classification of successional stages in regenerating tropical forest from Landsat TM data. Remote Sensing of Environment, 55, 205-216.

Franklin, S.E., Wulder, M.A., Lavigne, M.B. 1996. Automated derivation of geographic window sizes for use in remote sensing digital image texture analysis. Computers and Geosciences, 22(6), 665-673.

Franklin, S.E., Wulder, M.A., Gerylo, G.R. 2001. Texture analysis of IKONOS panchromatic data for Douglas-fir forest age class separability in British Columbia. International Journal of Remote Sensing, 22, 2627-2632.

Freitas, R.M., Shimabukuro, Y.E. 2008. Combining wavelets and linear spectral mixture model for MODIS satellite sensor time-series analysis. Journal of Computational Interdisciplinary Sciences, 1(1), 51-56.

Fricker, G.A., Saatchi, S.S., Meyer, V., Gillespie, T.G., Sheng, Y. 2012. Application of semiautomated filter to improve waveform lidar sub-canopy elevation model. Remote Sensing, 4, 1494-1518.

Fukuda, S., Hirosawa, H. 1999. A wavelet-based texture feature set applied to classification of multifrequency polarimetric SAR images. IEEE Transactions on Geoscience and Remote Sensing, 37(5), 2282-2286.

Gandullo, J.M. 1976. Contribución al estudio ecológico de la Sierra de Guadarrama. I. Delimitación de la zona y reseña geológica de la misma. Anales INIA. Serie recursos naturales, 2, 23-36.

Garguet-Duport, B., Girel, J., Chassery, J.M., Pautou, G. 1996. The use of multiresolution analysis and wavelets transform for merging of SPOT panchromatic and multispectral image data. Photogrammetric Engineering and Remote Sensing, 62(9), 1057-1066. 
Gibbs, H., Brown, S., Niles, J.O., Foley, J.A. 2007. Monitoring and estimating tropical forest carbon stocks: making REDD a reality. Environmental Research Letters, 2, 045023, DOI: http://dx.doi.org/10.1088/1748-9326/2/4/045023

Giorgino, T. 2009. Computing and visualizing Dynamic Time Warping alignments in R: the dtw package. Journal of Statistical Software, 31(7), 1-24.

Gordillo, E., Díaz, R., Martínez-Millán, J. 2001. Biodiversidad en el tercer inventario forestal nacional: primeros resultados de la valoración por medio de indicadores. $3^{\circ}$ Congreso Forestal Español. Sociedad Española de Ciencias Forestales, Granada.

Goetz, S.J., Wright, R.K., Smith, A.J., Zinecker, E., Schaub, E. 2003. IKONOS imagery for resource management: tree cover, impervious surfaces, and riparian buffer analyses in the midAtlantic region. Remote Sensing of Environment, 88, 195-208.

Goetz, S.T., Baccini, A., Laporte, N.T., Johns, T., Walker, W., Kellndorfer, J., Houghton, R.A., Sun, M., 2009. Mapping and monitoring carbon stocks with satellite observations: a comparison of methods. Carbon Balance and Management, 4(2), DOI: httpx://dx.doi.org:10.1186/17500680-4-2.

Goetz, S.J. 2011. The lost promise of DESDynI. Remote Sensing of Environment, 115, 2751.

Goetz, S., Dubayah, R. 2011. Advances in remote sensing technology and implications for measuring and monitoring forest carbon stocks and change, Carbon Management, 2(3), 231244.

Gómez, C. 2006. Estimación de volumen de P. sylvestris L. mediante imágenes Landsat y QuickBird en el Sistema Central español. DEA dissertation. Universidad de Valladolid, Spain, $32 \mathrm{pp}$.

Gómez, C., White, J.C., Wulder, M.A. 2011a. Characterizing the state and processes of change in a dynamic forest environment using hierarchical spatio-temporal segmentation. Remote Sensing of Environment, 115 (7), 1665-1679. DOI: http://dx.doi.org/10.1016/j.rse.2011.02.025

Gómez, C., Wulder, M.A., Montes, F., Delgado, J.A. 2011b. Forest structural diversity characterization in Mediterranean pines of Central Spain with QuickBird-2 imagery and canonical correlation analysis. Canadian Journal of Remote Sensing, 37 (6), 628-642. DOI: http://dx.doi.org/10.5589/m12-005

Gómez, C., Wulder, M.A., White, J.C., Montes, F., Delgado, J.A. 2012a. Characterizing 25 years of change in the area, distribution, and carbon stock of Mediterranean pines in Central Spain. International Journal of Remote Sensing. 33 (17), 5546-5573. DOI: http://dx.doi.org/10.1080/01431161.2012.663115

Gómez, C., Wulder, M.A., Montes, F., Delgado, J.A. 2012b. Modeling Forest Structural Parameters in the Mediterranean Pines of Central Spain using QuickBird-2 Imagery and 
Classification and Regression Tree Analysis (CART). Remote Sensing. 4 (1), 135-159. DOI: http://dx.doi.org/10.3390/rs4010135

Gong, P., Xu, B. 2003, Remote sensing of forests over time: change types, methods, and opportunities. In Remote Sensing of Forest Environments: Concepts and Case Studies, Wulder, M.A., S.E. Franklin, S.E. (eds.), (Dordrecht/Boston/London: Kluwer Academic Publishers).

Goodburn, J.M., Lorimer, C.G. 1998. Population structure in old-growth and managed northern hardwoods: an examination of the balanced diameter distribution concept. Forest Ecology and Management, 118(1-3), 11-29.

Goodwin, N.R., Magnussen, S., Coops, N.C., Wulder, M.A. 2010. Curve fitting of time series Landsat imagery for characterising a mountain pine beetle infestation disturbance. International Journal of Remote Sensing, 31(12) 3263-3271.

Goovaerts, P., Jazquez, G. M., Marcus, A. 2005. Geostatistical and local cluster analysis of high resolution hyperspectral imagery for detection of anomalies. Remote Sensing of Environment, 95, 351-367.

Goward, S.N., Masek, J.G., Cohen, W., Moisen, G., Collatz, G.J., Healey, S., Houghton, R.A., Huang, C., Kennedy, T., Law, B., Powell, S., Turner, D., Wulder, M.A. 2008. Forest disturbance and North American carbon flux. EOS, Transactions, American Geophysical Union, 89(11), 105-107.

Greenberg, J.A., Dobrowsky, S.Z., Ustin, S.L. 2005. Shadow allometry: Estimating tree structural parameters using hyperspatial image analysis. Remote Sensing of Environment, 97, 15-25.

Gringarten, E., Deutsch, C.V. 2001. Teacher's aide: variogram interpretation and modelling. Mathematical Geology, 33(4), 507-534.

Guindon, B., Edmonds, C.M. 2002. Large-Area Land-Cover Mapping through Scene-Based Classification Compositing. Photogrammetric Engineering and Remote Sensing, 68(6), 589596.

Hair, J.F., Anderson, R.E., Tatham, R.L., Black, W.C. 1998. Multivariate data analysis. 5th Edition, Prentice Hall. New Jersey, USA.

Hannah, L., Lohse, D., Hutchinson, Ch., Carr, J.L., Lankerani, A. 1994. A preliminary inventory of human disturbance of World ecosystems. Ambio, 23(4-5), 246-250.

Harrell, P.A., Bourgeau-Chavez, L.L., Kasischke, E.S., French, N.H.F., Christensen, N.L., 1995. Sensitivity of ERS-1 and JERS-1 RADAR data to biomass and stand structure in Alaskan boreal forest. Remote Sensing of Environment, 54, 247-260.

Hall-Beyer, M. 2007. GLCM Tutorial Home Page; Available online: http://www.fp.ucalgary.ca/mhallbey/tutorial.htm (accessed on 13 October 2011). 
Hall, F.G., Bergen, K., Blair, J.B., Dubayah, R., Houghton, R., Hurtt, G., Kellndorfer, J., Lefsky, M., Ranson, J., Saatchi, S., Shugart, H.H., Wickland, D. 2011. Characterizing 3D vegetation from space. Remote Sensing of Environment, 115, 2753-2775.

Hansen, M. J., Franklin, S. E., Woudsmaa, C. G., Peterson, M. 2001. Caribou habitat mapping and fragmentation analysis using Landsat MSS, TM, and GIS data in the North Columbia Mountains, British Columbia, Canada. Remote Sensing of Environment, 77, 50-65.

Hansen, M.J., Loveland, T.R. 2012. A review of large area monitoring of land cover change using Landsat data. Remote Sensing of Environment, 122, 66-74.

Haralick, R.M., Shanmugan, K., and Dinstein, I. 1973. Texture features for image classification. IEEE Transactions on Systems, Man and Cybernetics, 3, 6, 610-621. DOI: http://dx.doi.org/10.1109/TSMC.1973.4309314.Haralick, R.M., Bryant, W.F. 1976. Documentation of Procedures for Textural/Spatial Pattern Recognition Techniques; Technical Report 278-1; Remote Sensing Laboratory, University of Kansas: Lawrence, KS, USA, 1976.

Harrel, P.A., Bourgeau-Chavez, L.L., Kasischke, E.S., French, N.H.F., Christensen, N.L. 1995. Sensitivity of ERS-1 and JERS-1 RADAR data to biomass and stand structure in Alaskan boreal forest. Remote Sensing of Environment, 54, 247-260.

Harmon, M.E., Ferrel, W.K., Franklin, J.F. 1990. Effects on carbon storage of conversion of oldgrowth forests to young forests. Science, 247, 699-702.

Hay, G. J., Marceau, D. J., Dubé, P., Bouchard, A. 2001. A multiscale framework for landscape analysis: Object-specific analysis and upscaling. Landscape Ecology, 16, 471-490.

Hay, G.J., Castilla, G., Wulder, M.A., Ruiz, J.R. 2005. An automated object-based approach for the multiscale image segmentation of forest scenes. International Journal of Applied Earth Observation and Geoinformation, 7, 339-359.

Healey, S.P., Yang, Z., Cohen, W.B., Pierce, D.J. 2006. Application of two regression-based methods to estimate the effects of partial harvest on forest structure using Landsat data. Remote Sensing of Environment, 101, 115-126.

Helmer, E.H., Brown, S., Cohen, W.B. 2000. Mapping montane tropical successional stage and land use with multi-date Landsat imagery. International Journal of Remote Sensing, 21, 21632183.

Herrero, C., Bravo, F. 2012. Can we get an operational indicator of forest carbon sequestration? A case study from two forest regions in Spain. Ecological Indicators, 17, 120-126.

Hese, S., Lucht, W., Schmullius, C., Barnsley, M., Dubayah, R., Knorr, D., Neumann, K., Riedel, T., Schrfter, K. 2005. Global biomass mapping for an improved understanding of the CO2 balance-the Earth observation mission Carbon-3D. Remote Sensing of Environment, 94, 94104. 
Hirata, Y. 2008. Estimation of stand attributes in Cryptomeria japonica and Chamaecyparis obtusa stands using QuickBird panchromatic data. Journal of Forest Research, 13, 147-154.

Hofmann, P., Blaschke, T. 2012. Object based change detection using temporal linkages. In: Proceedings of the 4th GEOBIA, May 7-9, Rio de Janeiro, Brazil, 634-638

Homer, C., Huang, C., Yang, L., Wylie, B., Coan, M. 2004. Development of a 2001 National LandCover Database for the United States. Photogrammetric Engineering and Remote Sensing, 70(7), 829-840.

Houghton, J.T., Meira Filho, L.G., Lim, B., Treanton, K., Mamaty, I., Bonduki, Y., Griggs, D.J., Callander, B.A. 1997. Revised 1996 Guidelines for National Greenhouse Gas Inventories. IPCC/ OECD/IEA.

Houghton, R. A. 1999. The annual net flux of carbon to the atmosphere from changes in land use 1850-1990. Tellus, 51B:298-313.

Houghton, R.A. 2005. Aboveground Forest Biomass and the Global Carbon Balance. Global Change Biology, 11, 945-958.

Houghton, R.A., House, J.I., Pongratz, J., van del Werf, G.R., DeFries, R.S., Hansen, M.C., LeQuere, C., Ramankutty, N. 2012. Carbon emissions from land use and land-cover change. Biogeosciences, 9, 5125-5142.

Huang, C., Wylie, B., Yang, L., Homer, C., Zylstra, G. 2002. Derivation of a tasseled cap transformation based on Landsat 7 at-satellite reflectance. International Journal Remote Sensing, 23, 1741-1748.

Hussain, M., Chen, D., Cheng, A., Wei, H., Stanley, D. 2013. Change detection from remotely sensed images: from pixel-based to object-based approaches. ISPRS Journal of Photogrammetry and Remote Sensing, 80, 91-106.

Hyde, P., Dubayah, R., Walker, W., Blair, B., Hofton, M., Hunsaker, C. 2006. Mapping forest structure for wildlife habitat analysis using multi-sensor (LiDAR, SAR/InSAR, ETM+, Quickbird) synergy. Remote Sensing of Environment, 102(1-2), 63-73.

HyyppäIGN. Plan Nacional de Teledetección (PNT); Versión 2.3; Ministerio de Fomento, Gobierno de España: Madrid, Spain, 2009.

Im, J., Jensen, J.R. 2005. A change detection model based on neighborhood correlation image analysis and decision tree classification. Remote Sensing of Environment, 99, 326-340.

IPCC, 2007. Fourth assessment report of the Intergovernmental Panel on Climate Change. Cambridge University Press, Cambridge, United Kingdom, and New York, NY, USA.

Irons, J.R, Dwyer, J.L., Barsi, J.A. 2012. The next Landsat satellite: The Landsat Data Continuity Mission. Remote Sensing of Environment, 122, 11-21. 
Jensen, J. R., Toll, D. L. 1982. Detecting residential land use development at the urban fringe. Photogrammetric Engineering and Remote Sensing, 48, 629-643.

Jensen, J.R. 2005. Introductory digital image processing. A remote sensing perspective. Third edition. Prentice Hall, NJ, USA.

Jha, C. S., Unni, N. V. M., 1994. Digital change detection of forest conversion of dry tropical forest region. International Journal of Remote Sensing, 15, 2543-2552.

Jin, S., Sader, S.A. 2005. Comparison of time series tasseled cap wetness and the normalized difference moisture index in detecting forest disturbances. Remote Sensing of Environment, 94, 364-372.

Johansen, K., Coops, N.C., Gergel, S.E., Stange, Y. 2007. Application of high spatial resolution satellite imagery for riparian and forest ecosystem classification. Remote Sensing of Environment, 110, 29-44.

Kajisa, T., Murakami, T., Mizoue, N., Yoshida, S. 2007. Differences in spectral trajectory with stand volume development between Japanese larch and Japanese oak in Hokkaido, Japan. Journal of Forest Research, 12, 435-441.

Kauth, R.J., Thomas, G.S. 1976. The tasseled cap-a graphic description of the spectral-temporal development of agricultural crops as seen in Landsat, In: Proceedings on the Symposium on Machine Processing of Remotely Sensed Data, West Lafayette, Indiana, June 29 - July 1, 1976, (West Lafayette, Indiana: LARS, Purdue University), pp. 41-51.

Kayitakire, F., Hamel, C., Defourny, P. 2006. Retrieving forest structure variables based on image texture analysis and IKONOS-2 imagery. Remote Sensing of Environment, 102(3-4), 390-401. DOI: http://doi:10.1016/j.rse.2006.02.022.

Ke, Y., Quackenbush, L.J., Im, J. 2010. Synergistic use of QuickBird multispectral imagery and LIDAR data for object-based forest species classification. Remote Sensing of Environment, 114, 1141-1154.

Kennedy, R.E., Yang, Z., Cohen, W.B. 2010. Detecting trends in forest disturbance and recovery using yearly Landsat time series: 1 . LandTrendr-Temporal segmentation algorithms. Remote Sensing of Environment, 114, 2897-2910.

Kennedy, R.E., Andréfouët, S., Gómez, C., Griffiths, P., Hais, M., Healey, S., Helmer, E.H., Hostert, P., Lyons, M., Meigs, G.W., Pflugmacher, D., Phinn, S., Powell, S., Scarth, P.F., Sen, S., Schroeder, T.A., Schneider, A.M., Sonnenschein, R., Vogelmann, J.E., Wulder, M.A., Zhu, Z. (Accepted). Bringing an ecological view of change to Landsat-based remote sensing. Frontiers in Ecology and Environment

Koch, B. 2010. Status and future of laser scanning, synthetic aperture radar and hyperspectral remote sensing data for forest biomass assessment. ISPRS Journal of Photogrammetry and Remote Sensing, 65, 581-590. 
Kollmann, F., 1959. Tecnología de la madera y sus aplicaciones. Translation of second edition. In: German of 'Tecnologie des Holzes und der Holzwerkstoffe: mit 1194 Abbildungen im Text und 6 Tafeln’. Springer, Berlín, Germany.

Krankina, O. N., Harmon, M. E. 1995. Dynamics of the dead wood carbon pool in northwestern Russian boreal forests. Water, Air and Soil Pollution, 82 (1-2) 227-238.

Krankina, O.N., Harmon, M.E., Cohen, W.B., Oetter, D.R., Zyrina, O., Duane, M.V. 2004. Carbon stores, sinks, and sources in forests of Northwestern Russia: can we reconcile forest inventories with remote sensing results?. Climatic Change, 67, 257-272.

Kurz, W.A., Apps, M.J. 1999. A 70-year retrospective analysis of carbon fluxes in the Canadian forest sector. Ecological Applications, 9, 526-547.

Labrecque, S., Fournier, R.A., Luther, J.E., Piercey, D., 2006. A comparison of four methods to map biomass from Landsat-TM and inventory data in western Newfoundland. Forest Ecology and Management, 226, 129-144.

Lähde, E., Laiho, O., Norokorpi, Y., Saska, T. 1999. Stand structure as the basis of diversity index. Forest Ecology and Management, 115(2-3), 213-220.

Lamonaca, A., Corona, P., Barbati, A. 2008. Exploring forest structural complexity by multi-scale segmentation of VHR imagery. Remote Sensing of Environment, 112, 2839-2849.

Law, B.E., Ryan, M.G., Anthoni, P.M. 1999. Seasonal and annual respiration of a ponderosa pine respiration. Global Change Biology, 5, 169-182.

Latham, J. 2008. FAO land cover mapping initiatives. In: Campbell, J.C., Jones, K.B., Smith, J.H., Koeppe, M.T. (eds.). North America land cover summit. Association of American Geographers, Washington, USA.

Lauer, D.T., Morain, S.A., Salomonson, V.V. 1997. The Landsat program: its origins, evolution and impacts. Photogrammetric Engineering and Remote Sensing, 63 (7), 831-838.

Lea, R., Blodgett, C., Diamond, D., Schanta, M. 2004. Using the tasseled cap transformation to identify change in the missouri ozark forests, In: Proceedings of the ASPRS Fall Conference: Images to Decisions: Remote Sensing Foundations for GIS Applications.

Leboeuf, A., Beaudoin, A., Fournier, R.A., Guindon, L., Luther, J.E., Lambert, M.C. 2007. A shadow fraction method for mapping biomass of northern boreal black spruce forests using QuickBird imagery. Remote Sensing of Environment, 110(4), 488-500.

Lefsky, M.A., Cohen, W.B., Parker, G.G., and Harding, D.J. 2002. Lidar remote sensing for ecosystem studies. Bioscience, 52, 19-30.

Lefsky, M.A., Cohen, W.B. 2003. Selection of remotely sensed data. In Remote Sensing of Forest Environments: Concepts and Case Studies, Wulder, M.A., Franklin, S.E. (eds.), (Dordrecht/Boston/London: Kluwer Academic Publishers). 
Lefsky, M.A., Hudak, A.T., Cohen, W.B., Acker, S.A. 2005. Patterns of covariance between forest stand and canopy structure in the Pacific Northwest. Remote Sensing of Environment, 95, 517531.

Lefsky, M.A. 2010. A global forest canopy height map from the Moderate Resolution Imaging Spectroradiometer and the Geoscience Laser Altimeter System. Geophysical Research Letters, 37, L15401, DOI: http://dx.doi.org/10.1029/2010GL043622.

Leckie, D.G., Gougeon, F.A., Walsworth, N., Paradine, D. 2003. Stand delineation and composition estimation using semi-automated individual tree crown analysis. Remote Sensing of Environment, 85, 355-369.

Leimgruber, P., Christen, C.A., Laborderie, A. 2005. The impact of Landsat satellite monitoring on conservation biology. Environmental Monitoring and Assessment, 106, 81-101.

LeQuéré, C., Raupach, M.R., Canadell, J.G., Marland, G., Bopp, L., Ciais, Ph., Conway, T.J., Doney, S.C., Feely, R.A., Foster, P., Friedlingstein, P., Gurney, K., Houghton, R.A., House, J.I., Huntingford, Ch., Levy, P.E., Lomas, M.R., Majkut, J., Metzl, N., Ometto, J.P., Peters, G.P., Prentice, I.C., Randerson, J.T., Running, S.W., Sarmiento, J.L., Schuster, U., Sitch, S., Takahashi, T., Viovy, N., van der Werf, G.R., Woodward, F.I. 2009. Trends in the sources and carbon sinks of carbon dioxide. Nature Geoscience, 2, 831-836.

LeQuéré, C., Andres, R.J., Boden, T., Conway, T., Houghton, R.A., House, J.I., Marland, G., Peters, G.P., van der Werf, G., Ahlstrom, A., Andrew, R.M., Bopp, L., Canadell, J.G., Ciais, P., Doney, S.C., Enright, C., Friedlingstein, P., Huntingford, C., Jain, A.K., Jourdain, C., Kato, E., Keeling, R.F., Goldewijk, K.K., Levis, S., Levy, P., Lomas, M., Poulter, B., Raupach, M.R., Schwinger, J., Sitch, S., Stocker, B.D., Viovy, N., Zaehle, S., Zeng, N. 2012. The global carbon budget 1959-2011. Earth Systems Science Data Discussion, 5, 1107-1157.

Le Toan, T., Quegan, S., Davidson, M.W.J., Balzter, H., Paillou, P., Papathanassiou, K., Plummer, S., Rocca, F., Saatchi, S., Shugart, H., and Ulander, L. 2011. The BIOMASS mission: mapping global forest biomass to better understand the terrestrial carbon cycle. Remote Sensing of Environment, 115(11), 2850-2860.

Li, A., Huang, Ch., Sun, G., Shi, H., Toney, C., Zhu, Z., Rollins, M.G., Goward, S.N., Masek, J.G. 2011. Modeling the height of young forests regenerating from recent disturbances in Mississippi using Landsat and ICESat data. Remote Sensing of Environment, 115, 1837-1849.

Lindsay, R.W., Percival, D.B., Rothrock, D.A. 1996. The discrete wavelet transform and the scale analysis of the surface properties of sea ice. IEEE Transactions on Geoscience and Remote Sensing, 34(3), 771-787.

Liski, J., Lehtonen, A., Palosuo, T., Peltoniemi, M., Eggers, T., Muukkonen, P., Mäkipää, R. 2006. Carbon accumulation in Finland's forests 1922-2004 - an estimate obtained by combination of forest inventory data with modeling of biomass, litter and soil. Annals of Forest Science, 63, 687-697. 
Liu, W., Song, C., Schroeder, T.A., Cohen, W.B. 2008. Predicting forest successional stages using multitemporal Landsat imagery with forest inventory and analysis data. International Journal of Remote Sensing, 29(13), 3855-3872.

Loveland, T.R., Dwyer, J.L. 2012. Landsat: building a strong future. Remote Sensing of Environment, 122, 22-29.

Lozano, F.J., Suárez-Seoane, S., Kelly, M., Luis, E. 2008. A multi-scale approach for modeling fire occurrence probability using satellite data and classification trees: A case study in a mountainous Mediterranean region. Remote Sensing of Environment, 112, 708-719.

Lu, D., Mausel, P., Brondizio, E., Moran, E. 2002. Above-Ground Biomass estimation of Successional and Mature Forests Using TM Images in the Amazon Basin. In: Proceedings of Symposium on Geospatial Theory, Processing and Applications, Otawa, ON, Canada, 9-12 July 2002.

Lu, D., Mausel, P., Brondizio, E., Moran, E. 2004. Change detection techniques. International Journal of Remote Sensing, 25 (12), 2365-2407.

Lu, D., Batistella, M., 2005. Exploring TM image texture and its relationships with biomass estimation in Rondônia, Brazilian Amazon. Acta Amazônica, 35(2), 249-257.

Lu, D. 2006. The potential and challenge of remote sensing-based biomass estimation. International Journal of Remote Sensing, 27, 1297-1328.

Lu, D., Chen, Q., Wang, G., Moran, E., Batistella, M., Zhang, M., Laurin, G.V., Saah, D., 2012. Aboveground forest biomass estimation with Landsat and LiDAR data and uncertainty analysis of the estimates. International Journal of Forestry Research, vol. 2012, Article ID 436537, 16 pp. DOI: http://dx.doi.org/10.1155/2012/436537

Lunetta, R., Johnson, D.M., Lyon, J., Crotwell, J. 2004. Impacts of imagery temporal frequency on land-cover change detection monitoring. Remote Sensing of Environment, 89, 444-454.

Luther, J.E., Fournier, R.A., Piercey, D.E., Guindon, L., Hall, R.J. 2006. Biomass mapping using forest type and structure derived from Landsat TM imagery. International Journal of Applied Earth Observation and Geoinformation, 8, 173-187.

Lyons, M.B, Phinn, S.R., Roelfsema, C.M. 2012. Long term land cover and seagrass mapping using Landsat and object-based image analysis from 1972 to 2010 in the coastal environment of South East Queensland, Australia. ISPRS Journal of Photogrammetry and Remote Sensing, 71, 34-46.

Maas H.G., Bienert A., Scheller S., Keane E. 2008. Automatic forest inventory parameter determination from terrestrial laser scanner data. International Journal of Remote Sensing, 29, 1579-1593. 
Mäkipää, R., Lehtonen, A., Peltoniemi, M. 2008. Monitoring carbon stock changes in European forests using forest inventory data. In: Dolman, A.J., Freibauer, A., Valentini, R. (eds.). The continental-scale greenhouse gas balance of Europe. Ecological Studies 203: 191-210.

Mallat, S., Hwang, W.L. 1992. Singularity detection and processing with wavelets. IEEE Transactions on Information Theory, 38(2), 617-643.

Masek, J.G., Huang, Ch., Wolfe, R., Cohen, W., Hall, F., Kutler, J., Nelson, P. 2008. North American forest disturbance mapped from a decadal Landsat record. Remote Sensing of Environment, 112, 2914-2926.

Maselli, F. 2004. Monitoring forest conditions in a protected Mediterranean coastal area by the analysis of multiyear NDVI data. Remote Sensing of Environment, 89, 423-433.

Maselli, F., Chiesi, M., Montaghi, A., Pranzini, E. 2011. Use of ETM+ images to extend stem volume estimates obtained from LiDAR data. International Journal of Remote Sensing, 662671.

Martínez, B., Gilabert, M.A. 2009. Vegetation dynamics from NDVI time series analysis using the wavelet transform. Remote Sensing of the Environment, 113, 1823-1842.

McDermid, G.J., Smith, I.U. 2008. Mapping the distribution of whitebark pine (Pinus albicaulis) in Waterton Lakes National Park using logistic regression and classification tree analysis. Canadian Journal of Remote Sensing, 34, 356-366.

McDonald, G.T., Lane, M.B. 2004. Converging global indicators for sustainable forest management, Forest Policy and Economics, 6, 63-70.

McElhinny, C., Gibbons, Ph., Brack, C., Bauhus, J. 2005. Forest and Woodland stand structural complexity: its definition and measurement. Forest Ecology and Management, 218(1-3), 1-24.

McRoberts, R.E., Tomppo, E.O. 2007. Remote sensing support for national forests inventories. Remote Sensing of Environment, 110, 412-419.

Merino de Miguel, S., Solana Gutiérrez, J., González Alonso, F. 2010. Análisis de la estructura espacial de las masas de Pinus pinaster Aiton de la Comunidad de Madrid mediante imágenes de alta resolución espacial. Forest Systems, 19, 18-35.

Merlo, M., Croitoru, L. 2005. Valuing Mediterranean Forests - Towards Total Economic Value. CABI Publishing. Wallingford, Oxfordshire, UK. 397 pp.

Meyers, S.D., Kelly, B.G., O’Brien, J.J. 1993. An introduction to wavelet analysis in oceanography and meteorology: with application to the dispersion of Yanai waves. American Meteorological Society, 121, 2858-2866.

MMA. 2002. Plan Forestal Español. http://www.magrama.gob.es/es/agua/temas/planificacionhidrologica/pfe_tcm7-30496.pdf (Accessed 13 August 2013) 
MMA. 2009. Anuario de Estadística Forestal 2009; Ministerio de Agricultura, Alimentación y Medio Ambiente. Madrid, Spain, pp. 92.

Montero, G. Muñoz, M., Donés, J., Rojo, A. 2004. Fijación de CO2 por Pinus sylvestris L. y Quercus pyrenaica Willd. en los montes "Pinar de Valsaín” y "Matas de Valsaín”. Sistemas y Recursos Forestales, 13(2), 399-415.

Montero, G., Ruiz-Peinado, R., Muñoz, M. 2005. Producción de biomasa y fijación de CO2 por parte de los bosques españoles. Monografías INIA: Serie Forestal nº 13, Madrid, 270 pp

Montero, G., Serrada, R. 2013. La situación de los bosques y el sector forestal en España. $6^{\circ}$ Congreso forestal español. Sociedad Española de Ciencias Forestales, Vitoria.

Montes, F., Rubio, A., Barbeito, I., Cañellas, I. 2008. Characterization of the spatial structure of the canopy in Pinus sylvestris L. stands in Central Spain from hemispherical photographs. Forest Ecology and Management, 255, 580-590.

Mora, B., Wulder, M.A., White, J.C. 2010. Segment-constrained regression tree estimation of forest stand height from very high spatial resolution panchromatic imagery over a boreal environment, Remote Sensing of Environment, 114, 2474-2484.

Mora, B., Wulder, M.A., White, J.C., Hobart, G. 2013. Modeling stand height, volume, and biomass from very high spatial resolution satellite imagery and samples of airborne LiDAR. Remote Sensing, 5, 2308-2326. DOI: http://dx.doi.org/10.3390/rs5052308.

Moran, P.A.P. 1948. The interpretation of statistical maps. Journal of the Royal Statistical Society: Series B: Methodological, 10(2), 243-251.

Motz, K., Sterba, H., Pommerening, A. 2010. Sampling measures of tree diversity. Forest Ecology and Management, 260(11), 1985-1996.

Næsset, E. 1997. Determination of mean tree height of forest stands using airborne laser scanner data. ISPRS Journal of Photogrammetry, 52, 49-56.

Narayan, C., Fernandes, P.M., van Brusselen, J., Schuck, A. 2007. Potential for CO2 emissions mitigation in Europe through prescribed burning in the context of the Kyoto protocol. Forest Ecology and Management, 251, 164-173.

Neumann, M., Starlinger, F. 2001. The significance of different indices for stand structure and diversity in forests. Forest Ecology and Management, 145(1-2), 91-106.

Niedermeier, A., Romaneeben, E., Lehner, S., 2000. Detection of coastlines in SAR images using wavelet methods. IEEE Transactions on Geoscience and Remote Sensing, 38(5), 2270-2281.

Nijland, W., Addink, E.A., de Jong, S.M., Van der Meer, F.D. 2009. Optimizing spatial image support for quantitative mapping of natural vegetation. Remote Sensing of Environment, 113, 771-780. 
O’Neill, R.V., DeAngelis, D.L., Waide, J.B., Allen, T.F. 1986. A Hierarchical Concept of Ecosystems. Princeton University Press, Princeton.

Palace, M., Keller, M., Asner, G.P., Hagen, S., Braswell, B. 2008. Amazon forest structure from IKONOS satellite data and the automated characterization of forest canopy properties. Biotropica, 40, 141-150.

Pal, M., Mather, P.M. 2008. An assessment of the effectiveness of decision tree methods for land cover classification. Remote Sensing of Environment, 86, 554-565.

Pan, Y., Birdsey, R.A., Fang, J., Houghton, R., Kauppi, P.E., Kurz, W.A., Phillips, O.L., Shvidenko, A., Lewis, S.L., Canadell, J.G., Ciais, Ph., Jackson, R.B., Pacala, S., McGuire, A.D., Piao, Sh., Rautiainen, A., Sitch, S., Hayes, D. 2011. A large and persistent carbon sink in the World's forests. Science, 333, 988-993. DOI: http://dx.doi.org/10.1126/science.1201609

Pascual, C., García Abril, A., García Montero, L.G., Martín Fernández, S., Cohen, W.B. 2008. Object-based semi-automatic approach for forest structure characterization using lidar data in heterogeneous Pinus sylvestris stands. Forest Ecology and Management, 255, 3677-3685.

Pasher, J., King, D.J. 2010. Multivariate forest structure modeling and mapping using high resolution airborne imagery and topographic information. Remote Sensing of Environment, 114(8), 1718-1732.

Patenaude, G., Milne, R., Dawson, T.P. 2005. Synthesis of remote sensing approaches for forest carbon estimation: reporting to the Kyoto Protocol. Environmental Science and Policy, 8, 161178

Peddle, D.R., Teillet, Ph.M., Wulder, M.A. 2003. Radiometric processing. In: Remote Sensing of Forest Environments: Concepts and Case Studies, Wulder, M.A., Franklin, S.E. (eds.), (Dordrecht/Boston/London: Kluwer Academic Publishers).

Penman, J., Gytarsky, M., Hiraishi, T., Krug, T., Kruger, D., Pipatti, R., Buendia, L., Miwa, K., Ngara, T., Tanabe, K., Wagner, F., 2003. Good Practice Guidance for Land Use, Land-Use Change and Forestry. Intergovernmental Panel on Climate Change (IPCC), Hayama, Japan.

Percival, D.B., Wang, M., Overland, J.E. 2004. An introduction to wavelet analysis with applications to vegetation time series. Community Ecology, 5(1), 19-30.

Peterson, U., Nilson, T. 1993. Successional reflectance trajectories in northern temperate forests. International Journal Remote Sensing, 14, 609-613.

Petit, C.C., Lambin, E.F. 2001. Integration of multi-source remote sensing data for land cover change detection. International Journal of Geographical Information Science, 15, 785-803.

Pflugmacher, D., Cohen, W.B., Kennedy, R.E. 2012. Using Landsat-derived disturbance history (1972-2010) to predict current forest structure. Remote Sensing of Environment, 122, 146-165.

Potapov, P., Yaroshenko, A., Turubanove, S., Dubinin, M., Laestadius, L., Thies, C., Aksenov, D., Egorov, A., Yesipova, Y., Glushkov, I., Kapachevskiy, M., Kostikova, A., Manisha, A., 
Tsybikova, E., Zhuravleva, I. 2008. Mapping the World's Intact Forest Landscapes by Remote Sensing. Ecology and Society, 13 (2):51.

Potter, C., Tan, P-N., Kumar, V., Kucharik, Ch., Klooster, S., Genovese, V., 2003. Major disturbance events in terrestrial ecosystems detected using global satellite data sets. Global Change Biology, 9, 1005-1021.

Potter, C., Tan, P-N., Kumar, V., Steinbach, M., Klooster, S., Kumar, V., Myneni, R., Genovese, V., 2005. Recent history of large-scale ecosystem disturbances in North America derived from the AVHRR satellite record. Ecosystems, 8 (7), 808-824.

Powell, S.L., Cohen, W.B., Healey, S.P., Kennedy, R.E., Moisen, G.G, Pierce, K.B., Ohmann, J.L. 2010. Quantification of live aboveground biomass dynamics with Landsat time-series and field inventory data: A comparison of empirical modeling approaches. Remote Sensing of Environment, 114, 1053-1068.

Pregitzer, K. and Euskirchen, E. 2004. Carbon cycling and storage in world forests: biome patterns related to forest age. Global Change Biology, 10(12), 2052-2077, DOI: http://dx.doi.org/10.1111/j.1365-2486.2004.00866.x

Proisy, Ch., Couteron, P., Fromard, F. 2007. Predicting and mapping mangrove biomass from canopy grain analysis using Fourier-based textural ordination of IKONOS images. Remote Sensing of Environment, 109, 379-392.

Raja, R.A.A., Anand, V., Kumar, A.S., Maithani, S., Kumar, V.A. 2013. Wavelet Based Post Classification Change Detection Technique for Urban Growth Monitoring. Journal of Indian Society Remote Sensing, 41(1), 35-43.

Ratanamahatana, Ch.A., Keogh, E. 2005. Three myths about Dynamic Time Warping data mining. SIAM International Conference on Data Mining (SDM), Newport Beach, California, April 2123.

Rivas-Martínez, S., 1963. Estudio de la vegetación y flora de la Sierra de Guadarrama y Gredos. Anales del Instituto Botánico A.J. Cavanilles, 21, 5-325.

Rocchini, D., Balkenhol, N., Carter, G. A., Foody, G. M., Gillespie, T. W., He, K. S., Kark, S., Levin, N., Lucas, K., Luoto, M., Nagendra, H., Oldeland, J., Ricotta, C., Southworth, J., Neteler, M. 2010. Remotely sensed spectral heterogeneity as a proxy of species diversity: Recent advances and open challenges. Ecological Informatics, 5(5), 318-329.

Roder, A., Kuemmerle, T., Hill, J., 2005. Extension of retrospective datasets using multiple sensors. An approach to radiometric intercalibration of Landsat TM and MSS data. Remote Sensing of Environment, 95, 195-210.

Rosenqvist, Å., Milne, A., Lucas, R., Imhoff, M., Dobson, C. 2003. A review of remote sensing technology in support of the Kyoto Protocol. Environmental Science and Management, 6, 441455. 
Rouse, J.W. Haas R.H., Schell J.A., Deering D.W. 1973. Monitoring vegetation systems in the Great Plains with ERTS. In: Fraden S.C., Marcanti E.P., Becker M.A. (eds.). Third ERTS-1 Symposium, 10-14 Dec. 1973, NASA SP-351, Washington D.C. NASA, pp. 309-317.

Rouvinen, S., Kuuluvainen, T. 2005. Tree diameter distributions in natural and managed old Pinus sylvestris-dominated forests. Forest Ecology and Management, 208(1-3), 45-61.

Rubin, B.D., Manion, P.D., Faber-Langendoen, D. 2006. Diameter distributions and structural sustainability in forests. Forest Ecology and Management, 222(1-3), 427-438.

Ruiz-Peinado R., Río M., Montero G., 2011. New models for estimating the carbon sink capacity of Spanish softwood species. Forest Systems, 20(1), 176-188.

Sakamoto, T., Yokozawa, M., Toritani, H., Shibayama, M., Ishitsuka, N., Ohno, H. 2005. A phenology detection method using time-series MODIS data. Remote Sensing of Environment, 96, 366-374.

Sales, M.H., Souza, C.M.Jr., Kyriadidis, Ph.C., Roberts, D.A., Vidal, E. 2007. Improving spatial distribution estimation of forest biomass with geostatistics: A case study for Rondônia, Brazil. Ecological Modelling, 205, 221-230.

Salvador, R., Pons, X. 1998. On the applicability of Landsat TM images to Mediterranean forest inventories. Forest Ecology and Management, 104, 193-208.

Shettigara, V.K., Sumerling, G.M. 1998. Height Determination of Extended Objects Using Shadows in SPOT Images. Photogrammetric Engineering and Remote Sensing, 64(1), 35-44.

Simhadri, K.K., Iyengar, S.S., Holyer, R.J., Lybanon, M., Zachary, J.M. 1998. Wavelet-based feature extraction from oceanographic images. IEEE Transactions on Geoscience and Remote Sensing, 36(3), 767-778.

Singh, A. 1989. Digital change detection techniques using remotely-sensed data. International Journal of Remote Sensing, 10(6), 989-1003.

Siry, J.P., Cubbage, F.W., Ahmed, M.R. 2005. Sustainable forest management: global trends and opportunities. Forest Policy and Economics, 7, 51-561.

Smith, J. H. 2008. North American Land Cover Summit, Introduction. In: Campbell, J.C., Jones, K.B., Smith, J.H., Koeppe, M.T. (eds.). North America land cover summit. Association of American Geographers, Washington, USA.

Song, C., Woodcock, C.E., 2003. Monitoring forest succession with multitemporal Landsat images: factors of uncertainty. IEEE Transactions on Geoscience and Remote Sensing, 41, 2257-2267.

Soenen, S.A., Peddle, D.R., Hall, R.J., Coburn, C.A., Hall, F.G. 2010. Estimating aboveground forest biomass from canopy reflectance model inversion in mountainous terrain. Remote Sensing of Environment, 114, 1325-1337. 
Solomon, D.S., Gove, J.H. 1999. Effects of uneven-age management intensity on structural diversity in two major forest types in New England. Forest Ecology and Management, 114(2-3), 265-274.

St-Louis, V., Pidgeon, A.M., Radeloff, V.C., Hawbaker, T.J., Clayton, M.K. 2006. High-resolution image texture as a predictor of bird species richness. Remote Sensing of Environment, 105(4), 299-312.

Stoney, W. E. (Noblis Inc.). 2008. ASPRS Guide to Land Imaging Satellites, 15 pp.

St-Onge, B., Cavayas, F. 1995. Estimating forest stand structure from high resolution imagery using the directional variogram. International Journal of Remote Sensing, 16(11), 1999-2021.

Suárez, J.C., Ontiveros, C., Smith, S., Snape, S. 2005. Use of airborne LiDAR and aerial photography in the estimation of individual tree heights in forestry. Computers and Geosciences, 31, 253-262.

Tan, K., Piao, S., Peng, C., Fang, J. 2007. Satellite-based estimation of biomass carbon stocks for northeast China's forests between 1982 and 1999. Forest Ecology and Management, 240, 114121.

Tolomeo, R., Lawson, T., Lokey, G., Dunn, C., Stein, C., Overton, J., 2009. The Landsat Program Is Not Meeting the Goals and Intent of the Land Remote Sensing Policy Act of 1992, Audit report. Report No. IG-09-021 (assignment no. A-08-019-00) (Washington, DC: NASA).

Tomppo, E., Nilsson, M., Rosengre, M., Aalto, P., Kennedy, P. 2002. Simultaneous use of LandsatTM and IRS-1C WiFS data in estimating large area tree stem volume and aboveground biomass. Remote Sensing of Environment, 82, 156-171.

Tomppo, E., Gschwantner, Th., Lawrence, M., McRoberts, R.E. (eds.) 2010. National Forest Inventories - Pathways for common reporting. Springer, 612 pp.

Toutin, T. 2004. Review article: Geometric processing of remote sensing images: models, algorithms and methods. International Journal of Remote Sensing, 25(10), 1893-1924.

Trotter, C.M., Dymond, J.R., Goulding, C. J. 1997. Estimation of timber volume in a coniferous plantation forest using Landsat TM. International Journal of Remote Sensing, 18(10), 22092223.

Turner, M.G. 1989. Landscape ecology: the effect of pattern on process. Annual Review of Ecology and Systematics, 20, 171-197.

Turner, D.P., Cohen, W.B., Kennedy, R.E., Fassnacht, K.S., Briggs, J.M. 1999. Relationship between leaf area index and Landsat TM spectral vegetation indices across three temperate zone sites. Remote Sensing of Environment, 70, 52-68.

Turner, D.P., Guzy, M., Lefsky, M., Ritts, W.D., van Tuyl, W., Law, B.E. 2004. Monitoring Forest Carbon Sequestration with Remote Sensing and Carbon Cycle Modeling. Environmental Management, 33(4) 457-466. 
UNFCCC, 1997. Kyoto protocol to the United Nations Framework convention on climate change. Document FCCC/CP/1997/7/Add.1. Available at http://www.unfccc.int (Accessed 05 September 2013)

Vallejo, R. 2005. El mapa forestal de España escala 1:50.000 (MFE50) como base del tercer inventario forestal nacional. Cuadernos de la Sociedad Española de Ciencias Forestales, 19, 205-210.

Varga, P., Chen, H.Y.H., Klinka, K. 2005. Tree-size diversity between single-and mixed-species stands in three forest types in western Canada. Canadian Journal of Remote Sensing, 35, 593601.

Velichko, V.M., Zagoruyko, N.G. 1970. Automatic recognition of 200 words. International Journal of Man-Machine Studies, 2, 223-234.

Verbesselt, J., Hyndman, R., Newnham, G., Culvenor, D. 2010. Detecting trend and seasonal changes in satellite image time series. Remote Sensing of Environment, 114, 106-115.

Villa, G., Arozarena, A., Peces, J.J., Domenech, E. 2009. Plan nacional de teledetección: estado actual y perspectivas futuras. In: Proceedings of Teledetección: agua y desarrollo sostenible. XIII Congreso de la Asociación Española de Teledetección, Calatayud, Spain, 23-26 September 2009; pp. 521-524.

Walsh, S.J., Brown, D.G., Geddes, C.A., Weiss, D.J., McKnight, S., Hammer, E.S., Tuttle, J.P. 2009. Pattern-process relations in the alpine and subalpine environments: a remote sensing and GIScience perspective. Chapter 2. In: Development in Earth Surface Processes. Elseveir.

Wilson, E.H., Sader, S.A. 2002. Detection of forest harvest type using multiple dates of Landsat TM imagery. Remote Sensing of Environment, 80, 385-396.

White, J.C., Gómez, C., Wulder, M.A., Coops, N.C. 2010. Characterizing temperate forest structural and spectral diversity with Hyperion EO-1 data. Remote Sensing of the Environment, 114, 1576-1589.

White, J.C., Wulder, M.A., Gómez, C., Stenhouse, G. 2011. A history of habitat dynamics: characterizing 35 year of stand replacing disturbance. Canadian Journal of Remote Sensing, 37(2), 234-251.

Woodcock, C.E., Allen, R., Anderson, M., Belward, A., Bindschadler, R., Cohen, W.B., Gao, F., Goward, S.N., Helder, D., Helmer, E., Nemani, R., Oreopoulos, L., Schott, J., Thenkabail, P.S., Vermote, E.F., Vogelmann, J., Wulder, M.A., Wynne, R. 2008. Free access to Landsat imagery. Science, 320, 1011.

Wulder, M.A., LeDrew, E.F., Franklin, S.E., Lavigne, M.B. 1998. Aerial texture information in the estimation of northern deciduous and mixed wood forest leaf area index (LAI). Remote Sensing of Environment, 64, 64-76. 
Wulder, M., Franklin, S. 2002. Spatial and spectral variability due to Landsat image acquisition date: The impact on image classification, In: Proceedings of the International Geoscience and Remote Sensing Symposium (IGARSS) and 24th Canadian Remote Sensing Symposium, June 24-28, Toronto, IEEE, Piscataway, NJ.

Wulder, M.A., White, J.C., Niemann, K.O., Nelson, T. 2004a. Comparison of airborne and satellite high spatial resolution data for the identification of individual trees with local maxima filtering. International Journal of Remote Sensing, 25(11), 2225-2232.

Wulder, M.A., Kurz, W.A., Gillis, M. 2004b. National level forest monitoring and modeling in Canada. Progress in Physical Planning, 61, 365-381.

Wulder, M. A., White, J. C., Bentz, C., Alvarez, M. F., Coops, N. 2006. Estimating the probability of mountain pine beetle red attack damage. Remote Sensing of Environment, 101(2), 150-166.

Wulder, M.A., White, J.C., Han, T., Coops, N.C., Cardille, J.A., Holland, T., Grills, D. 2008a. Monitoring Canada's forests. Part 2: National forest fragmentation and pattern. Canadian Journal of Remote Sensing, 34(6) 563-584.

Wulder, M.A., White, J.C., Fournier, R.A., Luther, J.E., Magnussen, S. 2008b. Spatially explicit large area biomass estimation: three approaches using forest inventory and remotely sensed imagery in a GIS. Sensors, 8, 529-560.

Wulder, M.A., White, J.C., Goward, S.M., Masek, J.G., Irons, J.R., Herold, M., Cohen, W.B., Loveland, Th.R., Woodcock, C.E. 2008c. Landsat continuity: issues and opportunities for land cover monitoring. Remote Sensing of Environment, 112, 955-969.

Wulder, M.A., Bater. C.W., Coops, N.C., Hilker, T., White, J.C. 2008d. The role of LiDAR in sustainable forest management. The Forestry Chronicle, 84(6), 807-826.

Wulder, M.A., White, J.C., Hay, G.J., Castilla, G. 2008e. Towards automated segmentation of forest inventory polygons on high spatial resolution satellite imagery. The Forestry Chronicle, 84(2), 221-230.

Wulder, M.A., White, J.C., Coops, N.C., Butson, C.R. 2008f. Multi-temporal analysis of high spatial resolution imagery for disturbance monitoring. Remote Sensing of Environment, 112, 2729-2740.

Wulder, M.A., White, J.C., Masek, J.G., Dwyer, J., Roy, D.P. 2011. Continuity of Landsat observations: Short term considerations. Remote Sensing of Environment, 115, 747-751.

Wulder, M. A., Masek, J. G., Cohen, W. B., Loveland, T. R., Woodcock, C. E. 2012a. Opening the archive: How free data has enabled the science and monitoring promise of Landsat. Remote Sensing of Environment, 122, 2-10.

Wulder, M.A., White, J.C., Nelson, R.F., Næsset, E., Ole Ørka, H., Coops, N.C., Hilker, T., Bater, C.W., Gobakken, T. 2012b. Lidar sampling for large-area forest characterization: A review. Remote Sensing of Environment, 121, 196-209. 
Wulder, M.A., Coops, N.C., Hudak, A.T., Morsdorf, F., Nelson, G., Newnham, R., Vastaranta, M. 2013. Status and prospects for LiDAR remote sensing of forested ecosystems. Canadian Journal of Remote Sensing, 39(s1): S1-S5, 10.5589/m13-051.

Zhang, X., Zhao, Y., Ashton, M.S., Lee, X. 2012. Measuring carbon in forests, In: Managing forests carbon in a changing climate, (Ashton, M.S., Tyrrell, M.L., Spalding, D., Gentry, B. (eds.). Springer.

Zheng, D., Rademacher, J., Chen, J., Crow, T., Bresee, M., Le Moine, J., Ryu, S-R. 2004. Estimating aboveground biomass using Landsat 7 ETM+ data across a managed landscape in northern Wisconsin, USA. Remote Sensing of Environment, 93, 402-411.

Zhu, Z., Woodcock, C.E., Olofsson, P. 2012. Continuous monitoring of forest disturbance using all available Landsat images. Remote Sensing of Environment, 122, 75-91.

Zianis, D., Muukkonen, P., Mäkipää, R., Mencuccini, M. 2005. Biomass and Stem Volume Equations for Tree Species in Europe. Silva Fennica Monographs, 4. The Finnish Society of Forest Science. The Finnish Forest Research Institute. 63 pp 
Assessment of biomass and carbon dynamics in pine forests of the Spanish Central Range: a remote sensing approach 


\section{PUBLICATIONS}

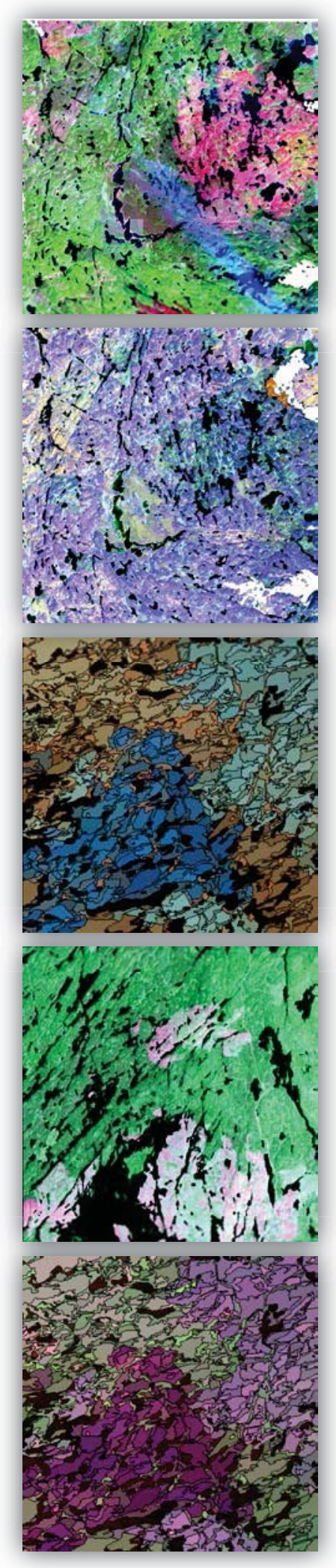


Assessment of biomass and carbon dynamics in pine forests of the Spanish Central Range: a remote sensing approach 


\section{CHAPTER I}

Cristina Gómez, Joanne C. White, Michael A. Wulder. 2011. Characterizing the state and processes of change in a dynamic forest environment using hierarchical spatiotemporal segmentation. Remote Sensing of Environment, 115, 1665-1679

\section{RESUMEN}

\section{Caracterización del estado y procesos de cambio en zona forestal dinámica mediante segmentación espacio-temporal}

Los cambios de naturaleza discreta en masas forestales, como abundancia, distribución y productividad, se detectan fácilmente mediante técnicas de teledetección. Sin embargo las transformaciones de naturaleza continua, como crecimiento y procesos de sucesión, son más difíciles de evaluar. En este trabajo se exploró la capacidad de las trayectorias espectrales generadas con una serie temporal de 35 años (1973-2008) de imágenes Landsat para caracterizar los procesos de cambio en una zona forestal muy dinámica del noroeste de Alberta, Canadá. Para caracterizar los procesos de cambio espacialmente difusos y temporalmente imprecisos se aplicó un método de segmentación de imágenes espaciotemporal y jerárquico. Tras un proceso de calibrado y normalización radiométrica de las imágenes Landsat, las componentes Verdor y Brillo de la Transformación Tasseled Cap (TTC) se combinaron formando el índice Tasseled Cap Angle (TCA). TCA es una medida de la proporción de vegetación a no vegetación (estado de ocupación), y su derivada temporal, el Indicador de Procesos (PI) es una medida de cambio en esa proporción a lo largo del tiempo. Ambos índices condensan en un único valor información de las longitudes de onda del visible e infrarrojo cercano, y facilitan el análisis de series temporales de paisaje forestal, pudiendo incorporar información de todos los sensores Landsat.

Combinando la secuencia original de TCA y su derivada temporal, se realizó el proceso de segmentación de imagen en tres niveles jerárquicos. Los niveles superior e inferior definen objetos homogéneos al inicio y fin del periodo de estudio respectivamente, mientras el nivel intermedio identifica trayectorias espectrales similares. Se describió la evolución a lo largo del tiempo de los valores TCA y PI. Las asociaciones espaciales y temporales de los procesos de cambio se evaluaron estadísticamente con el índice I de Moran.

El paisaje forestal experimentó multitud de transformaciones de tipo variado: desde perturbaciones drásticas con sustitución completa de la cubierta forestal a crecimiento 
progresivo y procesos de sucesión. Los resultados indican que la región está en continua transformación y mantiene una proporción elevada de vegetación a no vegetación. La proporción total de paisaje modificado en cada decenio analizado aumentó de 18\% y 14\% en los años 1970s y 1980s respectivamente, a valores superiores al 30\% y 33\% en los años 1990s y 2000s. En promedio, la proporción de vegetación a no vegetación aumentaba con anterioridad a 1981, disminuía entre 1981 y 1997, y se incrementaba de nuevo tras 1997. Se detectó un alto nivel de autocorrelación espacial en los procesos de cambio, con valores máximos del índice I de Moran 0.79 en 1973. A partir de 1981 las transformaciones del paisaje se hicieron más dispersas. También se observó correlación temporal localizada de los procesos de cambio, siendo el periodo 1990-1995 el de cambios más persistentes.

Palabras clave: Landsat, trayectoria espectral, Tasseled Cap Angle, TCA, Indicador de Procesos, PI, bosque, cambio, segmentación jerárquica espacio-temporal, seguimiento, modelo de paisaje, procesos del paisaje 


\title{
Characterizing the state and processes of change in a dynamic forest environment using hierarchical spatio-temporal segmentation
}

\author{
Cristina Gómez ${ }^{\mathrm{a}}$, Joanne C. White ${ }^{\mathrm{b}}$, Michael A. Wulder ${ }^{\mathrm{b}, *}$ \\ a Sustainable Forest Management Research Institute, ETS de Ingenierías Agrarias, Universidad de Valladolid, Palencia, 34004, Spain
}

${ }^{b}$ Canadian Forest Service (Pacific Forestry Centre), Natural Resources Canada, Victoria, British Columbia, Canada V8Z 1M5

\section{A R T I C L E I N F O}

Article history:

Received 23 September 2010

Received in revised form 21 February 2011

Accepted 27 February 2011

Available online 6 April 2011

\section{Keywords:}

Landsat

Spectral trajectory

Tasseled Cap Angle

TCA

Process indicator

PI

Forest

Change

Hierarchical spatio-temporal segmentation

Monitoring

Landscape pattern

Landscape process

\begin{abstract}
A B S T R A C T
Discrete changes in forest abundance, distribution, and productivity are readily detectable using a number of remotely sensed data sources; however, continuous changes such as growth and succession processes are more difficult to monitor. In this research we explore the potential of spectral trajectories generated from a 35-year (1973-2008) time-series of Landsat imagery to characterize change processes in a dynamic forest environment in northwestern Alberta, Canada. We propose a method of hierarchical spatio-temporal segmentation that enables the characterization of change processes that are spatially diffuse and temporally imprecise. Calibrated imagery from Landsat sensors are radiometrically normalized and two metrics derived from the Tasseled Cap Transformation components, greenness and brightness, are used to generate the Tasseled Cap Angle (TCA). The TCA is a measure of the proportion of vegetation to non-vegetation (the occupation state), and its derivative, the Process Indicator (PI), is a measure of change in this proportion through time. These indices condense information from the visible and near-infrared wavelengths, and facilitate lengthy time series analysis of forest landscape change using data from all Landsat sensors.

A combination of the original TCA and its derivative sequence are input to a three level hierarchical segmentation process with the highest and lowest levels defining homogeneous objects at the initial and final date, and the intermediate level identifying trajectories with similar change processes. The development through time of the TCA and PI are described, and the spatial and temporal associations of processes are statistically assessed using the Moran's Index.

A full range of change types were identified on the landscape, from stand replacing disturbances to more subtle growth and succession processes. Results indicate that the study area is in a constant state of change, and maintains a high average proportion of vegetation to non-vegetation. The amount of total landscape modified per decade increased from $18 \%$ and $14 \%$ in the 1970 s and 1980 s respectively, to more than $30 \%$ and $33 \%$ in the 1990s and 2000s. On average, the proportion of vegetation to non-vegetation was increasing prior to 1981 , decreasing between 1981 and 1997, and increasing post-1997. There was a high degree of spatial autocorrelation amongst change processes, with a maximum Moran's I of 0.79 in 1973; landscape change became more spatially disperse and widespread after 1981 . Temporal correlation of change processes was observed locally, with the period 1990-1995 having the most persistent change.
\end{abstract}

Crown Copyright @ 2011 Published by Elsevier Inc. All rights reserved.

\section{Introduction}

Forests are naturally dynamic ecosystems in continuous change with a key role in water (Van Dijk and Bruijnzeel, 2001) and carbon cycles (Muukkonen \& Heiskanen, 2007), and in wildlife habitat quality (Nadkarni et al., 2004). Ecological benefits provided by forests depend on the stage of development, health condition, spatial distribution, and structural characteristics (Numa et al., 2009; Spies et al., 1994; Wulder et al., 2008a). The ecological and economic services delivered by forests are markedly altered after disturbances

\footnotetext{
* Corresponding author. Tel.: +1 250363 6090; fax: +1 2503630775 .

E-mail address: mike.wulder@nrcan.gc.ca (M.A. Wulder).
}

such as fire or harvest, and are more steadily modified when subtle growth, natural succession, or decay occur.

Insights into patterns, rates, and trends of landscape changes are necessary to understand forest dynamics, enable preservation, and assess the effectiveness of management approaches (Hayes \& Cohen, 2007; Huang et al., 2009a). Remotely sensed data have become a major information source for change detection (Lu et al., 2004) and are possibly the only feasible and cost-effective option for extensive areas (Lunetta et al., 2004). The Landsat series of satellites, the first of which was launched in 1972, provides a lengthy temporal sequence of images, and is unique among Earth observing satellites with imagery systematically collected to ensure global coverage, processed to an end-user applications ready state, and available via the Internet without cost. The spatial resolution $(30 \mathrm{~m})$, revisit cycle (16 days), 
and spatial extent $(185 \mathrm{~km} \times 185 \mathrm{~km})$ of Landsat data are well suited to characterizing forest change (Wulder et al., 2008b).

Our goal is to explore the capacity of spectral trajectories generated from a 35-year time-series of Landsat images for exploration and analysis of spatially and temporally diffuse change in a dynamic forest environment. For this purpose we develop a hierarchical spatio-temporal segmentation method that combines information at various spatial and temporal resolutions; the persistence of relations between objects at the multilevel scale is assured by its hierarchical character. Specific objectives of this study are:

1. To characterize forest landscape change using an index generated from the Tasseled Cap Transformation components Greenness and Brightness, as well as the first derivative of this index. This index characterizes the proportion of vegetation to non-vegetation in a pixel and uses spectral channels that enable bridging across all Landsat sensors.

2. To incorporate both spatial and temporal properties into a hierarchical segmentation process to capture landscape-level change and incorporate spatial information regarding these change units through time.

3. To analyze the spatial and temporal correlations of changes through time over an area with changing amounts, rates, and related spatia distributions of disturbance in a study area important from both ecological (habitat) and economic perspectives.

\section{Background}

\subsection{Disturbances and subtle change}

Abundant research effort has focused on the assessment of disturbances in large area monitoring programs. Stand replacing disturbances, such as clearcuts and wildfires that drastically modify the landscape and require a lengthy period of time to recover their initial state, can be detected with confidence using remotely sensed data (Coops et al., 2006), particularly Landsat data. For example, Cohen et al. (1998) applied and compared various methods for mapping clearcuts in Western Oregon, achieving results with greater than $90 \%$ accuracy. In the same region, Cohen et al. (2002) characterized the rate and distribution of stand replacing disturbance over a 23-year period with MSS and TM images, finding public land more affected by natural disturbance, while private land was more intensely harvested. Healey et al. (2005) compared the ability of four Tasseled Cap (TC) structures in detecting harvest disturbance; a newly developed Disturbance Index (DI) was the best performer in areas with slower succession rates. The DI was later used by Masek et al. (2008) to compile a 10-year record of forest disturbances in North America, reporting omission errors of $30-60 \%$ and commission errors of $20-30 \%$.

Less studied is the characterization of subtle, slow, continuous change related to partial harvest and natural regeneration or decay processes, which have less obvious effects on the landscape (Coops et al., 2006). Forest successional stages have been described (Cohen et al., 1995; Helmer et al., 2000; Jakubauskas, 1996), but studying the transitions between development stages is less common: Peterson and Nilson (1993) described trajectories of reflectance change in secondary succession of mono-specific birch and pine stands in Estonia; Schroeder et al. (2007) characterized patterns of recovery post-harvest in Western Oregon, and Vogelmann et al. (2009) characterized forest decline and mortality caused by persistent insect defoliation from 1988 to 2006 in New Mexico.

\subsection{Time series of images and spectral trajectory}

Two images acquired at different dates may be sufficient for identifying landscape change (Coppin \& Bauer, 1996); however, the use of more than two image dates is recognized as a superior technique when the objective is to characterize the rate of change (as opposed to just the presence or absence of change) (Goodwin et al., 2008). A time series of remotely sensed images enables the identification of a greater range of processes (Gillanders et al., 2008) as well as the characterization of temporal patterns. Dense time-series are particularly useful for detecting change in very dynamic forests with a fast recovery rate (Huang et al., 2009b; Lunetta et al., 2004). Interpretation of a sequence of images, or temporal trajectory, makes it possible to characterize vegetation dynamics on different temporal scales (Bontemps et al., 2008). With the extensive Landsat image archive of the USGS being made freely available to the public (Woodcock et al., 2008) it has become possible to obtain a considerable number of images for long-term monitoring of ecosystems and for trajectory analysis approaches (Linke et al., 2009).

\subsection{Object analysis approach for change detection}

Object-based analysis has increased in the Earth Observation community in the last decade (Blaschke, 2010; Hay et al., 2005) as an alternative to pixel based analysis. Among the strengths of objectbased analysis for change detection are the reduction of misregistration and shadowing effects (Johansen et al., 2010) and the inclusion of contextual information.

The spatial resolution of the imagery selected is crucial in the definition of objects analogous to forest stands. Landsat medium spatial resolution is well suited to the detection of change in forest environments at the stand level. The study of change with an object approach, and particularly the definition of objects can be done in a number of ways: if using various images, the segments can first be defined on a reference image and compared later in other dates (Hall \& Hay, 2003); alternatively, objects could be defined by a pre-existing GIS layer as in Walter (2004); a third approach is the simultaneous segmentation of various dates of images (Bontemps et al., 2008; Desclée et al., 2006).

\section{Methods}

\subsection{Study area}

The study area covers $13,818 \mathrm{~km}^{2}$ of the Foothills boreal forest region (Rowe, 1972) on the eastern side of the Rocky Mountains, Alberta, Canada (Fig. 1). It is a transition zone between boreal and sub-alpine forest regions with lodgepole pine (Pinus contorta Dougl.ex Loudon), trembling aspen (Populus tremuloides Michx), and balsam poplar (Populus balsamifera L.) as prevalent pioneer tree species appearing after catastrophic events. Other species normally found in older stands are white spruce (Picea glauca (Moench) Voss) and black spruce (Picea mariana (Mill.) BSP) and less frequently white birch (Betula papyrifera Marsh.), tamarack (Larix laricina (Du Roi) K. Kock), balsam fir (Abies balsamea (L.)) and alpine fir (Abies lasiocarpa (Hook.) Nutt.). Elevation ranges from 600 to $2500 \mathrm{~m}$.

The area is rich in live and fossilized natural resources (Alberta Sustainable Resource Development, 2009) and provides important habitat for grizzly bear (Ursus arctos L.) (Nielsen et al., 2004) and woodland caribou (Rangifer tarandus caribou Gmelin). Industrial extraction activities such as oil and gas, mining, and forest harvesting have been ongoing since the 1950s (Andison, 1998), with an increased intensity in recent decades (Schneider et al., 2003).

\subsection{Data}

We used a time sequence of fourteen images (Table 1 ) acquired between 1973 and 2008 by the Landsat series of satellites with various sensors: the Multi-Spectral Scanner (MSS), the Thematic Mapper (TM), and the Enhanced Thematic Mapper Plus (ETM+). All images were selected within the summer and early fall seasons for 


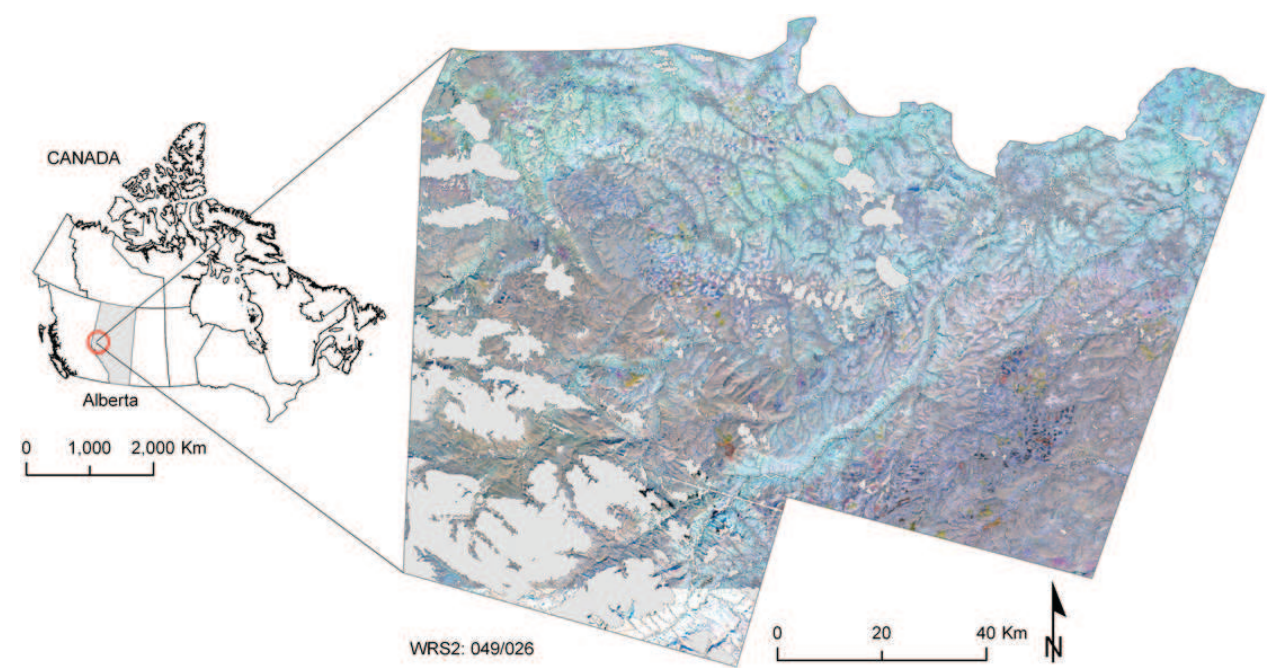

Fig. 1. Location of the study area. The inset displays a combination of Tasseled Cap Angle (TCA) layers of years 2001 (red), 2002 (green), 2004 (blue); areas of clouds and altitude over $1700 \mathrm{~m}$ are masked out.

consistency in forest phenological condition (Wulder et al., 2004). Images were obtained from the United States Geological Survey (USGS), the Global Land Cover Facility (GLCF), and the Canada Centre for Remote Sensing (CCRS) archives.

\subsection{Image preprocessing}

Preprocessing of a sequence of images for change detection has two critical stages: spatial registration to assure positional coincidence of features, and radiometric calibration and normalization to ensure that changes in spectral reflectance correspond to actual change events. Failure to correctly perform either of these two could trigger significant errors in the analysis and lead to misinterpretation of change events (Lu et al., 2004).

All but two of the images were acquired in an orthocorrected format. The two images received in raw format were geometrically corrected using Toutin's model (PCI Geomatica) and registered to the 1995 TM base image using 250 Ground Control Points (GCPs) and the thin plate spline algorithm. All of the MSS images were resampled from their original $57 \mathrm{~m}$ spatial resolution to $30 \mathrm{~m}$. Finally, an image-

Table 1

Landsat time-series of imagery used in the study.

\begin{tabular}{lllll}
\hline Landsat/sensor & Path/row & $\begin{array}{l}\text { Date } \\
\text { (dd/mm/yyyy) }\end{array}$ & $\begin{array}{l}\text { Sun elevation } \\
\text { (degrees) }\end{array}$ & Source \\
\hline 1/MSS & $50 / 22$ & $16 / 09 / 1973$ & 36.21 & GLCF \\
2/MSS & $50 / 22$ & $27 / 09 / 1976$ & 30.40 & CCRS \\
2/MSS & $50 / 22$ & $25 / 07 / 1978$ & 49.00 & GLCF \\
2/MSS & $50 / 22$ & $14 / 08 / 1981$ & 46.10 & CCRS \\
5/TM & $46 / 22$ & $06 / 09 / 1990$ & 37.38 & USGS \\
5/TM & $46 / 22$ & $23 / 07 / 1991$ & 50.25 & USGS \\
5/TM & $46 / 22$ & $04 / 09 / 1995$ & 36.99 & USGS \\
5/TM & $46 / 22$ & $25 / 09 / 1997$ & 32.21 & CCRS \\
7/ETM+ & $46 / 22$ & $25 / 09 / 2000$ & 32.82 & USGS \\
7/ETM+ & $46 / 22$ & $28 / 09 / 2001$ & 31.70 & USGS \\
7/ETM+ & $46 / 22$ & $15 / 09 / 2002$ & 36.48 & USGS \\
5/TM & $46 / 22$ & $11 / 08 / 2004$ & 47.31 & CCRS \\
5/TM & $46 / 22$ & $30 / 06 / 2006$ & 55.86 & USGS \\
5/TM & $46 / 22$ & $06 / 08 / 2008$ & 48.80 & USGS \\
\hline
\end{tabular}

CCRS: Canadian Centre for Remote Sensing.

GLCF: Global Land Cover Facility.

USGS: United States Geological Survey. to-image registration was used to co-register all of the images to the base image with a RMS error of less than $30 \mathrm{~m}$ (1 pixel).

Robust radiometric preprocessing is essential for monitoring landscape change (Lu et al., 2004) and for linking images with biophysical phenomena (Gong \& Xu, 2003); it is particularly challenging if images from various sensors are included in the analysis (Roder et al., 2005). We used the approach of Han et al. (2007) to convert digital numbers to Top of Atmosphere (TOA) radiance with coefficients recommended by Chander et al. (2009). Greenness and Brightness components of the Tasseled Cap Transformation (TCT) (Crist \& Cicone, 1984; Huang et al., 2002; Kauth \& Thomas, 1976) were calculated and normalized to the reference image Greenness and Brightness, as in Powell et al. (2008). For relative radiometric normalization we applied IR-MAD (Iteratively Reweighted Multivariate Alteration Detection) (Canty et al., 2004) as recommended by Schroeder et al. (2006) for temporal spectral trajectories. This automatic process is based on the invariance property of MAD transformation and performs an orthogonal linear regression (Canty \& Nielsen, 2008) of the target image pixels on to the reference image pixels; the process is invariant to linear transformations (Canty et al., 2004; Nielsen et al., 1998). The reference was a Landsat-5 TM image free of clouds and haze, dated 1995, in the middle of the series. The process of normalization reduces the amount of artifacts due to illumination or atmospheric variations, enabling more reliable detection of true change (Song et al., 2001).

\subsection{Tasseled Cap Angle (TCA)}

The Tasseled Cap Transformation (TCT) (Crist, 1985; Crist \& Cicone, 1984; Huang et al., 2002; Kauth \& Thomas, 1976) is a linear transform of the original Landsat spectral space that has been broadly employed in forestry applications (Cohen \& Goward, 2004). It has served to characterize forest structure (Cohen et al., 2002; Hansen et al., 2001), condition (Healey et al., 2006; Wulder et al., 2006), successional state (Helmer et al., 2000; Peterson \& Nilson, 1993), and also for change detection (Jin \& Sader, 2005; Lea et al., 2004). The first two orthogonal components of the TCT, Brightness (B) and Greenness $(G)$ define the vegetation plane (Crist \& Cicone, 1984) (Fig. 2a) and are a practical bridge between MSS and TM-ETM+ imagery (Powell et al., 2008).

The study of forest stands' spectral behavior in the vegetation plane provides insights into forest cover densities (Cohen et al., 1995; 1998) 
and forest development stages (Peterson \& Nilson, 1993; Price \& Jakubauskas, 1998). The B component is by definition a positive value, whereas $G$ depends on the contrast between the visible and nearinfrared bands (Table 2), with exposed soil having negative values (Gillanders et al., 2008) and vegetated areas having positive values.

The Tasseled Cap Angle (TCA), defined as the angle formed by G and $B$ in the vegetation plane (Eq. 1), condenses in a single value the information of the relation G/B (Fig. 2a) and represents essentially the proportion of vegetation to non-vegetation. A range of studies in coniferous forests have confirmed higher values of $G$ and lower values of $B$ in dense cover classes when compared to open stands or clearcuts (Cohen et al., 1995; Price \& Jakubauskas, 1998). Accordingly, dense forest stands show higher TCA values than more open stands or bare soil (Fig. 2a). We evaluated the TCA in the study area, assessing values over a set of 5000 stand replacement disturbance events dated between 1972 and 2008, finding TCA in recent clearcuts significantly lower than in any other cover stage of the forest and a clear increasing tendency with time-since-disturbance (Fig. 2b).

$\mathrm{TCA}=\arctan (G / B)$

The range of values of the TCA is scene dependent, as are the TCT components (Crist \& Cicone, 1984). An absolute assessment of forest density with the TCA would require local calibration with field data. On the contrary, evaluating relative changes of TCA does not require calibration: increments or reductions in the proportion of vegetation to non vegetation results in a concomitant change of TCA values.

The TCA images for each date were combined into a single, multiband image file, hereafter called TCA image for further analysis. To describe the forest landscape cover with the TCA we define the occupation state characterizing categories of proportion of vegetation to non-vegetation: areas more densely occupied by vegetation have higher values of TCA than areas with less dense vegetation; the bare soil situation, with zero proportion of vegetation is illustrated with negative values of the TCA.

\subsection{Image masks}

To reduce the detection of false changes, we excluded areas with elevations greater than $1700 \mathrm{~m}$, water bodies, clouds and cloud shadows prior to analysis. High elevation areas were identified with a digital elevation model, water bodies were identified with 1:50,000 National Hydrology Network data; clouds and cloud shadows were
Table 2

Coefficients used for calculation of TCT indices.

\begin{tabular}{rlrrrrrr}
\hline Sensor & Component & $\mathrm{R}$ & $\mathrm{G}$ & $\mathrm{B}$ & $\mathrm{NIR}$ & SWIR1 & SWIR2 \\
\hline MSS & Brightness & 0.433 & 0.632 & 0.586 & 0.264 & $\mathrm{~N} / \mathrm{A}$ & $\mathrm{N} / \mathrm{A}$ \\
& Greenness & -0.290 & -0.562 & 0.600 & 0.491 & $\mathrm{~N} / \mathrm{A}$ & $\mathrm{N} / \mathrm{A}$ \\
$\mathrm{TM}$ & Brightness & 0.3037 & 0.2793 & 0.4343 & 0.5585 & 0.5082 & 0.1863 \\
& Greenness & -0.2848 & -0.2435 & -0.5436 & 0.7243 & 0.0840 & -0.1800 \\
$\mathrm{ETM}+$ & Brightness & 0.3561 & 0.3972 & 0.3904 & 0.6966 & 0.2286 & 0.1596 \\
& Greenness & -0.3344 & -0.3544 & -0.4556 & 0.6966 & -0.0242 & -0.2630 \\
\hline
\end{tabular}

identified using a semi-automatic approach for each image. The area remaining for analysis, after all masks were applied to the TCA image, was approximately $12,740 \mathrm{~km}^{2}$.

\subsection{Process indicator (PI): the TCA derivative}

The spectral profile of the TCA image at each pixel characterizes the evolution or trajectory of its TCA value over time. Each pixel trajectory was approximated with a Lagrange second order polynomial (Appendix A), which enables interpolation with uneven intervals among occurrences.

The interpolated TCA image was derived with respect to time (years), producing a new cube with the same number of bands as the TCA image, hereafter called Process Indicator (PI) image, where each pixel's spectral profile is the derivative of its corresponding input image's profile (Fig. 3). Values of this new image represent the rate of TCA change over time, and unlike image difference methods, this technique assigns a value to each input date. The PI profile is the derivative of a smoothed curve, and is appropriate for detecting continuous subtle changes such as natural succession and decay, and progressive decadence due to disease or insect attack, which are difficult to assess with traditional change detection techniques (Coops et al., 2006).

\subsection{Hierarchical spatio-temporal segmentation}

Image segmentation is the partitioning of an image into homogeneous spatial units (Devereux et al., 2004) based on one or more attributes to facilitate visualization and analysis of spatially correlated properties; basic subdivisions contain information about raster attributes, shape, and position. Hierarchical spatio-temporal segmentation is a technique for exploration and analysis of changing properties a

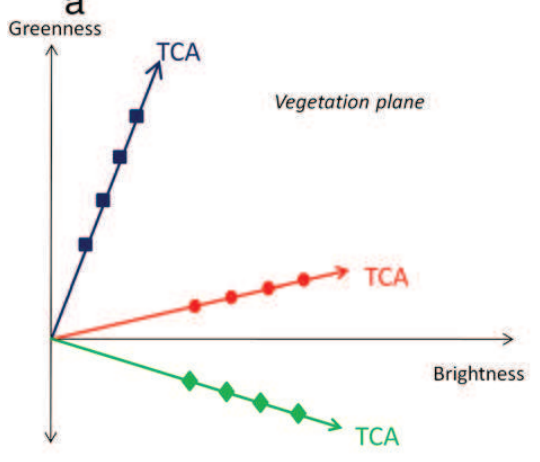

- Higher proportion of vegetation-non vegetation - Lower proportion of vegetation-non vegetation Bare soil

\section{b}

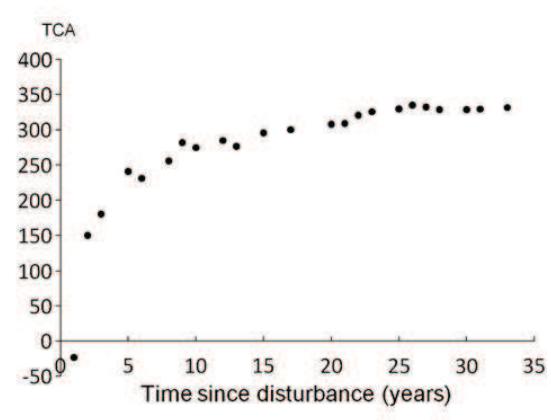

Fig. 2. (a) Tasseled Cap Transformation Brightness and Greenness components form the vegetation plane (Crist \& Cicone, 1984). The TCA is the arc tangent formed by Greenness and Brightness. Forest stands with a higher proportion of vegetation-non vegetation show higher values of TCA, bare soil shows negative TCA. (b) TCA average values of disturbed areas in the study area in the last 35 years; recent clearcuts show negative TCA value. 


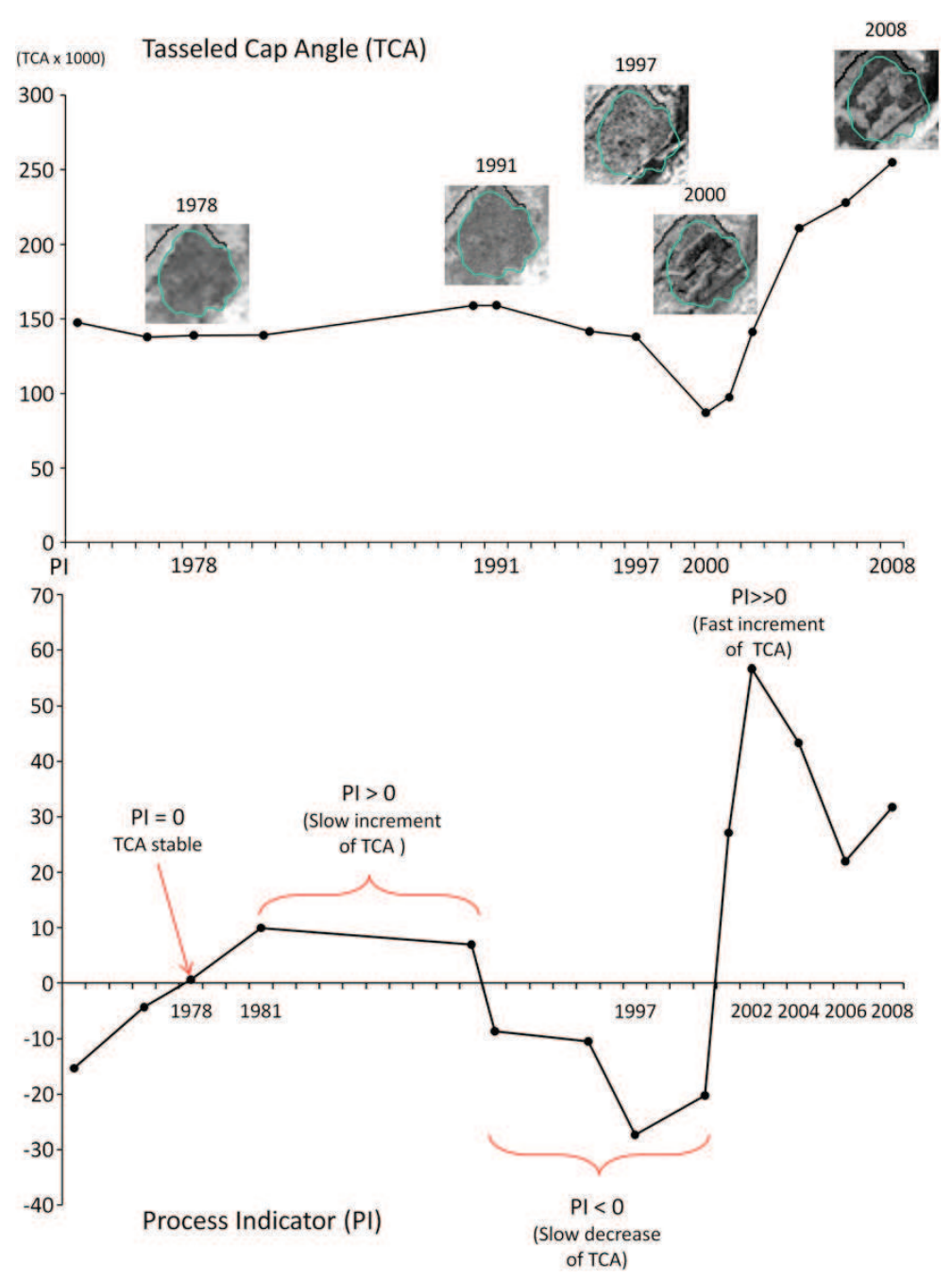

Fig. 3. TCA (1973-2008) and PI (1976-2006) trajectories of a L1 object. The PI is calculated as the derivative of the TCA curve (interpolated with a second order Lagrange polynomial). PI values correspond to each date.

of the landscape at various spatial and temporal scales: an image is divided in a hierarchy of levels, each one inheriting or passing on the boundaries of its objects to the subsequent level. The attributes of the spatial units, e.g. the spectral trajectory can be analyzed. The underlying assumption is that forest change processes are spatially and temporally correlated at certain scales.

There is no unique and singular solution to how an image partitions the landscape (Burnett \& Blaschke, 2003) for ecological analysis and no single spatial scale is optimal for characterizing the multiple options in which the image can be divided (Hay et al., 2005). Attempting to interpret processes with a multi-scale segmentation requires the definition of semantic rules to relate lower level landscape units to higher levels of organization (Burnett \& Blaschke, 2003). Three is the minimum number of levels recommended for landscape analysis (O'Neill et al., 1986).

The current landscape in the study area is highly fragmented as a result of natural factors and human activities (Andison, 1998), and spatial units at the same occupation state are smaller than a few decades ago. We define two levels of segmentation based on initial (1973) and final (2008) TCA values (L3 and L1 respectively). The smaller objects in L1 made up larger homogeneous spatial units at the beginning of the period considered; each of them has evolved following a different process path. An intermediate process level (L2) defined by the PI trajectory (change process) links both state levels (Fig. 4).

We introduce a mixed top-down/bottom-up approach whereby information at higher levels of the segmentation hierarchy (top: larger objects) is used to derive information at lower levels of the segmentation hierarchy (bottom: smaller objects) and vice versa (Hay et al., 2001). The order followed in the definition of objects in a hierarchical multi-scale segmentation of the landscape incorporating state and processes is important for interpretation and analysis. At the state levels L1 and L3, intra-object TCA variability is smaller that interobject variability. The intermediate process level L2 acts as a bridge between the actual conditions (2008 TCA) and the initial state (1973 TCA), its segments have had a similar changing path (PI trajectory) during the study period (1973-2008). Adjacent objects in level 2 followed a significantly different evolution path, and there is more variability in the process path between objects than within objects (Definiens, 2005).

The process of segmentation is performed with Definiens Cognition Network Technology ${ }^{\circledR}$ (Baatz \& Schäpe, 2000; Definiens, 2005). L1 is defined with scale parameter 10 , color-shape 0.7-0.3, smoothness-compactness 0.5-0.5 (Wulder \& Seemann, 2003); the 


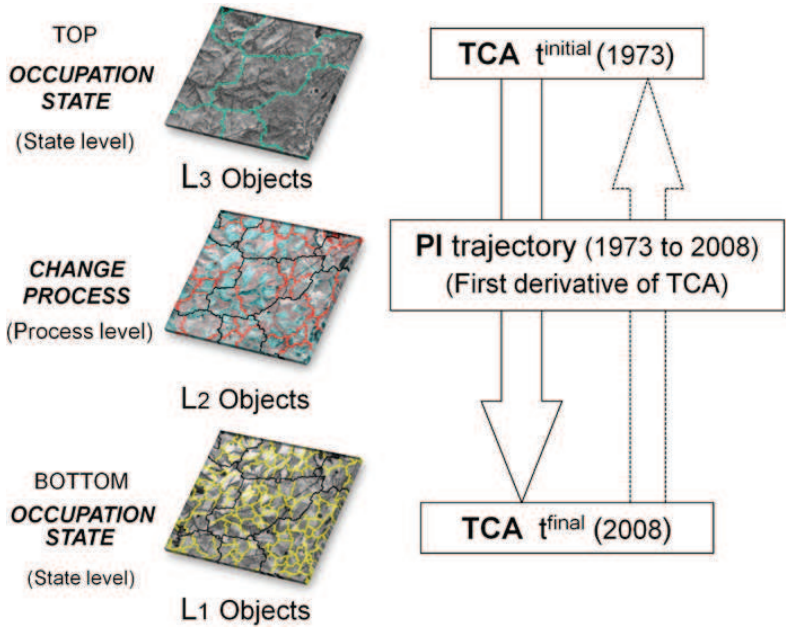

Fig. 4. Hierarchical spatio-temporal segmentation process. Bottom level 1 of homogeneous actual occupation state objects serves as base for the creation of top level 3 representing homogeneous occupation state objects at initial date. Objects of the intermediate process level are limited in size and boundaries by both occupation state levels.

scale is 20 for $\mathrm{L} 2$ and $\mathbf{5 0}$ for L3. In defining the process level all PI layers are equally weighted.

3.8. Spatio-temporal correlation of forest occupation states and forest change processes

Once objects were defined, we sought to describe how occupation states and change processes were arranged across the study area within single years, and whether the condition of an object in one year was related to its condition and its neighborhoods' in a subsequent year. Thus, we required spatial statistics that could be calculated both at a local scale and a global scale, and could include both intra- and inter-year effects. We employed the Moran's Index (Moran, 1948) statistic (Appendix B) implemented in $\mathrm{GeoDa}^{\mathrm{TM}}$ which is a free software dedicated to spatial data analysis (Anselin et al., 2006).

Moran's I can be interpreted as a spatially weighted form of Pearson's correlation coefficient (Goovaerts et al., 2005): positive and negative $z$-values point to positive and negative spatial correlation of objects' values respectively, and a zero value indicates there is no spatial association in the dataset. The Moran scatterplot facilitates visual exploration and interpretation of the global value of Moran's I (Anselin, 1993) (Fig. 5): the distribution of the cloud of points (observation versus spatial lag (neighbor's weighted averaged values)) reflects the pattern of spatial association, and the slope of the regression line is an estimation of the global Moran's I.

For explicitly spatial description, local associations (clusters) and outliers can be identified and analyzed with a Local Indicator of Spatial Analysis (LISA) (Anselin, 1995). In this study we implemented the local Moran's I for detection of local patterns of forest occupation state and forest change processes, and created maps of clusters (LISA cluster map) that identify and classify (high-high, low-low, high-low and low-high) locations with significant association.

Spatial and temporal correlations of objects' TCA and PI values were assessed independently as a variable evaluated at multiple dates. LISA analysis of univariate data enables detection of spatial patterns of correlation at a single date. Furthermore, the option of bivariate LISA analysis facilitates temporal analysis of the spatial correlation, detecting if there is any association between the variable measured at a reference time and the same variable measured in the neighborhood at a different time (Anselin, 2003). In all our spatial analysis we defined the neighborhoods with the first order Queen's

\section{Moran's I scatterplot}

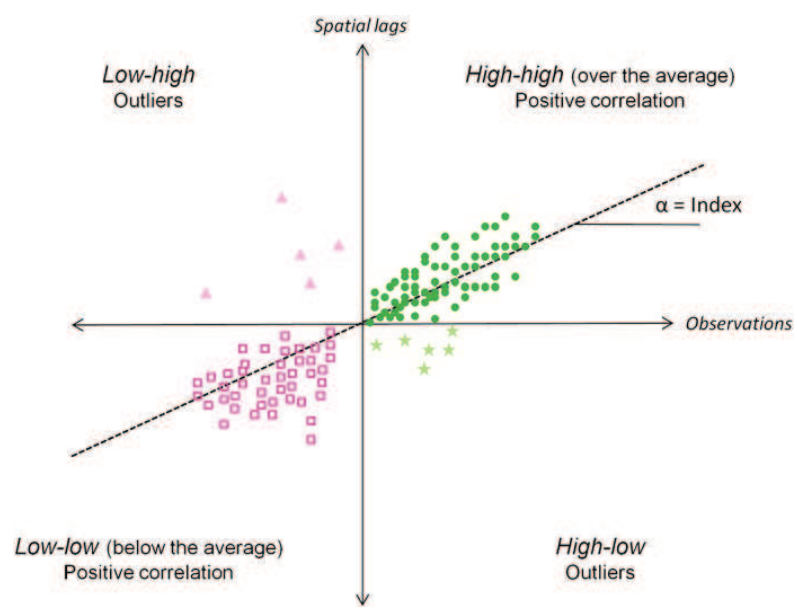

Fig. 5. Moran's I scatterplot. The slope of the regression line is an estimation of the global Moran's I. Relative density of points in the correlation quadrants indicates how the global measure of spatial association is determined by association between high and/or low values.

contiguity measure, i.e. each object's neighborhood consists of all other segments sharing some boundary with it.

\section{Results}

\subsection{Hierarchical spatio-temporal segmentation}

The hierarchical spatio-temporal segmentation yielded a number of objects at each level of segmentation with the average size per object shown in Table 3. There are $4.46 \mathrm{~L} 2$ objects per each L3 object on average, and 3.27 L1 objects in each L2 object on average. The average size of the smaller objects (L1) is approximately 40 ha.

Most of the statistical summaries and results shown in the following sections concern L1 objects; results at other levels of segmentation show similar trends.

\subsection{Landscape occupation state-TCA}

Considering the entire study area, the mean value of the objects' TCA is consistently greater than 190 over the whole period of analysis, and describes a landscape with a high proportion of vegetation to nonvegetation. Between 1997 and 2001, the mean TCA was at its lowest, with the minimum mean TCA occurring in 1997 (minimum average TCA value, Table 4, Fig. 6)-the coincidence of three consecutive late season images in this period encourages a cautious interpretation. After 2001, TCA values trend upwards, indicating a global average increase in the proportion of vegetation to non-vegetation.

The standard deviation of the TCA (Fig. 6, Table 4) indicates that the lowest dispersion in objects' TCA values occurred before 1990images from the MSS era, with 6-bit rather than the 8-bit radiometric

Table 3

Characteristics of hierarchical spatio-temporal segments.

\begin{tabular}{llllr}
\hline Level & Similarity & $\begin{array}{l}\text { Attribute for } \\
\text { definition }\end{array}$ & $\begin{array}{l}\text { Mean size } \\
\text { (ha) }\end{array}$ & $\begin{array}{l}\text { Number } \\
\text { objects }\end{array}$ \\
\hline L3 & Initial occupation state & 1973 TCA & 634.4 & 2021 \\
L2 & Change process trajectory & 1973-2008 PI & 141.9 & 9032 \\
L1 & Final occupation state & 2008 TCA & 43.1 & 29544 \\
\hline
\end{tabular}


Table 4

Statistics of TCA and PI values at L1 level.

\begin{tabular}{|c|c|c|c|c|c|c|c|c|c|c|c|c|c|c|}
\hline TCA & 1973 & 1976 & 1978 & 1981 & 1990 & 1991 & 1995 & 1997 & 2000 & 2001 & 2002 & 2004 & 2006 & 2008 \\
\hline Mean & 227.13 & 229.99 & 241.33 & 244.05 & 231.83 & 232.73 & 226.40 & 195.23 & 204.64 & 201.81 & 235.93 & 240.01 & 237.69 & 244.56 \\
\hline Std deviation & 74.21 & 59.55 & 66.24 & 66.02 & 80.78 & 84.46 & 87.18 & 91.88 & 95.05 & 95.73 & 83.23 & 80.19 & 81.59 & 78.90 \\
\hline Kurtosis & 5.57 & 2.14 & 5.55 & 6.30 & 4.58 & 10.03 & 8.62 & 10.74 & 15.34 & 13.48 & 7.43 & 7.96 & 8.30 & 8.89 \\
\hline Skewness & -1.21 & -0.58 & -0.86 & -0.93 & -1.21 & -1.92 & -1.99 & -2.45 & -2.98 & -2.66 & -1.67 & -1.77 & -1.75 & -1.90 \\
\hline Min. & -463.92 & -83.08 & -450.94 & -491.11 & -322.71 & -646.56 & -505.43 & -566.48 & -735.87 & -701.26 & -457.65 & -499.27 & -539.34 & -502.49 \\
\hline Max. & 432.41 & 432.66 & 399.30 & 417.55 & 438.03 & 407.07 & 441.63 & 446.87 & 454.64 & 447.31 & 447.03 & 413.21 & 399.25 & 405.40 \\
\hline PI & & 1976 & 1978 & 1981 & 1990 & 1991 & 1995 & 1997 & 2000 & 2001 & 2002 & 2004 & 2006 & \\
\hline Mean & & 7.10 & 7.03 & -4.75 & -5.66 & -2.71 & -18.75 & -10.88 & 3.29 & 15.64 & 19.10 & 0.88 & 2.27 & \\
\hline Std deviation & & 20.30 & 26.14 & 18.88 & 21.38 & 16.28 & 34.41 & 25.15 & 17.90 & 25.31 & 30.58 & 17.32 & 12.93 & \\
\hline Kurtosis & & 7.65 & 1.26 & 8.97 & 12.10 & 11.91 & 1.58 & 8.55 & 11.51 & 2.64 & 4.83 & 6.22 & 14.94 & \\
\hline Skewness & & 1.05 & 0.06 & -1.07 & -2.30 & -1.21 & -0.58 & -1.21 & -0.70 & 1.00 & 0.73 & -0.12 & -0.20 & \\
\hline Min. & & -338.31 & -227.89 & -217.41 & -320.04 & -235.86 & -310.10 & -420.88 & -369.72 & -109.03 & -213.48 & -128.77 & -126.84 & \\
\hline Max. & & 189.68 & 134.98 & 314.38 & 97.04 & 108.96 & 164.26 & 202.64 & 144.69 & 284.95 & 378.67 & 185.01 & 214.39 & \\
\hline
\end{tabular}

resolution of later Landsat sensors encourages cautious interpretation; since that time, the standard deviation has been higher, with a maximum in year 2001, which was the ceiling of diversity of occupation states at L1. As we would expect, from a high cover state, increased variance implies reduced cover, with non-vegetation locations (stand replacing disturbances) intermingled with forest stands at various stages of coverage and growth.

The histograms of TCA distribution at all dates are similar, with a maximum occurring between values 220 and 240, but some differences are apparent (Fig. 6). Of particular note is the variation, by year, of negative TCA values, indicative of non-vegetated areas, and of the high positive TCA objects that have a high proportion of vegetation or are densely occupied. To gain better insights of these changes, the range of TCA values over the scene was split in four categories, with a criterion based on the statistical distribution (the mean TCA, considering all dates, \pm one standard deviation (i.e. 140 ,
310), and zero). Groups were labeled as Negative (TCA below zero, corresponding to non-vegetated objects), Low, Medium, and High, having an increasing proportion of vegetation to non-vegetation. Objects were classified in these four groups and their progression through TCA categories analyzed at quasi-decadal intervals: from 1973 to 1981 ; 1981-1990; 1990-2000 and 2000-2008. Objects for which the TCA value changed category from initial to final date in each decade were counted (Fig. 7).

In the 1970s, 17.8\% of all L1 objects (5273) changed the occupation state enough to switch TCA category. Among these, $47 \%$ evolved from medium to high and $31 \%$ from low to medium: there was a clear net change towards higher densities and abundant interchange in the high and medium groups-areas with high coverage and also common change events inducing average TCA variations. In the 1980s, 13.8\% of all L1 objects (4083) changed their occupation state sufficiently to switch TCA category. The high to medium and vice versa changes were again marked,
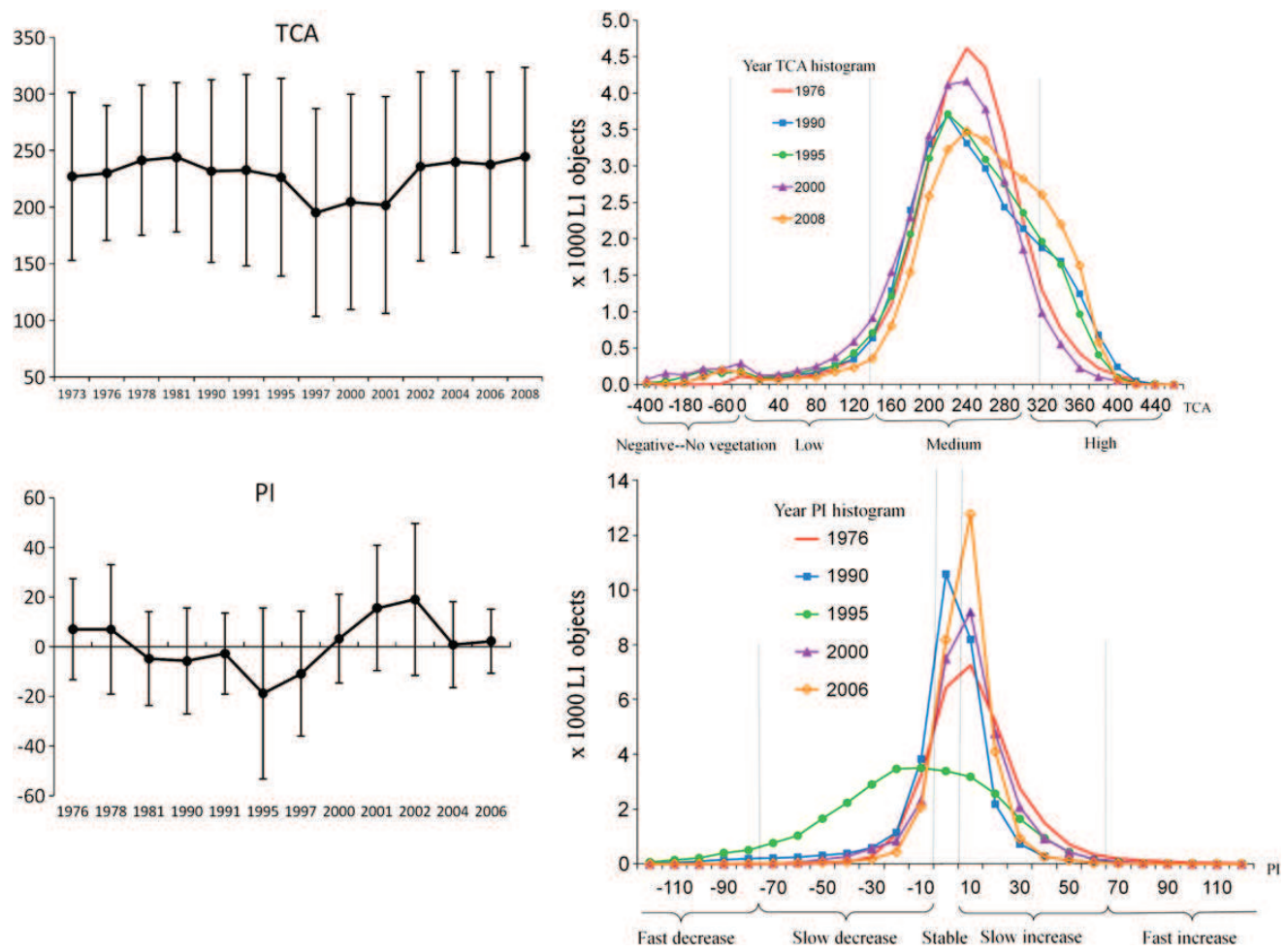

Fig. 6. Mean \pm 1 standard deviation of TCA values of L1 objects (other object levels show similar trends) (left). Histograms of TCA and PI distribution (right). 


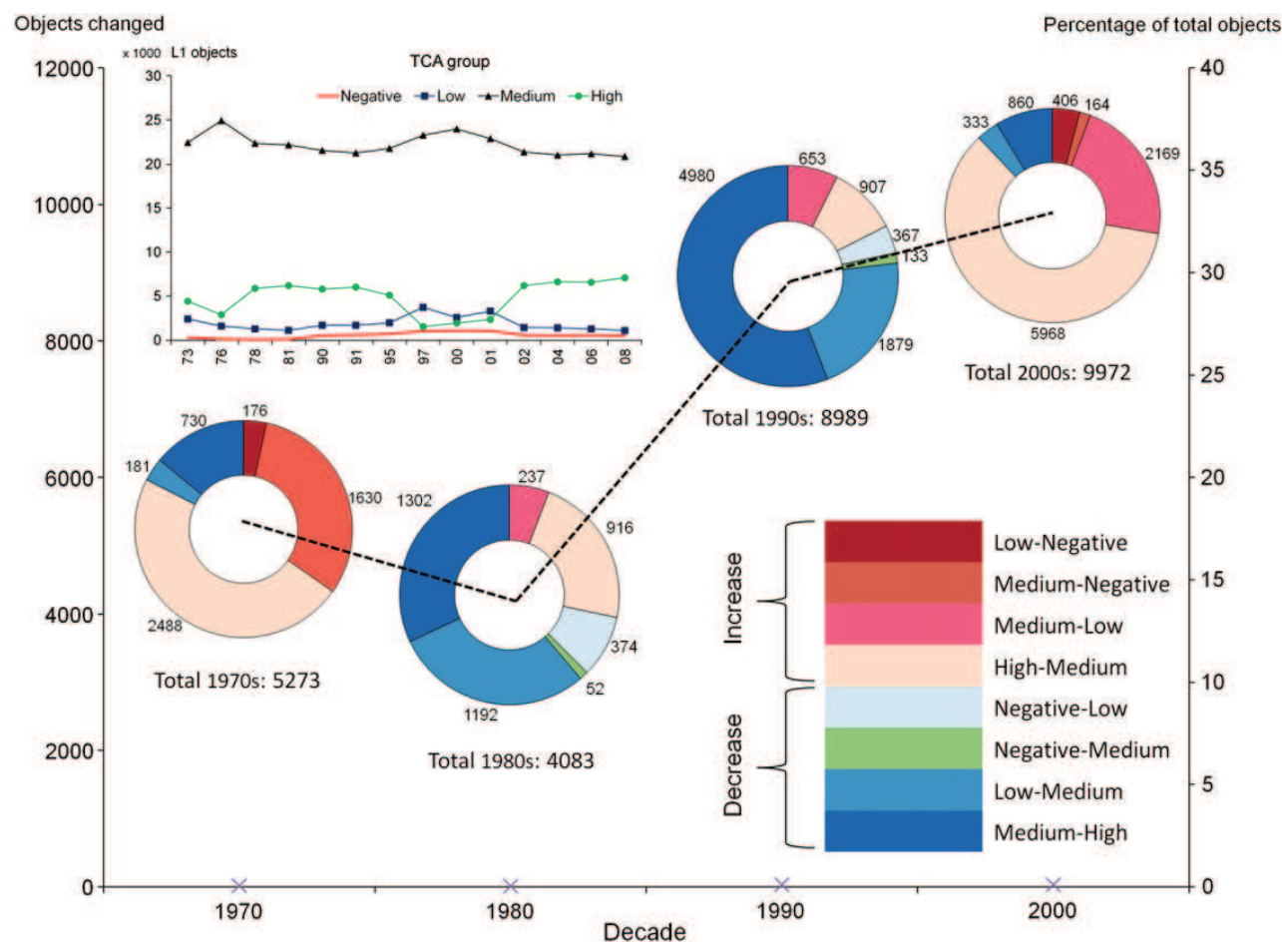

Fig. 7. Changing objects between TCA categories in each of the last four decades. Evolution of total number of objects in different TCA groups at level 1 (top left inset) (other levels of segmentation show similar trend).

with a net $11 \%$ change from high to medium. Medium to low changes accounted $29 \%$ of all changing objects; the overall change was towards lowering density. In the 1990s, 30.4\% of all L1 objects (8989) switched the occupation state sufficiently to move TCA category, relating a transition over the landscape towards lower canopy cover densities: more than half of the changes in TCA category (56\%) occurred from the high group to the medium group, followed by transition from medium to low (22\%).

The last period analyzed, 2000-2008, experienced the highest rate of TCA category switches: $9972 \mathrm{~L} 1$ objects (33.7\% of the total) swapped occupation state group. Among these, $60 \%$ exchanged from medium to high, $22 \%$ from low to medium, and $9 \%$ moved from high to medium. Despite the frequency of transformations produced in this time period, the global average occupation state was maintained (Fig. 6).

We considered all mathematical options of transition amongst these TCA categories; in reality, however, frequent swaps at the spatial scale considered only occurred between adjacent groups, reflecting that changes of occupation state at the landscape level occur in a progressive manner. Transitions such as high to negative, high to low, or negative to high were infrequent or nonexistent in the study area at the time and spatial scale considered; such drastic changes would reveal alterations in occupation state produced by typical stand replacing disturbances such as fire, windthrow, or an accumulation of forest harvesting.

Summarizing change by decade is a useful approach, but sometimes a more detailed temporal examination is necessary for detecting trends. The total number of objects in each TCA category (Fig. 7 left inset) reveals changing tendencies and aids in understanding fluctuations in the global average (Fig. 6). TCA medium category objects are significantly more common than any other group between 1973 and 2008, oscillating between $67 \%$ and $84 \%$ of the total number of objects. The diminution of high objects between 1997 and 2001 is noteworthy and mathematically explains the decrease in the TCA global average (Fig. 6). Negative and low categories of TCA are the least common objects for all dates, with a slight increment in low objects between 1997 and 2000; but late season images used to study this period (1997-2000) could somehow have conditioned lower values of the TCA.

\subsection{Landscape change processes-PI}

The average PI value describes the global state of change at the landscape level; assessing this average at consecutive dates (Fig. 6) permits examination of trends in the study area. Prior to 1981, low positive values of the PI indicate a slow increasing rate in the proportion of vegetation to non-vegetation: the landscape is in an average state of forest growth. From 1981 to 1997, the average PI values are negative, indicating a decline in the proportion of vegetation to non-vegetation mainly caused by forest harvesting and, to a lesser extent, other disturbances; in the 2000s PI values are again positive (Table 4, Fig. 6 ). The standard deviation of PI values (Table 4, Fig. 6) is relatively high for the entire period indicating that this forest landscape is very dynamic and that there is a great variety of change processes occurring simultaneously.

Although the variation in the interval between image dates was considered when computing the PI values, the dearth of image data in the 1980s limits the analysis of trends. Further, the effect of late season imagery on PI values has to be considered in the interpretation of changes. Despite these facts, a general decline in the occupation state (negative PI average) is observed in the 1980s and 1990s (Table 4, Fig. 6) and a time of frequent and diverse changes reflected by the high values of the PI standard deviation.

For most image dates, the distribution of polygons with different change processes (PI values) is unimodal (Fig. 6), with the majority of objects having a mean PI value close to zero (i.e., stable). The sample was divided in groups of PI values for exploration of changing patterns. With no ground truth to determine splitting thresholds, we used statistical criteria. The stable group, with PI close to zero, is a relevant group, representing areas with no change in the proportion 
of vegetation to non-vegetation. The slow increase and slow decrease groups were defined approximately by the values of the mean \pm two standard deviations of PI at all dates (i.e., 60 and -70). The fast increase and fast decrease groups include the remaining extreme values (Fig. 6).

Objects in the fast decrease group (i.e., being highly disturbed), are the smallest group in all time periods (Fig. 8): there is a small proportion of the landscape with a rapid net loss of vegetation. Similarly, objects in the fast increase group (i.e., in a state of rapid emergence or occupation) are also relatively infrequent. In contrast, the slow increment PI objects (i.e., growing stands) are normally the most frequent, with the exception of 1995 and 1997, when slow decrease (i.e., decay by aging, disease, or partial harvest) was more common.

4.4. Spatial autocorrelation of forest occupation states and forest change processes

Global values of Moran's I show there is a consistent positive and high spatial autocorrelation of forest occupation states (TCA values) during the period from 1973 to 2008 (Table 5), with an average value of 0.643 at the L1 level of segmentation, and slightly lower for larger levels (results not shown). Change processes (PI values) are also positively and highly spatially correlated, with an average global Moran's I of 0.636 (Table 5). Whilst Moran's I values of TCA do not follow a clear trend, Moran's I values for PI generally decrease through time (Fig. 9): similar change processes were spatially more concentrated at the beginning of the period of analysis, and have progressively lost spatial association, turning the landscape into a mosaic of change processes with smaller but more spread disturbance events and subsequent recovery. Observation of Fig. 9 suggests there is no apparent correspondence between global spatial associations of TCA and PI values over time, state and process seem to have a different pattern.

Exploration of the Moran's scatterplot informs about patterns of spatial autocorrelation, in particular if associations are between values over or below the average. As an example, the 1997 scatterplot of occupation states (TCA) (Fig. 9, 1) illustrates that spatial associations at this date are produced between a large range of values below the average (Fig. 9, panel 1, notation A). Spatial associations are also produced between values over, but close to the average (Fig. 9, panel 1 , notation B). In this case a few points in the upper left and lower right quadrants depict spatial outliers with a markedly different occupation state compared to those neighboring; for instance these areas relate to changed areas (island polygons) amid unchanged forest areas (or the converse, unchanged islands amidst change).
The pattern of spatial association shown by the Moran's scatterplot of change processes (PI values) in 1973 is different, the distribution of points in both quadrants of positive correlation is similar (Fig. 9, 2): there is spatial association between values below and over the average, i.e., processes of change are spatially associated, whether they are related with growth, disturbance or stabilization.

The temporal correlation of occupation states (TCA) and change processes (PI) is explored by studying the bivariate (temporal) Moran's I. The spatial association of the target variable at two consecutive dates is evaluated (Table 5) to investigate the impact of particular occurrences on its neighborhood over time; care with different time intervals is necessary for interpretation. Results show a global positive correlation of TCA at all time intervals (similar occupation states are spatially associated at consecutive dates, which seems very natural in the absence of disturbance), with a minimum of 0.352 in period 1976 1978 and a maximum of 0.656 in period 1978-1981. Bivariate (temporal) global Moran's I of PI is in most cases positive (Table 5) and not very large; a maximum of 0.494 occurs in period 2000-2001 and a minimum of -0.032 in period $1997-2000$. The pattern of Moran's scatterplot of TCA (2000-2001 as an example in Fig. 9, 3) is similar to the univariate case, with TCA values dispersed in the lowlow quadrant and few outliers. In the PI example (1978-1981), the temporal Moran's scatterplot is an agglomeration of points around zero, different to the univariate case: while the univariate picture shows clustering of similar change processes, there is not a clear pattern of association in the bivariate case (Fig. 9, 4 ) and areas at varying change processes of growth or decay at consecutive dates are intermingled.

Local analysis with a map of clusters can provide spatially explicit information on clustering (Fig. 10) informing and characterizing local associations; it is a useful tool for visual interpretation. The examples in Fig. 10 illustrate the association type of change processes (PI) in the study area for the period investigated (1973-2008). Red polygons denote association of values greater than average (high-high), blue polygons association of values less than average (low-low); purple polygons are high-low outliers (with a value greater than the mean at the initial date, and surrounded by polygons with values less than the mean at the second date) and green denotes low-high outliers (with a value less than the mean at the initial date, and surrounded by polygons with values greater than the mean at the second date). Polygons of the same type grouped together indicate larger homogeneous areas with respect to the variable analyzed, as occurs in 1995-1997, whereas small groups of clusters or isolated patches indicate a more heterogeneous landscape, as is the case in 1978-1981.

Despite the low values of global Moran's I for temporal PI correlation (Table 5), local analysis and examination of the cluster maps reveal that there is a substantial number of change process clusters of all categories.

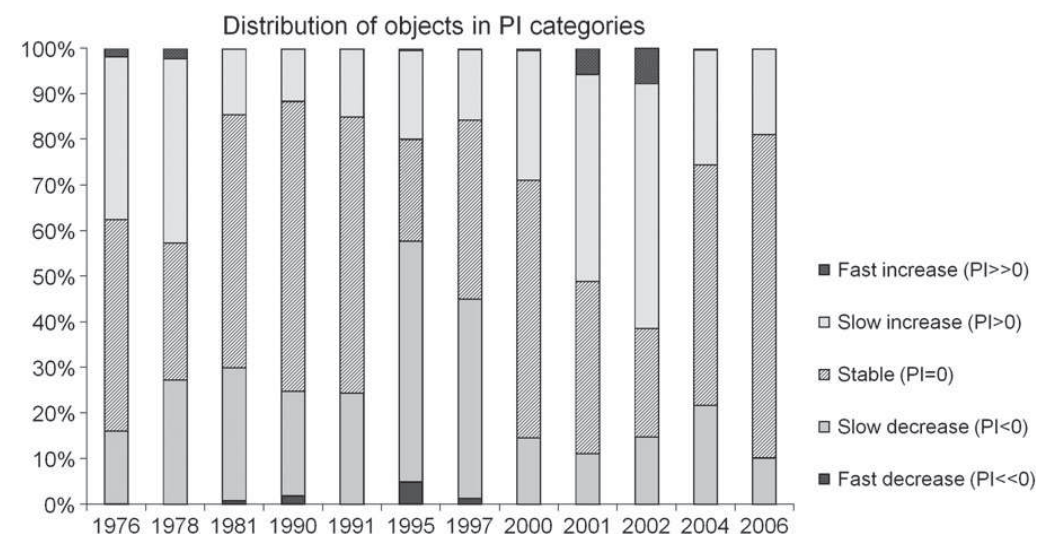

Fig. 8. Evolution of change process (PI) categories of level 1 objects. 
Table 5

Values of Moran's Index of univariate (spatial) and bivariate (temporal) TCA and PI. All correlations with p-value $<0.001$.

\begin{tabular}{lllllllllllllll}
\hline Spatial & 1973 & 1976 & 1978 & 1981 & 1990 & 1991 & 1995 & 1997 & 2000 & 2001 & 2002 & 2004 & 2006 & 2008 \\
\hline TCA & 0.6740 & 0.5397 & 0.6959 & 0.6709 & 0.6804 & 0.6813 & 0.6625 & 0.6083 & 0.5087 & 0.5983 & 0.6601 & 0.6723 & 0.6848 & 0.6657 \\
PI & 0.7940 & 0.6365 & 0.7275 & 0.6095 & 0.6690 & 0.6422 & 0.6880 & 0.6521 & 0.6311 & 0.6860 & 0.6070 & 0.5086 & 0.5691 & 0.5336 \\
& & & & & & & & & & & & \\
Temporal & & $73-76$ & $76-78$ & $78-81$ & $81-90$ & $90-91$ & $91-95$ & $95-97$ & $97-00$ & $00-01$ & $01-02$ & $02-04$ & $04-06$ & $06-08$ \\
\hline TCA & & 0.3959 & 0.3523 & 0.6557 & 0.6003 & 0.6522 & 0.6290 & 0.5112 & 0.5637 & 0.5744 & 0.5284 & 0.6235 & 0.6448 & 0.6512 \\
PI & & 0.1170 & 0.2259 & 0.0434 & 0.4209 & 0.1729 & 0.3140 & 0.4668 & -0.0321 & 0.2301 & 0.4940 & 0.2360 & 0.1307 & 0.0397 \\
\hline
\end{tabular}

The varying time intervals between available image data makes inference of trends in temporal association less reliable; a periodic series of images would facilitate a thorough temporal study. To investigate a possible trend, we calculated global and local correlations at quasiquinquennial intervals: 1976-1981, 1981-1990, 1990-1995, 1995-2000, and 2000-2006, and analyzed total amounts of each category of local clusters (Table 6, Fig. 10). Given the location (latitude and alpine transition) combined with local forest productivity levels influencing successional processes, five to ten years is an adequate period to capture and portray the forest stand dynamics occurring; however, to detect more frequent changes, a complete series of annual images would be required.

The highest number of significant $(\mathrm{p}<0.001)$ spatial clusters occur in the central periods, 1995-2000 and 2000-2005 (Fig. 11, Table 6), a time with persistent change. It is between 1981 and 1990 when more
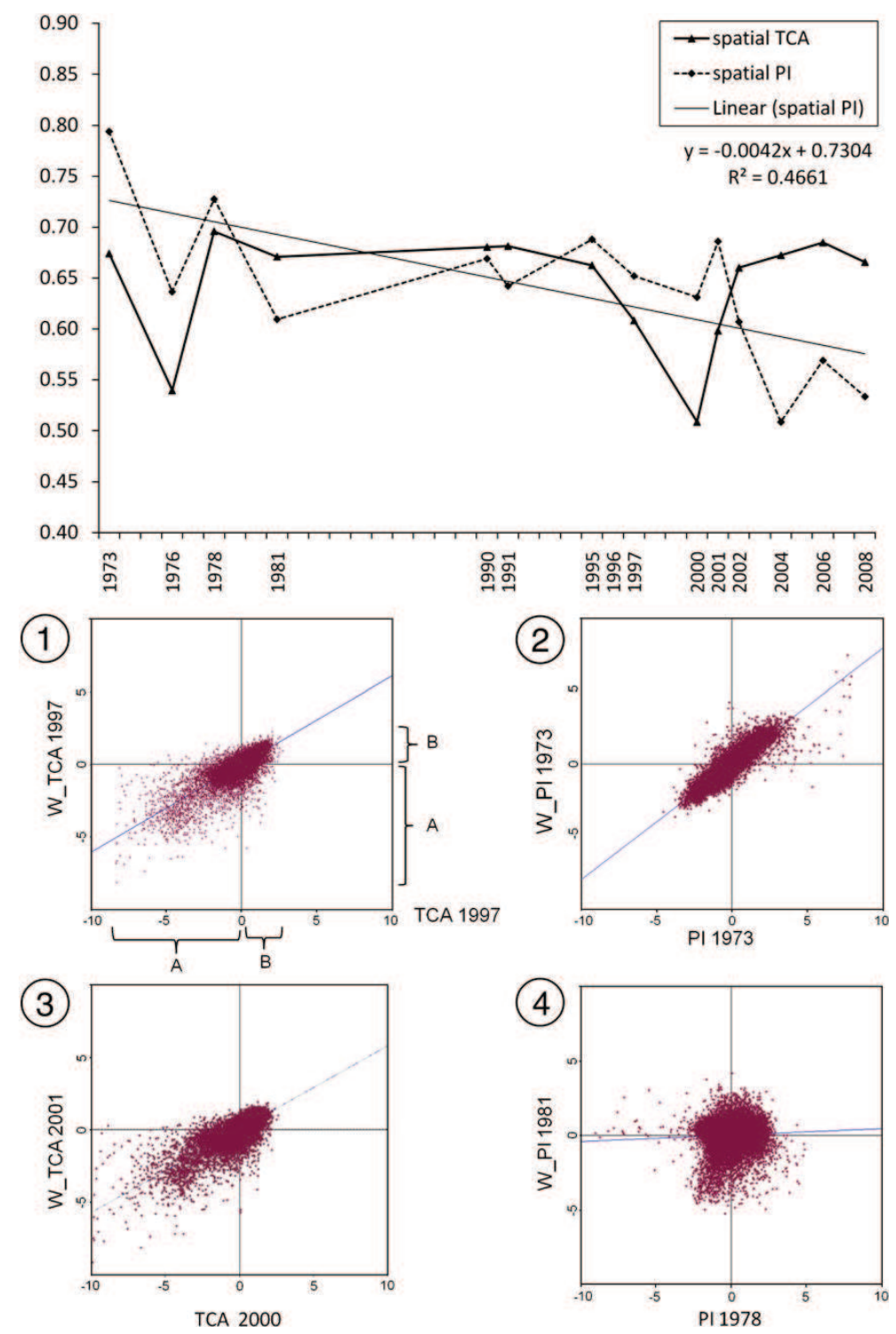

Fig. 9. TCA and PI spatial global Moran's I trends (top). Spatial (univariate: 1,2) and temporal (bivariate: 3, 4) Moran's I scatterplots of TCA and PI (bottom). 

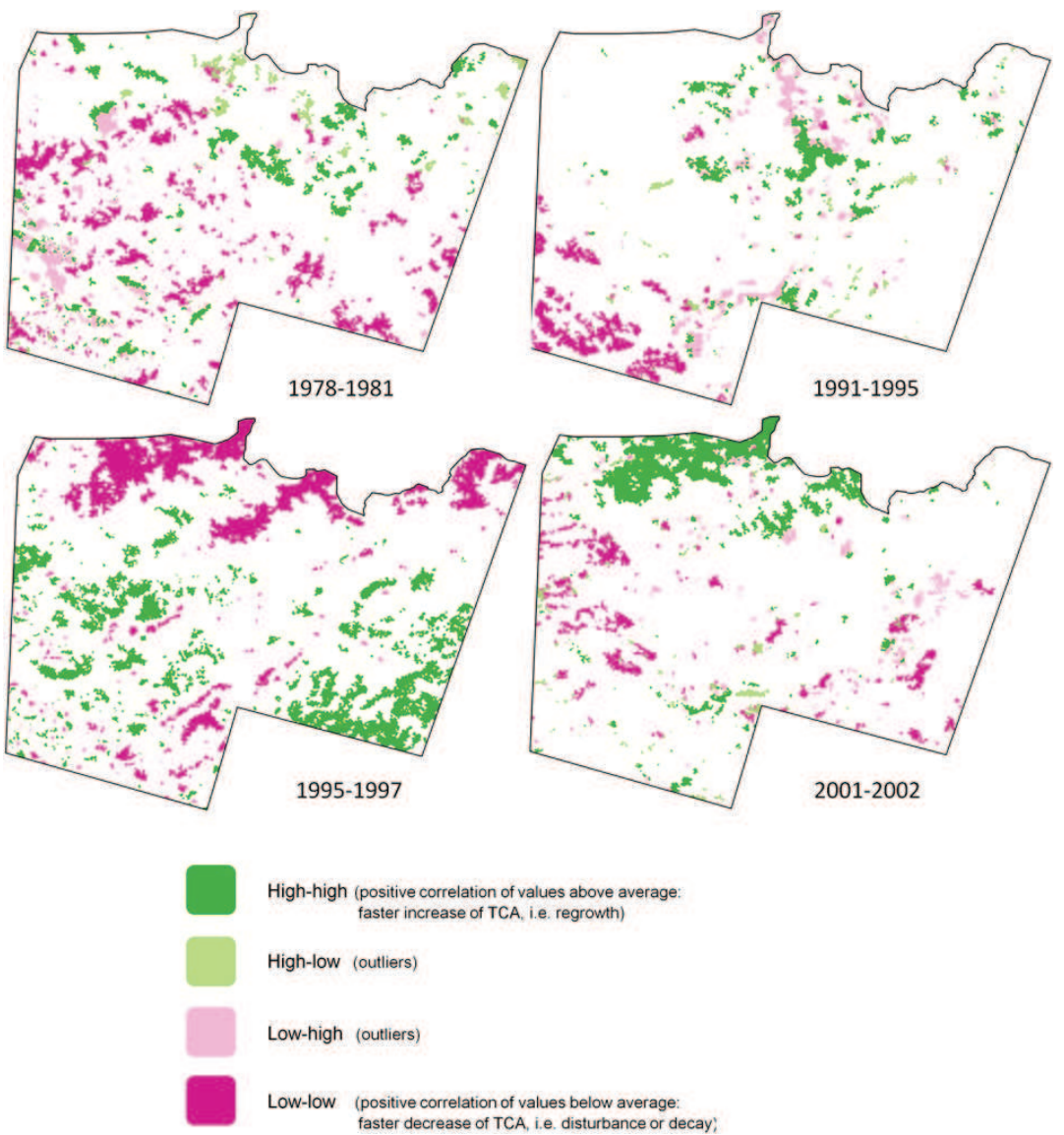

Fig. 10. LISA maps of temporal association PI clusters; only significant polygons $(\mathrm{p}<0.01)$ are colored.

positive spatial associations of change processes happens; interestingly, in this longer time lapse spatio-temporal associations are equally distributed between processes over the average (regrowth) and below the average (disturbance and decay) change process. A close look at the original images reveals that clearcutting practices and subsequent regrowth were more concentrated in fewer areas than during more recent dates. The time interval is an important parameter to control in the analysis of temporal correlation of change processes for accurate and reliable reports and conclusions, and although global values of correlation do not give exhaustive information, local analysis can give important and detailed spatial information.

\section{Discussion}

The Tasseled Cap derived indices employed in this work are valuable tools for the capture and assessment of forest cover condition

Table 6

Number of significant PI $(\mathrm{p}<0.01)$ clusters for quasi-quinquennial intervals.

\begin{tabular}{rrrrrr}
\hline Cluster & $1976-1981$ & $1981-1990$ & $1990-1995$ & $1995-2000$ & $2000-2006$ \\
\hline High-high & 612 & 1559 & 1448 & 890 & 1192 \\
Low-low & 501 & 1239 & 885 & 561 & 370 \\
Total positive & 1113 & 2798 & 2333 & 1451 & 1562 \\
High-low & 1273 & 349 & 1788 & 2411 & 1205 \\
Low-high & 1015 & 306 & 2023 & 2393 & 1280 \\
Total outliers & 2288 & 655 & 3811 & 4804 & 2485 \\
Total & 3401 & 3453 & 6144 & 6255 & 4047 \\
\hline
\end{tabular}

and change. The Tasseled Cap Angle reports the proportion of vegetation to non-vegetation (occupation state) in a defined area and its derivative, the Process Indicator informs the current process of change. These indices condense information from the visible and NIR wavelengths, and facilitate comparison of data from all of the Landsat

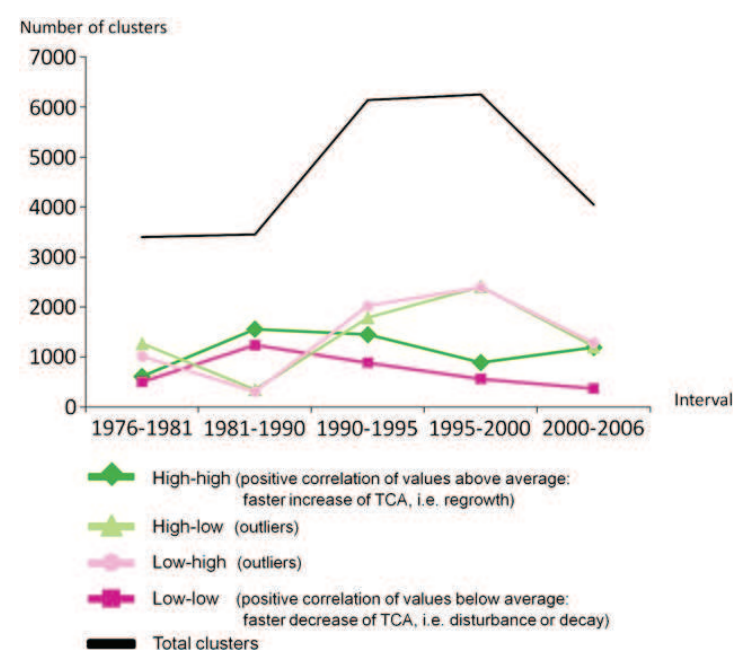

Fig. 11. Evolution of significant clusters per quasi-quinquennial period. 
sensors, enabling the study of forest landscape change with a lengthy series of historical satellite images dating from 1973 to 2008. Results of our study indicate that the landscape change was more spatially clustered prior to 1981, but that change became more widespread and dispersed in later years. Certain periods had a more intense change, as indicated by their temporal spatial correlation.

Forest landscapes, particularly managed forest landscapes, are dynamic ecosystems with a number of different change processes ongoing at any given time. Although a variety of remote sensing techniques have the capacity to detect stand replacing events, the detection of subtle alterations that result in only minor spectral changes remains a challenge (Goodwin et al., 2010) as different phenology and illumination of images induce detection of false change. With disrupting artifacts suppressed, the PI would be able to account for a wide variety of change types, providing information of slight or substantial modifications that is leveraged by a temporal series of three or more normalized images: low positive values of PI indicate a slow increment in the occupation state due to natural growth, while low negative values of PI point to natural processes of decay, such as aging or disease, or human induced modifications such as partial harvest or thinning (Table 7). More notable and fast changes in the occupation state, like a disturbance with reduction of vegetation or a process of vegetation emergence are indicated with high negative or positive values, respectively. The capacity to relate both positive and negative changes is a powerful aspect of the PI, enabling insights relating to both forest (vegetation) gain and loss.

The TCA and PI, as derived from the TCT, are relative to the scene considered and would require a process of normalization to enable comparisons between different sites. If field data are not available, a study of relative change is the best option for the examination of trends. The availability of ground data for calibrating these indices could enable them to work as a look up table for other attributes, such as cover percentage, seral stage, or biomass content, facilitating forest monitoring efforts (e.g., Powell et al., 2010).

Analyzing a temporal series of images supports the assessment of trends and rates of change that otherwise might be missed with only a bi-temporal change detection approach (Lunetta et al., 2004). The adequate interpretation of tendencies is conditioned by the time interval between consecutive images, and the scarcity of data for any one period may preclude a complete understanding of the landscape change. A decadal interval might be sufficient for preparing a summary of conditions and for planning silvicultural treatments and wood extractions, but more frequent information is required for monitoring of forest health and biomass. Jin and Sader (2005) recommend a period of three to five years for interpretation of condition and change in a forest area, but the ideal number of images and acquisition timing is site dependent (Wilson \& Sader, 2002) and often restricted by image availability. We used a quasi-quinquennial interval for evaluation of change processes (PI) and a decadal interval for summary of change in the landscape state (TCA) obtaining sound and useful outcomes.

As long as temporal factors are considered, the interpretation of TCA and PI may be combined to provide insights on the change processes that are active in a forest landscape: varying rates of cover

Table 7

Interpretation of TCA and PI values.

\begin{tabular}{|c|c|c|c|}
\hline \multicolumn{2}{|l|}{ Value } & \multirow{2}{*}{$\begin{array}{l}\text { TCA } \\
\text { Occupation state } \\
\text { High proportion Veg-nonVeg }\end{array}$} & \multirow{2}{*}{$\begin{array}{l}\text { PI } \\
\text { Change process } \\
\text { Emergence }\end{array}$} \\
\hline Positive & High & & \\
\hline & Low & Low proportion Veg-nonVeg & Growth \\
\hline Zero & & Greenness $=0$ & Stable \\
\hline \multirow[t]{2}{*}{ Negative } & Low & Non-vegetated & $\begin{array}{l}\text { Decrease (natural decay } \\
\text { or partial harvest) }\end{array}$ \\
\hline & High & Non-vegetated & Disturbance \\
\hline
\end{tabular}

change could have different effects on dense or open forests and could trigger different phenomena. A simultaneous view of occupation states defining the landscape pattern and current change processes could help understanding the relation between pattern and process, a recursive question difficult to solve in landscape ecology (Turner, 1989; Walsh et al., 2009).

Although there is no confirmed link between these indices and ecological succession stages, the combined interpretation acts to facilitate analysis of succession patterns. The contextual temporal information given by the TCA enables proper interpretation of change that may be confounded with traditional techniques (Masek et al., 2008). The TCA provides information of vegetation proportion and the PI gives an instantaneous picture of the change process; together with some ecological knowledge, forest seral stages may be identified (i.e., young stand growing, young stand with disease, mature stand in decay, recovery from disturbance, or other situation). It must be noted that in order to enable accurate understanding of a trajectory of change, some knowledge of the local ecology is always required. Fig. 12 depicts possible interpretation of consecutive change processes for a homogeneous area.

The object oriented approach implemented to help in the analysis of change at the landscape level provides meaningful reporting units, that is, objects analogous to forest stands. The spatial scale is a key parameter for assessment of ecological processes; we opted for a data driven method in the definition of spatial units, based on homogeneity of areas at the initial and final dates of the period (1973 and 2008). Establishing the hierarchy on the variables of interest, the transmission of significant information between levels is assured: initial and final state levels are connected through an intermediate level of processes accounting for the entire trajectory of change. Different intermediate levels could be defined for specific applications. For example, a forest health monitoring study may be interested in the progress of defined segments since the time of infection, and subtle changes could be detected from that point on. We reported the state and change of forest landscape with objects of a mean size of approximately 40 ha, with a common initial state and intermediate history of change; however, the method allows any sized object to be used, enabling the selection of the most appropriate size given the ecological processes operating in the area.

Spatial and temporal autocorrelation is a complex and scale dependent phenomenon that is expected in natural environments. In the time period analyzed, some relations and patterns were unveiled for occupation state and change processes. The spatial correlation of occupation state was always positive; change processes were also positively correlated at the global spatial level and with a decreasing tendency over time. Temporal spatial autocorrelation of change processes was found in local aggregations, necessitating further analysis with local measure to understand the local variability.

\section{Conclusion}

The study of environmental long term historical change is facilitated with the free access to the United States Geological Survey Landsat data archive. Extensive areas can now be monitored retrospectively with techniques that incorporate multi-temporal information in a spatially explicit manner, and which are capable of seamlessly integrating data from a variety of sensors. An index derived from the well known TCT, the Tasseled Cap Angle, and its derivative, the Process Indicator, have demonstrated the potential for characterizing the change in state and process in a dynamic forest area, enabling detection of subtle changes as well as more obvious stand-replacing disturbances. Combined, the interpretation of the TCA and its derivative, the PI, provides a simultaneous view of the occupation state and the change processes that are operating in a forest landscape, thereby enabling some understanding of the elusive relationships between landscape pattern and process-a recursive question of landscape ecology. A hierarchical 


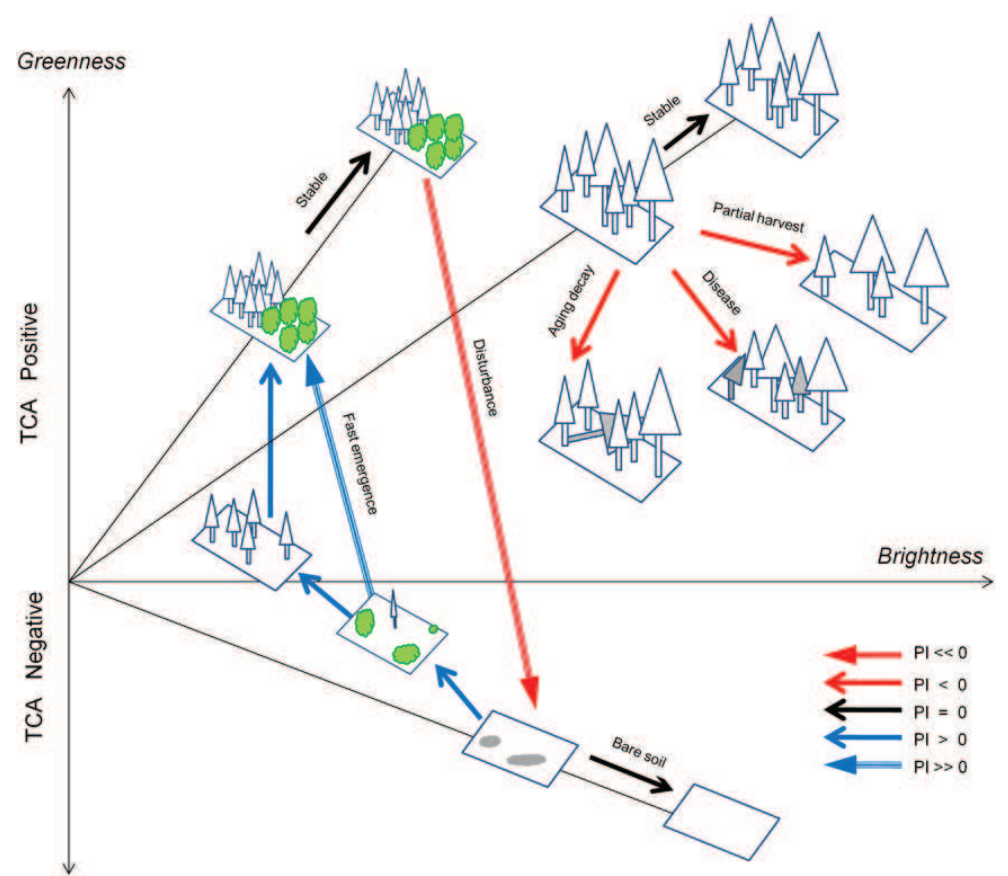

Fig. 12. Relative TCA values of various occupation states of the coniferous forest in the study area and PI values of changing processes.

segmentation process incorporating spatial and temporal properties provides flexibility in the establishment of the scale of analysis. Spatial statistics applied to multipixel objects enable assessment of spatial and temporal correlation of change events at the landscape level. Applications that require temporally detailed and spatially explicit information, such as forest succession studies, forest health monitoring, habitat models, and biomass or carbon accounting programs, will benefit from the use of these tools that provide dynamic information of the forest state and processes. Further work to link TCA and PI values with better known scales of forest variables is recommended to facilitate interpretation.

\section{Acknowledgements}

We acknowledge the Government Related Initiatives Program (GRIP) of the Canadian Space Agency (CSA) for supporting the project "EcoMonitor: Northern Ecosystem Climate Change Monitoring From Space" that enabled implementation of this research. The constructive comments of the anonymous reviewers are thanked for providing insightful, detailed, and helpful directions.

\section{Appendix A. Lagrange interpolation of the TCA}

The Lagrange interpolating polynomial of the TCA profile at each pixel is given by:

$f_{2}(t)=\sum_{i=0}^{2} L_{i}(t) f\left(t_{i}\right)$

where $f_{2}(t)$ stands for the 2nd order polynomial that approximates the function $T C A=f(t)$ given at 3 data points as $\left(t_{0}, T C A_{0}\right),\left(t_{1}, T C A_{1}\right)$, $\left(t_{2}, T C A_{2}\right)$, and the Lagrangian weights are:

$L_{i}(t)=\prod_{\substack{j=0 \\ j \neq i}}^{n} \frac{t-t_{j}}{t_{i}-t_{j}}$
The polynomial formula for the interpolated TCA at each pixel is therefore:

$$
\begin{aligned}
\operatorname{TCA}(t)= & \left(\frac{t-t_{1}}{t_{0}-t_{1}}\right)\left(\frac{t-t_{2}}{t_{0}-t_{2}}\right) \operatorname{TCA}\left(t_{0}\right)+\left(\frac{t-t_{0}}{t_{1}-t_{0}}\right)\left(\frac{t-t_{2}}{t_{1}-t_{2}}\right) \operatorname{TCA}\left(t_{1}\right) \\
& +\left(\frac{t-t_{0}}{t_{2}-t_{0}}\right)\left(\frac{t-t_{1}}{t_{2}-t_{1}}\right) \operatorname{TCA}\left(t_{2}\right) t_{0} \leq t \leq t_{2} .
\end{aligned}
$$

The PI or derivative of this polynomial can be expressed as:

$$
\begin{aligned}
\mathrm{PI}(t)= & \frac{2 t-t_{1}-t_{2}}{\left(t_{0}-t_{1}\right)\left(t_{0}-t_{2}\right)} \mathrm{TCA}\left(t_{0}\right)+\frac{2 t-t_{0}-t_{2}}{\left(t_{1}-t_{0}\right)\left(t_{1}-t_{2}\right)} \mathrm{TCA}\left(t_{1}\right) \\
& +\frac{2 t-t_{0}-t_{1}}{\left(t_{2}-t_{0}\right)\left(t_{2}-t_{1}\right)} \mathrm{TCA}\left(t_{2}\right), t_{0} \leq t \leq t_{2}
\end{aligned}
$$

\section{Appendix B. Moran's Index}

Moran's Index can be expressed as:

$$
I=\frac{N}{\sum_{i} \sum_{j} w_{i j}} * \frac{\sum_{i} \sum_{j} w_{i j}\left(x_{i}-\mu\right)\left(x_{j}-\mu\right)}{\sum_{i}\left(x_{i}-\mu\right)^{2}}
$$

where $x_{i}$ is the variable of interest $x$ measured at location $i, N$ the number of observations, $\mu$ the mean of the variable, and $w_{i j}$ are the elements of the spatial weights matrix, which express the membership of observations in the neighborhood set for each location (Anselin, 1992).

A standardized $z$-value is reported for ease of interpretation.

$z_{i}=\frac{I_{i}-E\left(I_{i}\right)}{\sqrt{V\left(I_{i}\right)}}$ 


\section{References}

Alberta Sustainable Resource Development (2009). Annual report 2008/2009. Edmonton, Alberta, Canada: Alberta Resource Development.

Andison, D. W. (1998). Temporal patterns of age-class distributions on foothills landscapes in Alberta. Ecography, 21, 543-550.

Anselin, L. (1992). Spatial data analysis with GIS: An introduction to application in the social sciences. Technical Report 92-10. University of California, Santa Barbara: National Center for Geographic Information and Analysis.

Anselin, L. (1993). The Moran Scatterplot as an ESDA tool to assess local instability in spatial association. Research paper 9330. University of California, Santa Barbara: Regional Research Institute, West Virginia University and National Center for Geographic Information and Analysis.

Anselin, L. (1995). Local indicators of spatial association-LISA. Geographical Analysis, 27, $93-115$.

Anselin, L. (2003, June 16). An introduction to spatial autocorrelation analysis with GeoDa University of Illinois, Urbana-Champaign: Spatial Analysis Laboratory, Department of Agricultural and Consumer Economics.

Anselin, L., Syabri, I., \& Kho, Y. (2006). GeoDa: An introduction to spatial data analysis. Geographical Analysis, 38, 5-22.

Baatz, M., \& Schäpe, M. (2000). Multiresolution segmentation: An optimization approach for high quality multi-scale image segmentation. In J. Strobl, T. Blaschke, \& G. Griesebner (Eds.), Proceedings of Angewandte Geographische Informationsverarbeitung XII (pp. 12-23). Salzburg: Beiträge zum AGIT Symposium.

Blaschke, T. (2010). Object based image analysis for remote sensing. ISPRS Journal of Photogrammetry and Remote Sensing, 65, 2-16.

Bontemps, S., Bogaert, P., Titeux, N., \& Defourny, P. (2008). An object-based change detection method accounting for temporal dependences in time series with mediun to coarse spatial resolution. Remote Sensing of Environment, 112, 3181-3191.

Burnett, C., \& Blaschke, T. (2003). A multiscale segmentation object relationship modelling methodology for landscape analysis. Ecological Modelling, 168, 233-249.

Canty, M. J., \& Nielsen, A. A. (2008). Automatic radiometric normalization of multitemporal satellite imagery with the iteratively re-weighted MAD transformultitemporal satellite imagery with the iteratively re-weig
mation. Remote Sensing of Environment, 112, 1025-1036.

Canty, M. J., Nielsen, A. A., \& Schmidt, M. (2004). Automatic radiometric normalization of multitemporal satellite imagery. Remote Sensing of Environment, 91, 441-451.

Chander, G., Markham, B. L., \& Helder, D. H. (2009). Summary of current radiometric calibration coefficients for Landsat MSS, TM, ETM +, and EO-1 ALI sensors. Remote Sensing of Environment, 113, 893-903.

Cohen, W., Fiorella, M., Gray, J., Helmer, E., \& Anderson, K. (1998). An efficient and accurate method for mapping forest clearcuts in the Pacific Northwest usin Landsat imagery. Photogrammetry Engineering \& Remote Sensing, 64(4), 293-300.

Cohen, W., \& Goward, S. (2004). Landsat's role in ecological applications of remote sensing. Bioscience, 54, 535-545.

Cohen, W. B., Spies, T. A., Alig, R. A., Oetter, D. R., Maiersperger, T. K., \& Fiorella, M. (2002). Characterizing 23 years (1972-95) of stand replacement disturbance in Western Oregon forests with Landsat imagery. Ecosystems, 5, 122-137.

Cohen, W., Spies, T. A., \& Fiorella, M. (1995). Estimating the age and structure of forests in a multi-ownership landscape of western Oregon, U.S.A. International Journal of Remote Sensing, 16(4), 721-746.

Coops, N., Wulder, M., \& White, J. (2006). Identifying and describing forest disturbance and spatial pattern: Data selection issues and methodological implications. Chapter 2. In M. Wulder, \& S. Franklin (Eds.), Forest disturbance and spatial pattern: Remote sensing and GIS approaches. Boca Raton, Florida, USA: Taylor and Francis 264 pp.

Coppin, P. R., \& Bauer, M. E. (1996). Change detection in forest ecosystems with remote sensing digital imagery. Remote Sensing Reviews, 13, 207-234.

Crist, E. P. (1985). A TM tasseled cap equivalent transformation for reflectance facto data. Remote Sensing of Environment, 17, 301-306.

Crist, E. P., \& Cicone, R. C. (1984). A physically based transformation of Thematic Mapper data-The TM tasseled Cap. IEEE Transactions on Geoscience and Remot Sensing, 22(23), 256-263.

Definiens (2005). Definiens eCognition version 5 object oriented image analysis user guide. AG, Munich, Germany: Definiens.

Desclée, B., Bogaert, P., \& Defourny, P. (2006). Forest change detection by statistical object based method. Remote Sensing of Environment, 102, 1-11.

Devereux, B. J., Amable, G. S., \& Costa Posada, C. (2004). An efficient image segmentation algorithm for landscape analysis. International Journal of Applied Earth Observation and Geoinformation, 6, 47-61.

Gillanders, S. N., Coops, N. C., Wulder, M. A., \& Goodwin, N. R. (2008). Application of Landsat satellite imagery to monitor land-cover changes at the Athabasca Oil Sands, Alberta, Canada. Canadian Geographer, 52(4), 466-485.

Gong, P., \& Xu, B. (2003). Chapter 11: Remote sensing of forests over time: Change types, methods, and opportunities. Remote Sensing of Forest Environments: Concepts an Case Studies. Dordrecht/Boston/London: Kluwer Academic Publishers.

Goodwin, N. R., Coops, N. C., Wulder, M. A., Gillanders, S., Schroeder, T. A., \& Nelson, T. (2008). Estimation of insect infestation dynamics using a temporal sequence of Landsat data. Remote Sensing of Environment, 112, 3680-3689.

Goodwin, N. R., Magnussen, S., Coops, N. C., \& Wulder, M. A. (2010). Curve fitting of time-series Landsat imagery for characterizing a mountain pine beetle infestation. International Journal of Remote Sensing, 31(12), 3262-3271.

Goovaerts, P., Jazquez, G. M., \& Marcus, A. (2005). Geostatistical and local cluster analysis of high resolution hyperspectral imagery for detection of anomalies Remote Sensing of Environment, 95, 351-367.

Hall, O., \& Hay, G. (2003). A multiscale object specific approach to digital change detection. International Journal of Applied Earth Observation and Geoinformation, 4 311-327.
Han, T., Wulder, M. A., White, J. C. Coops, N. C., Alvarez, M. F., \& Butson, C. (2007) An efficient protocol to process Landsat images for change detection with Tasselled Cap Transformation. IEEE Geoscience and Remote Sensing Letters, 4(1), 147-151.

Hansen, M. J., Franklin, S. E., Woudsmaa, C. G., \& Peterson, M. (2001). Caribou habita mapping and fragmentation analysis using Landsat MSS, TM, and GIS data in the North Columbia Mountains, British Columbia, Canada. Remote Sensing of Environment, $77,50-65$.

Hay, G. J., Castilla, G., Wulder, M. A., \& Ruiz, J. R. (2005). An automated object-based approach for the multiscale image segmentation of forest scenes. International Journal of Applied Earth Observation and Geoinformation, 7, 339-359.

Hay, G. J., Marceau, D. J., Dubé, P., \& Bouchard, A. (2001). A multiscale framework for landscape analysis: Object-specific analysis and upscaling. Landscape Ecology, 16, $471-490$

Hayes, D. J., \& Cohen, W. B. (2007). Spatial, spectral and temporal patterns of tropical forest cover change as observed with multiple scales of optical satellite data. Remote Sensing of Environment, 106, 1-16.

Healey, S. P., Cohen, W. B., Zhiqiang, Y., \& Krankina, O. (2005). Comparison of Tasseled Cap-based Landsat data structures for use in forest disturbance detection. Remote Sensing of Environment, 97, 301-310.

Healey, S. P., Yang Z., Cohen, W. B., \& Pierce, D. J. (2006). Application of two regressionbased methods to estimate the effects of partial harvest on forest structure using Landsat data. Remote Sensing of Environment, 101, 115-126.

Helmer, E. H., Brown, S., \& Cohen, W. (2000). Mapping montane tropical successional stage and land use with multi-date Landsat imagery. International Journal of Remote Sensing, 21(11), 2163-2183.

Huang, Ch., Goward, S. N., Masek, J. G., Gao, F., Vermote, E. F., Thomas, N., et al. (2009). Development of time series stacks of Landsat images for reconstructing forest disturbance history. International Journal of Digital Earth, 1, 1-25.

Huang, Ch., Goward, S. N., Schleeweis, K., Thomas, N., Masek, J. G., \& Zhu, Z. (2009). Dynamics of national forests assessed using Landsat record: Case studies in eastern United States. Remote Sensing of Environment, 113, 1430-1442.

Huang, C., Wylie, B., Yang, L., Homer, C., \& Zylstra, G. (2002). Derivation of a tasselled cap transformation based on Landsat 7 at-satellite reflectance. International Journal of Remote Sensing, 23(8), 1741-1748.

Jakubauskas, M. E. (1996). Thematic Mapper characterization of lodgepole pine sera stages in Yellowstone National Park, USA. Remote Sensing of Environment, 56, $118-132$

Jin, S., \& Sader, S. A. (2005). Comparison of time series tasseled cap wetness and the normalized difference moisture index in detecting forest disturbances. Remote Sensing of Environment, 94, 364-372.

Johansen, K., Arroyo, L. A., Phinn, S. \& Witte, C. (2010). Comparison of geo-object based and pixel-based change detection of riparian environments using high spatial resolution multi-spectral imagery. Photogrammetric Engineering and Remote Sensing, 76(2), 123-136.

Kauth, R. J., \& Thomas, G. S. (1976). The tasseled cap-A graphic description of the spectral-temporal development of agricultural crops as seen in Landsat. Proceedings on the Symposium on Machine Processing of Remotely Sensed Data, West Lafayette, Indiana, June 29-July 1, 1976 (pp. 41-51). West Lafayette, Indiana: LARS, Purdue University.

Lea, R., Blodgett, C., Diamond, D., \& Schanta, M. (2004). Using the Tasseled Cap Transformation to identify change in the Missouri Ozark forests. Proceedings of the ASPRS Fall Conference Images to Decisions: Remote Sensing Foundations for GIS Applications. Kansas City, Missouri.

Linke, J. McDermid, G. J. Laskin, D. N., MacLane, A. J. \& Hall-Beyer, M. (2009). A disturbance inventory framework for flexible and reliable landscape monitoring. Photogrammetric Engineering and Remote Sensing, 75(8), 981-995.

Lu, D., Mausel, P., Brondizio, E., \& Moran, E. (2004). Change detection techniques. International Journal of Remote Sensing, 25(12), 2365-2407.

Lunetta, R., Johnson, D. M., Lyon, J., \& Crotwell, J. (2004). Impacts of imagery tempora frequency on land-cover change detection monitoring. Remote Sensing of Environment, 89, 444-454

Masek, J. G., Huang, Ch., Wolfe, R., Cohen, W., Hall, F., Kutler, J., et al. (2008). North American forest disturbance mapped from a decadal Landsat record. Remote Sensing of Environment, 112, 2914-2926.

Moran, P. A. P. (1948). The interpretation of statistical maps. Journal of the Royal Statistical Society: Series B: Methodological, 10(2), 243-251.

Muukkonen, P., \& Heiskanen, J. (2007). Biomass estimation over a large area based on standwise forest inventory data and ASTER and MODIS satellite data: A possibility to verify carbon inventories. Remote Sensing of Environment, 107, 617-624.

Nadkarni, N. M., Parker, G. G., Rinker, H. B., \& Jarzen, D. M. (2004). The nature of fores canopies. Chapter 1. In Margaret D. Lowman, \& Nalini M. Nadkarni (Eds.), Forest canopies (Physiological ecology). : Elsevier Academic Press $501 \mathrm{pp}$.

Nielsen, S. E., Boyce, M. S., \& Stenhouse, G. B. (2004). Grizzly bears and forestry I. Selection of clearcuts by grizzly bears in west-central Alberta, Canada. Forest Ecology and Management, 199, 51-65.

Nielsen, A. A., Conradsen, K., \& Simpson, J. J. (1998). Multivariate Alteration Detection (MAD) and MAD postprocessing in multispectral, bitemporal image data: New approaches to change detection studies. Remote Sensing of Environment, 64,1-19.

Numa, C., Verdu, J. R., Sanchez, A., \& Galante, E. (2009). Effects of landscape structure on the spatial distribution of Mediterranean dung beetle diversity. Diversity and Distributions, 15 , 489-501.

O'Neill, R. V., DeAngelis, D. L., Waide, J. B., \& Allen, T. F. (1986). A hierarchical concept of ecosystems. Princeton: Princeton University Press.

Peterson, U., \& Nilson, T. (1993). Successional reflectance trajectories in northern temperate forests. International Journal of Remote Sensing, 14(3), 609-613. 
Powell, S. L., Cohen, W. B., Healey, S. P., Kennedy, R. E., Moisen, G. G., Pierce, K. B., et al. (2010). Quantification of live aboveground biomass dynamics with Landsat timeseries and field inventory data: A comparison of empirical modeling approaches. Remote Sensing of Environment, 114, 1053-1068.

Powell, S. L., Cohen, W. B., Yang, Z., Pierce, J. D., \& Alberti, M. (2008). Quantification of impervious surface in the Snohomish Water Resources Inventory Area of Western Washington from 1972-2006. Remote Sensing of Environment, 112, 1895-1908.

Price, K. P., \& Jakubauskas, M. E. (1998). Spectral retrogression and insect damage in lodgepole pine successional forests. International Journal Remote Sensing, 19, $1627-1632$

Roder, A., Kuemmerle, T., \& Hill, J. (2005). Extension of retrospective datasets using multiple sensors. An approach to radiometric intercalibration of Landsat TM and multiple sensors. An approach to radiometric intercalib
MSS data. Remote Sensing of Environment, 95, 195-210.

Rowe, J. S. (1972). Forest regions of Canada. Otawa, Canada: Canadian Forestry Service Department of the Environment.

Schneider, R. R., Stelfox, J. B., Boutin, S., \& Wasel, S. (2003). Managing the cumulative impacts of land uses in the Western Canadian Sedimentary Basin: A modeling approach. Conservation Ecology, 7(1), 8

Schroeder, T. A., Cohen, W. B., Song, C., Canty, M. J., \& Yang, Z. (2006). Radiometric correction of multi-temporal Landsat data for characterization of early successional forest patterns in western Oregon. Remote Sensing of Environment, 103, 16-26.

Schroeder, T. A., Cohen, W. B., \& Zhiqiang, Y. (2007). Patterns of Forest regrowth following clearcutting in Western Oregon as determined from Landsat time-series. following clearcutting in Western Oregon as deter
Forest Ecology and Management, 243, 259-273.

Song, C., Woodcock, C. E., Seto, K. C., Lenney, M. P., \& Macomber, S. A. (2001). Classification and change detection using Landsat data: when and how to correct atmospheric effects? Remote Sensing of Environment, 75, 230-244.

Spies, T. A., Ripple, W. J., \& Bradshaw, G. A. (1994). Dynamics and pattern of a managed coniferous forest landscape in Oregon. Ecological Applications, 4(3), 555-568.

Turner, M. G. (1989). Landscape ecology: the effect of pattern on process. Annual Review of Ecology and Systematics, 20, 171-197.
Van Dijk, A. I. J. M., \& Bruijnzeel, L. A. (2001). Modelling rainfall interception by vegetation of variable density using an adapted analytical model. Part 1. Model description. Journal of Hydrology, 247, 230-238.

Vogelmann, J. E., Tolk, B., \& Zhu, Z. (2009). Monitoring forest changes in the southwestern United States using multitemporal Landsat data. Remote Sensing of Environment, 113, 1739-1748.

Walsh, S.J., Brown, D.G., Geddes, C.A., Weiss, D.J., McKnight, S., Hammer, E.S., \& Tuttle, J.P. (2009). Pattern-process relations in the alpine and subalpine environments: a remote sensing and GIScience perspective. Chapter 2 in: Elseveir Ed. Development in Earth Surface Processes, 12.

Walter, V. (2004). Object-based classification of remote sensing data for change detection. ISPRS Journal of Photogrammetry \& Remote Sensing, 58, 225-238.

Wilson, E. H., \& Sader, S. A. (2002). Detection of forest harvest type using multiple dates of Landsat TM imagery. Remote Sensing of Environment, 80, 385-396.

Woodcock, C. E., Allen, R., Anderson, M., Belward, A., Bindschadler, R., Cohen, W., et al. (2008). Free access to Landsat imagery. Science, 320(5879), 1011.

Wulder, M. A., Franklin, S. E., \& White, J. C. (2004). Sensitivity of hyperclustering and labeling land cover classes to Landsat image acquisition date. International Journal of Remote Sensing, 10, 5337-5344.

Wulder, M. A., \& Seemann, D. (2003). Forest inventory height update through the integration of lidar data with segmented Landsat imagery. Canadian Journal of Remote Sensing, 29(5), 536-543.

Wulder, M. A., White, J. C., Bentz, C., Alvarez, M. F., \& Coops, N. (2006). Estimating the probability of mountain pine beetle red attack damage. Remote Sensing of Environment, 101(2), 150-166.

Wulder, M. A., White, J. C., Goward, S. N., Masek, J. G., Irons, J. R., Herold, M., et al. (2008). Landsat continuity: Issues and opportunities for land cover monitoring. Remote Sensing of Environment, 112, 955-969.

Wulder, M. A., White, J. C., Han, T., Coops, N. C., Cardille, J. A., Holland, T., et al. (2008a). Monitoring Canada's forests. Part 2: National forest fragmentation and pattern. Canadian Journal of Remote Sensing, 34(6), 563-584. 



\section{CHAPTER II}

Cristina Gómez, Michael A. Wulder, Joanne C. White, Fernando Montes, José A. Delgado, 2012. Characterizing 25 years of change in the area, distribution, and carbon stock of Mediterranean pines in Central Spain. International Journal of Remote Sensing, 33(17), 5546-5573

\section{RESUMEN}

\section{Caracterización de 25 años de cambio en la extensión, distribución, y almacenamiento} de carbono en pinares mediterráneos del Sistema Central español

Los pinares mediterráneos sufren cambios continuos bajo la influencia de factores naturales y humanos. La teledetección ofrece los medios necesarios para describir y caracterizar simultáneamente los cambios producidos en áreas extensas. En este trabajo se utilizó una serie temporal de imágenes Landsat para describir 25 años (1984-2009) de evolución en los pinares del Sistema Central español. Para identificar las variaciones en extensión y distribución de las masas arbóreas a escala de paisaje se utilizaron técnicas basadas en unidades espaciales, mediante segmentación de imágenes.

En ausencia de perturbaciones importantes, la incorporación de biomasa en masas forestales o su disminución en caso de existir extracciones, se relacionan directamente con variaciones en el carbono almacenado. De esta manera los cambios espectrales detectados mediante imágenes y asociados a variaciones de biomasa, pueden describir también procesos de almacenamiento de carbono. Para identificar la localización y las variaciones en extensión y distribución de los pinares, se utilizaron las bandas 3, 4, and 5 de Landsat y el índice Tasseled Cap Angle (TCA) derivado de las componentes verdor y brillo de la transformación Tasseled Cap (TCT). Para la tipificación de los procesos de almacenamiento o fuga de carbono, se utilizó el Indicador de procesos (PI), valor en cada momento de la derivada temporal de TCA, capaz de informar sobre la direccionalidad y la tasa de cambio. Los resultados mostraron un incremento del $40 \%$ en superficie de los pinares entre 1984 y 2009, de 1211 a 1698 kilómetros cuadrados. El incremento en superficie se produjo durante este periodo de forma irregular en el espacio y tiempo. La distribución de los pinares también varió, estando $765 \mathrm{~km}^{2}$ ocupados permanentemente y $945 \mathrm{~km}^{2}$ solo de forma transitoria o intermitente. Continuando con la lógica propuesta de los procesos de acumulación de carbono, se encontró que al final del periodo de análisis el $20 \%$ del área potencialmente ocupada por pinar aumentaba de forma neta el carbono fijado, mientras que el $40 \%$ experimentaba disminución neta. 
Assessment of biomass and carbon dynamics in pine forests of the Spanish Central Range: a remote sensing approach 


\title{
Characterizing 25 years of change in the area, distribution, and carbon stock of Mediterranean pines in Central Spain
}

\author{
CRISTINA GÓMEZ*†, MICHAEL A. WULDER $\ddagger$ JOANNE C. WHITE \\ FERNANDO MONTES§ and JOSÉ A. DELGADO† \\ $\dagger$ Sustainable Forest Management Research Institute, ETS de Ingenierías Agrarias, \\ Universidad de Valladolid, Palencia 34004, Spain \\ $\$$ Canadian Forest Service (Pacific Forestry Centre), Natural Resources Canada, Victoria, \\ British Columbia, Canada V8Z 1M5 \\ $\S$ Departamento de Sistemas y Recursos Forestales, CIFOR-INIA, Madrid 28040, Spain
}

(Received 20 January 2011; in final form 22 December 2011)

\begin{abstract}
Mediterranean pines are subject to continuous change under the influence of natural and human factors. Remotely sensed data provide a means to characterize these changes over large areas. In this study we used a time series of Landsat imagery to capture 25 years (1984-2009) of change in the pine-dominated forests of the Central Range in Spain. Object-based image analysis methods were used to identify landscape-level changes in the area and the distribution of forests. We also propose that in the absence of disturbance, biomass accrual is occurring (or depletion in cases where removal is evident) and may be related to changes to the carbon stock; we describe the detected spectral changes in terms of biomass changes as the carbon stocking process. The primary inputs for the identification of changes in the area and distribution of pine stands were Landsat bands 3, 4 and 5 and the Tasseled Cap Angle (TCA) - a metric derived from the greenness and brightness components of the Tasseled Cap Transformation (TCT). In the identification of carbon stocking processes the temporal derivative of the TCA, the Process Indicator (PI), was used to inform on the rate and directionality of the change present. Our results show that the total area of pine forest has increased by $40 \%$, from $1211 \mathrm{~km}^{2}$ to $1698 \mathrm{~km}^{2}$, during this period, with a variable rate of change. The distribution of pine-dominated forest has changed as well: there is an area of $765 \mathrm{~km}^{2}$ permanently covered with pines and $945 \mathrm{~km}^{2}$ found to be temporarily occupied. Following the logic of carbon stocking processes, our findings show that at the end of the analysis period, $20 \%$ of the potential pine area is increasing its carbon stock and $40 \%$ of this area is experiencing a decrease.
\end{abstract}

\section{Introduction}

Forests have been described as the most important land carbon sinks (Le Quéré et al. 2009) and therefore play a relevant role in the global carbon budget (Bravo et al. 2008). The global carbon balance is markedly altered by the extent of forests, as well as the biomass content per surface unit (Houghton 2005). The character of forests as a sink or source of carbon dioxide is determined by the ratio of respiration to net

*Corresponding author. Email: c.gomez@abdn.ac.uk

International Journal of Remote Sensing

ISSN 0143-1161 print/ISSN 1366-5901 online (C) 2012 Taylor \& Francis

http://www.tandf.co.uk/journals

http://dx.doi.org/10.1080/01431161.2012.663115 
primary production (Law et al. 1999), and this relation is strongly influenced by the stand successional stage (Odum 1969) and health condition (Brown 2002). Net ecosystem carbon balances are complex and multifaceted, resulting in evaluation difficulties (Schulze et al. 2000). To reduce complexity, a simple rule for above-ground forest components is that mature stands are more stable stocks of carbon and growing stands are net sinks of carbon (Goetz et al. 2006), but the age at which a forest becomes a net carbon sink varies according to forest type, site productivity and other factors (Goward et al. 2008). However, while carbon-capturing ability is difficult to determine, the stocking magnitude of a forest stand is undoubtedly proportional to the biomass it stores (Masera et al. 2003, Houghton 2007).

A map of the dynamics of distribution, biomass content and succession stages of forests through time is an invaluable tool for spatially explicit assessment of forest carbon stocks, sinks and sources (Powell et al. 2010). Together with a timeline of change events, the effectiveness of management approaches can be evaluated (Hayes and Cohen 2007, Huang et al. 2009). Medium spatial resolution remotely sensed data (i.e. 10-100 m pixel) is well suited to characterize forest change (Wulder et al. 2008b) and is the only feasible, cost-effective option for extensive areas (Lunetta et al. 2004). Since 1972, the United States Geological Survey (USGS) has been archiving Landsat images. In 2008 the USGS opened the archive to unfettered public access to analysis-ready images (Woodcock et al. 2008), removing access and cost limitations and creating a myriad opportunities for characterizing both spatial and temporal landscape processes (Goodwin et al. 2008, Olsson 2009, Verbesselt et al. 2010, Potapov et al. 2011).

In this work we aim to characterize the changes in area, distribution and carbon stocking processes of pines in the Central Range of Spain over a period of 25 years (1984-2009) with a medium spatial resolution time series of images from the Landsat programme. We apply a multilevel object oriented methodology for identification and classification of pine-dominated areas, and analyse trends in carbon stocking processes at the stand level with an index derived from the Tasseled Cap Transformation (TCT). The specific objectives of the study are:

1. to assess changes in the extent of a Mediterranean forest, where natural change is relatively slow and human-induced change has historically been controlled, with a multilevel object-oriented methodology;

2. to identify with spatial precision the distribution of pines in the Central Range of Spain and variations occurring in three sub-periods during the last 25 years (1984-2009); and

3. to characterize carbon stocking areas with an index derived from the TCT, assessing trends of change over a 25 year period (1984-2009).

\section{Background}

\subsection{Mediterranean pine forests}

Mediterranean forests and woodlands cover 73 million ha, approximately $8.5 \%$ of the Mediterranean basin region (EFI 2009), and have a notable richness in species diversity (Myers et al. 2000). In Mediterranean ecosystems, pine forests generate nonwood products (Calama and Montero 2007) and serve important ecological functions including water regulation, erosion control and provision of recreational opportunities 
and wildlife habitat (Merlo and Croitoru 2005). Pine forests have a significant carbon sink capacity that could help signatory countries of the Kyoto protocol achieve their targets for the reduction of greenhouse gas emissions (Myneni et al. 2001).

\subsection{Monitoring change in Mediterranean forests}

In Spain, similar to other Mediterranean countries, a National Forest Inventory (NFI) provides periodical detailed data for the assessment of biomass and carbon pools through sampling and reporting supported by statistics (MMA 2008). The NFI's 10 year re-measurement cycle enables comparison of data over time, but, similar to other sample-based NFIs, has some known limitations, including the discrete character of the sampling, which obliges extrapolation of data (Salvador and Pons 1998), and the use of different basic cartography in subsequent updates of the NFI database (Villaescusa et al. 2001). Also, a decade can be too long an interval in areas undergoing rapid change that need up-to-date information and more frequent reporting on change events (FAO 2010). Some researchers have explored the potential of remotely sensed data in quantifying change in Mediterranean environments (table 1), especially integrating both forest disturbance and recovery; to the best of our knowledge no one has developed a method for the characterization of carbon stock change focused on this unique ecosystem.

\subsection{Retrospective analysis of change}

Monitoring change over large areas, and particularly historical change, is only feasible with satellite data (Nielsen et al. 1998, Townsend et al. 2009). Satellite imagery provides consistent and repeatable measurements at an appropriate spatial scale (Kennedy et al. 2007) for regional land-cover assessment. The repetitive data acquisition, synoptic view and digital format suitable for computer processing have made remotely sensed imagery the major data source for change detection during the last few decades (Wulder et al. 2008b). Medium spatial resolution satellite sensors such as those of the Landsat series (Multi Spectral Scanner (MSS), Thematic Mapper (TM) and Enhanced Thematic Mapper Plus (ETM+)) are well suited to capture forest cover and change at the stand level in support of research and reporting, relating both natural and anthropogenic drivers of change (Achard et al. 2007, Olander et al. 2008, White et al. 2011).

Now that almost four decades of Landsat images have been made freely available to the public (Woodcock et al. 2008), an unprecedented opportunity for change research has emerged. The study of a time series of images (i.e. more than two images) has two main advantages over the use of traditional two-date change detection approaches: the first is the ability to study long-term trends in spectral response (Vogelmann et al. 2009) while controlling the variability associated with solar angle, atmospheric effects (Wulder et al. 2008a) and phenology (Sonnenschein et al. 2011). The second advantage is the opportunity to determine rates of change (Gillanders et al. 2008a).

Extensive research is currently directed at assessing historical change in boreal and temperate forests with increasingly sophisticated image-processing algorithms (e.g. Huang et al. 2009, Olsson 2009, Kennedy et al. 2010, Powell et al. 2010) that take advantage of the temporal information leveraged by a dense series of calibrated images. Determining long-term change in Mediterranean forests using an image trajectory approach remains to be explored further. 
Mediterranean pine dynamics of Central Spain

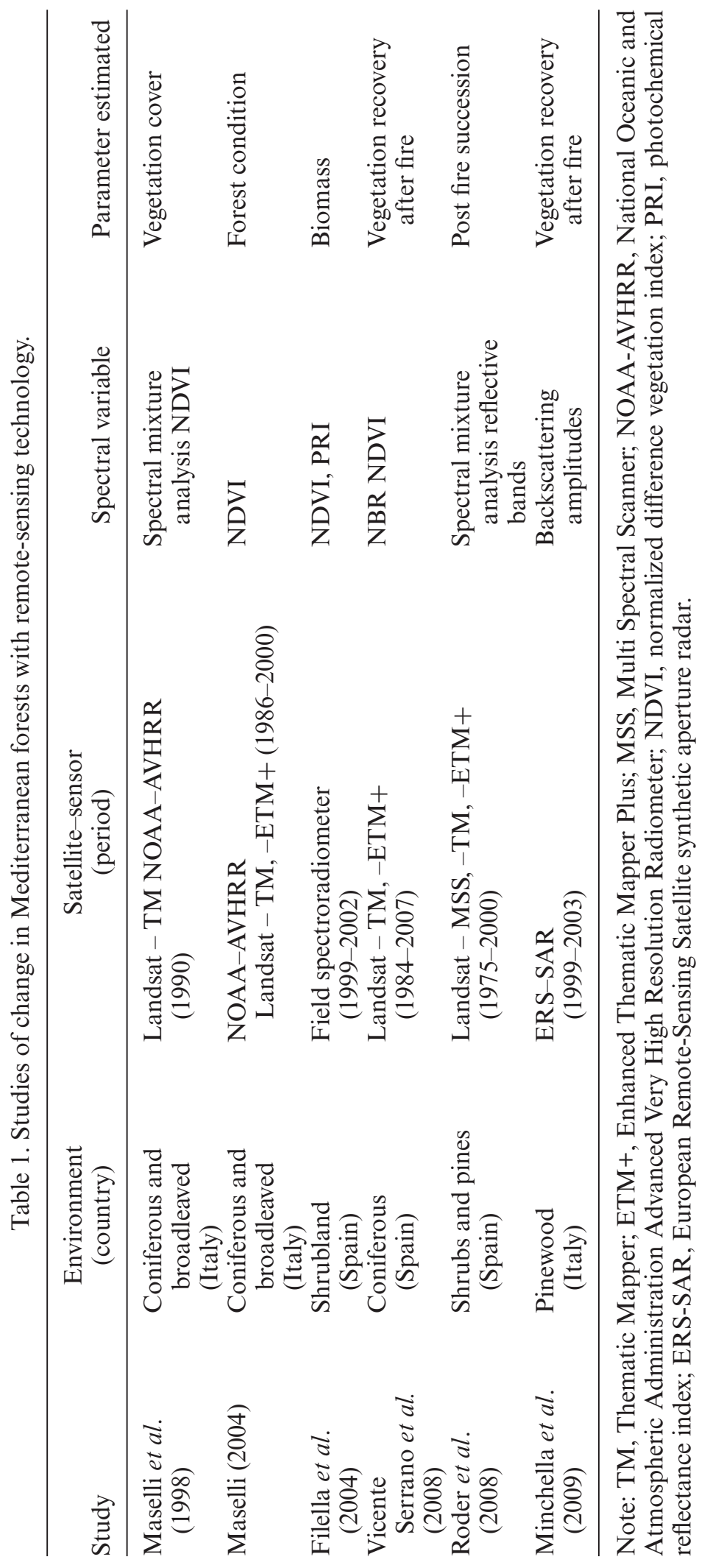




\section{Methods}

\subsection{Study area}

The area of interest covers approximately 1 million ha in the Central Range of Spain, occupying part of the Ávila, Segovia, Madrid, Guadalajara and Toledo provinces. It is centred at latitude $40^{\circ} 37^{\prime} 56^{\prime \prime} \mathrm{N}$ and longitude $-4^{\circ} 6^{\prime} 47^{\prime \prime}$ E. Pines (Pinus sylvestris L., Pinus pinaster Ait., Pinus nigra Arn.) are the dominant tree species, except in the most western area where broadleaf species (Quercus pyrenaica Willd.) dominate. Forests extend to elevations of 2000 m, beyond which shrubs (Cytisus sp., Genista sp., Erica sp., Echinospartum sp.) are the prevalent vegetation (Rivas-Martínez 1963).

\subsection{Satellite images}

With the recent public access to the Landsat archive (Woodcock et al. 2008) it is now possible to freely download over the Internet (glovis.usgs.gov) a time series of images for almost any area of the Earth (Wulder et al. 2011). As an additional source of data, the Spanish Instituto Geográfico Nacional (IGN) has been compiling and pre-processing abundant Landsat imagery since 2008 as part of the Plan Nacional de Teledetección (PNT) and making it available for research (Villa et al. 2009).

Still, the acquisition of a historical time series of multiple adjacent Landsat images (relatively cloud-free) is a complicated task (Homer et al. 2004). We focused our research on a single Landsat scene (WRS-2 Path 201, Row 032) (figure 1) as it encompasses the most extensive continuous pine stands of the Central Range. Anniversary images were selected when possible (table 2), as recommended for monitoring studies (Wulder and Franklin 2002). In order to capture stable phenological conditions and to avoid the presence of snow in high altitudes, summer images were selected. The spectral suitability of early summer images (years 2000, 2001 and 2005) was thoroughly checked through the processing stages to detect and avoid possible phenology artefacts.

Our time series consisted of nine Landsat TM and two ETM+ (Scan Line Corrector (SLC) on) images. To ensure a more complete time series, we increased our tolerance to a small amount of cloud cover in the images, but still, a yearly time series of images was not possible to obtain and the time step is not constant; there is a gap in the sequence of images in the 1990s corresponding to the private sector distribution era (Tolomeo et al. 2009). Longer intervals between images may reduce detection accuracy for subtle changes (Wilson and Sader 2002, Jin and Sader 2005).

\subsection{Auxiliary data}

The Mapa Forestal Español (MFE50) is the digital version of the Ruiz de la Torre forest map of Spain for the year 2000. In the construction of this map, the source of data consisted of aerial photography and field notes. Polygons interpreted on the aerial photographs were transferred to the 1:50 000 National Topographic Map (MTN) and this original paper map version was later digitized. This GIS database encompasses 68 attributes to characterize vegetation units. Some relevant attributes for the identification of pine forest areas are dominant species and crown cover (that is, the proportion of area covered by the horizontal projection of the canopy (as a percentage)).

Field data from plot-based inventories such as the NFI and other local management plans were used at various stages of the research, being of particular value in 


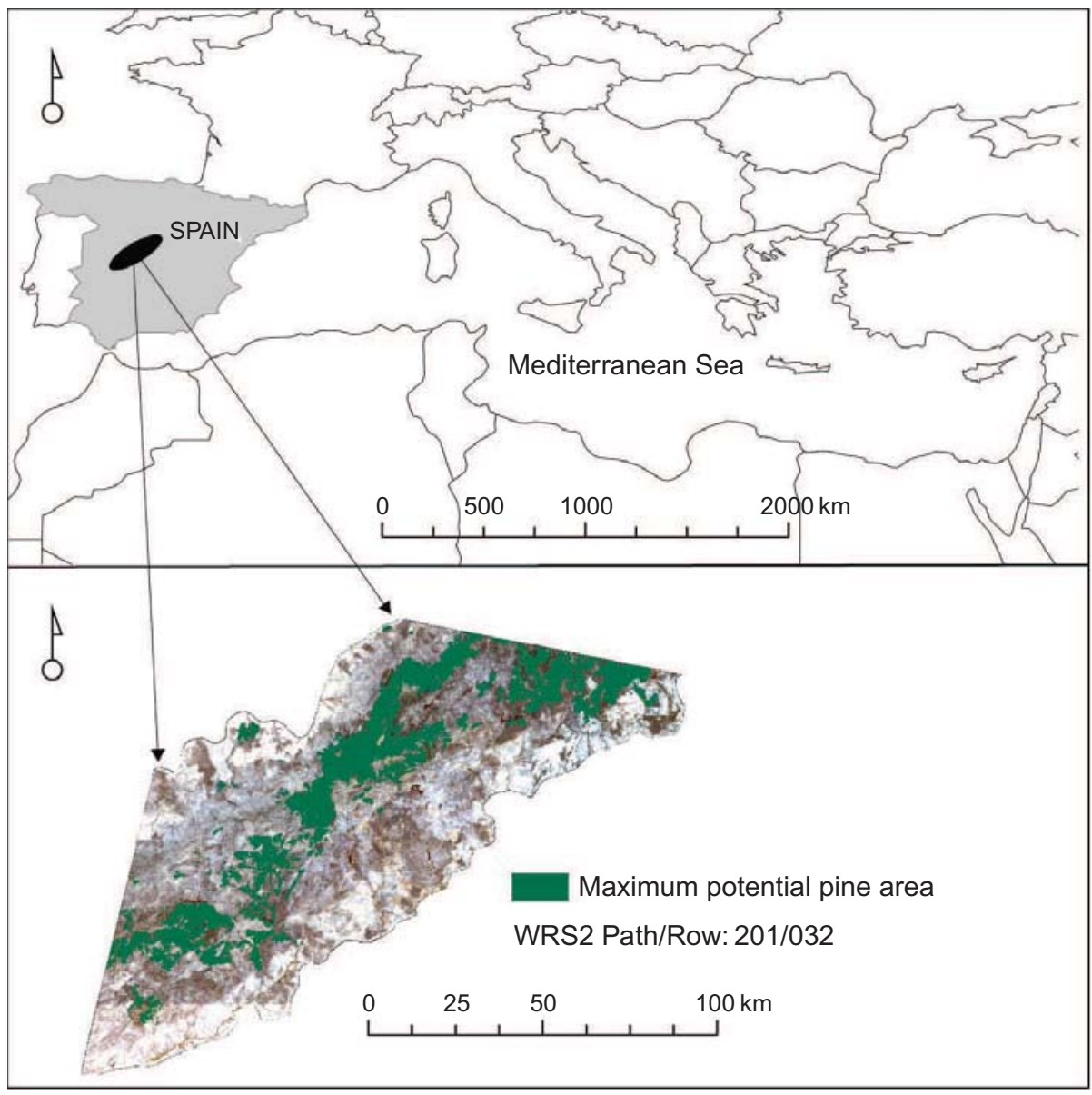

Figure 1. Location of the study area.

Table 2. List of Landsat images used in the study.

\begin{tabular}{llcc}
\hline Landsat/sensor & \multicolumn{1}{c}{ Source } & \multicolumn{1}{c}{ Date } & Sun elevation $\left(^{\circ}\right)$ \\
\hline 5/TM & EarthExplorer & 18 August 1984 & 52.89 \\
5/TM & EarthExplorer & 11 August 1987 & 54.11 \\
4/TM & EarthExplorer & 11 August 1990 & 54.38 \\
4/TM & EarthExplorer & 14 August 1991 & 51.68 \\
7/ETM+ & EarthExplorer & 22 August 2000 & 54.87 \\
7/ETM+ & EarthExplorer & 6 June 2001 & 64.24 \\
5/TM & EarthExplorer & 17 June 2002 & 62.20 \\
5/TM & EarthExplorer & 7 August 2003 & 56.50 \\
5/TM & Aurensis & 25 August 2004 & 53.15 \\
5/TM & Junta de Castilla y León & 24 May 2005 & 62.80 \\
5/TM & EarthExplorer & 23 August 2009 & 54.48 \\
\hline
\end{tabular}

Notes: TM, Thematic Mapper; ETM+, Enhanced Thematic Mapper Plus.

Reference image for radiometric normalization (22 August 2000) is highlighted.

accuracy assessment during the confidence-building stage. Standard forest variables such as species, number of trees per plot and diameter at breast height are measured and updated on a decadal basis. 


\subsection{Pre-processing}

All images were orthocorrected with a $30 \mathrm{~m}$ digital elevation model (DEM) derived from 1:10 000 digital cartography (sitcyl.org) and co-registered to the UTM 30N (datum WGS84) coordinate system with root mean square errors (RMSEs) of less than half a pixel. Twenty-five ground control points were manually identified in the images and used for adjustment.

A robust radiometric correction is essential in change detection applications (Coppin et al. 2004, Lu et al. 2004) and when image values are related to biophysical phenomena (Gong and $\mathrm{Xu}$ 2003). It is particularly challenging if images from various sensors are included in the analysis (Roder et al. 2005). We applied a relative radiometric normalization to the sequence of images; the reference image was selected in the middle of the time series for its good quality and absence of haze (table 1). Digital Numbers (DNs) were converted to top of atmosphere (TOA) reflectance following instructions and recommended coefficients from Chander et al. (2009), which give the recommended calibration for each Landsat sensor (including changes occurring over the lifetime of a given sensor). Atmospheric effects on the reference image were corrected with the cosine-Theta (COST) model (Chávez 1988). All other images were normalized to the reference image with the Iterative Reweighted Multivariate Alteration Detection (IR-MAD) process (Canty et al. 2004) - an automatic ordination algorithm recommended for spectral trajectory analysis (Schroeder et al. 2006). Image normalization transforms images to a common radiometric scale, minimizing Sun, sensor and view angles, as well as atmospheric differences among images. The process of normalization reduces the amount of artefacts due to illumination or atmospheric variations, enabling a more reliable detection of true change (Song et al. 2001).

\subsection{Tasseled Cap Transformation and Tasseled Cap Angle}

The Tasseled Cap Transformation (TCT) (Kauth and Thomas 1976, Crist and Cicone 1984, Crist 1985, Huang et al. 2002) has been broadly employed in forestry studies of structure (Cohen et al. 2001, Hansen et al. 2001), condition (Healey et al. 2006, Wulder et al. 2006), successional state (Peterson and Nilson 1993, Helmer et al. 2000) and change detection (Lea et al. 2004, Jin and Sader 2005) in various forest environments.

The TM brightness $(B)$ component is by definition (Crist and Cicone 1984) a positive value, whereas the greenness $(G)$ component depends on the contrast between visible and near-infrared bands (table 3), with exposed soil having negative values (Price and Jakubauskas 1998, Gillanders et al. 2008b) and vegetated areas positive values. $G$ and $B$ components define the vegetation plane (Crist and Cicone 1984) (figure 2). Studying the spectral behaviour of forest stands in the vegetation plane provides insights into forest cover densities and forest development stages (table 4).

A range of studies in coniferous forests has confirmed higher values of $G$ and lower values of $B$ in dense forest cover classes when compared with open stands or clearcuts (Cohen et al. 1995, Healey et al. 2005). The Tasseled Cap Angle (TCA) index, defined as the angle formed by $G$ and $B$ in the vegetation plane (equation (1)) and first used by Powell et al. (2010) for modelling biomass in coniferous and mixed forests of Arizona and Minnesota (USA), condenses the $G / B$ information to a single value (Gómez et al. 2011): dense forest stands exhibit higher values of TCA than open stands or bare soil (figure 2). 
Table 3. Coefficients used for calculation of Thematic Mapper TCT indices.

\begin{tabular}{lcrrrrrr}
\hline Sensor & Component & \multicolumn{1}{c}{ Red } & \multicolumn{1}{c}{ Green } & \multicolumn{1}{c}{ Blue } & NIR & SWIR1 & SWIR2 \\
\hline TM & Brightness & 0.3037 & 0.2793 & 0.4343 & 0.5585 & 0.5082 & 0.1863 \\
& Greenness & -0.2848 & -0.2435 & -0.5436 & 0.7243 & 0.0840 & -0.1800 \\
ETM+ & Brightness & 0.3561 & 0.3972 & 0.3904 & 0.6966 & 0.2286 & 0.1596 \\
& Greenness & -0.3344 & -0.3544 & -0.4556 & 0.6966 & -0.0242 & -0.2630 \\
\hline
\end{tabular}

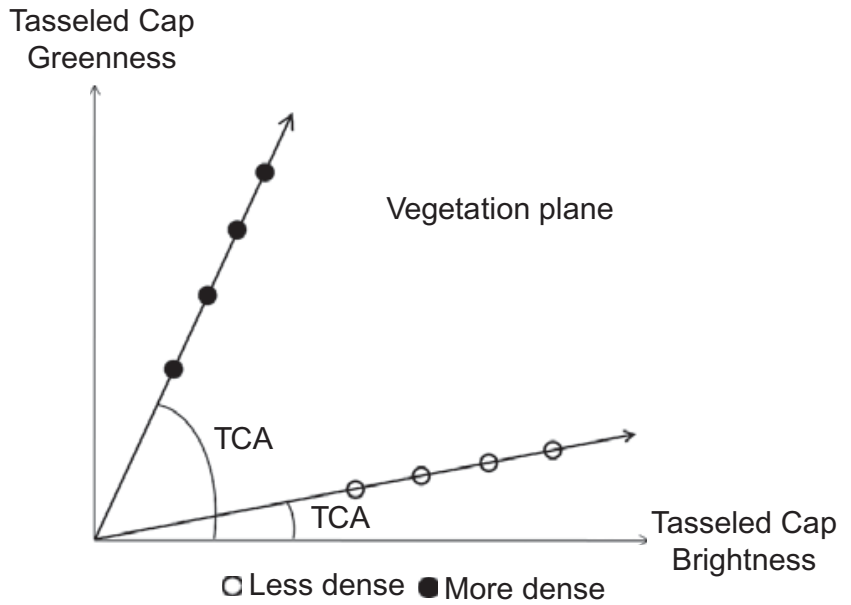

Figure 2. Vegetation plane formed by TCT greenness and brightness components. The TCA is the angle formed by these components: TCA $=\arctan (G / B)$.

$$
\mathrm{TCA}=\arctan \left(\frac{G}{B}\right)
$$

Considering these notions, we explored the relationship of the TCA to forest density variables at the stand level in the Mediterranean pines of the study area. Data from plot-based field inventories were krigged to $30 \mathrm{~m}$ spatial resolution and regressed with values of the TCA at the stand level. The entire range of basal area (BA) representative of the study area was included in the correlation analysis. To support later analyses, we find that, as expected, the TCA and BA are linearly related, with a high and positive value of correlation (coefficient of determination, $R^{2}=0.80$ ).

We calculated the angle between normalized $G$ and $B$ components (equation (1)) for our time series of images. As derived from the TCT, the TCA range of values is scene dependent (Crist and Cicone 1984). Based on the strong relation between TCA and density variables in the study area we posit that analysing the TCA values over a time series of images provides information on relative changes in the density of forest stands: the TCA is stable if there is no change in density (constant $\mathrm{BA}$ ); an increment in BA (e.g. natural regeneration or plantation stand maturity or increase of crown closure) results in a concomitant increase in the TCA and conversely, when the BA diminishes (e.g. after a partial harvest or thinning operation, or after a disturbance such as a fire), the TCA value decreases (figure 3 ). The eleven TCA layers were combined in a single image, noted hereafter as the TCA image. 


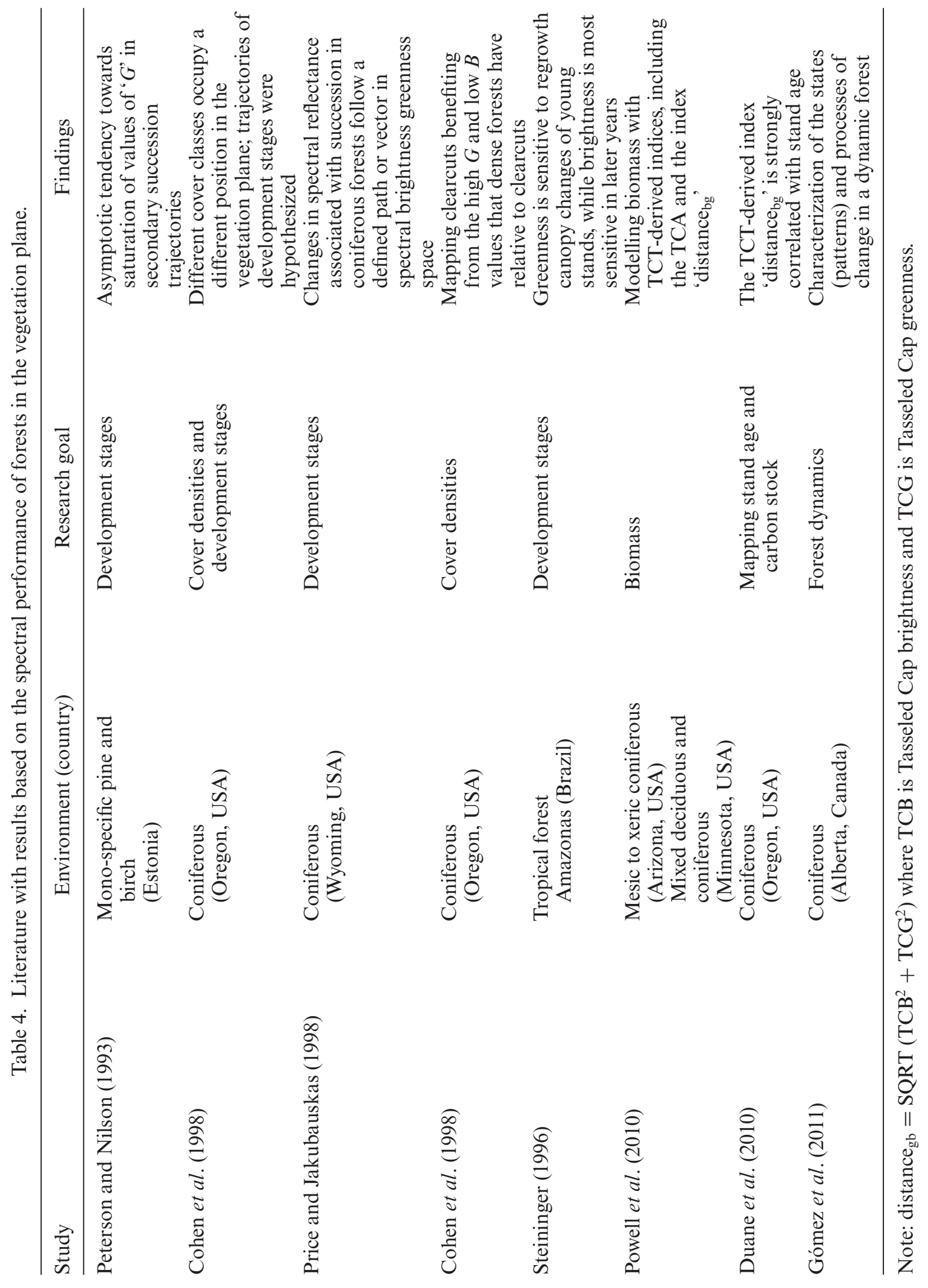




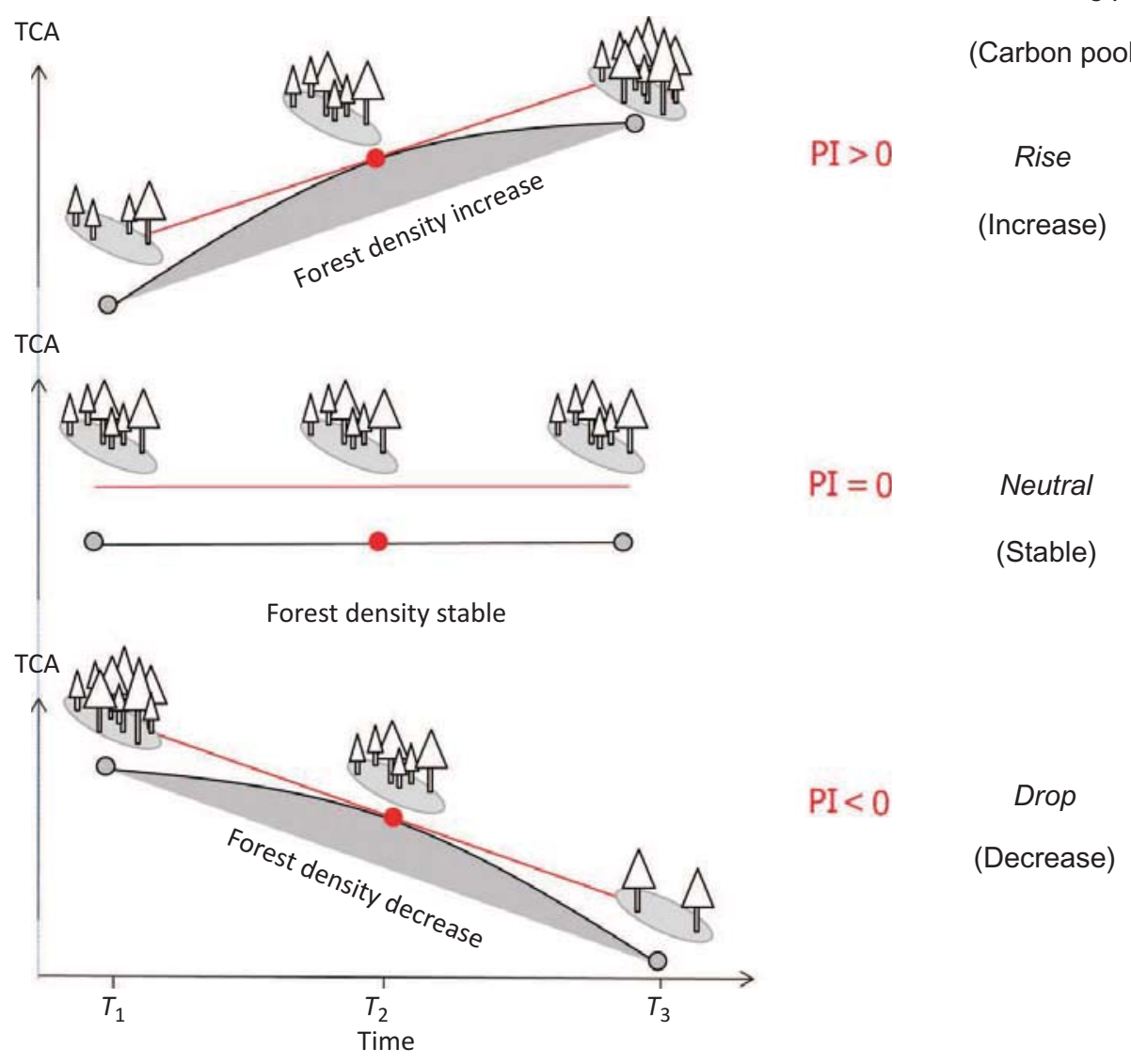

Figure 3. Process Indicator (PI) and carbon stocking processes.

\subsection{The Process Indicator}

Each pixel TCA profile was approximated with a Lagrange second-order polynomial (which enables interpolation with uneven intervals among occurrences), and its derivative with respect to time (years) was calculated. The result is a multiband spectral image with the same number of bands as the original TCA image, which we define as the Process Indicator (PI) image (Gómez et al. 2011). The PI image illustrates at each pixel the rate of TCA change over time. As the TCA provides information about the relative forest density at each date, the PI similarly gives information on the rate of change in forest density at each time. For example, a high positive value of PI indicates a relatively fast rise of TCA (e.g. a stand rapidly augments density by rapid growth or quickly develops towards crown closure); a high negative value of PI indicates a relatively fast drop of TCA value (and stand density) (e.g. after a stand-replacing disturbance or a strong thinning). Moderate values of PI refer to slow and slight changes in TCA value, such as a lowered density after a partial harvest (negative PI) or increasing density with slow natural growth or development (positive PI). Relative changes in carbon pools associated with changes in forest density can be similarly assessed (figure 3). PI values are direct indicators of processes of change and constitute a practical tool to monitor temporal relative changes; for an estimation of absolute values of change, a thorough calibration of the index would be required. 


\subsection{Classification of pine-dominated areas and change over time}

To identify pine-dominated areas and assess changes in extent and distribution over the period 1984-2009, we implemented a methodology supported by a supervised classification based on objects. Four images that divide the period into three epochs of approximately similar duration (i.e. 1984-1990, 1990-2000 and 2000-2009) were independently classified. Input data for classification were normalized bands 3, 4 and 5 of the Landsat image, and the TCA layer, which incorporates information on vegetation density. Each of the four images was individually segmented into three hierarchical levels (scale parameter 1, 2 and 5; colour-shape 0.9-0.1; smoothness 0.5) with Definiens Cognition Network Technology ${ }^{\circledR}$ (Baatz and Schäpe 2000, Definiens 2005). Only one class (pine) was to be retained but we considered a seven class scheme to reduce the error in change detection (Fuller et al. 2003). The image dated 2000 was classified first and its accuracy assessed with reference data from the MFE (Mapa Forestal Español) and NFI. The nearest neighbour classification algorithm used in classifying the other three images was trained with the spectral signatures of samples acquired for the reference classification (i.e. year 2000 image); in so doing, the robustness of the radiometric normalization assured comparable results. Objects classified as pine in any of the three hierarchical levels (scale 1,2 and 5) were merged and the resulting areas at each date (i.e. 1984, 1990, 2000 and 2009) were compared in a GIS for an assessment of change.

\subsection{Assessment of carbon stocks}

We defined the maximum potential pine area (MPPA) for the period 1984-2009 as the overall union of pine areas at any of the four dates considered. The MPPA represents the maximum extent occupied by pines at any time during this period, and it encompasses a region persistently occupied by pines (permanent) and other areas that have only been intermittently covered with pines during the last 25 years (intermittent) (figure 4).

Segmenting the landscape into homogeneous spatial units facilitates visualization and analysis of its properties. There is no unique way of partitioning the landscape for ecological analysis (Burnett and Blaschke 2003) and no single spatial scale is optimal
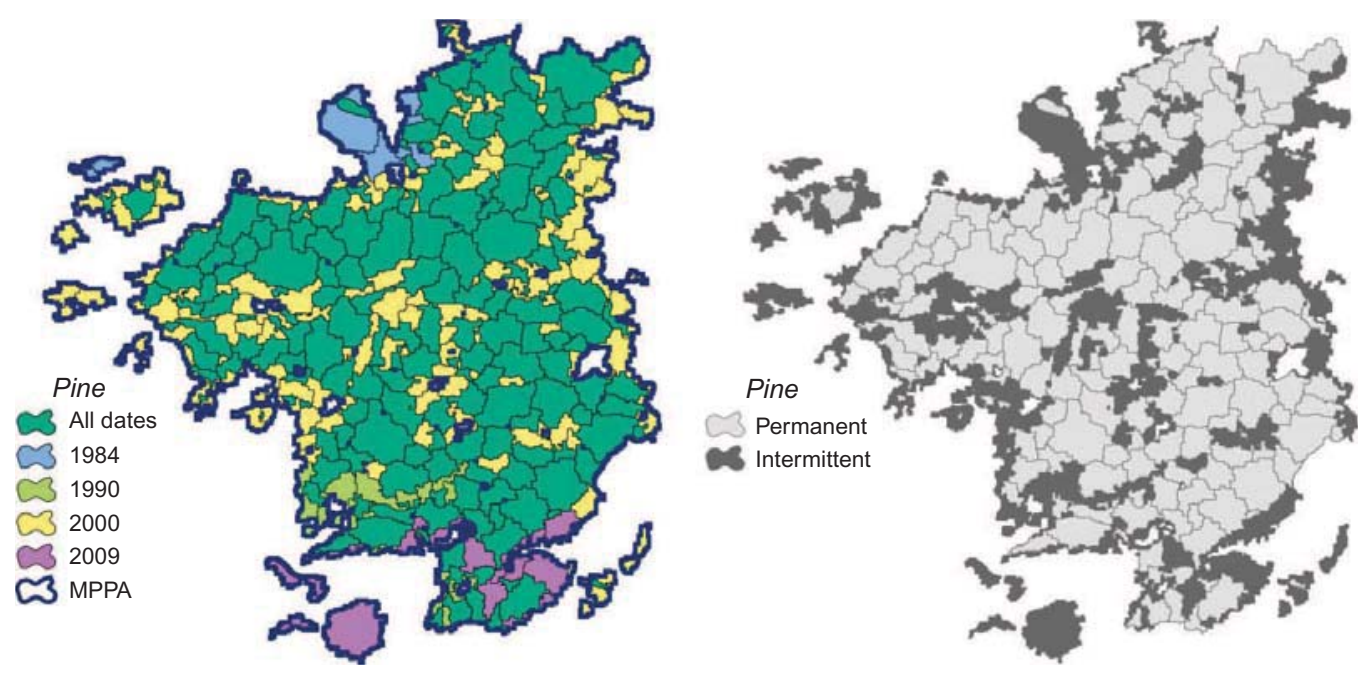

Figure 4. Schematic definition of the MPPA, permanent and intermittent areas. 
for characterizing the multiple options into which it can be divided (Hay et al. 2005). We chose the TCA 2000 image, completely free of clouds, for delineation of reference units for analysis (also in keeping with the classification reference image used). The parameters applied for definition of spatial units with homogeneous forest density at this date (year 2000) were scale 10, colour 0.9 and smoothness 0.5 . Internal variation of the TCA (and forest density) in these segments is lower than the difference with their neighbours (Definiens 2005). Objects affected by small cloudy patches or cloud shadows in any of the images were excluded from analysis.

Relative rates of change of the TCA (surrogate of forest stand density) and concomitant relative rates of change of carbon stock associated with each segment were examined with its Process Indicator value at each date. Trends and rates of change of carbon stocks were analysed and statistically assessed.

\section{Results}

\subsection{Change in area and distribution}

The applied method enabled the assessment of the area and distribution of pines in the Central Range and also the description of changes that occurred over the 25 year period from 1984 to 2009 with spatially explicit detail. For an exhaustive account of changes in the area occupied by pines in each sub-period (i.e. 1984-1990, 1990-2000 and 2000-2009), the following concepts are used.

- Stable: area classified as pine on the initial and final date of the analysis period.

- Increment: area classified as pine on the final date but was a different land-cover class on the initial date of the analysis period.

- Reduction: area classified as pine on the initial date and not on the final date of the analysis period.

- Net change: Increment - Reduction $(>0$ or $<0)$.

- Changed: Increment + Reduction. Area subject to change.

- Potential area: Stable + Changed. Area occupied by pine on initial and/or final date of the analysis period.

From the initial date (1984) to the final date (2009) there has been a $40 \%$ increment in the area dominated by pine species, a result confirmed by the NFI updates (NFI2 and NFI3) (González-Alonso et al. 2006) and mainly attributed to agricultural land abandonment. During the first sub-period (1984-1990), there was abundant transformation: an extent equivalent to $57 \%$ of the original pine area changed, producing a net increment similar to $36 \%$ of the original extent. In the second sub-period (1990-2000) the amount of area changed was less notable, equivalent to $33 \%$ of the extent of pine on the initial date (1990) and with a net loss of $17 \%$ of the pinedominated area. This decade maintained the most extensive stable area of the three sub-periods. In the course of the last sub-period (2000-2009) the Increment was 3.6 times the Reduction of the pine area, resulting in a net change equivalent to $25 \%$ of the area occupied by pines in 2000. All results are summarized in table 5 and mapped in figure 5.

Pines cover a discontinuous area in the Central Range, frequently broken up by topographic features and human activities such as agriculture or urban development. Three regions or units can be distinguished in the study area: a central region of almost continuous and permanent pine coverage (B in figure 5); a southern relatively large region with discontinuous spatial and temporal pine coverage (A in figure 5); and a 
Table 5. Pine area and changes during three sub-periods.

\begin{tabular}{|c|c|c|c|c|c|c|c|c|}
\hline Year & $\begin{array}{c}\text { Pine } \\
\text { area (ha) }\end{array}$ & Period & $\begin{array}{c}\text { Increment } \\
*(\% \text { of } \\
\text { initial })\end{array}$ & $\begin{array}{l}\text { Reduction } \\
*(\% \text { of } \\
\text { initial })\end{array}$ & $\begin{array}{c}\text { Net } \\
\text { change } \\
*(\% \text { of } \\
\text { initial })\end{array}$ & $\begin{array}{l}\text { Changed } \\
*(\% \text { of } \\
\text { initial })\end{array}$ & $\begin{array}{l}\text { Potential } \\
*(\% \text { of } \\
\text { initial })\end{array}$ & $\begin{array}{l}\text { Stable } \\
*(\% \text { of } \\
\text { initial })\end{array}$ \\
\hline 1984 & 121144 & 1984-1990 & $\begin{array}{l}56496 \\
(46.6)\end{array}$ & $\begin{array}{l}12858 \\
(10.6)\end{array}$ & $\begin{array}{c}43638 \\
(36.0)\end{array}$ & $\begin{array}{l}69354 \\
(57.2)\end{array}$ & $\begin{array}{l}177365 \\
(146.4)\end{array}$ & $\begin{array}{c}108011 \\
(89.2)\end{array}$ \\
\hline 1990 & 164622 & 1990-2000 & $\begin{array}{c}12502 \\
(7.6)\end{array}$ & $\begin{array}{l}41306 \\
(25.1)\end{array}$ & $\begin{array}{l}-28804 \\
(-17.5)\end{array}$ & $\begin{array}{l}53808 \\
(32.7)\end{array}$ & $\begin{array}{l}177023 \\
(107.5)\end{array}$ & $\begin{array}{c}123215 \\
(74.8)\end{array}$ \\
\hline 2000 & 135980 & 2000-2009 & $\begin{array}{l}47149 \\
(34.7)\end{array}$ & $\begin{array}{c}13001 \\
(9.6)\end{array}$ & $\begin{array}{l}34148 \\
(25.1)\end{array}$ & $\begin{array}{l}60150 \\
(44.2)\end{array}$ & $\begin{array}{c}182757 \\
(134.4)\end{array}$ & $\begin{array}{c}122607 \\
(90.2)\end{array}$ \\
\hline 2009 & 169825 & & & & & & & \\
\hline \multirow{2}{*}{\multicolumn{8}{|c|}{$\begin{array}{l}\text { Overall total stable } \\
\text { Overall total potential }\end{array}$}} & $\begin{array}{r}91349 \\
197144\end{array}$ \\
\hline & & & & & & & & 197144 \\
\hline
\end{tabular}

Note: *Equivalent to the area on initial date of the sub-period.

smaller region ( $\mathrm{C}$ in figure 5 ) with a high proportion of permanent pine coverage. As a general rule, changes in the distribution of pines have occurred at the boundaries of permanently covered areas in all three regions (figure 5). Increments in the pine area, probably motivated by natural colonization or by plantation of agriculture abandoned lands were common in the three regions during the period 1984-1990, mostly located in region C during the intermediate period (1990-2000) and particularly frequent in region A during the period 2000-2009. On the other side, reductions of the pine area were more frequent in region $\mathrm{C}$ during the initial period, distributed across regions $\mathrm{A}$ and $\mathrm{B}$ during the intermediate stage and similarly distributed across regions $\mathrm{A}$ and C in the last period (2000-2009). Clear cutting is a forestry technique in disuse in the Central Range and all wood extractions are now of low intensity; however, a few stand-replacing disturbances due to fire have been identified.

\subsection{Classification accuracy assessment}

A thematic accuracy assessment aims to provide information on the validity of the results and it can only be as good as the reference data used (Foody 2009). We assessed the accuracy of the pine class in the year 2000, for which field data were available. Our confidence that other classifications have similar validity is based on the robustness of the radiometric calibration and normalization applied and the transference of spectral signatures. The process of accuracy assessment was specifically designed for this application; it includes the steps described by Congalton and Plourde (2001) and provides information of the classification reliability.

After visual inspection and approval of the map, field plot data of the NFI3 (dated 2000) were referenced for specific analysis of the omission error incurred, i.e. pine areas on the ground that our image classification did not capture. Ninety-two per cent of the pine-dominated NFI3 plots (730 plots) fell inside pine classified segments; some of the remaining NFI3 pine-dominated plots had very low coverage fraction (below 20\%), a criterion for exclusion from our pine class. Consequently, seventeen plots $(2 \%$ in number) were in error by omission. To assess the magnitude of the commission error (i.e. areas classified as pine that were not considered as such by the reference data), a surface approach was implemented. Because assessing the accuracy of objects with 



Period 1990-2000
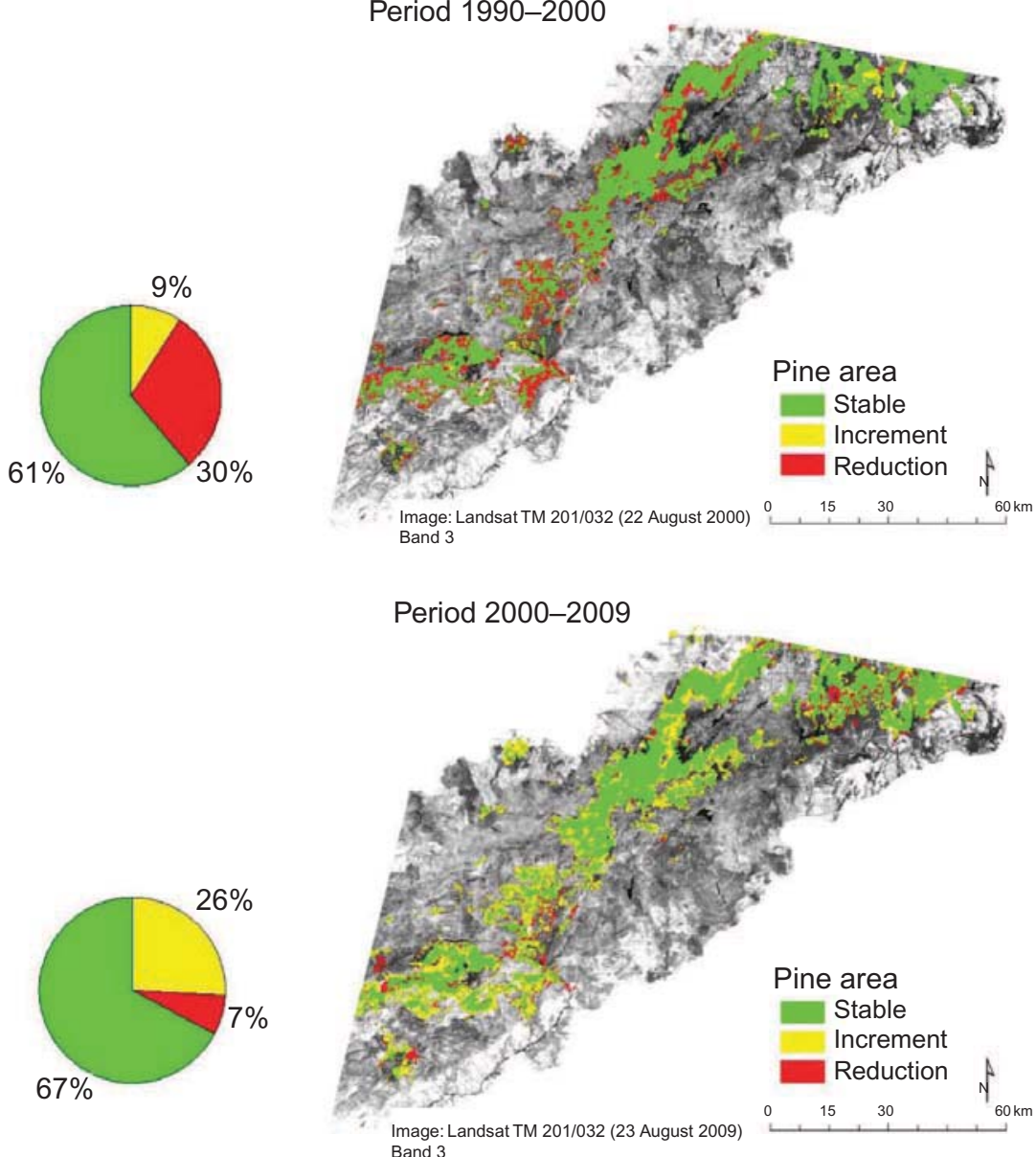

Figure 5. Maps of stable and changed area in the three periods (1984-1990, 1990-2000 and 2000-2009). Green is the area that remains as pine during the period, red shows the reduced pine area and yellow shows the increased pine area. The study area (top left inset) is divided in three sections (A, B and C) to facilitate the description of change over the three periods of interest. 
punctual field measures is especially difficult in a non-homogeneous landscape, we used the MFE for assessment of the commission error. When a level 5 pine segment was outside an MFE pine polygon, it was deemed erroneous: this occurred in 181 cases (an area representing $1.8 \%$ of the total classified pine area). The MFE had been derived using generalization criteria that make it not sufficiently adequate for assessment of our lower levels of segmentation and classification.

\subsection{Trends in landscape carbon stocking}

After segmenting the MPPA and vetting cloud and cloud shade-affected segments, 5042 objects remained for analysis, representing the extent and percentages shown in table 6.

Change in carbon stock was evaluated over the MPPA. The global average PI indicates the average performance of these forests as carbon pools; studying how the average PI changes over time permits inference of carbon stock trends. A low average PI during the 25 year period, in the range -15 to 15 , reveals the overall carbon neutral quality of these pine forests: on average the rate of change of carbon stocks is slow. The highest PI average occurred in 2000 (average PI 12.91) and the lowest PI average in 2002 (average PI -11.91, figure 6(a)). Prior to 1990 the mean PI is relatively low and remains steady; from 1991 to 2000 the PI tended to increase, but our scarcity of data during this time period precludes detailed description. In the last decade there is a tendency towards lower PI averages, with transitional fluctuations (figure $6(a)$ ); in this time period higher values of the PI standard deviation denote the increasing complexity of landscape carbon pools.

It is worth emphasizing that the PI is an indicator of processes and not of states; it does not enable estimation of absolute carbon stocks, but indicates relative rates of

Table 6. Characteristics of the maximum potential pine area (MPPA) segments after vetting and removing cloud affected objects.

\begin{tabular}{lcccc}
\hline & No. of objects & Area (ha) & Average size (ha) & Area percentage (\%) \\
\hline Permanent & 1981 & 76545 & 38.6 & 44.7 \\
Intermittent & 3061 & 94570 & 30.9 & 55.3 \\
Potential & 5042 & 171116 & 33.9 & 100.0 \\
\hline
\end{tabular}
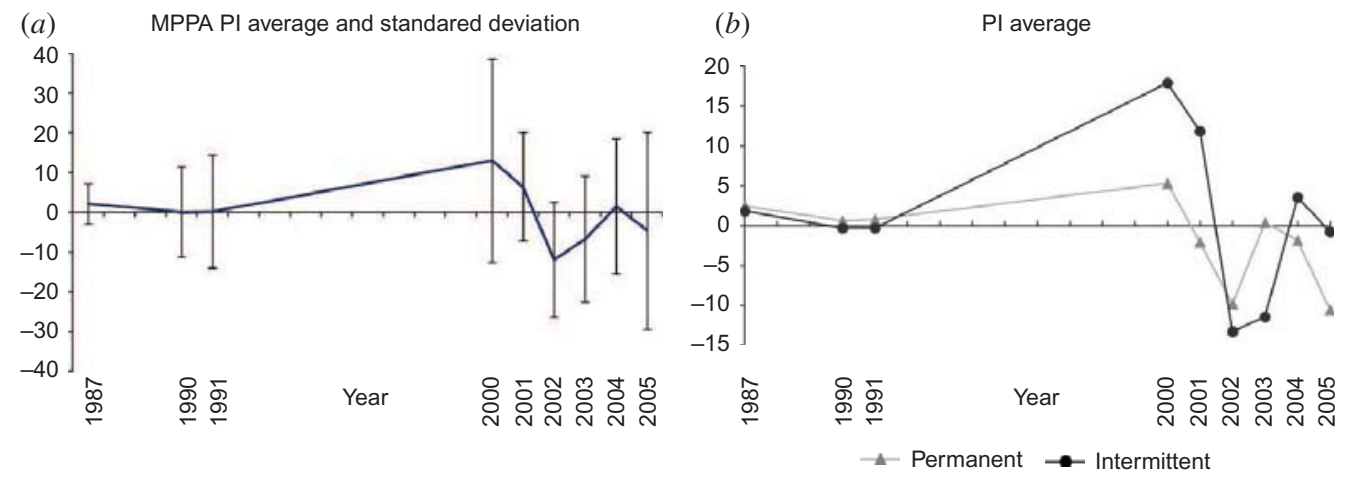

Figure 6. Average PI values during the period 1984-2009. (a) Average and standard deviation (shown by the error bars) in the MPPA; $(b)$ average values for the permanent and intermittent areas. 
change in carbon stocks: a positive PI value indicates that the forest is in a process of augmenting its carbon storage (e.g. density increment by natural growth); a negative PI value indicates that the forest is in a process of reducing its carbon storage (e.g. diminution of density in a thinning operation).

Changes over time of the PI average follow a similar trend in areas of permanent and intermittent pine coverage (figure 6(b)). Maximum and minimum PI values are coincident in time: year 2000 is the maximum PI - i.e. the maximum average rate of positive change (fast rise of carbon stocks); year 2002 is the minimum PI - i.e. the minimum average rate of negative change (fast drop of carbon stocks). However, fluctuations of the PI average are notably more accentuated in the intermittent area. The PI standard deviations and range of values are lower in permanent than in intermittent areas (table 7), corroborating the more stable character of the persistent pines.

\subsection{Assessment of carbon pooling areas}

Assessment of the trends of change in carbon stocks was feasible by exploring densityhomogeneous landscape units. The PI values of homogeneous elements defined in 2000 with the TCA (forest density proxy) are normally distributed, with a mean value very close to zero on all dates (figure 7) and standard deviation around 40 (table 7). As expected, the distribution is narrow on initial dates, with a low variance of PI; the variance increases steadily before 1991 and more notably later. The global stability of the landscape carbon stocks decreases progressively (figure 7) during the period of analysis: areas with relatively steady carbon stocks (i.e. not modifying forest density) at initial dates develop towards higher carbon stocks (e.g. density increment) or lower (e.g. density drop) carbon stocks.

To facilitate interpretation of these results and to produce more detailed information on the spatial distribution of carbon pooling changes over time, we established five categories of PI values, based on the statistical distribution present (figure 7, table 8). The carbon stock of objects in the neutral group is not in a process of change; the slow drop and slow rise groups are in a slow process of changing their carbon stock towards lower or higher levels, respectively, and the fast rise and fast drop groups are in a relatively rapid process of changing their carbon stock towards higher or lower levels, respectively. The scene-specific character of the PI values produces results relative to the area; comparison with results in other areas would require a thorough calibration of values.

All segments were classified at each date in one of these five categories (table 8); the number of objects and the area in each of the carbon pooling groups at each date was assessed. On average there was $64 \%$ of the area in a neutral carbon pooling process over the entire period (figure 8(a), table 9 ). The maximum area in this process group

Table 7. Statistics of the overall PI values (all dates considered).

\begin{tabular}{lccc}
\hline & Potential & Permanent & Intermittent \\
\hline Mean & 1.065 & 1.018 & 1.096 \\
Standard deviation & 40.920 & 37.596 & 42.935 \\
Kurtosis & 15.912 & 9.533 & 17.938 \\
Skewness & -0.09700 & 0.29412 & -0.26743 \\
Minimum & -794.60 & -495.49 & -794.60 \\
Maximum & 784.77 & 473.84 & 784.77 \\
\hline
\end{tabular}




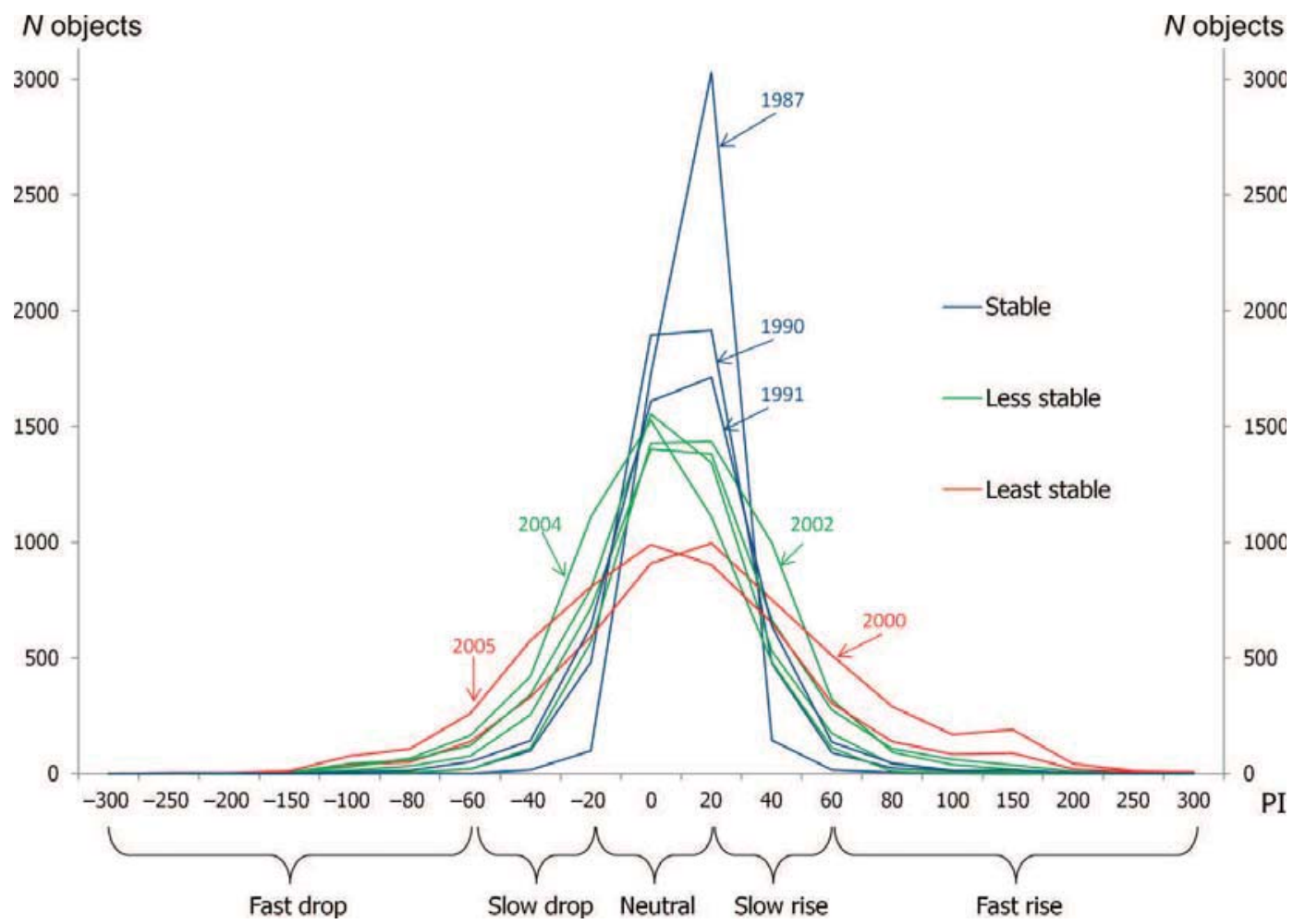

Figure 7. Distribution of MPPA 2000 objects' PI values at different dates.

Table 8. Classification of PI values in carbon stocking classes. Groups are defined based on statistical distribution criteria.

\begin{tabular}{lcc}
\hline PI & $\begin{array}{c}\text { Carbon stocking } \\
\text { process }\end{array}$ & Simplified class \\
\hline$<-60$ & Fast drop & Drop \\
-60 to -20 & Slow drop & Neutral \\
-20 to 20 & Stable & Rise \\
$20-60$ & Slow rise & \\
$>60$ & Fast rise & \\
\hline
\end{tabular}

occurred in 1987 (96\% of total area) and the minimum in 2005 (40\% of total area). The neutral area followed a consistent lowering trend over time (figure $8(b)$ ). On average, only $2 \%$ of the potential area was in fast rise and a similar $2 \%$ of the area was in fast drop carbon stocking processes during the period (table 9). Slow rise and slow drop carbon stocking processes represent equivalent areas along this period, with an overall average of $17 \%$ and $15 \%$, respectively (table 9 ).

Because the fast rise and fast drop categories made up very small proportions, we considered a more simplified classification in further description: rise, neutral and drop are the three categories considered (table 8). Neutral is the area maintaining the carbon stock without significant change, and as mentioned before, it was diminishing over time to balance an increasing activation of carbon pools (figure 8(b)): larger areas were progressively entering processes of rising or dropping carbon stock. 
Mediterranean pine dynamics of Central Spain
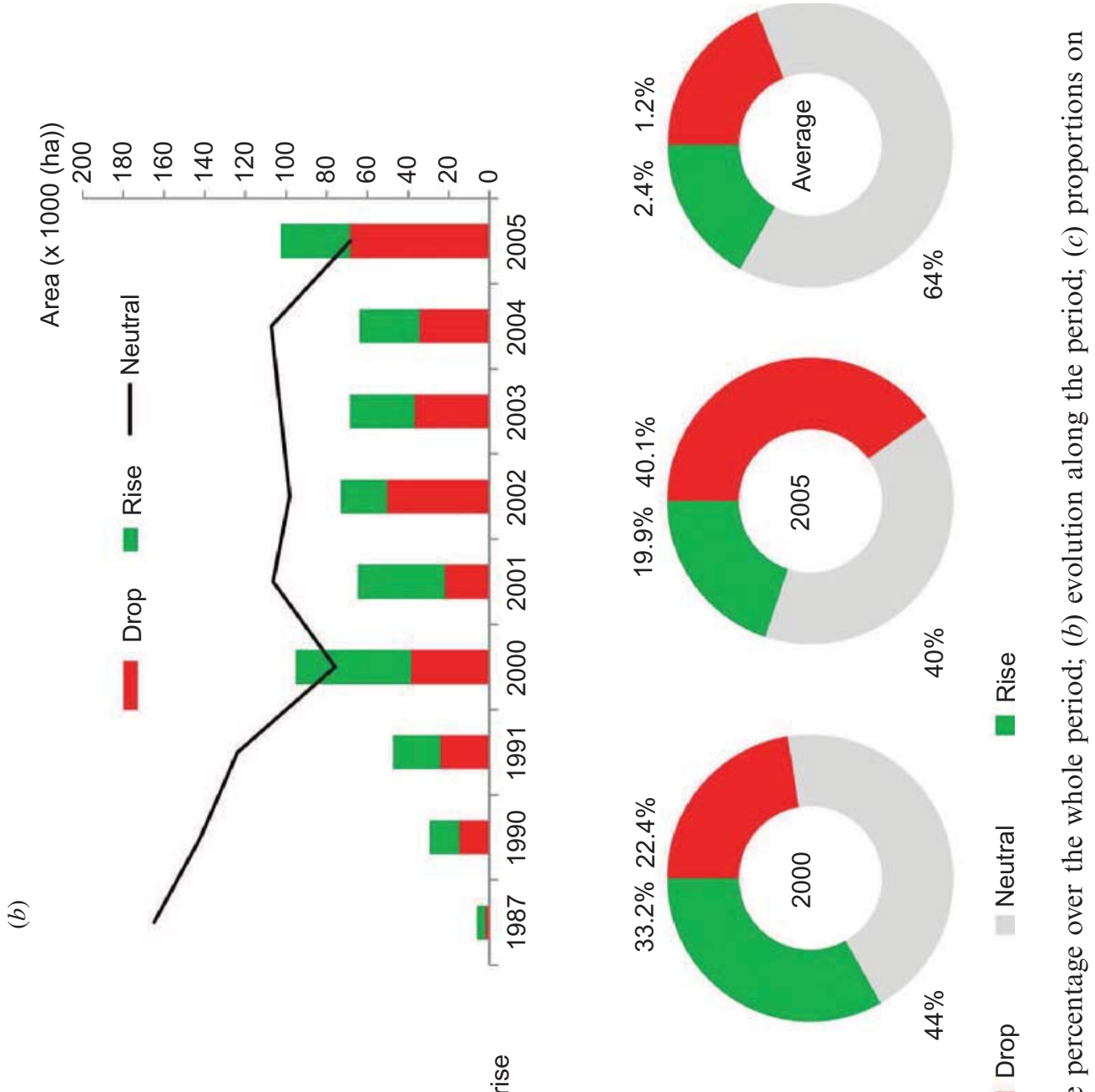

을

필

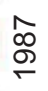

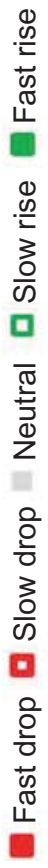

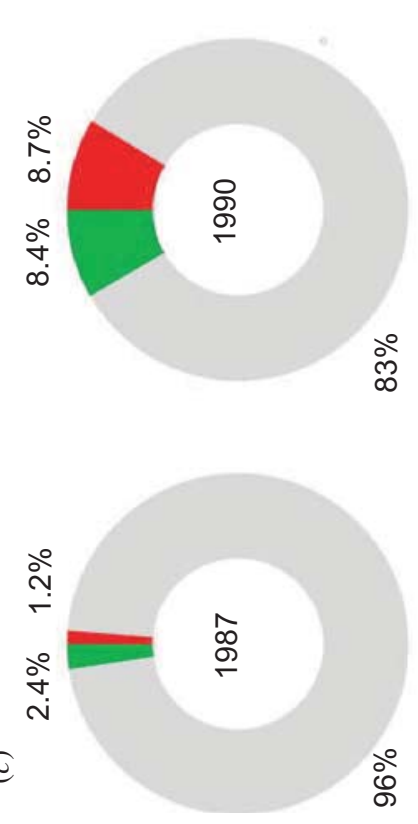

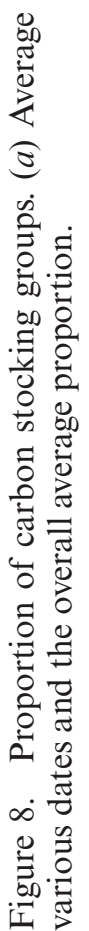


Table 9. Area proportion (\%) of carbon stocking groups.

\begin{tabular}{lrrrrrrrrrr}
\hline Process & 1987 & 1990 & 1991 & 2000 & 2001 & 2002 & 2003 & 2004 & 2005 & Average \\
\hline Fast rise & 0.06 & 0.21 & 0.50 & 9.11 & 1.62 & 0.29 & 0.50 & 2.13 & 4.04 & 2.05 \\
Slow rise & 2.31 & 8.19 & 12.96 & 24.05 & 23.44 & 12.84 & 18.00 & 15.10 & 15.87 & 14.75 \\
Rise & 2.37 & 8.40 & 13.47 & 33.16 & 25.06 & 13.13 & 18.50 & 17.23 & 19.91 & 16.80 \\
Neutral & 96.37 & 82.91 & 72.39 & 44.36 & 62.08 & 57.43 & 60.03 & 62.62 & 40.05 & 64.25 \\
Slow drop & 1.24 & 8.48 & 13.64 & 19.51 & 12.63 & 26.65 & 18.66 & 18.80 & 32.58 & 16.91 \\
Fast drop & 0.02 & 0.22 & 0.50 & 2.97 & 0.23 & 2.79 & 2.81 & 1.35 & 7.46 & 2.04 \\
Drop & 1.27 & 8.70 & 14.14 & 22.48 & 12.86 & 29.44 & 21.47 & 20.15 & 40.04 & 18.95 \\
Net active & 1.10 & -0.30 & -0.67 & 10.68 & 12.20 & -16.31 & -2.97 & -2.92 & -20.13 & -2.15 \\
$\quad$ (rise' & & & & & & & & & & \\
$\quad$ minus & & & & & & & & & & \\
$\quad$ 'drop') & & & & & & & & & & \\
\hline
\end{tabular}

Before 2000 , more than $70 \%$ of the MPPA area was neutral and after that it fluctuated between $40 \%$ and $64 \%$. The area in a process of rising carbon stock reached a minimum proportion in $1987(2 \%)$ and a maximum proportion in $2000(33 \%)$. The area in a process of dropping carbon stock reached a maximum proportion in 2005 $(40 \%)$ and a minimum in $1987(2 \%)$. The area fractions in different categories of carbon stocking process at various dates are shown in figure $8(c)$.

\subsection{Intermittent and permanent area carbon pooling}

In order to determine whether the area permanently covered with pine and the area only intermittently covered follow similar carbon pooling trends during the time studied, these areas were analysed separately. We found that the neutral area - stands in which carbon stock is not changing appreciably - follow a linear decreasing trend in both areas, although it was more pronounced in the intermittent area (figure $9(a)$ ). The permanent area has a more equitable distribution of areas in the process of rising and dropping carbon stocks, with distributions only out of the 30:70 range on two occasions (2003 and 2005, figure $9(b)$ ). The intermittent area shows a relatively equitable distribution of areas in the process of rising and dropping carbon stock, except in the initial years of the last decade, when distributions reached the 80:20 range.

Observing the enlargement of area ongoing processes of rising or dropping carbon stock, it is clear that a carbon pooling activation has occurred in the last 25 years. Designated as an active area in figure 10, the changing area shapes a trend complementary to neutral (figure 9(a)). Rising and dropping areas have been compensated for, driving the net area chrono-line very close to zero (figure 10). Contributions of the permanent and intermittent regions are shown.

\section{Discussion}

Variations in the area and distribution of pines occurred during the last 25 year period in the Central Range of Spain were assessed with a multilevel object-based classification of normalized images acquired at regular intervals. Further, the time series of Landsat images and two spectral indices derived from the TCT enabled description and analysis of changes in carbon stocking pools. The TCA is strongly correlated with 
(a)

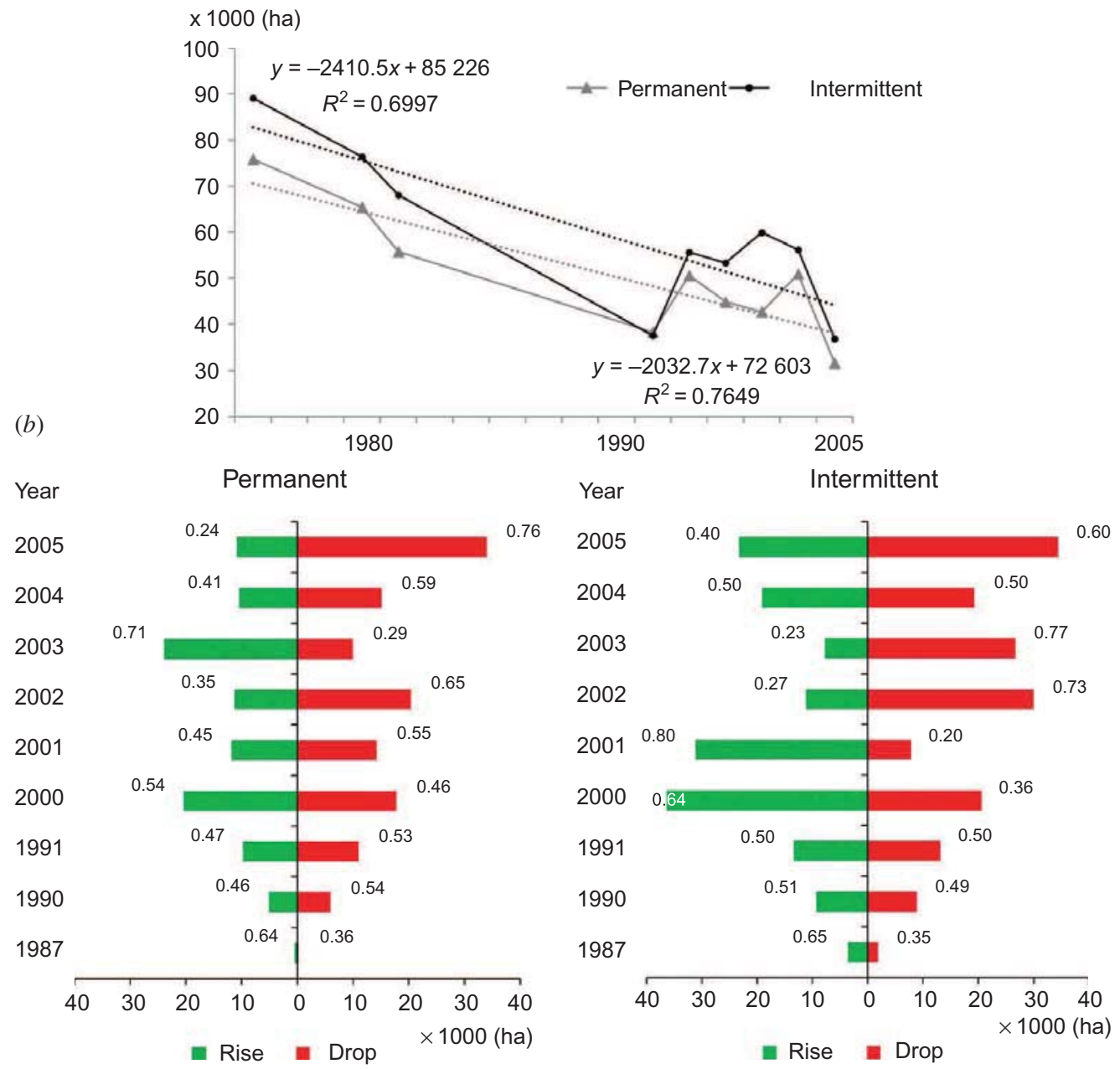

Figure 9. Evolution of carbon stocking areas. (a) The neutral carbon stocking area shows a clear tendency to diminish; $(b)$ rise and drop in permanent and intermittent areas. Percentage proportions of rise and drop are indicated next to the bars.

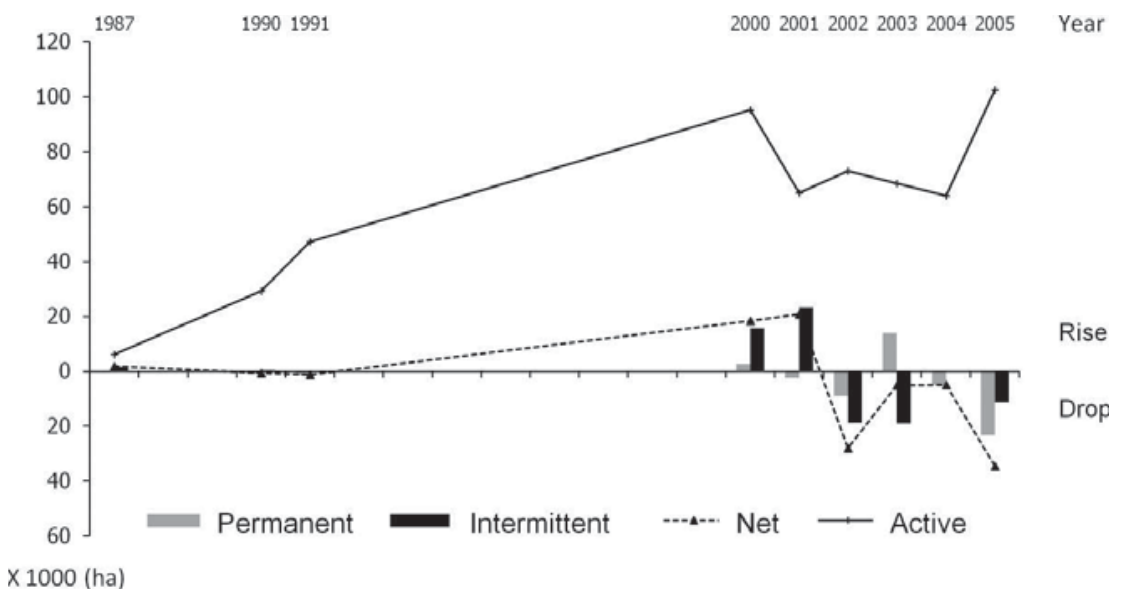

Figure 10. Carbon stocking net area. $($ net $=\operatorname{abs}(($ rise $)-($ drop $)))$. 
forest stand density in the study area, and its derivative, the PI, characterizes rates of changing processes. Results indicate that the pine-dominated area in the Central Range has increased by $40 \%$ from the initial to the final date; there is an area permanently covered with pines and a large extent only temporarily occupied during these decades. Carbon stocking pools have been activated in the second half of the analysis period, when larger areas show faster rates of rise and fall of carbon stocking.

Land use in the study area is governed by national and regional administrations, and land-use changes do not proliferate. Moreover, pines in the Central Range have been managed in a sustainable manner for several decades (Bravo et al. 2010), with extractions of light intensity and assurance of regeneration by natural methods or plantation; clear cutting is not a local forest management practice. We expected small variations of pine area during the 25 year period of analysis, except in sporadic fire disturbed areas. The approach applied for land-cover classification is based on objects with contextual information (Johansen et al. 2010) and includes the TCA among the input features to aid in sorting stand density. Thanks to the multilevel character of each date classification, simultaneous detection of larger stands with the required characteristics (species and density) and undersized objects in patchy areas was possible; this technique is of particular interest in distinguishing smaller changes in distribution that would otherwise blur into larger objects or be rejected as a speckle effect in a pixel-based classification.

Class signatures from samples in the reference image (date 2000) were used to classify other images (date 1984, 1990, 2009) assuring identical classification criteria. For assessment of classification accuracy, the independent reference information required (Congalton and Green 1999) was only available for one date; we relied on the exhaustive process of radiometric normalization and assumed similar accuracy in other classifications (accuracy $>90 \%$ ). One of the difficulties when comparing the Spanish NFI data for assessment of change is the declared disparity of base cartography used in each repetition (Vallejo 2005). With a historical series of good quality images available, retrospective studies of change become feasible and offer increased precision. In this work we classified images acquired at time intervals similar to NFI repetitions (10 years), and our results are in agreement with other studies based on field data comparison (i.e. indicating a trend of increment in forest area). The spatially detailed information provided and the capacity to readily incorporate data at intermediate dates for more detailed reports are some key strengths of methods based on remotely sensed data.

Obtaining reference independent information with sufficient temporal frequency for validation of change maps is complicated (Lu et al. 2004, Cohen et al. 2010). Visual validation of changes was possible in the eastern area (Madrid province) where online historical aerial photography is available (http://gestiona.madrid.org) at varying time steps. We could readily corroborate the spatial location of change events, but the exact time of occurrence was more complicated, especially when the time step of our series of images differed markedly from the reference data; subtle changes could only be visually compared. The decadal frequency of typical field data is insufficient for the validation of frequent change maps. Further, more work is needed in developing methods for the evaluation of historical change accuracy; some strategies incorporating high spatial resolution images are emerging, like the TimeSync tool from Cohen et al. (2010), which incorporates images from Google Earth. Although this is an invaluable source of data, Google Earth images are only available for a short historic period and its global coverage is not complete with a sufficiently dense frequency, making 
design-based methods (Thomas et al. 2011) the most feasible option for our situation in Central Spain.

The TCA index is relatively new, but the relation of greenness to brightness components of the TCT for characterizing forest density classes and successional stages has been used before in various forest environments. In our study area the TCA is strongly related to forest density; with three or more consecutive images the PI enables the characterization of relative rates of change in forest density and carbon stocks. TCA and its derivative, the PI, resulting from the TCT, are scene dependent (Crist and Cicone 1984). Possible artefacts induced by annual phenology dissimilarities are minimized by a rigorous process of normalization. We analysed trends in carbon stocking for the MPPA (area potentially covered by pine during the whole period) and assessed rates of change, comparing the area permanently covered with pines and the area intermittently covered. There is a trend towards activation of carbon pools, but the intermittent area shows a higher variability of processes and the area of permanent pine confers a more neutral carbon pooling character. We focused our analysis on change processes, but a combined interpretation of the TCA and its derivative, the PI, can provide a simultaneous view of forest density and change processes going on, thereby enabling some understanding of the elusive relationships between landscape patterns and processes - a recursive question of landscape ecology. Further work to calibrate the TCA values with quantitative density estimations is recommended to permit a simultaneous characterization of patterns and processes.

The PI continuous scale of values provides versatility in change detection capacity and enables the characterization of rapid (high PI values) and slow (low PI values) rates of change. With an adequate time interval between images, subtle changes in forest density can be detected; this is of particular interest in the Mediterranean area, where the majority of forests are subject to some drought and are relatively slow growing compared with other temperate areas (Merlo and Croitoru 2005). In managed forests, partial harvest or thinning operations might be detected (low negative PI value) and later recovery of density tracked (positive PI value). If the silvicultural goal is to maintain a constant value of BA, a time series of PI values would remain close to zero. Assessment of the absolute values of carbon sinks and sources remains an ongoing question (Houghton 2003) but historic trends of relative carbon stock changes can be assessed, and the effect of management practices monitored with detailed spatial information. A PI-based approach is especially informative for locations characterized by subtle, non-stand-replacing disturbances.

\section{Conclusions}

The availability of a long time series of Landsat images offers an opportunity for retrospective historical studies of forest change. Temporally dynamic models relating spectral properties and forest structural condition facilitates the evaluation of changing trends. A relatively new index derived from the TCT, the TCA has supported the assessment of change in the area and distribution of Mediterranean pines in Central Spain for a 25 year period. Although absolute values of carbon fluxes were not assessed, characterization of changing trends in relative carbon stock was assessed with the Process Indicator (PI), the TCA derivative, and further characterized by sub-periods of time, with subtle change detection also enabled and demonstrated. The spatial definition of sources and sinks as well as changing trends over time are 
a valuable contribution for the global issue of carbon budgeting reports and for evaluation of management strategies.

\section{Acknowledgements}

This work was done under the project, 'Estructura, dinámica y selvicultura para la conservación y el uso sostenible de los bosques en el Sistema Central' (VA-096A05), with funding from Consejería de Educación, Junta de Castilla y León, Plan Regional I+D + I. Field data were provided by Consejería de Medio Ambiente y Ordenación Territorial de Castilla y León.

\section{References}

Achard, F., Defries, R., Hansen, M., Mayaux, P. and Stibig, H.-J., 2007, Pantropical monitoring of deforestation, Environmental Research Letters, 2, 045022, doi:10.1088/1748-9326/2/4/045022.

BAAtz, M. and SCHÄPE, M., 2000, Multiresolution segmentation: an optimization approach for high quality multi-scale image segmentation. In Proceedings of the Angewandte Geographische Informationsverarbeitung XII Beiträge zum AGIT Symposium, J. Strobl, T. Blaschke and G. Griesebner (Eds.), Salzburg (Karlsruhe: Herbert Wichmann Verlag), pp. 12-23.

Bravo, F., Bravo-oviedo, A. and Diaz-Balteiro, L., 2008, Carbon sequestration in Spanish Mediterranean forests under two management alternatives: a modeling approach. European Journal of Forest Research, 127, pp. 225-234.

Bravo, F., Osorio, L.F., Pando, V. and Del Peso, C., 2010, Long-term implications of traditional forest regulation methods applied to Maritime pine (Pinus pinaster Ait.) forests in central Spain: a century of management plans. iForest, 3, pp. 33-38.

Brown, S., 2002, Measuring carbon in forests: current status and future challenges. Environmental Pollution, 116, pp. 363-372.

Burnett, C. and Blaschke, T., 2003, A multiscale segmentation object relationship modelling methodology for landscape analysis. Ecological Modelling, 168, pp. 233-249.

Calama, R. and Montero, G., 2007, Cone and seed production from stone pine (Pinus pinea L.) stands in Central Range (Spain). European Journal of Forest Research, 126, pp. 23-35.

Canty, M.J., Nielsen, A.A. and Schmidt, M., 2004, Automatic radiometric normalization of multitemporal satellite imagery. Remote Sensing of Environment, 91, pp. 441-451.

Chander, G., Markham, B.L. and Helder, D.H., 2009, Summary of current radiometric calibration coefficients for Landsat MSS, TM, ETM+, and EO-1 ALI sensors. Remote Sensing of Environment, 113, pp. 893-903.

ChÁvez, P.S., 1988, An improved dark object subtraction technique for atmospheric scattering correction of multispectral data. Remote Sensing of Environment, 24, pp. 459-479.

Cohen, W.B., Fiorella, M., Gray, J., Helmer, E. and Anderson, K., 1998, An efficient and accurate method for mapping forest clearcuts in the Pacific Northwest using Landsat imagery. Photogrammetric Engineering \& Remote Sensing, 64, pp. 293-300.

Cohen, W.B., Maiersperger, T.K., Spies, T.A. and Oetter, D.R., 2001, Modelling forest cover attributes as continuous variables in a regional context with thematic mapper data. International Journal of Remote Sensing, 22, pp. 2279-2310.

Cohen, W.B., Spies, T.A. and Fiorella, M., 1995, Estimating the age and structure of forests in a multi-ownership landscape of western Oregon, U.S.A. International Journal of Remote Sensing, 16, pp. 721-746.

Cohen, W.B., YAng, Z. and Kennedy, R., 2010, Detecting trends in forest disturbance and recovery using yearly Landsat time series: 2. TimeSync - Tools for calibration and validation. Remote Sensing of Environment, 114, pp. 2911-2924. 
Congalton, R.G. and Green, K., 1999, Assessing the Accuracy of Remotely Sensed Data: Principles and Practices, 137 p (Boca Raton, FL: Lewis Publishers).

Congalton, R.G. and Plourde, L.C., 2001, Sampling methodology, sample placement, and other important factors in assessing the accuracy of remotely sensed forest maps. International Journal of Wildlife Fire, 10, pp. 321-328.

Coppin, P., Jonckheere, I., Nackaerts, K. and Muys, B., 2004, Digital change detection methods in ecosystem monitoring: a review. International Journal of Remote Sensing, 25, pp. 1565-1596.

CRist, E.P., 1985, A TM Tasseled Cap equivalent transformation for reflectance factor data. Remote Sensing of Environment, 17, pp. 301-306.

CRist, E.P. and Cicone, R.C., 1984, A physically based transformation of Thematic Mapper data - the TM tasseled Cap. IEEE Transactions on Geoscience and Remote Sensing Vol $G E-, 22$, pp. 256-263.

Definiens, 2005, Definiens eCognition Version 5 Object Oriented Image Analysis User 5 Guide (Munich: Definiens, AG).

Duane, M.V., Cohen, W.B., Campbell, J.L., Hudiburg, T., Turner, D.P. and Weyermann, D.L., 2010, Implications of alternative field-sampling designs on landsat-based mapping of stand age and carbon stocks in oregon forests. Forest Science, 56, pp. 405-416.

European Forest Institute, Mediterranean Regional Office, 2009, A Mediterranean forest research agenda-MFRA 2010-2020.

FAO, 2010. Evaluación de los recursos forestales mundiales 2010, Informe Nacional: España. FRA 2010/196, 63 p.

Filella, I., Peñuelas, J., Llorens, L. and Estiarte, M., 2004, Reflectance assessment of seasonal and annual changes in biomass and $\mathrm{CO}_{2}$ uptake of a Mediterranean shrubland submitted to experimental warming and drought. Remote Sensing of Environment, 90, pp. 308-318.

Foody, G.M., 2009, The impact of imperfect ground reference data on the accuracy of land cover change estimation. International Journal of Remote Sensing, 30, pp. 3275-3281.

Fuller, R.M., Smith, G.M. and Devereux, B.J., 2003, The characterization and measurement of land cover change through remote sensing: problems in operational applications? International Journal of Applied Earth Observations and Geoinformation, 4, pp. 243-253.

Gillanders, S.N., Coops, N.C., Wulder, M.A., Gergel, S. and Nelson, T., 2008a, Multitemporal remote sensing of landscape dynamics and pattern change: describing natural and anthropogenic trends. Progress in Physical Geography, 32, pp. 503-528.

Gillanders, S.N., Coops, N.C., Wulder, M.A. and Goodwin, N.R., 2008b, Application of Landsat satellite imagery to monitor land-cover changes at the Athabasca Oil Sands, Alberta, Canada. The Canadian Geographer, 52, pp. 466-485.

Goetz, S.J., Fiske, G.J. and Bunn, A.G., 2006, Using satellite time-series data sets to analyze fire disturbance and forest recovery across Canada. Remote Sensing of Environment, 101, pp. 352-365.

Gómez, C., White, J.C. and Wulder, M.A., 2011, Characterizing the state and processes of change in a dynamic forest environment using hierarchical spatio-temporal segmentation. Remote Sensing of Environment, 115, pp. 1665-1679.

Gong, P. and XU, B., 2003, Remote sensing of forests over time: change types, methods, and opportunities. In Remote Sensing of Forest Environments: Concepts and Case Studies, M.A. Wulder and S.E. Franklin (Eds.), (Dordrecht/Boston/London: Kluwer Academic Publishers).

González-Alonso, F., Merino-De-Miguel, S., Roldán-Zamarron, A., GarcíaGigorro, S. and Cuevas, J.M., 2006, Forest biomass estimation through NDVI composites. The role of remote sensed data to assess Spanish forests as carbon sinks. International Journal of Remote Sensing, 27, pp. 5409-5415. 
Goodwin, N.R., Coops, N.C., Wulder, M.A., Gillanders, S., Schroeder, T.A. and Nelson, T., 2008, Estimation of insect infestation dynamics using a temporal sequence of Landsat data. Remote Sensing of Environment, 112, pp. 3680-3689.

Goward, S.N., Masek, J.G., Cohen, W.B., Moisen, G., Collatz, G.J., Healey, S., Houghton, R.A., Huang, C., Kennedy, R., Law, B., Powell, S., Turner, D. and Wulder, M.A., 2008, Forest disturbance and North American Carbon Flux. Earth Observation Systems, 89, pp. 105-108.

Hansen, M.J., Franklin, S.E., Woudsma, C. and Peterson, M., 2001, Forest structure classification in the North Columbia mountains using Landsat TM tasseled cap wetness component. Canadian Journal of Remote Sensing, 27, pp. 20-32.

Hay, G.J., Castilla, G., Wulder, M.A. and Ruiz, J.R., 2005, An automated object-based approach for the multiscale image segmentation of forest scenes. International Journal of Applied Earth Observation and Geoinformation, 7, pp. 339-359.

Hayes, D.J. and Cohen, W.B., 2007, Spatial, spectral and temporal patterns of tropical forest cover change as observed with multiple scales of optical satellite data. Remote Sensing of Environment, 106, pp. 1-16.

Healey, S.P., Cohen, W.B., Zhiqiang, Y. and Krankina, O.N., 2005, Comparison of tasseled cap-based landsat data structures for use in forest disturbance detection. Remote Sensing of Environment, 97, pp. 301-310.

Healey, S.P., Yang, Z., Cohen, W.B. and Pierce, D.J., 2006, Application of two regressionbased methods to estimate the effects of partial harvest on forest structure using Landsat data. Remote Sensing of Environment, 101, pp. 115-126.

Helmer, E.H., Brown, S. and Cohen, W.B., 2000, Mapping montane tropical successional stage and land use with multi-date Landsat imagery. International Journal of Remote Sensing, 21, pp. 2163-2183.

Homer, C., Huan, C.H., Yang, L., Wylie, B. and Coan, M., 2004, Development of a 2001 national land-cover database for the United States. Photogrammetric Engineering \& Remote Sensing, 70, pp. 829-884.

Houghton, R.A., 2003, Why are estimates of terrestrial carbon balance so different? Global Change Biology, 9, pp. 500-509.

Houghton, R.A., 2005, Aboveground forest biomass and the global Carbon balance. Global Change Biology, 11, pp. 945-958.

Houghton, R.A., 2007, Balancing the global carbon budget. Annual Review of Earth and Planetary Sciences, 35, pp. 313-347.

Huang, C., Goward, S.N., Schleeweis, K., Thomas, N., Masek, J.G. and Zhu, Z., 2009, Dynamics of national forests assessed using Landsat record: case studies in eastern United States. Remote Sensing of Environment, 113, pp. 1430-1442.

Huang, C., Wylie, B., Yang, L., Homer, C. and Zylstra, G., 2002, Derivation of a tasseled cap transformation based on Landsat 7 at-satellite reflectance. International Journal of Remote Sensing, 23, pp. 1741-1748.

Jin, S. and SAder, S.A., 2005, Comparison of time series tasseled cap wetness and the normalized difference moisture index in detecting forest disturbances. Remote Sensing of Environment, 94, pp. 364-372.

Johansen, K., Arroyo, L.A., Phinn, S. and Witte, C., 2010, Comparison of geo-object based and pixel-based change detection of riparian environments using high spatial resolution multi-spectral imagery. Photogrammetric Engineering \& Remote Sensing, 76, pp. 123-136.

Kauth, R.J. and Thomas, G.S., 1976, The tasseled cap - a graphic description of the spectraltemporal development of agricultural crops as seen in Landsat. In Proceedings of the Symposium on Machine Processing of Remotely Sensed Data, 29 June-1 July 1976, West Lafayette, IN (West Lafayette, IN: LARS, Purdue University), pp. 41-51.

Kennedy, R.E., Cohen, W.B. and Schroeder, T.A., 2007, Trajectory-based change detection for automated characterization of forest disturbance dynamics. Remote Sensing of Environment, 110, pp. 370-386. 
Kennedy, R.E., Yang, Z. and Cohen, W.B., 2010, Detecting trends in forest disturbance and recovery using yearly Landsat time series: 1. LandTrendr - temporal segmentation algorithms. Remote Sensing of Environment, 114, pp. 2897-2910.

Law, B.E., Ryan, M.G. and Anthoni, P.M., 1999, Seasonal and annual respiration in a ponderosa pine ecosystem. Global Change Biology, 5, pp. 169-182.

Lea, R., Blodgett, C., Diamond, D. and Schanta, M., 2004, Using the tasseled cap transformation to identify change in the Missouri Ozark Forests. In Proceedings of the ASPRS Fall Conference. Images to Decisions: Remote Sensing Foundations for GIS Applications, 12-16 September, Kansas City, Missouri (Bethesda, MD: American Society of Photogrammetry and Remote Sensing).

Le Quéré, C., Raupach, M.R., Canadell, J.G., Marland, G., Bopp, L., Ciais, P., Conway, T.J., Doney, S.C., Feely, R.A., Foster, P., Friedlingstein, P., Gurney, K., Houghton, R.A., House, J.I., Huntingford, C., Levy, P.E., Lomas, M.R., Majkut, J., Metzl, N., Ometto, J.P., Peters, G.P., Prentice, I.C., Randerson, J.T., Running, S.W., Sarmiento, J.L., Schuster, U., Sitch, S., Takahashi, T., Viovy, N., van Der Werf, G.R. and Woodward, F.I., 2009, Trends in the sources and sinks of carbon dioxide. Nature Geoscience, 2, pp. 831-836.

Lu, D., Mause, P., Brondizios, E. and Moran, E., 2004, Change detection techniques. International Journal of Remote Sensing, 25, pp. 2365-2407.

Lunetta, R., Johnson, D.M., Lyon, J. and Crotwell, J., 2004, Impacts of imagery temporal frequency on land-cover change detection monitoring. Remote Sensing of Environment, 89, pp. 444-454.

Maselli, F., 2004, Monitoring forest conditions in a protected Mediterranean coastal area by the analysis of multiyear NDVI data. Remote Sensing of Environment, 89, pp. 423-433.

Maselli, F., Gilabert, M.A. and Conese, C., 1998, Integration of high and low resolution NDVI Data for monitoring vegetation in mediterranean environments. Remote Sensing of Environment, 63, pp. 208-218.

Masera, O.R., Garza-Caligaris, J.F., Kanninen, M., Karjalainen, T., Liski, J., Nabuurs, G.J., Pussinen, A., De Jong, B.H.J. and Mohren, G.M.J., 2003, Modeling carbon sequestration in afforestation, agroforestry and forest management projects: the CO2FIX V.2 approach. Ecological Modelling, 164, pp. 177-199.

Merlo, M. and Croitoru, L., 2005, Valuing Mediterranean Forests - Towards Total Economic Value, 397 p. (Oxfordshire: CABI Publishing).

Minchella, A., Del Frate, F., Capogna, F., Anselmi, S. and Manes, F., 2009, Use of multitemporal SAR data for monitoring vegetation recovery of Mediterranean burned areas. Remote Sensing of Environment, 113, pp. 588-597.

MMA, 2008. Historia del Inventario Forestal Nacional de España. Available online at: http://www.marm.es/es/biodiversidad/temas/inventarios-nacionales/inventario-forestalnacional/index_historia_inventario_forestal_espana.aspx (accessed 13 February 2012).

Myers, N., Mittelmeier, R.A., Mittelmeier, C.G., Da Fonseca, G.A.B. and Kent, J., 2000, Biodiversity hotspots for conservation priorities. Nature, 403, pp. 853-858.

Myneni, R.B., Dong, J., Tucker, C.J., Kaufmann, R.K., Kauppi, P.E., Liski, J., Zhou, L., Alexeyev, V. and Hughes, M.K., 2001, A large carbon sink in the woody biomass of Northern Forests. Proceedings of the National Academy of Science, 98, pp. 14784-14789.

Nielsen, A.A., Conradsen, K. and Simpson, J.J., 1998, Multivariate Alteration Detection (MAD) and MAD postprocessing in multispectral, bitemporal image data: new approaches to change detection studies. Remote Sensing of Environment, 64, pp. 1-19.

Odum, E.P., 1969, The strategy of ecosystem development. Science, 164, pp. 262-270.

Olander, L., Gibbs, H.K., Steininger, M., Swenson, J.J. and Murray, B.C., 2008, Reference scenarios for deforestation and forest degradation in support of REDD: a review of data and methods. Environmental Research Letters, 3, 025011, doi:10.1088/1748-9326/3/2/025011. 
Olsson, H., 2009, A method for using Landsat time series for monitoring young plantations in boreal forests. International Journal of Remote Sensing, 19, pp. 5117-5131.

Peterson, U. and Nilson, T., 1993, Successional reflectance trajectories in northern temperate forests. International Journal of Remote Sensing, 14, pp. 609-613.

Potapov, P., Turubanova, S. and Hansen, M.C., 2011, Regional-scale boreal forest cover and change mapping using Landsat data composites for European Russia. Remote Sensing of Environment, 115, pp. 548-561.

Powell, S.L., Cohen, W.B., Healey, S.P., Kennedy, R.E., Moisen, G.G., Pierce, K.B. and Ohmann, J.L., 2010, Quantification of live aboveground biomass dynamics with Landsat time-series and field inventory data: a comparison of empirical modeling approaches. Remote Sensing of Environment, 114, pp. 1053-1068.

Price, K.P. and Jakubauskas, M.E., 1998, Spectral retrogression and insect damage in lodgepole pine successional forests. International Journal of Remote Sensing, 19, pp. $1627-1632$.

Rivas-Martínez, S., 1963, Estudio de la vegetación y flora de la Sierra de Guadarrama y Gredos. Anales del Instituto Botánico A.J. Cavanilles, 21, pp. 5-325.

Roder, A., Hill, J., Duguy, B., Alloza, J.A. and Vallejo, R., 2008, Using long time series of Landsat data to monitor fire events and post-fire dynamics and identify driving factors. A case study in the Ayora region (eastern Spain). Remote Sensing of Environment, 112, pp. 259-273.

Roder, A., Kuemmer le, T. and Hill, J., 2005, Extension of retrospective datasets using multiple sensors. An approach to radiometric intercalibration of Landsat TM and MSS data. Remote Sensing of Environment, 95, pp. 195-210.

Salvador, R. and Pons, X., 1998, On the applicability of Landsat TM images to Mediterranean forest inventories. Forest Ecology and Management, 104, pp. 193-208.

Schroeder, T.A., Cohen, W.B., Song, C., Canty, M.J. and Yang, Z., 2006, Radiometric correction of multi-temporal Landsat data for characterization of early successional forest patterns in western Oregon. Remote Sensing of Environment, 103, pp. 16-26.

Schulze, E.D., Wirth, C. and Heimann, M., 2000, Climate change: managing forests after Kyoto. Science, 22, pp. 2058-2059.

Song, C., Woodcock, C.E., Seto, K.C., Lenney, M.P. and Macomber, S.A., 2001, Classification and change detection using Landsat TM data: when and how to correct atmospheric effects? Remote Sensing of Environment, 75, pp. 230-244.

Sonnenschein, R., Kuemmerle, T., Udelhoven, T., Stellness, M. and Hostert, P., 2011, Differences in Landsat-based trend analyses in drylands due to the choice of vegetation estimate. Remote Sensing of Environment, 115, pp. 1408-1420.

Steininger, M.K., 1996, Tropical secondary forest regrowth in the Amazon: age, area and change estimation with Thematic Mapper data. International Journal of Remote Sensing, 17, pp. 9-27.

Thomas, N.E., Huang, C.H., Goward, S., Powell, S., Rishmawi, K., Schleeweis, K. and Hinds, A., 2011, Validation of North American Forest Disturbance dynamics derived from Landsat time series stacks. Remote Sensing of Environment, 115, pp. 19-32.

Tolomeo, R., Lawson, T., Lokey, G., Dunn, C., Stein, C. and Overton, J., 2009, The Landsat Program Is Not Meeting the Goals and Intent of the Land Remote Sensing Policy Act of 1992, Audit report. Report No. IG-09-021 (assignment no. A-08-019-00) (Washington, DC: NASA).

Townsend, P.A., Lookingbill, T.R., Kingdon, C.C. and Gardner, R.H., 2009, Spatial Pattern Analysis for Monitoring Protected Areas. Remote Sensing of Environment, 113, pp. 1410-1420.

VAllejo, R., 2005, El mapa forestal de España escala 1:50.000 (MFE50) como base del tercer inventario forestal nacional. Cuadernos De La Sociedad Española De Ciencias Forestales, 19, pp. 205-210. 
Verbesselt, J., Hyndman, R., Newnham, G. and Culvenor, D., 2010, Detecting trend and seasonal changes in satellite image time series. Remote Sensing of Environment, 114, pp. 106-115.

Vicente-Serrano, S.M., Perez-Cabello, F. and Lasanta, T., 2008, Assessment of radiometric correction techniques in analyzing vegetation variability and change using time series of Landsat images. Remote Sensing of Environment, 112, pp. 3916-3934.

Villa, G., Arozarena, A., Peces, J.J. and Domenech, E., 2009, Plan nacional de teledetección: estado actual y perspectivas futuras. In XIII Congreso de la Asociación Española de Teledetección. Teledetección: agua y desarrollo sostenible, 23-26 Septiembre, S.M. Aranda and L.F. Fornos (Eds.), Calatayud, Spain, pp. 521-524.

Villaescusa, R., Vallejo, R. and De La Cita, J., 2001, Actualización del Mapa Forestal de España. In III Congreso Nacional Forestal, 25-28 September, Granada, Spain (Granada: Junta de Andalucía), pp. 153-158.

Vogelmann, J.E. and Tolk, B., Zhu, Z., 2009, Monitoring forest changes in the Southwestern United States using multitemporal landsat data. Remote Sensing of Environment, 113, pp. 1739-1748.

White, J.C., Wulder, M.A., Gómez, C. and Stenhouse, G., (2011), A history of habitat dynamics: characterizing 35 years of stand replacing disturbance. Canadian Journal of Remote Sensing, 37, pp. 234-251.

Wilson, E.H. and SADER, S.A., 2002, Detection of forest harvest type using multiple dates of Landsat TM imagery. Remote Sensing of Environment, 80, pp. 385-396.

Woodcock, C.E., Allen, R., Anderson, M., Belward, A., Bindschadler, R., Cohen, W.B., Gao, F., Goward, S.N., Helder, D., Helmer, E., Nemani, R., Oreopoulos, L., Schott, J., Thenkabail, P.S., Vermote, E.F., Vogelmann, J., Wulder, M.A. and Wynne, R., 2008, Free access to Landsat imagery. Science, 320, pp. 1011.

Wulder, M.A. and Franklin, S.E., 2002, Spatial and spectral variability due to Landsat image acquisition date: the impact on image classification. In Proceedings of the International Geoscience and Remote Sensing Symposium (IGARSS) and 24th Canadian Remote Sensing Symposium, 24-28 June, Toronto (Piscataway, NJ: IEEE), pp. 13031306.

Wulder, M.A., Ortlepp, S.M., White, J.C. and Coops, N.C., 2008a, Impacts of sun-surfacesensor geometry upon multitemporal high spatial resolution satellite imagery. Canadian Journal of Remote Sensing, 34, pp. 455-461.

Wulder, M.A., White, J.C., Bentz, C., Alvarez, M.F. and Coops, N., 2006, Estimating the probability of mountain pine beetle red attack damage. Remote Sensing of Environment, 101, pp. 150-166.

Wulder, M.A., White, J.C., Goward, S.N., Masek, J.G., Irons, J.R., Herold, M., Cohen, W.B., Loveland, T.R. and Woodcock, C.E., 2008b, Landsat continuity: issues and opportunities for land cover monitoring. Remote Sensing of Environment, 112, pp. 955-969.

Wulder, M.A., White, J.C., Masek, J.G., Dwyer, J. and Roy, D.P., 2011, Continuity of Landsat observations: short term considerations. Remote Sensing of Environment, 115, pp. $747-751$. 


\section{CHAPTER III}

Cristina Gómez, Michael A. Wulder, Fernando Montes, José A. Delgado, 2012. Modeling

Forest Structural Parameters in the Mediterranean Pines of Central Spain using QuickBird-2 Imagery and Classification and Regression Tree Analysis (CART).

Remote Sensing, 4, 135-159. doi:10.3390/rs4010135

\section{RESUMEN}

\section{Modelización de parámetros estructurales en los pinares mediterráneos del Sistema Central español mediante imágenes QuickBird-2 y CART}

El diámetro cuadrático medio, el área basal y el número de pies por hectárea son parámetros descriptivos de la estructura forestal, relevantes en el cálculo de volúmenes maderables y en la estimación de biomasa, y son por tanto medidas clave en los inventarios forestales. La información que proporciona el inventario forestal es indispensable para llevar a cabo una gestión sostenible de las masas forestales, así como para el conteo de carbono acumulado y para el desarrollo de cualquier estrategia de planificación regional. El tratamiento de imágenes obtenidas mediante teledetección se utiliza cada vez más para complementar los métodos tradicionales de medida y estimación de la estructura forestal, especialmente sobre grandes extensiones, y para evaluar cambios a lo largo del tiempo. Con frecuencia se estima de manera empírica las características forestales mediante imágenes de teledetección, a pesar de ciertas limitaciones conocidas y que son especialmente notables en zonas complejas como los bosques mediterráneos. En este trabajo se investigó la capacidad de las imágenes de alta resolución espacial $(<5 \mathrm{~m})$ y algunas técnicas relacionadas para modelizar parámetros de estructura a escala de rodal $(n=490)$ en pinares mediterráneos del centro de España. Las imágenes utilizadas son multiespectrales y pancromáticas, de resolución espacial $2.4 \mathrm{~m} \mathrm{y}$ $0.68 \mathrm{~m}$, recogidas por el satélite comercial QuickBird-2. A partir de estas imágenes se extrajo información espectral (del visible e infrarrojo cercano) y espacial (textura de imagen) que se utilizó en la modelización. La técnica estadística elegida para desarrollar los modelos de los parámetros estructurales es Classification and Regression Tree Analysis (CART). El diámetro cuadrático medio se pudo modelizar con precisión $\left(\mathrm{R}^{2}=0.8\right.$; $\left.\mathrm{RMSE}=0.13 \mathrm{~m}\right)$ dando un error medio del $17 \%$ mientras que el error medio en los modelos de área basimétrica fue del 22\% (RMSE $=5.79 \mathrm{~m}^{2} \mathrm{ha}^{-1}$ ). En cuanto a la densidad, aplicando categorías como suele hacerse en la gestión forestal, los modelos CART clasificaron correctamente el $70 \%$ de los rodales, con el resto en una categoría adyacente. En la estimación de parámetros forestales mediante teledetección, se suele obtener mayor precisión en zonas de cobertura media y en el rango inferior que estos parámetros muestran 
en la zona de estudio. Esta circunstancia quedó aquí corroborada por la estructura de los residuos de los modelos. Los resultados demuestran la capacidad de algunas propiedades de las imágenes de alta resolución tomadas desde satélite para informar sobre la estructura local de los pinares mediterráneos. El Plan Nacional de Teledetección español (PNT) comenzó recientemente la recogida de coberturas anuales de alta resolución sobre todo el territorio nacional, ofreciendo una oportunidad única para la estimación de la estructura forestal. Gracias a la frecuencia de los datos pueden detectarse las pérdidas o incorporaciones de árboles y refinar la estimación de los parámetros estructurales. Además, las imágenes de alta resolución y los productos derivados pueden utilizarse para producir sinergias, sin necesidad de entrar en competencia, con métodos de inventario tradicionales para la provisión de datos durante los ciclos de inventario y para detectar posibles perturbaciones.

Palabras clave: estructura forestal; alta resolución espacial; segmentación de imágenes; CART; seguimiento forestal 


\title{
Modeling Forest Structural Parameters in the Mediterranean Pines of Central Spain using QuickBird-2 Imagery and Classification and Regression Tree Analysis (CART)
}

\author{
Cristina Gómez ${ }^{1, *}$, Michael A. Wulder ${ }^{2}$, Fernando Montes ${ }^{3}$ and José A. Delgado ${ }^{1}$ \\ 1 Sustainable Forest Management Research Institute, Universidad de Valladolid, E-34004 Palencia, \\ Spain; E-Mail: joseant@latuv.uva.es \\ 2 Pacific Forestry Centre, Canadian Forest Service, Natural Resources Canada, Victoria, \\ BC V8Z 1M5, Canada; E-Mail: mike.wulder@nrcan.gc.ca \\ 3 Departamento de Sistemas y Recursos Forestales, CIFOR-INIA, Ctra. de La Coruña km 7.5, \\ E-28040 Madrid, Spain; E-Mail: fmontes@inia.es \\ * Author to whom correspondence should be addressed; E-Mail: c.gomez@abdn.ac.uk; \\ Tel.: +1-281-712-5614.
}

Received: 25 October 2011; in revised form: 4 January 2012 / Accepted: 4 January 2012 / Published: 10 January 2012

\begin{abstract}
Forest structural parameters such as quadratic mean diameter, basal area, and number of trees per unit area are important for the assessment of wood volume and biomass and represent key forest inventory attributes. Forest inventory information is required to support sustainable management, carbon accounting, and policy development activities. Digital image processing of remotely sensed imagery is increasingly utilized to assist traditional, more manual, methods in the estimation of forest structural attributes over extensive areas, also enabling evaluation of change over time. Empirical attribute estimation with remotely sensed data is frequently employed, yet with known limitations, especially over complex environments such as Mediterranean forests. In this study, the capacity of high spatial resolution (HSR) imagery and related techniques to model structural parameters at the stand level $(\mathrm{n}=490)$ in Mediterranean pines in Central Spain is tested using data from the commercial satellite QuickBird-2. Spectral and spatial information derived from multispectral and panchromatic imagery $(2.4 \mathrm{~m}$ and $0.68 \mathrm{~m}$ sided pixels, respectively) served to model structural parameters. Classification and Regression Tree Analysis (CART) was selected for the modeling of attributes. Accurate models were produced of quadratic mean diameter $(\mathrm{QMD})\left(\mathrm{R}^{2}=0.8 ; \mathrm{RMSE}=0.13 \mathrm{~m}\right)$ with an average error of $17 \%$ while basal area $(\mathrm{BA})$ models produced an average error of $22 \%\left(\mathrm{RMSE}=5.79 \mathrm{~m}^{2} / \mathrm{ha}\right)$.
\end{abstract}


When the measured number of trees per unit area $(\mathrm{N})$ was categorized, as per frequent forest management practices, CART models correctly classified $70 \%$ of the stands, with all other stands classified in an adjacent class. The accuracy of the attributes estimated here is expected to be better when canopy cover is more open and attribute values are at the lower end of the range present, as related in the pattern of the residuals found in this study. Our findings indicate that attributes derived from HSR imagery captured from space-borne platforms have capacity to inform on local structural parameters of Mediterranean pines. The nascent program for annual national coverages of HSR imagery over Spain offers unique opportunities for forest structural attribute estimation; whereby, depletions can be readily captured and successive annual collections of data can support or enable refinement of attributes. Further, HSR imagery and associated attribute estimation techniques can be used in conjunction, not necessarily in competition to, more traditional forest inventory with synergies available through provision of data within an inventory cycle and the capture of forest disturbance or depletions.

Keywords: forest structure; high spatial resolution; image segmentation; CART; monitoring

\section{Introduction}

Sustainable management of Mediterranean pine forests requires detailed and up-to-date information regarding structural parameters [1]. Wood volume and biomass content in forest stands, calculated with structural indicators such as mean height and quadratic mean diameter, are basic data for administration of resources. Moreover, increasingly important and emerging environmental concerns related to habitat protection, carbon accounting, and biodiversity, make reliable knowledge of forest resources a requirement for national and international reporting [2].

In Spain, as in many other countries, accurate information of structural parameters is usually obtained via direct measurements by crews on the ground of systematically sampled field inventories, based upon a network of plots located on a regular grid [3] that is also subject to prior stratification. Field surveys are often costly and typically not spatially exhaustive. Field surveys are also often collected over a given re-measurement period, which can preclude adequate updating of information for periodic reports, and are of questionable validity over dynamic or non-merchantable forests. Despite these concerns, ground based inventories provide reliable and detailed information for development of models such as yield tables per species and given location. It is the difficulties in portraying these plot based measures spatially that for many applications limit the utility of this information to address more broad forest monitoring and reporting objectives [4], especially in heterogeneous forests.

Satellite imagery has been shown to support forest inventories of extensive areas by providing timely observation, increasing the accuracy of area estimates, producing wall-to-wall thematic maps, and providing inventory estimates with acceptable bias and precision [5]. The spatially detailed information provided by high spatial resolution (HSR) imagery makes it an appropriate data source to 
aid in accurate estimation of structural parameters, and following suitable methods facilitates the characterization of subtle changes in forest structure through time [6].

The goal of this research is to explore the potential of HSR imagery to characterize forest structure in Mediterranean pines in the Central Range of Spain. Motivated by this purpose we examine the capacity of QuickBird-2 imagery to model the quadratic mean diameter, basal area, and number of trees per unit area at the stand level (as direct estimators of volume and biomass). Our specific objectives are:

- To model the relation between structural parameters (quadratic mean diameter, basal area, and number of stems per hectare) measured via field sampling and a set of spectral and spatial variables derived from HSR multispectral and panchromatic imagery.

- To test and verify the ability of Classification and Regression Trees (CART) as the statistical technique for modeling structural parameters.

- To identify the image derived variables with the greatest informative capacity in the modeling of structural parameters, assessing in particular the inclusion of image textural metrics in the models.

\section{Background}

Space-borne optical remote sensing is a reliable source of information for assessment of forest characteristics over wide areas [7]. The synoptic view and the regular acquisition cycle of image data, combined with the burgeoning selection of techniques available for attribute estimation, make remotely sensed data an appropriate and valuable source of data for assessment of forest condition and detection of change - offering information to augment costly and time consuming field campaigns for inventory update and re-measurement [8].

\subsection{High Spatial Resolution (HSR) Imagery}

Spatial resolution is an important consideration when using remote sensing for forest characterization [9]. Currently the spatial resolution of systems frequently used for vegetation characterization range from coarse (e.g., $1 \mathrm{~km}$ of the Advanced Very High Resolution Radiometer) to very high (e.g., $0.4 \mathrm{~m}$ of the GeoEye-1 sensor). The adequacy of remotely sensed data for a specific purpose (e.g., attribute level: tree, stand, landscape, region) is conditioned by its spatial resolution, which is also inversely related to the extent covered by the image [10], also known as the image footprint.

Medium spatial resolution data with pixels sized 10-100 m (e.g., Landsat Thematic Mapper (30 m), ASTER $(15 \mathrm{~m})$ ) are appropriate for characterization of forest condition [11] and monitoring of conditions and change at the forest stand level [12]. Certainly a key to the applications and monitoring success of Landsat is the ability to capture conditions and dynamics that relate human interaction with terrestrial ecosystems. However, more detailed spatial data available since the launch of various commercial satellites (e.g., IKONOS in 1999, Orbview-3 in 2003) provide the opportunity for more precise depiction of forest parameters and are poised to reduce estimation errors of forest attributes to an acceptable level for operational applications [13]. HSR imagery facilitates, for instance, the detection of individual tree characteristics [14], providing improved estimates of forest structural 
attributes [7]. Panchromatic imagery, with fine spatial resolution $(<1 \mathrm{~m})$ is particularly well suited for analysis of spatial relations through image texture measures $[15,16]$. Texture measures enable the combination of spatial detail of panchromatic imagery with unique spectral information conferred by multispectral imagery serving to leverage complementary information [17] that can be employed separately or with a pan-sharpening approach $[18,19]$. Spectral measures may be understood to inform on vegetation status, type, and condition with textural measures informing on vegetation structure.

Still, the dearth of established methods for image processing and the complex interactions between sun-sensor-surface geometry and forest structural characteristics [20], particularly in complex topographies, persist in making the use of HSR data challenging [6]. HSR imagery acquired using space-borne platforms allows for data collection over remote areas, with predictable georadiometic qualities, and information content analogous to mid-scale aerial photography-commonly used for forest inventory purposes. Lidar (Light detection and ranging) technology has a demonstrated capacity to characterize forest structure [21-24] albeit with high costs persisting to limit operational, wide-area applications [25]. Although lidar, with a capacity to collect highly detailed information regarding forest attributes, shows promise as a means to collect plot-like data for training attribute estimation algorithms applied to HSR imagery.

\subsection{HSR Related to Forest Structure}

The research literature is replete with studies relating forest structural parameters estimated from HSR satellite data (Table 1). Frequent techniques to obtain information from HSR images include crown isolation [26,27], shadow analysis [18,28], texture analysis [13,29,30], and geostatistical approaches [31-33]. The capacity to characterize forest structural attributes typically decreases as crown closure increases [6], with an asymptotic relationship predictably emerging for vertically distributed attributes of forest structure [34].

Table 1. Studies employing satellite HSR imagery for estimation of forest structural parameters.

\begin{tabular}{|c|c|c|c|c|c|}
\hline \multirow{2}{*}{ Study } & \multirow{2}{*}{ Attribute } & Environment & Sensor & Statistical Analysis & \multirow{2}{*}{ Best Result } \\
\hline & & Location & Data (spa. res., m) & Parameter & \\
\hline \multirow[b]{2}{*}{ [29] } & \multirow[b]{2}{*}{ Age class } & Sooke River watershed & IKONOS & ANOVA & \multirow{2}{*}{$\begin{array}{l}\text { Homogeneity in } \\
\text { large window } \\
\text { sizes performs } \\
\text { better than } \\
\text { variance }\end{array}$} \\
\hline & & $\begin{array}{l}\text { British Columbia } \\
\text { (Canada) }\end{array}$ & $\operatorname{Pan}(0.82)$ & Texture measures & \\
\hline \multirow{2}{*}[26]{} & \multirow{2}{*}{ Stem density } & Conifer plantation & IKONOS & Delineation & \multirow{2}{*}{$83 \%$ accuracy } \\
\hline & & Ontario (Canada) & $\operatorname{Pan}(0.87)$ & Tree crown delineation & \\
\hline \multirow[b]{2}{*}[35]{} & \multirow{2}{*}{$\begin{array}{l}\text { Diameter } \\
\text { Crown area } \\
\text { Stem density }\end{array}$} & Lake Tanoe Basin & IKONOS & Linear regression & \multirow{2}{*}{$\begin{array}{l}\mathrm{R}=0.67 \\
\mathrm{R}=0.77 \\
\mathrm{R}=0.87\end{array}$} \\
\hline & & California (USA) & Pan-sharpened (1) & Crown shadow & \\
\hline \multirow[b]{2}{*}[13]{} & \multirow{2}{*}{$\begin{array}{l}\text { Circumference } \\
\text { Height } \\
\text { Stand density } \\
\text { Age } \\
\text { Basal area }\end{array}$} & $\begin{array}{l}\text { Even aged Norway } \\
\text { spruce forest }\end{array}$ & IKONOS-2 & Linear regression & \multirow{2}{*}{$\begin{array}{l}\mathrm{R}^{2}=0.82 \\
\mathrm{R}^{2}=0.76 \\
\mathrm{R}^{2}=0.82 \\
\mathrm{R}^{2}=0.81 \\
\mathrm{R}^{2}=0.35\end{array}$} \\
\hline & & $\begin{array}{l}\text { Hautes-Fagnes } \\
\text { (Belgium) }\end{array}$ & $\operatorname{Pan}(0.87)$ & GLCM textural metrics & \\
\hline
\end{tabular}


Table 1. Cont.

\begin{tabular}{|c|c|c|c|c|c|}
\hline \multirow[b]{2}{*}{ [36] } & \multirow[b]{2}{*}{ Maximum height } & Conifers & QuickBird & Linear regression & \multirow[b]{2}{*}{$\mathrm{R}^{2}=0.66$} \\
\hline & & $\begin{array}{l}\text { Sierra Nevada } \\
\text { mountains California } \\
\text { (USA) }\end{array}$ & MS (2) & Reflectance & \\
\hline \multirow[t]{2}{*}{ [37] } & \multirow{2}{*}{$\begin{array}{l}\text { Height } \\
\text { Age } \\
\text { Crown closure }\end{array}$} & $\begin{array}{l}\text { Mature forest in the } \\
\text { foothills of the Rocky } \\
\text { Mountains }\end{array}$ & IKONOS & Decision tree & \multirow{2}{*}{$\begin{array}{l}\text { Accuracy } 49 \% \\
\text { Accuracy } 57 \% \\
\text { Accuracy } 85 \%\end{array}$} \\
\hline & & Alberta (Canada) & MS (4) and Pan (1) & Reflectance and texture & \\
\hline \multirow{2}{*}{ [28] } & \multirow{2}{*}{ Biomass } & Boreal spruce forest & QuickBird & Linear regression & \multirow{2}{*}{$\mathrm{R}^{2}=0.87$} \\
\hline & & Canada & Pansharpened (0.6) & Shadow fraction & \\
\hline \multirow[b]{2}{*}{ [31] } & \multirow[b]{2}{*}{ Mean crown size } & Conifer and hardwood & IKONOS & Linear regression & \multirow{2}{*}{$\begin{array}{l}\mathrm{R}^{2}=0.73 \\
\mathrm{RMSE}=0.10\end{array}$} \\
\hline & & North Carolina (USA) & Pan (not reported) & $\begin{array}{l}\text { Variogram } \\
\text { Image variance ratio }\end{array}$ & \\
\hline \multirow[b]{2}{*}{ [38] } & \multirow[b]{2}{*}{ Biomass } & Mangrove & IKONOS & Linear regression & \multirow[b]{2}{*}{$\mathrm{R}^{2}=0.92$} \\
\hline & & French Guiana & NIR (4) Pan (1) & $\begin{array}{l}\text { Fourier textural } \\
\text { ordination indices }\end{array}$ & \\
\hline \multirow{2}{*}{ [27] } & \multirow{2}{*}{$\begin{array}{l}\text { Stand density } \\
\text { Stand volume }\end{array}$} & $\begin{array}{l}\text { Coniferous plantations } \\
\text { in slopes }\end{array}$ & QuickBird & Modeling-allometry & \multirow{2}{*}{$\begin{array}{l}\mathrm{R}=0.82 \text { density } \\
\mathrm{R}=0.78 \text { volume }\end{array}$} \\
\hline & & $\begin{array}{l}\text { Shikoku Iskland } \\
\text { (Japan) }\end{array}$ & $\operatorname{Pan}(0.61)$ & Reflectance & \\
\hline \multirow{2}{*}{ [39] } & \multirow{2}{*}{$\begin{array}{l}\text { Crown width } \\
\text { Tree diameter } \\
\text { Stem frequency }\end{array}$} & Tropical forest & IKONOS & Allometric equations & \multirow{2}{*}{$\begin{array}{l}\text { Crown within } 3 \% \\
\text { of field measures }\end{array}$} \\
\hline & & Brazil & $\operatorname{Pan}(1.00)$ & Local extreme filter & \\
\hline \multirow[b]{2}{*}{ [18] } & \multirow[b]{2}{*}{ Volume } & Open Juniperus forest & QuickBird & Linear regression & \multirow{2}{*}{$\begin{array}{l}\mathrm{R}^{2}=0.67 \\
\mathrm{R}^{2}=0.51\end{array}$} \\
\hline & & Turkey & Pansharpened (0.61) & $\begin{array}{l}\text { Shadow area } \\
\text { Crown area }\end{array}$ & \\
\hline \multirow[b]{2}{*}{ [32] } & \multirow[b]{2}{*}{ Mean crown size } & Pine and poplar plant. & QuickBird & Variogram & \multirow[b]{2}{*}{ Error: $2.52-42 \%$} \\
\hline & & $\begin{array}{l}\text { Beijing and Shanxi, } \\
\text { (China) }\end{array}$ & $\operatorname{Pan}(0.61-0.67)$ & Reflectance & \\
\hline \multirow[b]{2}{*}{ [16] } & \multirow[b]{2}{*}{ Mean crown size } & Hardwoods & $\begin{array}{l}\text { IKONOS and } \\
\text { QuickBird }\end{array}$ & Linear regression & \multirow{2}{*}{$\begin{array}{l}\mathrm{R}^{2}=0.60 \\
\text { regression } \\
\mathrm{CD} \sim \text { variance ratio } \\
(\mathrm{RMSE}=0.82) \\
\mathrm{R}^{2}=0.74 \text { across } \\
\text { site comparison } \\
\mathrm{R}^{2}=0.52 \text { across } \\
\text { sensors }\end{array}$} \\
\hline & & $\begin{array}{l}\text { Ohio and North } \\
\text { Carolina (USA) }\end{array}$ & Pan (1) Pan (0.73) & Image variance ratio & \\
\hline \multirow{2}{*}{ [40] } & \multirow{2}{*}{ Mean stand height } & Boreal forest & QuickBird & Regression tree & \multirow{2}{*}{$\begin{array}{l}\mathrm{R}^{2}=0.53 \\
\mathrm{RMSE}=2.84 \mathrm{~m}\end{array}$} \\
\hline & & Yukon, Canada & $\operatorname{Pan}(0.68)$ & Reflectance & \\
\hline
\end{tabular}

\subsection{Status in the Use of Remote Sensing for Estimation of Forest Structure in Spain}

The Spanish Plan Nacional de Teledetección (PNT) is committed to acquiring complete national coverages of HSR satellite imagery annually [41] and to make data available for research at no cost. The acquisition phase started in 2008 [42], capitalizing upon archival data to backdate the database to 
2005 coverage. Initial coverage consist of SPOT5-HRG XS+P (2.5 m) data, with other sensors being considered for future acquisitions [43]. Access to this data represents a unique opportunity to incorporate HSR into Spanish forest inventories as an operational and low cost data source to meet a range of information needs. The data is to be collected with a primary focus on land-use land-cover change assessment [42], but capacity to generate information for forest monitoring and reporting can also be generated.

Encouraged by a readily available source of data there has recently been an increased interest by the Spanish research community in relation to remote sensing technologies and the potential application to forest environments, in particular the characterization of forest structure. Vázquez de la Cueva [44] explored relationships between forest structural attributes at the plot level (e.g., height, basal area, and crown canopy closure) and spectral information derived from Landsat Enhanced Thematic Mapper Plus (ETM+; $30 \mathrm{~m}$ pixel size) imagery combined with topographic data. The study considered three types of forest in Central Spain and applied a multivariate canonical ordination method. The author found a strong influence of vegetation type on the results, with a low percentage of variance explained precluding development of robust empirical models. Pascual et al. [45] used lidar data and a two stage object based methodology to characterize the structure of Pinus sylvestris L. stands in forests of Central Spain. Five structure types were defined based on height and density parameters. The median and standard deviation of height were found to be the most valuable for definition of structure types, with the approach developed being proposed for operational application suitable for inclusion in forest inventory procedures in support of forest management plans. Merino de Miguel et al. [33] investigated the strength of relations between dasometric parameters and textural variables in Pinus pinaster Ait. stands in Central Spain. The authors used geostatistical tools (i.e., variograms), calculated with orthophotography and IKONOS-2 imagery with original and degraded spatial resolutions. The authors found the strongest correlations when the variogram was calculated for spatial resolutions of $1 \mathrm{~m}$ and $2 \mathrm{~m}$. As such, opportunities to further explore the capacity of HSR imagery to estimate a range of forest structural parameters remain.

\section{Methods}

Below, and in Figure 1, we summarize the approach implemented and the data utilized in this research. Forest structural attributes (QMD, BA, and N) are derived from data measured on the field through a process of geostatistical interpolation. Spectral and spatial variables from HSR imagery direct the delineation of stand-like areas for summarizing data. Statistical models linking forest parameters and imagery data are built with CART and validated with numerical and graphical tools.

\subsection{Study Area and Field Data}

The study focuses on pines in the Central Range of Spain (Figure 2), an area mainly dominated by $P$. sylvestris L., P. pinaster Ait., and P. nigra Arn. species. Two sites representing different forest conditions were chosen for availability of field data. Pinar de Valsain (hereafter Valsain) is a 7,627 ha forest of Pinus sylvestris L. on the North facing slopes of Sierra de Guadarrama (Segovia). It is a multifunctional forest (timber production, recreation, and protection) with an established management plan since 1889 that has evolved from a rigid to a more flexible scheme over the subsequent decades. 
Management actions and recreational activities have had an impact on the forest structure [46]. Valle de Iruelas (hereafter Iruelas) is a 5,483 ha forest of P. pinaster Ait., P. sylvestris L., and P. nigra Arn. in Sierra de Gredos (Ávila). It is also a multifunctional forest (wood, resin, and pasture production, recreation, and wildlife habitat). Although the first management plan was approved in 1886, historical circumstances prevented its implementation. The production of resin during the twentieth century favoured old growth development and a complex history of fires has also conditioned the forest structure.

Figure 1. Schematic methodology followed in the study.

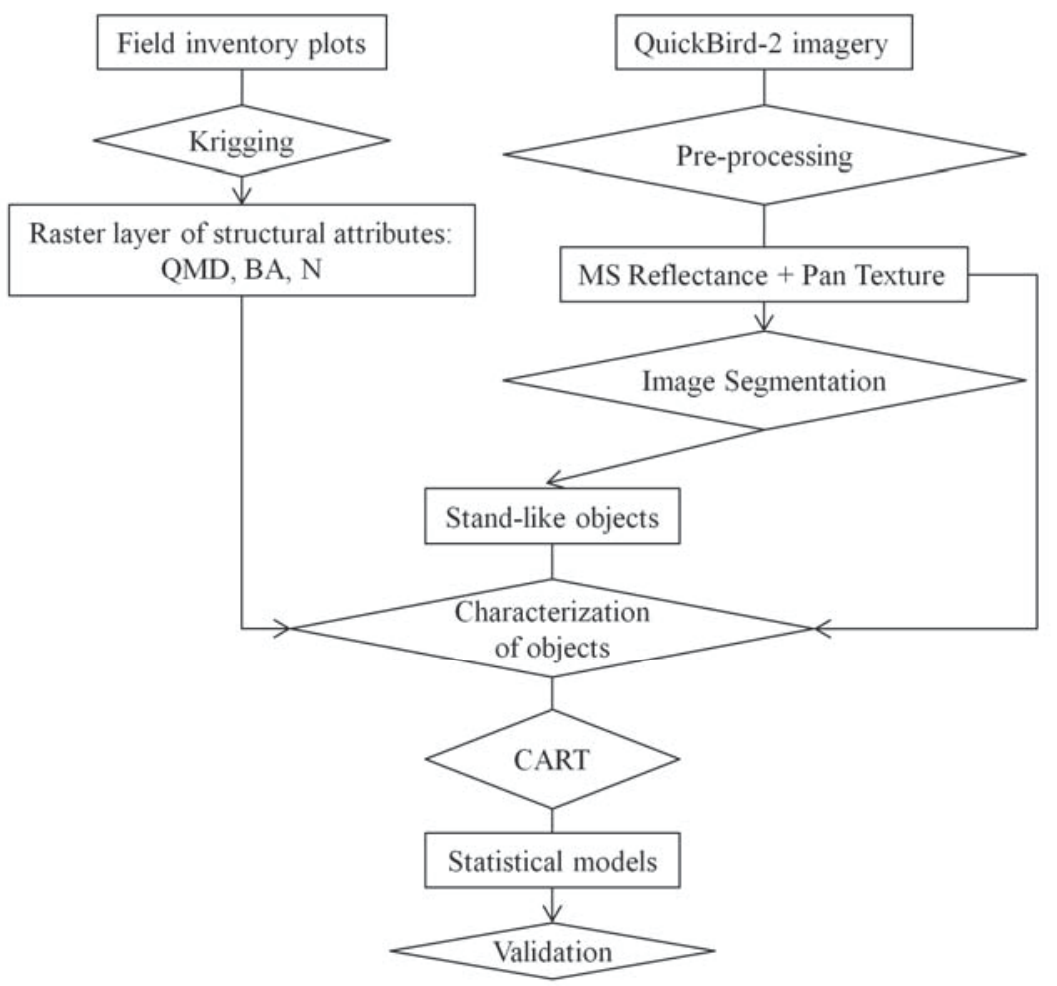

Systematic surveys based on ground sample plots are conducted periodically over the study sites measuring attributes including density, diameter at breast height (dbh), and height. For this study, data is from 2005 for Iruelas and 1999 for Valsain, with the latter updated to 2004 conditions using a locally appropriate growth model following procedures recommended by the Spanish National Forest Inventory. The quadratic mean diameter (QMD) and basal area (BA) were calculated at each inventory plot (Equations (1-2)) where the total number of trees per unit area $(\mathrm{N})$ was also available; expansion factors were used to scale values to a given area [47]. BA and QMD are adequate attributes for volume modeling at the stand level. QMD was preferred over the arithmetic mean diameter as it has a stronger correlation to stand volume [48].

$$
\begin{aligned}
& Q M D=\sqrt{\frac{\sum_{i} d_{i}^{2}}{N}} \\
& B A=\frac{\Pi}{4} * \sum_{i} d_{i}^{2}
\end{aligned}
$$


Figure 2. Location of the study sites. Insets show QMD values as kriged from inventory plots in the treed areas of Valle de Iruelas and Pinar de Valsain. Subset areas covered by 834 plots in Valsain and 661 plots in Iruelas were investigated in the study.

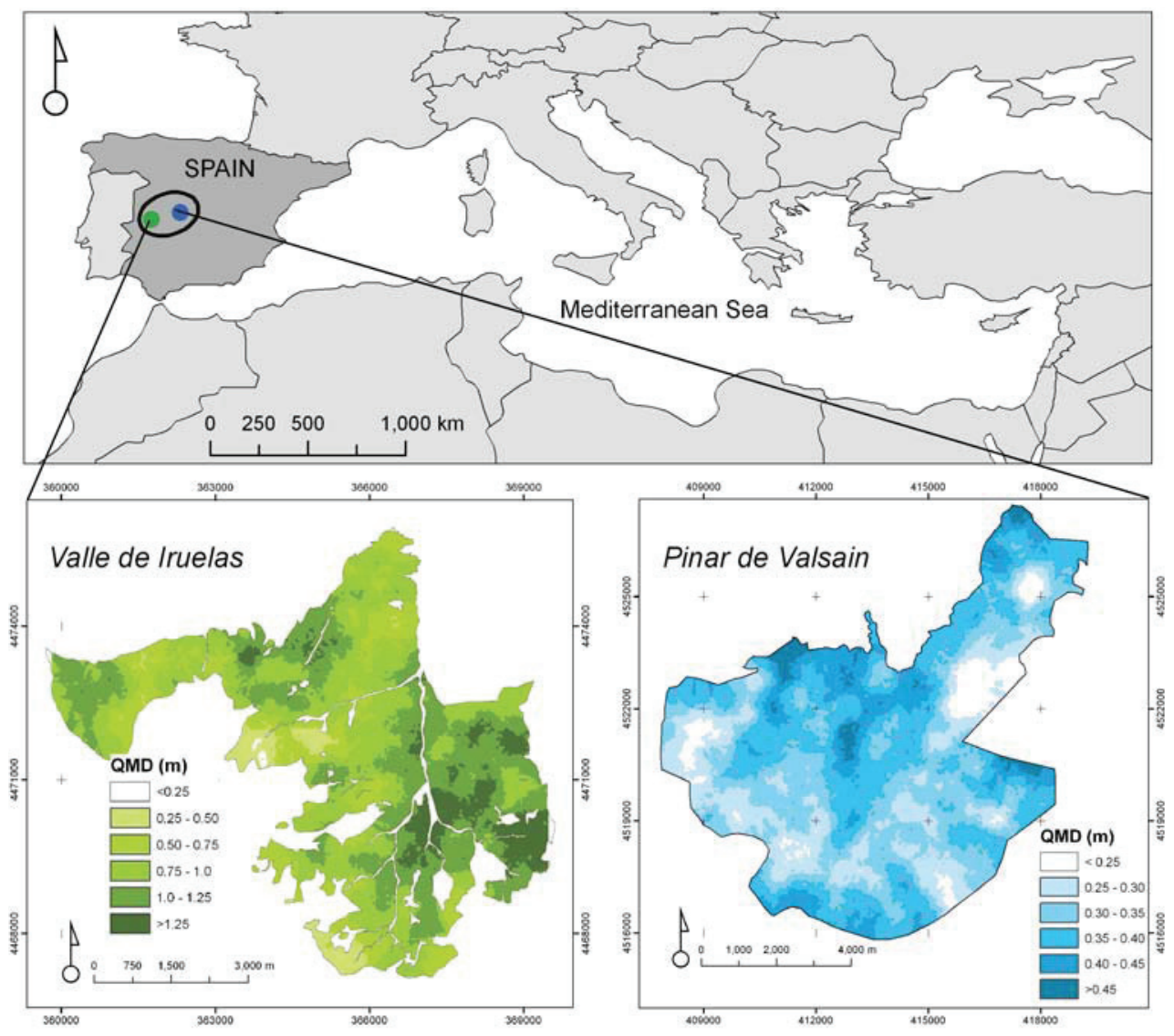

Geostatistics provides a means for extrapolation of measured values to unmeasured points and areas, and facilitates the derivation of thematic layers for integration with other data [49]. Kriging is a spatial interpolation method that yields the best possible estimation of the spatial variable of interest at every unmeasured point [50] and the error committed in the estimation is minimized and known at each point [51]. In this study we mapped the forest variables of interest (QMD, BA, and N) measured in ground plots located over grids sided $150 \mathrm{~m}$ in Iruelas and $200 \mathrm{~m}$ in Valsaín into raster layers through a process of ordinary kriging. The relative standard error (i.e., the standard error of the kriged surface relative to the mean attribute value at the polygon level) was on average $15 \%$ for the QMD kriged layer and $25 \%$ for the BA and $\mathrm{N}$ layers, similar to the variability found for multiple plots found within the same polygon. More accurate averaging is facilitated, as sampling is complete and spatial correlation of plot values is accounted for.

\subsection{HSR Imagery}

QuickBird-2 is an Earth Observation satellite launched by Digital Globe in 2001, providing data in five spectral bands (Table 2). It has the capacity to be oriented and to capture images off nadir enabling 
a temporal revisit of 2-6 days depending on latitude [52]. The pixel size of QuickBird-2 images is $2.4 \mathrm{~m}$ for the multispectral bands and $0.68 \mathrm{~m}$ for the panchromatic band (Table 2).

Two QuickBird-2 images, supplied in a georeferenced form by the data provider were used in this study, each covering one of the study sites (Figure 2, Table 2). Images were orthorectified with a Digital Elevation Model (DEM) derived from a contour vector map 1:10,000 (www.sitcyl.jcyl.es) and registered to aerial photography with $0.25 \mathrm{~m}$ pixels (www.sitcyl.jcyl.es). The multispectral and panchromatic bands were orthorectified separately with root mean square errors (RMSE) of 0.69-0.72 m (multispectral bands) and 0.66-0.81 m (panchromatic band). Images were resampled with cubic convolution to $2.0 \mathrm{~m}$ (multispectral bands) and $0.6 \mathrm{~m}$ (panchromatic band) for alignment with the regionally appropriate coordinate grid (UTM $30 \mathrm{~N}$ ) and to facilitate integration with rasterized attributes. Atmospheric correction of the multispectral images was performed with the COST model [53] using water bodies as dark objects and the atmosphere-scattered path radiance $\mathrm{L}_{\lambda}{ }^{\mathrm{p}}$ estimated with a relative spectral scattering DOS model $\left(\lambda^{-4}\right)$ under very clear atmospheric conditions [54].

Table 2. Characteristics of the satellite imagery used in the study.

\begin{tabular}{|c|c|c|}
\hline \multicolumn{3}{|c|}{ QuickBird-2 Imagery } \\
\hline \multirow{2}{*}{ Spatial resolution } & Multispectral & $2.4 \mathrm{~m}$ \\
\hline & Panchromatic & $0.68 \mathrm{~m}$ \\
\hline \multirow{6}{*}{ Bands } & Blue & $0.45-0.52 \mu \mathrm{m}$ \\
\hline & Green & $0.52-0.60 \mu \mathrm{m}$ \\
\hline & Red & $0.63-0.69 \mu \mathrm{m}$ \\
\hline & NIR & $0.76-0.90 \mu \mathrm{m}$ \\
\hline & Pan & $0.45-0.90 \mu \mathrm{m}$ \\
\hline & Valsaín & Iruelas \\
\hline Date (dd/mm/yyyy) & $19 / 05 / 2004$ & 05/08/2005 \\
\hline Sun elevation $\left(^{\circ}\right)$ & 58.4 & 72.0 \\
\hline
\end{tabular}

\subsection{Image Segmentation}

Image segmentation is the partitioning of images into uniform continuous spatial units [55]. Through the application of automated algorithms the criteria for homogeneity can be defined by the user, based on parameters such as tone or spatial pattern. Image objects or segments composed of various pixels provide supplementary features for image analysis, not available in pixel based analysis, such as local statistical relations of digital numbers [37], shape, size or context. That is, once segments are produced, objects (i.e., trees or groups of trees) or spatially constrained summaries of the digital numbers within the segment may be used to provide representative segment-level information [39]. In forest environments, the segments can often be considered as analogous to the manually delineated stands found in forest inventories [56].

Segmentation routines were applied to the QuickBird-2 images using Definiens Cognition Network Technology ${ }^{\circledR}[57,58]$. In the process of image segmentation the size of resulting objects is determined by the scale parameter and by the landscape characteristics; for instance a given scale value would 
produce larger objects in a homogeneous landscape and smaller objects in irregular areas. The scale parameter was 50 in Iruelas and 100 in Valsain. Other settings guiding the segmentation routine include color-shape 0.8-0.2 and smoothness-compactness $0.5-0.5$. The homogeneity criteria included the visible and NIR bands with similar weight, and an aspect layer derived from the DEM to incorporate topographic information as one of the possible structural driving factors [59] was weighted 0.1.

\subsection{Image Texture Metrics}

Image texture, defined by Haralick and Bryant [60] as "the pattern of spatial distributions of grey-tone", describes the relationship between elements of surface cover [61] and is one of the most valuable criteria in visual interpretation. The estimation of forest stand parameters is sometimes improved with a combination of spectral and spatial information [62] such as texture. Consequently a host of texture measures have been utilized to predict structural parameters in various environments $[13,29,55,63,64]$ and has shown particular utility in complex structures such as tropical forests for above ground biomass estimation $[17,65]$.

Table 3. Attributes used for modeling. The mean and standard deviation of each of these attributes was de facto used in the decision trees.

\begin{tabular}{ll}
\hline Predictor Variable & Description \\
\hline Reflectance & \\
\hline B1 (Blue) & Reflectance band 1 \\
B2 (Green) & Reflectance band 2 \\
B3 (Red) & Reflectance band 3 \\
B4 (NIR) & Reflectance band 4 \\
\hline Textural & \\
\hline$H_{-} S$ & Homogeneity Small window \\
Con_S & Contrast Small window \\
$E_{-} S$ & Entropy Small window \\
$H_{-} M$ & Homogeneity Medium window \\
Con_M & Contrast Medium window \\
$E_{-} M$ & Entropy Medium window \\
$H_{-} L$ & Homogeneity Large window \\
Con_L & Contrast Large window \\
E_L & Entropy Large window \\
\hline Topographic & \\
\hline Aspect & Orientation \\
\hline
\end{tabular}

We applied an approach for texture analysis based on measures derived from the Grey Level Coocurrence Matrix (GLCM) [66,67]. The GLCM is a tabulation of how often different combinations of pixel grey levels occur in an image [68] at a specific distance and orientation (within a particular processing kernel, or analysis window). Texture analysis is a multiscale phenomenon [69] and choosing the right window size to capture meaningful local variance without generalizing unrelated 
features [13] is one of its key challenges [70]. For selection of window sizes to calculate the GLCM texture measures we used the semivariogram approach [71,72]. Semivariograms were calculated for image subsets over five experimental structural plots in Valsain [73] and ten structurally different areas in Iruelas, identified with a combined approach based on inventory data and visual interpretation to cover all distinctive structural conditions. The range in the variogram indicates the distance beyond which pixel values are no longer correlated [71] and is an indication of the elements forming the texture present within the scene. The range is frequently associated with the most dominant elements in the scene, be it single tree crowns in open forests, or the canopy of groups of trees in close environments. Once the variograms were calculated, the range values were manually identified at the lag distance, where the variograms first flattened, corresponding with window sizes on the QuickBird-2 panchromatic band of $7 \times 7,9 \times 9$, and $13 \times 13$ pixels in Valsain and $7 \times 7,13 \times 13$, and $23 \times 23$ pixels in Iruelas. We considered three GLCM texture variables, that is, Homogeneity, Contrast, and Entropy for each size of window (Small, Medium, and Large) (Table 3) based on their high values of correlation with structural parameters observed and pre-analysis investigations (results not shown).

\subsection{Decision Tree}

One option to identify relations between variables in multivariate data sets resulting from object analysis is the use of decision tree data analysis [37] also known as Classification and Regression Trees (CART). Regression trees identify relationships between a single continuous response (dependent variable) and multiple, continuous and/or discrete, explanatory (independent) variables, through a binary recursive partitioning process, where the data are split repeatedly into increasingly homogeneous groups (nodes), using combinations of variables (rules) that best distinguish the variation of the response variable. Tree models do not make assumptions regarding the distribution of the input data $[74,75]$; plus, they are able to capture non linear relationships between variables and are robust to errors in the input and results. Tree modeling is a nonparametric method which basic theory is reported in Breiman et al. [76].

CART approaches have frequently been used in the environmental remote sensing community for classification and mapping [77-79] for modeling [80-82] and for forest characterization [83]. In the estimation of forest structural parameters with HSR satellite imagery, decision trees have been applied in diverse environments: Chubey et al. [37] used CART for analysis of percent species composition, crown closure, stand height, and age with IKONOS imagery based on analysis of objects in Alberta, Canada, obtaining the best estimations for species composition and crown closure. Goetz et al. [84] used IKONOS and shadow analysis to model and derive classified maps of canopy cover, with $97.3 \%$ overall accuracy, in Maryland, USA. Mora et al. [40] estimated mean height of forest stands in boreal coniferous forests in Yukon, Canada, obtaining a prediction accuracy of 53\% and an RMSE of $2.84 \mathrm{~m}$ on stand height. All of the abovementioned approaches suggest local models for estimation of forest structural parameters as an alternative tool for alleviation of often costly and time consuming field inventories.

\subsection{Applied Decision Tree}

For development of decision tree models each segment was characterized with the mean and standard deviation of the reflectance and texture variables described above (Table 3), and the mean 
values of the kriged forest structural parameters (QMD, BA, N) and topographic orientation. These sets of data were input for the CART analysis in Matlab®.

Samples were randomly split into calibration (two thirds) and validation (one third) sets. The representativeness of the subsamples was tested with a Multi Response Permutation Procedure (MRPP) [85,86]. This non-parametric method tests the hypothesis of no difference between two or more data sets for a range of parameters (i.e., the metrics used as inputs to the regression tree). To fit the model a cross validation process with ten iterations was performed; to avoid over-fitting we considered the establishment of a minimum number of cases in terminal nodes and pruning with the 1 SE rule [76].

\section{Results}

\subsection{Stand-Like Areas Produced by Segmentation of the QuickBird-2 Imagery}

Objects smaller than 0.5 ha produced in the process of segmentation were eliminated. Furthermore, screening outliers of reflectance and texture variables (i.e., segments which values were three or more standard deviations from the mean) enabled identification of objects that did not appear representative of known local forest conditions, typically corresponding with shepherding areas with buildings present in Valsain and objects dominated by bare soil in Iruelas. Thirty nine such unusual objects were removed as outliers for subsequent analysis. Finally the number of objects preserved for modeling was 490, with an average area of 5.3 ha. Table 4 lists the statistical descriptors of the structural attributes (QMD, BA, N) and topographic parameter (aspect) at the stand-like level. Figure 3 illustrates the distribution of the structural parameters.

Table 4. Statistical descriptors of structural (QMD, BA, N) and topographic (aspect) parameters of the stand-like objects obtained with the segmentation process and after removal of outliers. To fully capture the ecological meaning of the stand orientation and to avoid operational ambiguities we computed aspect values to be expressed as a non-polar complex number using the notation of Euler: Aspect $=\exp (-\mathrm{i} \times(\theta-\Pi / 2))$.

\begin{tabular}{lrrrr}
\hline & QMD(m) & $\mathbf{B A}\left(\mathbf{m}^{2} / \mathbf{h a}\right)$ & $\mathbf{N}(\mathbf{n} / \mathbf{h a})$ & Aspect $\left(\theta^{\circ}\right)$ \\
\hline Mean & 0.5715 & 26.5344 & 323.2064 & 168.5636 \\
Standard Error & 0.0138 & 0.5044 & 6.4277 & 4.3050 \\
Median & 0.3918 & 26.5148 & 306.461 & 155.2855 \\
Standard Deviation & 0.3062 & 11.1671 & 142.2839 & 95.2968 \\
Kurtosis & -0.7460 & -0.6941 & 0.1987 & -1.2352 \\
Skewness & 0.7943 & 0.2266 & 0.6035 & 0.1926 \\
Range & 1.2407 & 53.8552 & 805.0587 & 337.2344 \\
Minimum & 0.2148 & 5.8128 & 39.1273 & 10.1746 \\
Maximum & 1.4555 & 59.6681 & 844.186 & 347.4090 \\
\hline
\end{tabular}


Figure 3. Distribution of the structural parameters (QMD, BA, N) in the stand-like polygons produced with the segmentation of the satellite images. Note that QMD graph bins are not all equal.
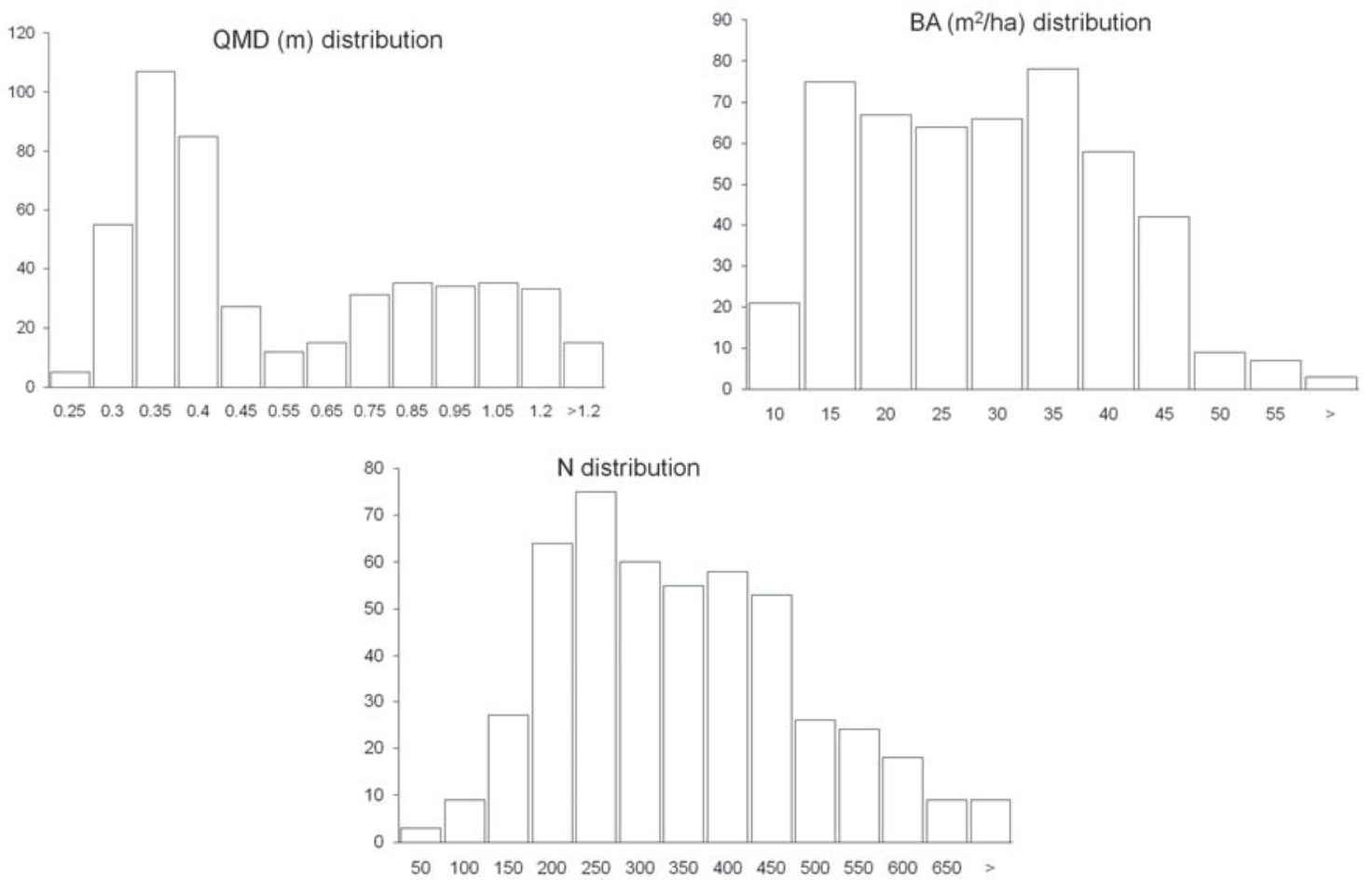

\subsection{Regression Trees}

Information regarding the calibration and validation subsamples is presented in Table 5. The MRPP test, performed including all stand level predictors, confirmed there were no significant differences between the calibration and validation datasets ( $p$-value 0.77 ).

Table 5. Number of samples used for calibration and validation of the CART models.

\begin{tabular}{cc}
\hline Samples & Stand-Like Segments \\
\hline Total & 490 \\
Calibration & 327 \\
Validation & 163 \\
\hline
\end{tabular}

Fitting all regression tree models was statistically significant $(p$-value $<0.001)$ and with high values of correlation (Table 6) between structural parameters and image predictors. To assess the performance of the models we applied them to the independent set of validation data, analyzing values of the Root Mean Square Error (RMSE) and correlation coefficient $\left(\mathrm{R}^{2}\right)$ (Table 6) and evaluating discrepancies between values measured on the field and values predicted by the regression tree models with the help of graphic tools (Figures 4 and 5).

Applied to the validation sample the models show varying strength of the relation between the structural parameters and the image variables used as predictors. The QMD model correlation value is the highest, followed by the BA model and with the $\mathrm{N}$ model ranking last (Table 6). The RMSE 
values, a means to measure the precision of the models, are moderate for QMD and BA, and relatively higher for $\mathrm{N}$ when a prediction of the exact number of trees is expected (Table 6). As practical decisions in forest management are often based on classes of attributes rather than exact values of structural parameters, we evaluated the performance of the CART model to classify values of $\mathrm{N}$. The measured number of trees per unit area $(\mathrm{N})$ was classified into density categories ranging from open $(\mathrm{N}<150)$ to closed $(\mathrm{N}>500)$ categories. The CART model classified $70 \%$ of the stand-like segments in the correct group, with all other segments classified in an adjacent class. The average relative error of the models was also evaluated as the percentage of RMSE respect to the average measured parameter (Table 6).

Table 6. Fitting and performance results of the regression tree models for QMD, BA, and N.

\begin{tabular}{lccccc}
\hline $\begin{array}{l}\text { Structural } \\
\text { Parameter }\end{array}$ & RMSE & $\begin{array}{c}\text { Validation } \\
\text { \% Average Error }\end{array}$ & $\mathbf{R}^{\mathbf{2}}$ & Rho & $\boldsymbol{p}$-value \\
\hline$Q M D$ & 0.13 & 17 & 0.80 & 0.89 & 1.81 e-59 \\
$B A$ & 5.79 & 22 & 0.70 & 0.85 & 7.08 e-47 \\
$N$ & 98.86 & 31 & 0.46 & 0.71 & 1.80 e-26 \\
\hline
\end{tabular}

Scatter plots in Figure 4 illustrate the relation of observed values of QMD (a), BA (b) and N (c) versus the corresponding estimated values of the validation subsample $(\mathrm{n}=163)$. The QMD model performs with very good accuracy for the smaller diameters, with points close to the 1:1 line, and more randomly spread to both sides for larger diameters. The BA model depicts a similar but less accurate pattern, while the $\mathrm{N}$ model shows increasing disagreement of observed to modeled values at the more dense stands. Noteworthy is a tendency of underestimation for parameters at high values (QMD $\geq 1.2$, $\mathrm{BA} \geq 50$, and $\mathrm{N} \geq 600$ ), likely as an expression of the well known saturation of optical sensors at increasingly high biophysical parameter values $[34,87]$. This kind of error is important to note with reference to volume and biomass estimation, since larger trees contribute more to these estimates [88], but it is of minor importance in this particular area where few stands are over the thresholds mentioned above (Figure 3; Table 4).

Figure 4. Plot of the observed structural parameters QMD (a), BA (b), and N (c), versus estimated values for the validation subsample $(n=163)$.
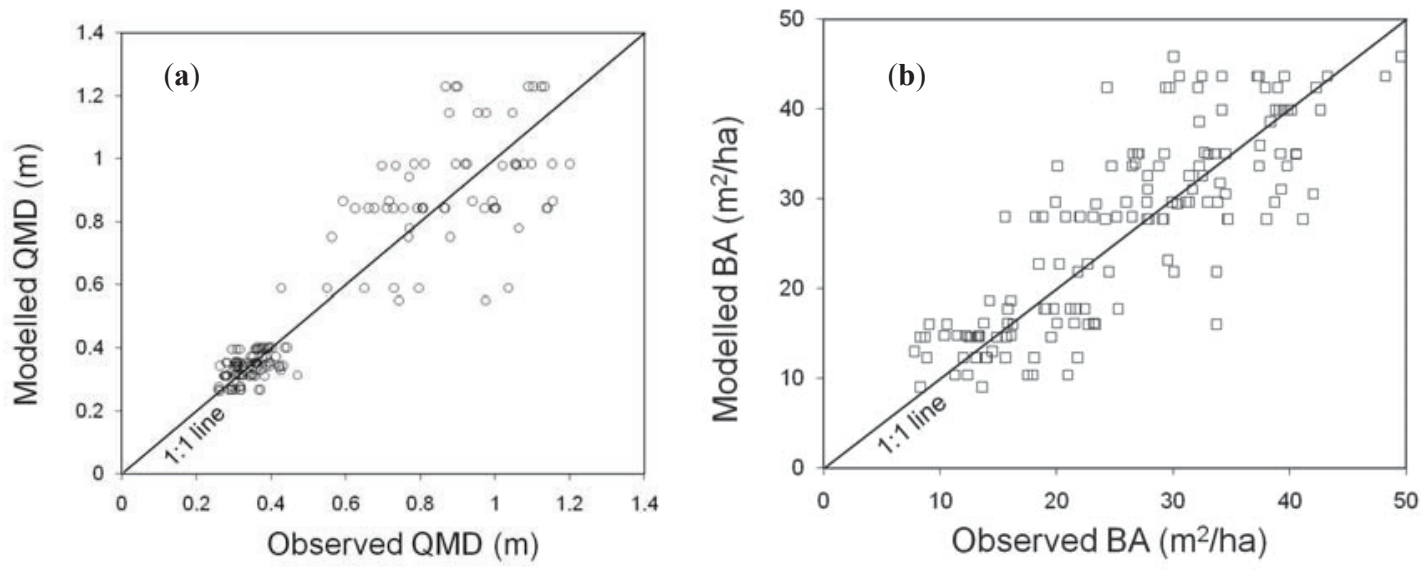
Figure 4. Cont.

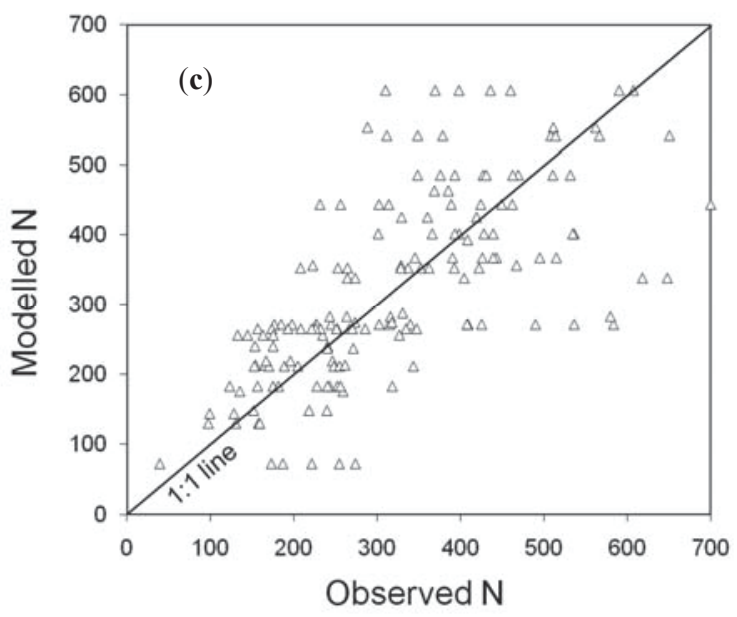

A closer look at the residuals confirms the relative precision of the QMD model (Figure 5(a)); an assessment of relative errors revealed that the relative error committed is below $20 \%$ in $76 \%$ of the validation sample $(\mathrm{n}=123)$. A comparison of $5 \mathrm{~cm}$ diametric classes between the estimated and observed data indicated an agreement in 53\% of the stand-like segments, with $19 \%$ falling in the adjacent class. Furthermore, the random distribution of residuals in the most frequent classes $(0.30-0.40)$ leads to an almost complete compensation of the average error. This optimistic result should be carefully considered, as averaged values over areas of different sizes could lead to miscalculations. The residuals in the BA model look randomly distributed (Figure 5(b)), but there is a higher number of underestimates ( $57 \%$ of the validation sample) and in these cases the absolute value of residuals is higher. In the $\mathrm{N}$ model $55 \%$ of the validation segments are underestimated; a tendency to underestimate lower values and overestimate higher densities is observed.

Figure 5. Plot of the observed $\mathrm{QMD}, \mathrm{BA}$, and $\mathrm{N}$ versus the residuals of the models. (a): QMD, (b): BA, (c): N.

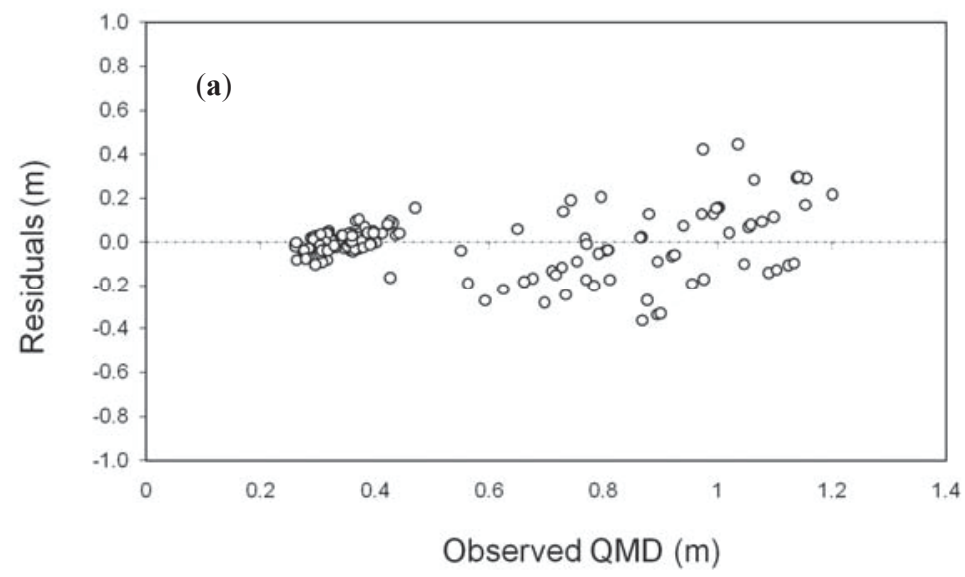


Figure 5. Cont.
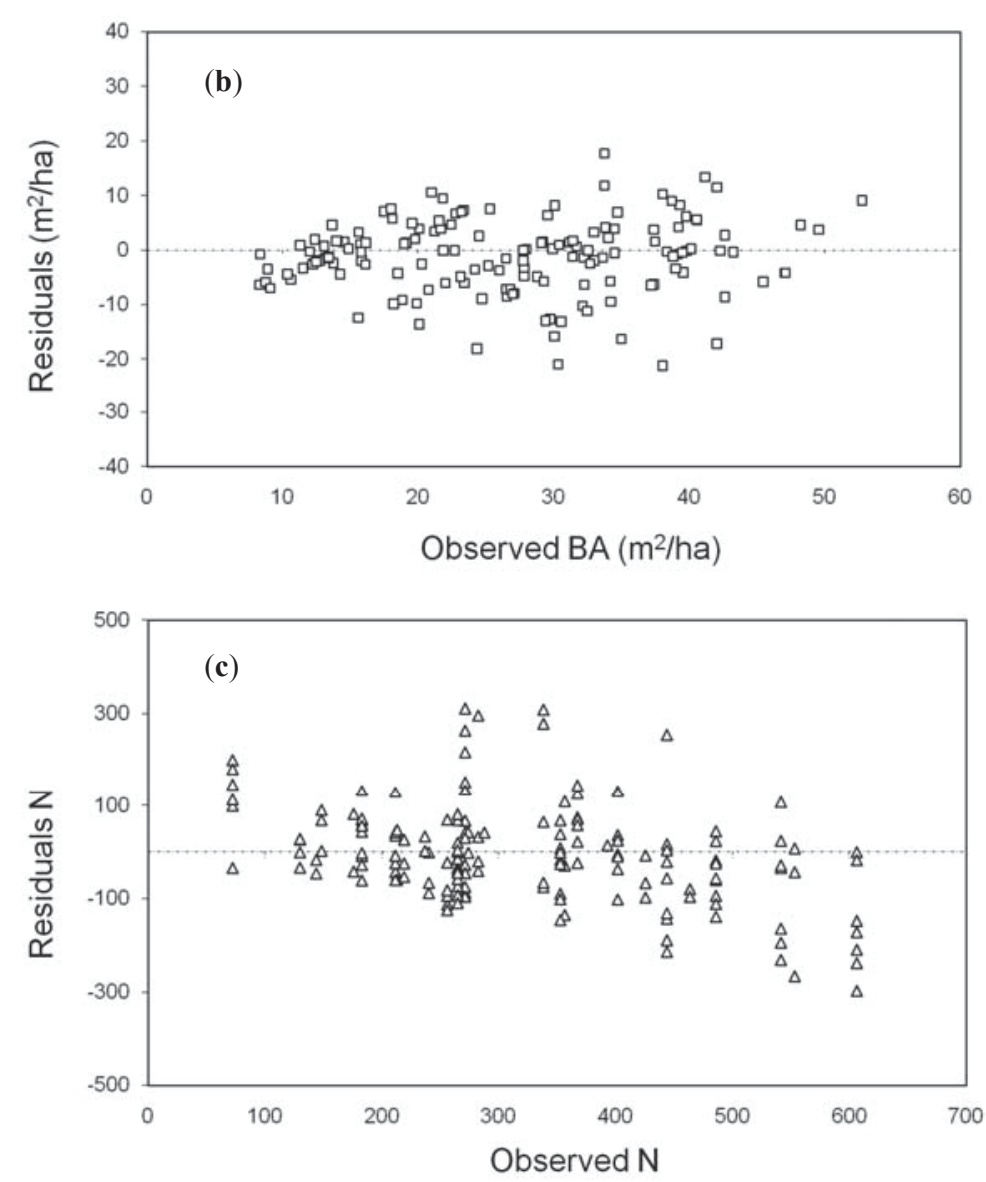

To reduce over-fitting and to make the models practical and operationally viable we established a minimum number of cases in terminal nodes $(n=80)$. Furthermore, examining the terminal nodes average values and the improvement of intra-group variance they represent from father nodes (i.e., decreased variance) appropriate pruning levels were determined. With these premises the number of terminal nodes obtained was between seven (for the QMD and BA models) and eight (for the $\mathrm{N}$ model) (Figure 6; Table 7).

The most relevant predicting variables determining decisions in the regression tree models are shown in Table 7. Noteworthy is the primacy of stdev B1 (standard deviation of blue reflectance) which enters all models in first place. All other reflectance bands (green, red and near-infrared) did also determine some branch rules (Figure 6). Among textural variables, contrast and entropy of various window sizes were the more relevant; homogeneity was not included in decision rules. A total of five or six variables were included in each of the models. 
Figure 6. Example of a regression tree model of QMD. Hollow boxes represent branch rules; elements fulfilling the rule go to the left, the rest go to the right. Values of terminal nodes average QMD of elements in the group.

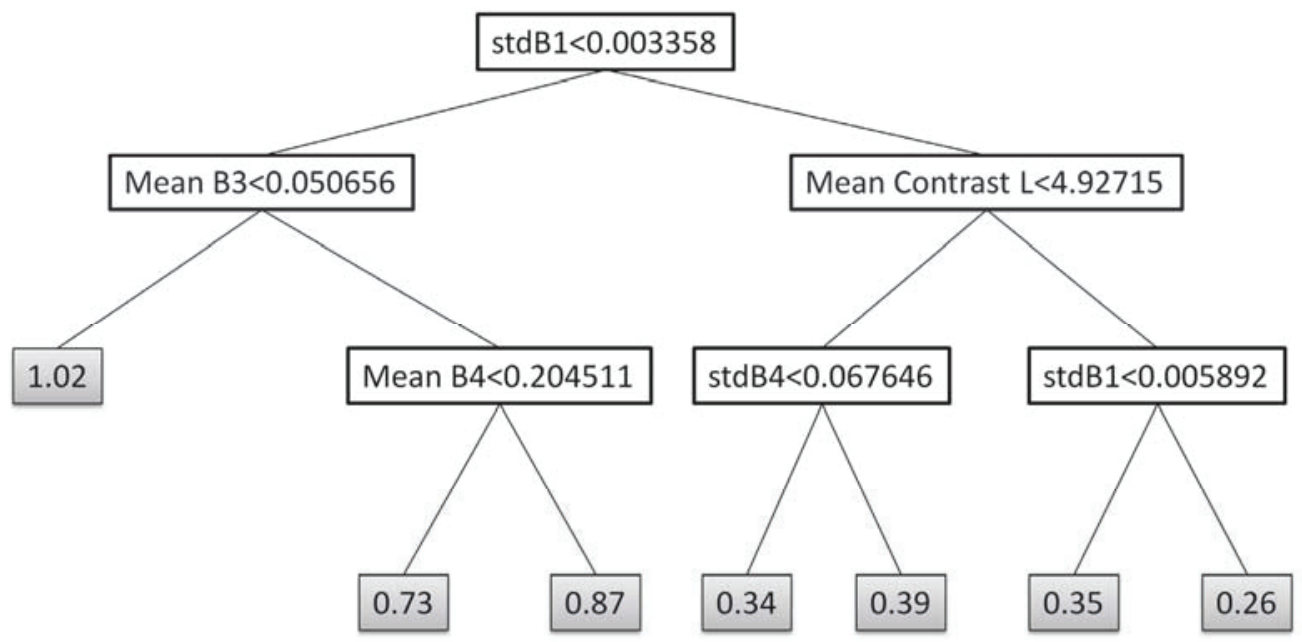

Table 7. Relevant predictors in regression trees of QMD, BA and $\mathrm{N}$ and number of terminal nodes.

\begin{tabular}{llc}
\hline Structural Parameter & Relevant Predictors & Terminal Nodes \\
\hline \multirow{4}{*}{$Q M D$} & Stdev B1 & \\
& Mean B3 & 7 \\
& Mean Contrast Larger window & \\
& Mean B4 \\
& Standard deviation B4 & \\
& Stdev B1 & \\
& Mean B3 & 7 \\
& Mean B1 & \\
& Standard deviation B2 & \\
& Mean Entropy Small window & \\
& Stdev B1 & \\
& Mean B1 & \\
& Standard deviation B4 \\
& Mean Entropy Medium window \\
& Mean B2 \\
& Mean B3 \\
\hline
\end{tabular}

\section{Discussion}

Structural parameters such as quadratic mean diameter, basal area, and number of trees per unit area of Mediterranean pines in Central Spain have been modeled with regression trees and with HSR reflectance and texture metrics from QuickBird-2 imagery as model inputs. Results, although limited by uncertainties in the reference data and processing techniques, show reasonable accuracy $\left(\mathrm{R}^{2}=0.8\right)$ and precision (estimation relative error $\sim 17 \%$ ) for the QMD model and robust models ( $>0.7$ ) for BA and $\mathrm{N}$ but with higher estimation relative error (22-31\%). 
Management plans were initiated in Spanish forests more than a hundred years ago [89]. Albeit the early start, only $19 \%$ of the treed forest area in Spain is currently governed by a management plan under formal implementation [90]. Often noted as a primary reason for this unfavorable proportion, is the high cost of field inventories, limiting surveys to forests with potential to produce economic revenue. However, with the increasing concern over environmental issues, current forest inventories are aimed at informing a variety of long-term objectives including biodiversity, carbon accounting, habitat protection and sustainable timber production [91]. Remote sensing can contribute to the ability to produce timely, cost efficient inventory estimates via image segmentation for stand delineation [45] and statistical modeling for assessment of attributes with acceptable precision [5]. HSR satellite sensors emerged a few years ago as promising data sources for forest inventory [6,92] providing consistent and frequent imagery. Our study demonstrates that in Mediterranean pines of Spain QuickBird-2 imagery and CART modeling would be useful and affordable for assisting in the assessment of forest areas with a variety of objectives (e.g., recreation, carbon storage), though caution is required to deal with inherent modeling uncertainties. Although remote sensing is not expected to replace completely field measurement any time in the near future [5] it would facilitate planning and management with realistic goals.

Among the strengths of HSR imagery is the high geometric fidelity [93] and the possibility of identification of individual elements such as trees or groups of trees. The unique capabilities of the QuickBird-2 instrument are exploited here by including texture metrics in the modeling, as image texture is influenced by biophysical parameters like crown diameter, distance between trees, tree positioning, LAI, and tree height. The historic limited use of texture parameters is often indicated as related to a paucity of appropriate software tools [94] and is being progressively overcome. Alternately, for monitoring programs with various dates of imagery and more than one scene, off-nadir view angles and differing solar and atmospheric conditions should be considered [20] as they may pose analysis difficulties.

Heterogeneous environments typically require a dense network of sample plots for an adequate assessment of varying conditions [95]; likewise, the capacity of a grid of inventory plots to capture the diversity of Mediterranean forests could be argued. With the complete coverage offered by remotely sensed data, selective sampling may become unnecessary, for instance if imputation techniques are applied. Furthermore, in applications where sampling is needed, segmentation of HSR images helps the design of sampling units by automatically and consistently defining homogeneous areas [96], otherwise delineated with human expert and costly effort. If adequately trained, segmentation algorithms have the ability to semi-automatically divide images into structurally homogeneous areas only requiring human revision [25], that can be used as strata to optimize the field sampling design [97] and also allowing the reduction of sample collection needs.

Tree models are easily interpreted and applied, with few statistical requirements imposed that make it an appropriate method of estimation in forest environments. Employing data from managed stands' field inventories in the support of modeling efforts has an intrinsic limitation related to the dearth of measurements of small trees; this circumstance is possibly related to a bias of the data considered as truth, and could partly excuse the underestimating trend of our models. All sources of uncertainty should be thoroughly considered for aiding the interpretation of modeling results. Our calibration dataset consisting of 327 stands is relatively large (66\% of the sample) as the accuracy of decision tree 
models tends to increase with increasing calibration sample size [70]. Mora et al. [40] in Yukon (Canada) demonstrated that a smaller calibration dataset (30\% of the sample) could perform adequately if there were difficulties to obtain reference information, making this method an even more appealing tool for inventory. With a simple structure, that is, low number of rules and final nodes, CART constitute a practical and parsimonious tool for classification of stands for management or planning. The acquisition of periodic HSR coverage of the whole territory by the PNT poses an unprecedented opportunity to use remote sensing for assessment of the structure of Spanish forests that managers should strongly consider.

\section{Conclusions}

High spatial resolution (HSR) satellite imagery, such as QuickBird-2, has information content enabling the modeling of structural parameters for the pine forests of Central Spain. In this research the quadratic mean diameter (QMD), basal area (BA), and number of trees per hectare $(\mathrm{N})$ of pines in the Central Range of Spain were modeled at the stand level with classification and regression trees (CART). Models were produced with average estimation errors suitable for planning purposes: predictions of QMD had an average error of $17 \%$ and BA an average error of $22 \%$, while $\mathrm{N}$ was correctly classified in $70 \%$ of the cases. Although some refinement of the techniques applied here is possible to support operational activities, this study has demonstrated that following the selection of appropriate statistical tools combined with the periodic acquisition of HSR imagery by the Spanish Plan Nacional de Teledetección (PNT) could be of great value to the forest community as a low cost option to support planning activities. Additional stakeholders could also be accommodated and supplied with wide-area estimates of forest structural attributes following the methods suggested in this research. The capacity to revise the estimates with new plot data in subsequent years and to incorporate depletions using change detection procedures also points to additional utility and value that can be created from the national PNT image collections.

\section{Acknowledgments}

This work was done under the project "Estructura, dinámica y selvicultura para la conservación y el uso sostenible de los bosques en el Sistema Central" (VA-096-A05) with funding from Consejería de Educación, Junta de Castilla y León, Plan Regional I+D+I. Field data was provided by Consejería de Medio Ambiente y Ordenación Territorial de Castilla y León. Brice Mora and Wolfgang Schwanghart are thanked for their help with data analysis.

\section{References}

1. European Forest Institute, Mediterranean Regional Office. A Mediterranean Forest Research Agenda-MFRA 2010-2020; EFIMED: Barcelona, Spain, 2009.

2. Chirici, G.; Barbati, A.; Corona, P.; Marchetti, M.; Travaglini, D.; Maselli, F.; Bertini, R. Non-parametric and parametric methods using satellite images for estimating growing stock volume in alpine and Mediterranean forest ecosystems. Remote Sens. Environ. 2008, 112, 2686-2700. 
3. Bravo, F.; Montero, G. High-grading effects on Scots pine volume and basal area in pure stands in northern Spain. Ann. For. Sci. 2003, 60, 11-18.

4. Bellassen, V.; Maire, G.; Dhote, J.F.; Ciais, P.; Viovy, N. Modelling forest management within a global vegetation model-Part 2: Model validation from a tree to a continental scale. Ecol. Model. 2011, 222, 57-75.

5. McRoberts, R.E.; Tomppo, E.O. Remote sensing support for national forests inventories. Remote Sens. Environ. 2007, 110, 412-419.

6. Falkowski, M.J.; Wulder, M.A.; White, J.C.; Gillis, M.D. Supporting large-area, sample-based forest inventories with very high spatial resolution satellite imagery. Prog. Phys. Geog. 2009, 33, 403-423.

7. Wulder, M.A. Optical remote sensing techniques for the assessment of forest inventory and biophysical parameters. Prog. Phys. Geog. 1998, 22, 449-476.

8. Wulder, M.A.; White, J.C.; Han, T.; Coops, N.C.; Cardille J.A.; Holland, T.; Grills, D. Monitoring Canada forests. Part 2: National forest fragmentation and pattern. Can. J. Remote Sens. 2008, 34, 563-584.

9. Wulder, M.A.; Hall, R.J.; Coops, N.C.; Franklin, S.E. High spatial resolution remotely sensed data for ecosystem characterization. Bioscience 2004, 54, 511-521.

10. Andersson, K.; Evans, T.P.; Richards, K.R. National forest carbon inventories: Policy needs and assessment capacity. Climatic Change 2009, 93, 69-101.

11. Cohen, W.; Goward, S. Landsat's role in ecological applications of remote sensing. BioScience 2004, 54, 535-545.

12. Wulder, M.A.; White, J.C.; Goward, S.N.; Masek, J.G.; Irons, J.R.; Herold, M.; Cohen, W.B.; Loveland, T.R.; Woodcock, C.E. Landsat continuity: Issues and opportunities for land cover monitoring. Remote Sens. Environ. 2008, 112, 955-969.

13. Kayitakire, F.; Hamel, C.; Defourny, P. Retrieving forest structure variables based on image texture analysis and IKONOS-2 imagery. Remote Sens. Environ. 2006, 102, 390-401.

14. Colombo, R.; Bellingeri, D.; Fasolini, D.; Marino, C.M. Retrieval of leaf area index in different vegetation types using high resolution satellite data. Remote Sens. Environ. 2003, 83, 120-131.

15. Ouma, Y.O.; Ngigi, T.G.; Tateishi, R. On the optimization and selection of wavelet texture for feature extraction from high resolution satellite imagery with application towards urban tree delineation. Int. J. Remote Sens. 2006, 27, 73-104.

16. Song, C.; Dickinson, M.B.; Su, L.; Zhang, S.; Yaussey, D. Estimating average tree crown size using spatial information from IKONOS and QuickBird images: Across-sensor and across-site comparisons. Remote Sens. Environ. 2010, 114, 1099-1107.

17. Lu, D.; Mausel, P.; Brondizio, E.; Moran, E. Above-Ground Biomass estimation of Successional and Mature Forests Using TM Images in the Amazon Basin. In Proceedings of Symposium on Geospatial Theory, Processing and Applications, Otawa, ON, Canada, 9-12 July 2002.

18. Ozdemir, I. Estimating stem volume by tree crown area and tree shadow area extracted from pan-sharpened QuickBird imagery in open Crimean juniper forests. Int. J. Remote Sens. 2008, 29 , 5643-5655.

19. Pu, R.; Landry, S.; Yu, Q. Object-based urban detailed land cover classification with high spatial resolution IKONOS imagery. Int. J. Remote Sens. 2011, 32, 3285-3308. 
20. Wulder, M.A.; Ortlepp, S.M.; White, J.C.; Coops, N.C. Impact of sun-surface sensor geometry upon multitemporal high spatial resolution satellite imagery. Can. J. Remote Sens. 2008, 34, 455-461.

21. Lefsky, M.A.; Cohen, W.B.; Acker, S.A.; Parker, G.G.; Spies, T.A.; Harding, D. Lidar remote sensing of the canopy structure and biophysical properties of Douglas-fir Western Hemlock forests. Remote Sens. Environ. 1999, 70, 339-361.

22. Lim, K.; Treitz, P.; Baldwin, K.; Morrison I.; Green, J. Lidar remote sensing of biophysical properties of tolerant northern hardwood forests. Can. J. Remote Sens. 2003, 29, 658-678.

23. Riaño, D.; Chuvieco, E.; Condés, S.; González-Matesanz, J.; Ustin, S.L. Generation of crown bulk density for Pinus sylvestris L. from lidar. Remote Sens. Environ. 2004, 92, 345-352.

24. Zhao, K.; Popescu, S.; Meng, X.; Pang, Y.; Agca, M. Characterizing forest canopy structure with lidar composite metrics and machine learning. Remote Sens. Environ. 2011, 115, 1978-1996.

25. Wulder, M.A.; White, J.C.; Hay, G.J.; Castilla, G. Towards automated segmentation of forest inventory polygons on high spatial resolution satellite imagery. Forest. Chron. 2008, 84, 221-230.

26. Gougeon, F.A.; Leckie, D.G. The individual tree crown approach applied to IKONOS images of a coniferous plantation area. Photogram. Eng. Remote Sensing 2006, 72, 1287-1297.

27. Hirata, Y. Estimation of stand attributes in Cryptomeria japonica and Chamaecyparis obtusa stands using QuickBird panchromatic data. J. Forest Res. 2008, 13, 147-154.

28. Leboeuf, A.; Beaudoin, A.; Fournier, R.A.; Guindon, L.; Luther, J.E.; Lambert, M.C. A shadow fraction method for mapping biomass of northern boreal black spruce forests using QuickBird imagery. Remote Sens. Environ. 2007, 110, 488-500.

29. Franklin, S.E.; Wulder, M.A.; Gerylo, G.R. Texture analysis of IKONOS panchromatic data for Douglas-fir forest age class separability in British Columbia. Int. J. Remote Sens. 2001, 22, 2627-2632.

30. Ozdemir, I.; Norton, D.A.; Ozkan, U.Y.; Mert, A.; Senturk, O. Estimation of tree size diversity using object oriented texture analysis and ASTER imagery. Sensors 2008, 8, 4709-4724.

31. Song, C. Estimating tree crown size with spatial information of high resolution optical remotely sensed imagery. Int. J. Remote Sens. 2007, 28, 3305-3322.

32. Feng, Y.; Li, Z.; Tokola, T. Estimation of stand mean crown diameter from high-spatial-resolution imagery based on a geostatistical method. Int. J. Remote Sens. 2010, 31, 363-378.

33. Merino de Miguel, S.; Solana Gutiérrez, J.; González Alonso, F. Análisis de la estructura espacial de las masas de Pinus pinaster Aiton de la Comunidad de Madrid mediante imágenes de alta resolución espacial. Forest Syst. 2010, 19, 18-35.

34. Duncanson, L.I.; Niemann, K.O.; Wulder, M.A. Integration of GLAS and Landsat TM data for aboveground biomass estimation. Can. J. Remote Sens. 2010, 36, 129-141.

35. Greenberg, J.A.; Dobrowsky, S.Z.; Ustin, S.L. Shadow allometry: Estimating tree structural parameters using hyperspatial image analysis. Remote Sens. Environ. 2005, 97, 15-25.

36. Hyde, P.; Dubayah, R.; Walker, W.; Blair, B.; Hofton, M.; Hunsaker, C. Mapping forest structure for wildlife habitat analysis using multi-sensor (LiDAR, SAR/InSAR, ETM+, Quickbird) synergy. Remote Sens. Environ. 2006, 102, 63-73.

37. Chubey, M.S.; Franklin, S.E.; Wulder, M.A. Object-based analysis of IKONOS-2 imagery for extraction of forest inventory parameters. Photogramm. Eng. Remote Sensing 2006, 72, 383-394. 
38. Proisy, Ch.; Couteron, P.; Fromard, F. Predicting and mapping mangrove biomass from canopy grain analysis using Fourier-based textural ordination of IKONOS images. Remote Sens. Environ. 2007, 109, 379-392.

39. Palace, M.; Keller, M.; Asner, G.P.; Hagen, S.; Braswell, B. Amazon forest structure from IKONOS satellite data and the automated characterization of forest canopy properties. Biotropica 2008, 40, 141-150.

40. Mora, B.; Wulder, M.A.; White, J.C. Segment-constrained regression tree estimation of forest stand height from very high spatial resolution panchromatic imagery over a boreal environment. Remote Sens. Environ. 2010, 114, 2474-2484.

41. Arozarena A. El Plan Nacional de Observación del territorio en España como sistema básico de información Medio Ambiental. In Congreso Nacional del Medio Ambiente, Cumbre del Desarrollo Sostenible, Madrid, Spain, 1-5 December 2008.

42. Villa, G.; Arozarena, A.; Peces, J.J.; Domenech, E. Plan nacional de teledetección: estado actual y perspectivas futuras. In Proceedings of Teledetección: agua y desarrollo sostenible. XIII Congreso de la Asociación Española de Teledetección, Calatayud, Spain, 23-26 September 2009; pp. 521-524.

43. IGN. Plan Nacional de Teledetección (PNT); Versión 2.3; Ministerio de Fomento, Gobierno de España: Madrid, Spain, 2009.

44. Vázquez de la Cueva, A. Structural attributes of three forest types in central Spain and Landsat ETM+ information evaluated with redundancy analysis. Int. J. Remote Sens. 2008, 29, 5657-5676.

45. Pascual, C.; García Abril, A.; García Montero, L.G.; Martín Fernández, S.; Cohen, W.B. Object-based semi-automatic approach for forest structure characterization using lidar data in heterogeneous Pinus sylvestris stands. Forest Ecol. Manag. 2008, 255, 3677-3685.

46. Montes, F.; Sánchez, M.; Río, M.; Cañellas, I. Using historic management records to characterize the effects of management on the structural diversity of forests. Forest Ecol. Manag. 2004, 207, 279-293.

47. Bravo, F.; Río, M.; Pando, V.; San Martín, R.; Montero, G.; Ordoñez, C.; Cañellas, I. El diseño de las parcelas del inventario forestal nacional y la estimación de variables dasómetricas. In $E l$ Inventario Forestal Nacional, Elemento Clave para la Gestión Forestal Sostenible; Bravo, F., Rio, M., Peso, C., Eds.; Fundación General de la Universidad de Valladolid: Valladolid, Spain, 2002; pp. 19-35.

48. Curtis, R.O.; Marshall, D.D. Why quadratic mean diameter? West. J. Appl. For. 2000, 15, 137-139.

49. Chica-Olmo, M. La geoestadística como herramienta de análisis en la gestión forestal. Cuad. Soc. Esp. Cienc. For. 2005, 19, 47-55.

50. Curran, P.J.; Atkinson, P.M. Geostatistics and remote sensing. Prog. Phys. Geog. 1998, 22, 61-78.

51. Clark, I. Practical Geostatistics; Geostokos Limited: Scotland, UK, 2001. Available online: http://w3eos.whoi.edu/12.747/resources/pract_geostat/pg1979_latex.pdf (accessed on 17 May 2011).

52. DigitalGlobe. QuickBird Imagery Products FAQ; Houston, TX, USA, 2005. Available online: http://www.satimagingcorp.com/satellite-sensors/quickbird_imagery_products.pdf (accessed on 17 October 2011). 
53. Chavez, P.S. Image-based atmospheric corrections - Revisited and improved. Photogramm. Eng. Remote Sensing 1996, 62, 1025-1036.

54. Chavez, P. An improved dark object subtraction technique for atmospheric scattering correction of multispectral data. Remote Sens. Environ. 1988, 24, 459-479.

55. Devereux, B.J.; Amable, G.S.; Costa Posada, C. An efficient image segmentation algorithm for landscape analysis. Int. J. Appl. Earth Obs. Geoinf. 2004, 6, 47-61.

56. Hay, G.J.; Castilla, G.; Wulder, M.A.; Ruiz, J.R. An automated object-based approach for the multiscale image segmentation of forest scenes. Int. J. Appl. Earth Obs. Geoinf. 2005, 7, 339-359.

57. Baatz, M.; Schäpe, M. Multiresolution segmentation-An optimization approach for high quality multi-scale image segmentation. In Angewandte Geographische Informations-Verarbeitung XII.; Strobl, J., Blaschke, T., Griesebner, G., Eds.; Wichmann Verlag: Karlsruhe, Germany, 2000; pp. 12-23.

58. Definiens. Definiens Professional 5 User Guide; Definiens: Munich, Germany, 2006.

59. Salvador, R.; Pons, X. On the applicability of Landsat TM images to Mediterranean forest inventories. Forest Ecol. Manag. 1998, 104, 193-208.

60. Haralick, R.M.; Bryant, W.F. Documentation of Procedures for Textural/Spatial Pattern Recognition Techniques; Technical Report 278-1; Remote Sensing Laboratory, University of Kansas: Lawrence, KS, USA, 1976.

61. Wulder, M.A.; LeDrew, E.F.; Franklin, S.E.; Lavigne, M.B. Aerial texture information in the estimation of northern deciduous and mixed wood forest leaf area index (LAI). Remote Sens. Environ. 1998, 64, 64-76

62. Lu, D. The potential and challenge of remote sensing-based biomass estimation. Int. J. Remote Sens. 2006, 27, 1297-1328.

63. Franklin, S.E.; Hall, R.J.; Moskal, L.M.; Maudie, A.J.; Lavigne M.B. Incorporating texture into classification of forest species composition from airborne multispectral images. Int. J. Remote Sens. 2000, 21, 61-79.

64. Couteron, P.; Pelissier, R.; Nicolini, E.A.; Paget, D. Predicting tropical forest stand structure parameters from Fourier transform of very high-resolution remotely sensed canopy images. $J$. App. Ecol. 2005, 42, 1121-1128.

65. Lu, D.; Batistella, M. Exploring TM image texture and its relationships with biomass estimation in Rondonia, Brazilian Amazon. Acta Amazonica 2005, 35, 249-257.

66. Haralick, R.M.; Shanmugan, K.; Dinstein, I. Texture features for image classification. IEEE T. Syst. Man Cyb. 1973, 3, 610-621.

67. Caridade, C.M.R.; Marca, A.R.S.; Mendonca, T. The use of texture for image classification of black \& white air photographs. Int. J. Remote Sens. 2008, 29, 593-607

68. Hall-Beyer, M. GLCM Tutorial Home Page; 2007. Available online: http://www.fp.ucalgary.ca/ mhallbey/tutorial.htm (accessed on 13 October 2011).

69. Ahearn, S.C. Combining Laplacian images of different spatial frequencies (scales): Implications for remote sensing analysis. IEEE Trans. Geosci. Remote Sens. 1988, 26, 826-831.

70. Ferro, C.; Warner, T. Scale and texture in digital image classification. Photogramm. Eng. Remote Sensing 2002, 68, 51-63. 
71. Johansen, K.; Coops, N.C.; Gergel, S.E.; Stange, Y. Application of high spatial resolution satellite imagery for riparian and forest ecosystem classification. Remote Sens. Environ. 2007, 110, 29-44.

72. Nijland, W.; Addink, E.A.; de Jong, S.M.; Van der Meer, F.D. Optimizing spatial image support for quantitative mapping of natural vegetation. Remote Sens. Environ. 2009, 113, 771-780.

73. Montes, F.; Rubio, A.; Barbeito, I.; Cañellas, I. Characterization of the spatial structure of the canopy in Pinus sylvestris L. stands in Central Spain from hemispherical photographs. Forest Ecol. Manag. 2008, 255, 580-590.

74. Pal, M.; Mather, P.M. An assessment of the effectiveness of decision tree methods for land cover classification. Remote Sens. Environ. 2003, 86, 554-565.

75. Baccini, A.; Laporte, N.; Goetz, S.J.; Sun, M.; Dong, H. A first map of tropical Africa's above-ground biomass derived from satellite imagery. Environ. Res. Let. 2008, 3, 045011

76. Breiman, L.; Friedman, J.H.; Olshen, R.A.; Stone, C.J. Classification and Regression Trees; Chapman and Hall/CRC: Boca Raton, FL, USA, 1984; p. 358.

77. Brown de Colstoun, E.C.; Story, M.H.; Thompson, C.; Commisso, K.; Smith, T.G.; Irons, J.R. National Park vegetation mapping using multitemporal Landsat 7 data and a decision tree classifier. Remote Sens. Environ. 2003, 85, 316-327.

78. Mcdermid, G.J.; Smith, I.U. Mapping the distribution of whitebark pine (Pinus albicaulis) in Waterton Lakes National Park using logistic regression and classification tree analysis. Can. J. Remote Sens. 2008, 34, 356-366.

79. Ke, Y.; Quackenbush, L.J.; Im, J. Synergistic use of QuickBird multispectral imagery and LIDAR data for object-based forest species classification. Remote Sens. Environ. 2010, 114, 1141-1154.

80. Andrew, M.E.; Ustin, S.L. Habitat Suitability Modeling of an invasive plant with advanced remote sensing data. Divers. Distrib. 2009, 15, 627-640.

81. Im, J.; Jensen, J.R. A change detection model based on neighborhood correlation image analysis and decision tree classification. Remote Sens. Environ. 2005, 99, 326-340.

82. Lozano, F.J.; Suárez-Seoane, S.; Kelly, M.; Luis, E. A multi-scale approach for modeling fire occurrence probability using satellite data and classification trees: A case study in a mountainous Mediterranean region. Remote Sens. Environ. 2008, 112, 708-719.

83. Falkowski, M.J.; Evans, J.; Martinuzzi, S.; Gessler. P.E.; Hudak, A.T. Characterizing forest succession with lidar data: an evaluation for the Inland Northwest, USA. Remote Sens. Environ. 2009, 113, 946-956.

84. Goetz, S.J.; Wright, R.K.; Smith, A.J.; Zinecker, E.; Schaub, E. IKONOS imagery for resource management: tree cover, impervious surfaces, and riparian buffer analyses in the mid-Atlantic region. Remote Sens. Environ. 2003, 88, 195-208.

85. Biondini, M.E.; Mielke, P.W., Jr.; Berry, K.J. Data-dependent permutation techniques for the analysis of ecological data. Vegetatio 1988, 75, 161-168.

86. Mielke, P.W., Jr.; Berry, K.J. Permutation Methods: A Distance Function Approach; Springer Series in Statistics; Springer: New York, NY, USA, 2001.

87. Foody, G.M.; Cutler, M.E.; McMorrow, J.; Pelz, D.; Tangki, H.; Boyd, D.S.; Douglas, I. Mapping the biomass of Bornean tropical rain forest from remotely sensed data. Global Ecol. Biogeogr. 2001, 10, 379-387. 
88. Wulder, M.A.; Niemann, K.O.; Goodenough, D.G. Error reduction methods for local maximum filtering. Can. J. Remote Sens. 2002, 28, 667-671.

89. Bernués, D. La gestión forestal sostenible en Aragon. Foresta 2008, 43, 104-107.

90. MMA. Anuario de Estadística Forestal 2008; Ministerio de Medio Ambiente y Medio Rural y Marino: Madrid, Spain, 2008; p. 96.

91. Wulder, M.A.; Kurz, W.A.; Gillis, M. National level forest monitoring and modeling in Canada. Prog. Phys. Plan. 2004, 61, 365-381.

92. Culvenor, D.S. Extracting individual tree information: A survey of techniques for high spatial resolution imagery. In Remote Sensing of Forest Environments: Concepts and Case Studies; Wulder, M.A., Franklin, S.E. Eds.; Kluwer Academic Publishers: Boston, MA, USA, 2003; pp. 255-277.

93. Aguilar, M.A.; Agüera, F.; Aguilar, F.J.; Carvajal, F. Geometric accuracy assessment of the orthorectification process from very high resolution satellite imagery for common agricultural policy purposes. Int. J. Remote Sens. 2008, 29, 7181-7197.

94. Bruniquel-Pinel, V.; Gastellu-Etchegorry, J.P. Sensitivity of texture of high resolution images of forest to biophysical and acquisition parameters. Remote Sens. Environ. 1998, 65, 61-85.

95. Maselli, F. Monitoring forest conditions in a protected Mediterranean coastal area by the analysis of multiyear NDVI data. Remote Sens. Environ. 2004, 89, 423-433.

96. Leckie, D.G.; Gougeon, F.A.; Walsworth, N.; Paradine, D. Stand delineation and composition estimation using semi-automated individual tree crown analysis. Remote Sens. Environ. 2003, 85, 355-369.

97. Lamonaca, A.; Corona, P.; Barbati, A. Exploring forest structural complexity by multi-scale segmentation of VHR imagery. Remote Sens. Environ. 2008, 112, 2839-2849.

(C) 2012 by the authors; licensee MDPI, Basel, Switzerland. This article is an open access article distributed under the terms and conditions of the Creative Commons Attribution license (http://creativecommons.org/licenses/by/3.0/). 



\section{CHAPTER IV}

Cristina Gómez, Michael A. Wulder, Fernando Montes, José A. Delgado, 2011. Forest structural diversity characterization in Mediterranean pines of Central Spain with QuickBird-2 imagery and canonical correlation analysis. Canadian Journal of Remote Sensing, 37(6), 628-642.

\section{RESUMEN}

\section{Diversidad estructural en pinares mediterráneos del Sistema Central español mediante imágenes QuickBird-2 y análisis de correlación canónica}

El conocimiento de la variabilidad estructural proporciona información sobre la biodiversidad en los bosques, ya que estructuras forestales irregulares se asocian a una mayor complejidad de la vegetación. La caracterización de la diversidad estructural mediante teledetección contribuye al seguimiento de los ecosistemas, al desarrollo de estrategias de gestión y a la producción de informes. En este trabajo se investigó las relaciones entre la diversidad de estructura en pinares mediterráneos del Sistema Central español y las variables derivadas de imágenes de alta resolución espacial obtenidas con el satélite comercial QuickBird-2 (pixel de tamaño 2.4 m multiespectral y 0.68 m pancromática).

Se caracterizó la diversidad estructural a escala de parcela $(\mathrm{N}=1022)$ como combinación lineal de varias medidas de dispersión (MAD: desviación absoluta de la mediana) en relación a las medias equivalentes locales, considerando los diámetros de troncos individuales, alturas y diámetros de copa. Paralelamente se evaluaron las variaciones espectrales en las bandas del visible e infrarrojo cercano, así como varias medidas de textura extraídas de las imágenes pancromáticas y evaluadas con varios tamaños de ventana. Estas medidas espectrales y de textura se calcularon sobre áreas circulares de 0.3 ha en correspondencia con las parcelas medidas sobre terreno. El análisis de correlación canónica ayudó en la identificación de las combinaciones de reflectancia y medidas de textura que mayor relación tienen con la diversidad estructural forestal $(\mathrm{R} \sim 0.89)$. Se encontró que la diversidad de reflectancia tiene mayor capacidad que las medidas de textura para describir la diversidad estructural forestal cuando las masas son homogéneas ( $\mathrm{R} \sim 0.47$ versus $\mathrm{R} \sim 0.39$ ), mientras que la textura cobra relevancia en el modelo cuando la estructura forestal es compleja ( $\mathrm{R} \sim 0.88$ versus $\mathrm{R} \sim 0.63$ ). A pesar de que los resultados están definidos empíricamente por las condiciones locales y las características de adquisición de las imágenes, demuestran la capacidad de las imágenes de alta resolución espacial para la 
descripción de la diversidad estructural en bosques del entorno Mediterráneo, un resultado de especial relevancia en España, donde el Plan Nacional de Teledetección ha comenzado la colección de una cobertura anual de imágenes de alta resolución espacial sobre todo el territorio nacional.

Palabras clave: diversidad estructural forestal, pinares mediterráneos, QuickBird-2, textura, reflectancia, análisis de correlación canónica, seguimiento, informes 


\title{
Forest structural diversity characterization in Mediterranean pines of central Spain with QuickBird-2 imagery and canonical correlation analysis
}

\author{
Cristina Gómez, Michael A. Wulder, Fernando Montes, and José A. Delgado
}

\begin{abstract}
Variation in forest structure provides information on vegetation complexity and provides insights on biodiversity. Characterizing forest structural diversity with remotely sensed data supports reporting, monitoring, and policy development. We explored the relationship between forest structural diversity in Mediterranean pines of the Spanish Central Range and variables derived from imagery captured with a commercial high spatial resolution satellite (QuickBird-2; with pixels sided $2.4 \mathrm{~m}$ multispectral and $0.68 \mathrm{~m}$ panchromatic). To combine multiple aspects of tree conditions at a stand level, "structural diversity" was characterized at the plot level $(N=1022)$ as a linear combination of the median of absolute differences of individual trees' bole diameter, height, and crown diameter measured on the field from the local median equivalents. Spectral reflectance variations in the visible and near-infrared, as well as image co-occurrence texture metrics from the panchromatic imagery at various window sizes were generated. All relationships to image-derived values were assessed against circular 0.3 ha areas corresponding with the field measured plots. Canonical correlation analysis aided in identification of combinations of reflectance and texture metrics most highly related with forest structural diversity $(R=0.89)$. Reflectance diversity was found to be more important than co-occurrence texture features in describing forest structural diversity when forest structure was limited $(R=0.47$ vs. $R=0.39$ ), whereas texture was more informative to the model when the forest structural diversity was high ( $R=0.88$ vs. $R=0.63$ ), relating more complex forest conditions. Our results, although empirically defined by the local conditions and image acquisition characteristics, demonstrated the potential in high spatial resolution imagery for description of forest structural diversity in forests of the Mediterranean environment, especially important for Spain where a national high spatial resolution image data base has been collected.
\end{abstract}

\begin{abstract}
Résumé. La variation de la structure forestière fournit de l'information sur la complexité de la végétation et apporte un éclairage quant à la biodiversité. La caractérisation de la diversité de la structure forestière à l'aide des données de télédétection est un outil utile pour la communication des données, le suivi et le développement de politiques. On a exploré la relation entre, d'une part, la diversité de la structure forestière dans les pins méditerranéens dans la cordillère centrale de l'Espagne et, d'autre part, les variables dérivées des images acquises par un satellite commercial à haute résolution spatiale (QuickBird-2 avec un espacement de pixels de 2,4 m en mode multispectral et de 0,68 $\mathrm{m}$ en mode panchromatique). Pour combiner les multiples aspects des conditions des arbres au niveau du peuplement, la "diversité structurale" a été caractérisée au niveau de la parcelle $(N=1022)$ comme étant une combinaison linéaire de la médiane des différences absolues du diamètre des troncs, de la hauteur et du diamètre de la couronne des arbres individuels mesurés sur le terrain à partir des équivalents de la médiane locale. On a ainsi généré des variations de la réflectance spectrale dans le visible et le proche infrarouge de même que des mesures de cooccurrence de la texture à partir des images panchromatiques pour diverses dimensions de fenêtre. Toutes les relations par rapport aux valeurs dérivées des images ont été évaluées en fonction de parcelles circulaires de 0,3 ha de superficie correspondant aux parcelles mesurées sur le terrain. Une analyse de corrélation canonique a permis d'identifier les combinaisons de mesures de réflectance et de texture les plus reliées à la diversité de la structure forestière $(R=0,89)$. On a pu observer que la diversité de la réflectance était plus importante que les caractéristiques de cooccurrence de la texture pour décrire la diversité structurale de la forêt lorsque la structure de la forêt était limitée ( $R=0,47$ vs. $R=0,39$ ), alors que la texture procurait plus d'information pour le modèle lorsque la diversité structurale de la forêt était élevée $(R=0,88$ vs. $R=0,63)$, montrant des conditions forestières plus complexes. Nos résultats, bien qu'empiriquement définis par les conditions locales et les caractéristiques d'acquisition
\end{abstract}

Received 22 September 2011. Accepted 28 November 2011. Published on the Web at http://pubs.casi.ca/journal/cjrs on 23 April 2012. C. Gómez ${ }^{1}$ and J.A. Delgado. Sustainable Forest Management Research Institute, Universidad de Valladolid, E-34004 Palencia, Spain. M.A. Wulder. Canadian Forest Service (Pacific Forestry Centre), Natural Resources Canada, Victoria, British Columbia, V8Z 1M5, Canada. F. Montes. Departamento de Sistemas y Recursos Forestales, CIFOR-INIA, Ctra. de La Coruña km 7.5, 28040 Madrid, Spain.

${ }^{1}$ Corresponding author (e-mail: c.gomez@abdn.ac.uk). 
d'image, démontrent le potentiel des images à haute résolution spatiale pour la description de la diversité structurale de la forêt dans les forêts en milieu méditerranéen, ce qui est particulièrement important dans le cas de l'Espagne où une base de données nationale d'images à haute résolution a été élaborée.

[Traduit par la Rédaction]

\section{Introduction}

Forest structural diversity is important for sustainable management (Río et al., 2003) and for conservation of biodiversity (Gil-Tena et al., 2010). Structurally complex forests are found to better contribute to recreational uses compared with plantations (Rydberg and Falck, 2000), and they provide a wider range of habitat conditions as well (Sullivan et al., 2001). The complexity in the arrangement of forest elements is also associated with the resilience to change, that is, the ability to adapt and respond to disturbances and perturbations (Rozdilsky and Stone, 2001; Elmqvist et al., 2003; García-López and Allué, 2011).

The structure of forest stands can be characterized by the size, age, and species distribution in vegetation layers, frequently focusing on the tree component (Poage and Tappeiner, 2005). Measures of forest structure often include vertically distributed features (e.g., dominant height, number, and distribution of strata) and horizontal features (e.g., crown size, gaps) (Spies and Franklin, 1991; Wulder et al., 2004), as well as species richness (Maltamo et al., 2005). The number and variation of relative abundance of different attributes across forest stands defines the forest complexity (McElhinny et al., 2005). When species richness is low, tree size variables such as height, diameter, and crown dimension may become the most important factors affecting structural diversity (Neumann and Starlinger, 2001) and a key aspect to assess stand biodiversity (Pommerineng, 2006).

A variety of indices have been developed to quantify tree size diversity (e.g., Shannon index, Gini coefficient, Simpson index) (McElhinny et al., 2005), requiring measurement of certain parameters on the ground for evaluation (Lexerod and Eid, 2006). Measures describing tree size diversity within stands are important to assess economical, ecological and social values of the forest (Lexerod and Eid, 2006). For an accurate description of stand structure a combination of various measures or resultant indices is often required (Rouvinen and Kuuluvainen, 2005). Furthermore, mapping and monitoring tree size diversity over large areas, and with a given temporal repetition for local and international reporting purposes, requires affordable methods from both economic and application perspectives. The synoptic view, extensive coverage, and the consistency and frequency of data acquisition, make remote sensing uniquely well suited as a source of information for the periodic assessment of forest structural diversity. Remote sensing provides data collected in a consistent and systematic fashion representing large areas at a known period in time (Wulder et al., 2004). The remotely sensed data can be integrated with ground data to extend and inform about local measures to represent wide areas in a consistent, practical, and repeatable manner. The goal of this research is to assess the potential of high spatial resolution imagery to characterize forest structural diversity in Mediterranean pines of the Spanish Central Range with the following objectives: (i) to determine and quantify the relationships between "forest structural diversity" measured at the plot level and data captured by a satellite-borne sensor in the form of visible and near-infrared (NIR) spectral reflectance as well as spatial combinations of panchromatic reflectance values, as related by texture metrics; (ii) to identify the relative relevance of reflectance measures versus texture metrics in characterizing the forest structural diversity; and (iii) to assess how the spectral diversity - structural diversity relationship varies under different conditions of forest density, i.e., determine if different relations occur in open versus closed forest conditions.

\section{Background}

Remote sensing has been widely used to characterize forest structure (St-Onge and Cavayas, 1995; Cho et al., 2009; Wolter et al., 2009) and forest structural complexity (Coops and Catling, 1997; Ozdemir et al., 2008; Pasher and King, 2010) with data acquired from a variety of sensor types representing a range of scales of information. Cohen et al. (1995) applied the Tasseled Cap Transformation components from medium spatial resolution Landsat imagery (30 m pixel size) to map four structurally different coniferous classes in Oregon, with an overall accuracy of $82 \%$. White et al. (2010) characterized forest canopy structural diversity in coastal temperate forests of Canada with hyperspectral data from Hyperion EO-1 and canonical correlation analysis. They found that age and height diversity are the structural attributes most strongly related to spectral diversity and concluded that in addition to species, structural diversity should be considered for assessment of biodiversity in coastal environments. Miura and Jones (2010) demonstrated that LiDAR (Light Detection and Ranging) is particularly valuable for description of vertical structure. They developed a protocol for characterization of the structure of a dry Eucalypt forest landscape using different laser pulse return properties from a waveform LiDAR system. The classification scheme consisted of eight structural categories and allowed the quantification of gaps in different layers. Hyde et al. (2006) tested the synergy of various types of sensors for estimation of structural parameters at the stand and at the landscape level in a range of forests environments in California. They concluded that LiDAR with Landsat Enhanced Thematic Mapper Plus $(\mathrm{ETM}+)$ was the best combination of sensors producing the most accurate regression models between forest structural parameters and remotely sensed metrics. The 
synoptic view and the range of techniques available for analysis of data make remote sensing valuable for assisting the assessment of forest structure conditions (Cohen and Goward, 2004).

The availability of high spatial resolution imagery has enabled the development and application of image analysis techniques such as "crown isolation" (Gougeon and Leckie, 2006; Hirata, 2008), "shadow analysis" (Greenberg et al., 2005; Leboeuf et al., 2007), "texture analysis" (Franklin et al., 2001; Kayitakire et al., 2006) or "geostatistical" approaches (Song, 2007; Feng et al., 2010) that individually, or combined, facilitate the study of forest structure and structure complexity at local spatial scales. Panchromatic imagery, with finer spatial resolution $(<1 \mathrm{~m}$ pixel size) than multispectral (MS) imagery is well suited for accurate identification of individual tree characteristics (Colombo et al., 2003), enabling the analysis of spatial relations through image texture measures (Ouma et al., 2006; Song et al., 2010). Combining the spatial detail of panchromatic imagery and the unique spectral information conferred by MS imagery leverages complementary information (Lu et al., 2002) that can be employed separately or with a pan-sharpening approach (Ozdemir 2008; Pu et al., 2011). It has been frequently noted that as crown closure increases the capacity to characterize forest structural attributes decreases (Falkowski et al., 2009), with leaf area index (LAI) as an example where an asymptote in LAI is typically reached (e.g., LAI approx. 3-3.5, crown closure 60\%). Based upon this understanding of the limitation of optical imagery and related analysis techniques, we posit that forest openness (e.g., open, semi-open, or closed) may indicate which technique is most appropriate for a particular site and that some techniques might be transferable between sensors and sites (Song et al., 2010).

In Mediterranean environments the study of forest structure and complexity has received heightened attention during recent years. Pascual et al. (2008) used LiDAR data and a two-stage object-based methodology to characterize the structure of Pinus sylvestris L. stands in forests of central Spain. Five structure types were defined based on height and density parameters. The median and standard deviation of height were the most valuable variables for definition of structure types. The approach applied was proposed for operational application in the inventory procedure and forest management plans. Vázquez de la Cueva (2008) explored the existence of relations between forest structural attributes at the plot level (e.g., height, density, basal area, and crown canopy closure) and spectral information derived from Landsat ETM + (30 m pixel size) imagery combined with topographic data. The study considered three types of forest in central Spain and applied a multivariate canonical ordination method (redundancy analysis). There was a strong influence of vegetation type on the results but the low percentage of variance explained by the statistical analysis precluded derivation of practical empirical models. Merino de Miguel et al. (2010) explored the existence of relations between dasometric parameters and textural variables in Pinus pinaster Ait. stands in central Spain. The research applied geostatistical tools such as the variogram, calculated with orthophotography and IKONOS-2 imagery of original and degraded spatial resolution and found the strongest correlations when the variogram was calculated for spatial resolutions of $1 \mathrm{~m}$ and $2 \mathrm{~m}$.

Lamonaca et al. (2008) explored forest structural complexity of a beech forest in Italy with a multilevel classification of QuickBird imagery. Applying field-based diversity indices of tree size, spacing, and species assemblage, they quantified structural heterogeneity amongst forest regions delineated by segmentation and evaluated the relationships between spatial heterogeneity in forest structure and segmented polygons. Their results supported the premise that a mixture of macro and micro structural heterogeneity is present within the beech forests investigated. Ozdemir et al. (2008) examined the potential of ASTER imagery ( $15 \mathrm{~m}$ pixel size) to estimate tree size diversity over forested landscapes in Turkey. With an object-oriented approach they related texture measures with diversity indices, finding the Gini coefficient more related with image parameters than the Shannon index. To the best of our knowledge there has not been any exploration of the capacity of high spatial resolution $(<5 \mathrm{~m}$ pixel size) imagery to characterize forest structural diversity in Mediterranean forests at the plot level.

\section{Methods}

Forest parameters measured in the field, analogous to those made in support of forest management inventories, were used to derive the structural diversity attributes. The spectral and spatial measures were generated from QuickBird-2 multispectral and panchromatic imagery. The relationship between the measures of forest structural diversity at the plot level and reflectance-texture diversity were then explored using Canonical Correlation Analysis (CCA) and the outputs were interpreted based on the correlations between the diversity measures and the canonical variates (Figure 1).

\section{Study area}

The study focused on two pine forests in the Central Range of Spain (Figure 2): Pinar de Valsaín (hereafter Valsaín) and Valle de Iruelas (hereafter Iruelas), with distinctive structural parameters derived from natural circumstances (e.g., species composition, site condition, disturbances) and human induced factors (e.g., silvicultural treatments and production use) (Table 1).

Valsaín is a 7627 ha forest of Pinus sylvestris L. on the north facing slopes of Sierra de Guadarrama (Segovia). It is a multifunctional forest, dedicated to timber production, recreational opportunities, and protection, with an established management plan since 1889 . The silvicultural system 


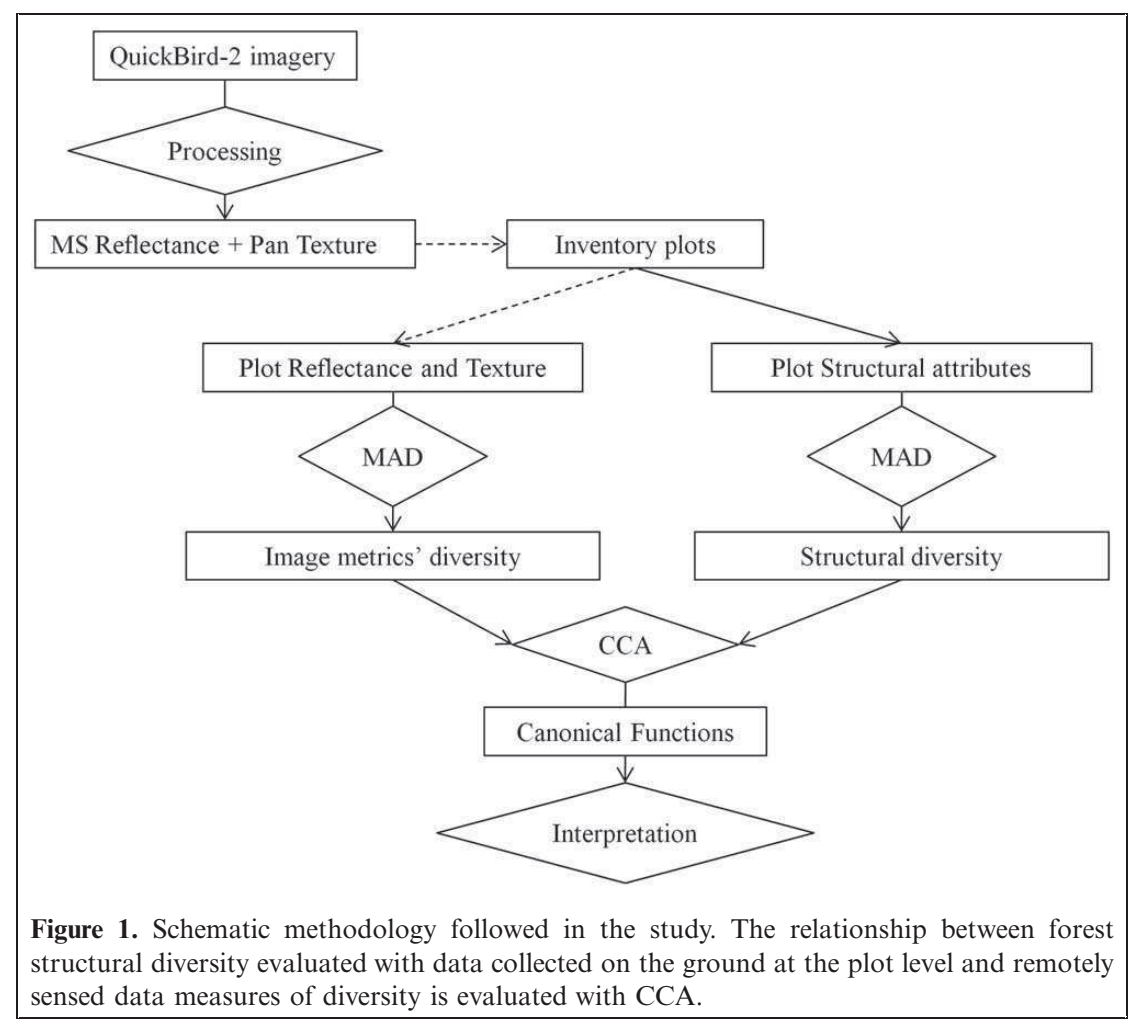

applied evolved from an initial uniform shelterwood system in permanent blocks (rotation of 120 years and regeneration period of 20 years) to a selective cuttings system until 1988, when a flexible management system was established to allow for revisions to the established plan with reference to the overall production objectives. Management actions and recreational activities such as trail walking, which have gained importance in recent decades and occur mainly at lower elevations, have had an impact on the forest structure (Montes et al., 2004).

Iruelas is a 5483 ha forest of $P$. pinaster Ait., P. sylvestris L., and P. nigra Arn. in Sierra de Gredos (Ávila). It is also a multifunctional forest producing wood, resin, and pastures and providing recreation opportunities such as trail walking, camping, and bird watching. Although the first management plan was approved in 1886, historical circumstances prevented an implementation directly following specification. The production of resin during the twentieth century favoured old growth development; a rich history of fires has also conditioned the forest structure.

\section{Forest structure diversity parameters}

Forest structure is difficult to characterize using a single variable (Lefsky et al., 2005) and requires information relating both vertical and horizontal distribution of vegetation elements. Horizontal structure largely concerns the spatial distribution and density of trees (St-Onge and Cavayas, 1995) and is frequently described through the diameter at breast height (DBH) or some derived statistics; vertical structure refers to tree height distribution requiring some height related parameter for description (Tappeiner II et al., 2007).

Plot-based forest inventories are periodically conducted for management in both study sites. Following local management inventory practices circular plots of $11 \mathrm{~m}$ radius, on average, are established over a regular grid with GPS providing precise location, with attributes such as $\mathrm{DBH}$, height, crown diameter, and number of trees being measured for all or a representative sample of trees in each plot. The distribution of structural parameters of individual trees follows an inverse J-shaped curve in Valsaín and Iruelas at a global level, as typically occurs in sustainably managed Mediterranean forests.

We derived "structure diversity attributes" from field measured mensurational data (Table 1); the Median Absolute Deviation (MAD) (Equation (1)) of the DBH (D $\mathrm{D}_{\mathrm{MAD}}$ ), height $\left(\mathrm{H}_{\mathrm{MAD}}\right)$ and crown diameter $\left(\mathrm{C}_{\mathrm{MAD}}\right)$ was calculated at the plot level for a total of 1022 plots (461 in Valsaín and 561 in Iruelas). MAD variables were normalized with a Box-Cox algorithm (Box and Cox, 1982). The "MAD metrics" are always positive and their values are directly related with structural diversity, i.e., plots with higher values of $\mathrm{D}_{\mathrm{MAD}}, \mathrm{H}_{\mathrm{MAD}}$, and $\mathrm{C}_{\mathrm{MAD}}$ are structurally more diverse 
Vol. 37, No. 6, December/décembre 2011

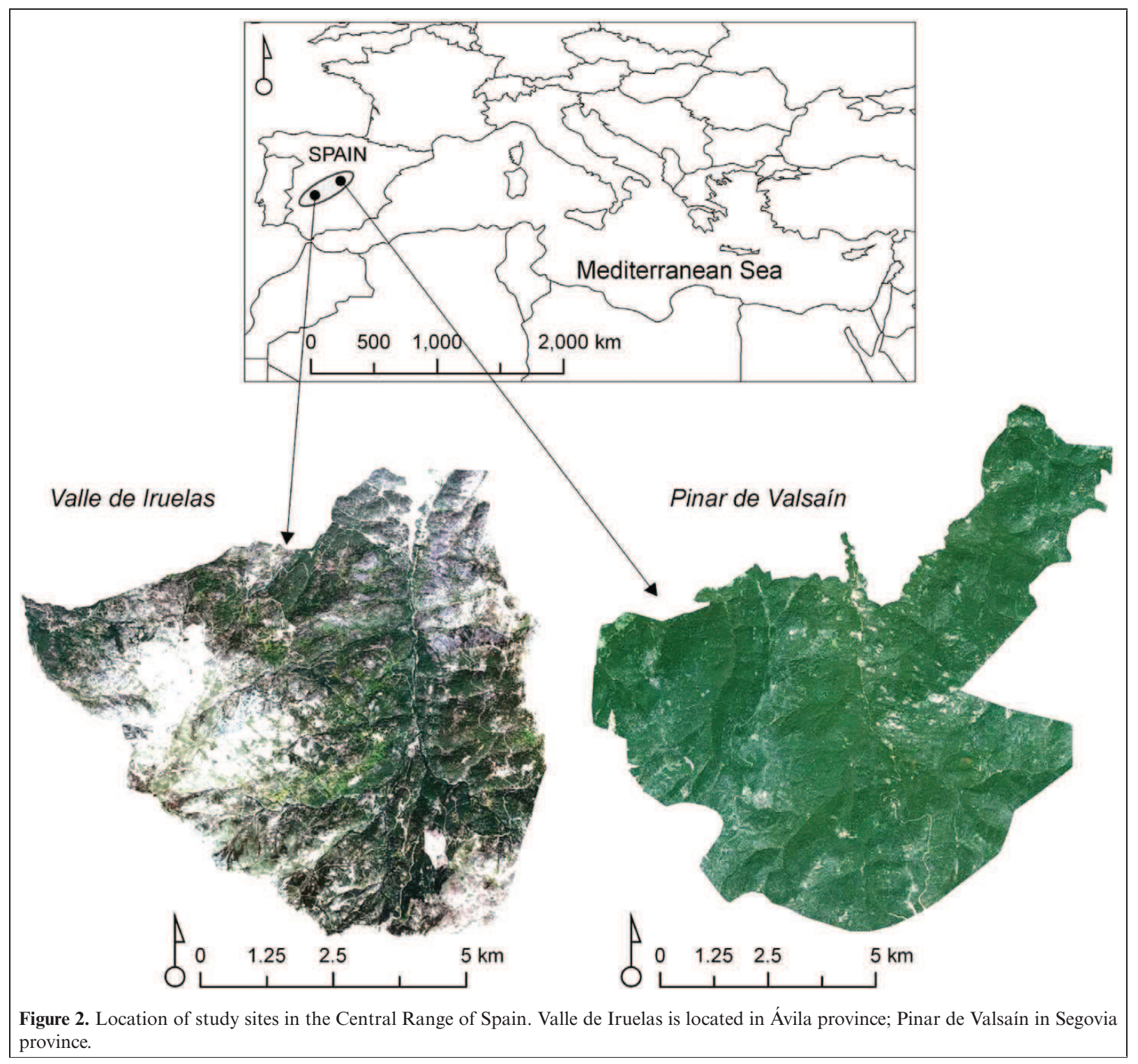

Table 1. Descriptive parameters of forest structural attributes measured on the ground.

\begin{tabular}{|c|c|c|c|c|c|c|c|c|c|c|c|c|}
\hline & \multicolumn{4}{|l|}{ Valsaín } & \multicolumn{4}{|l|}{ Iruelas } & \multicolumn{4}{|c|}{ Combined } \\
\hline & $\mathrm{DBH}$ & $\mathrm{H}$ & $\mathrm{C}$ & $\mathrm{N}$ & $\mathrm{DBH}$ & $\mathrm{H}$ & $\mathrm{C}$ & $\mathrm{N}$ & $\mathrm{DBH}$ & $\mathrm{H}$ & $\mathrm{C}$ & $\mathrm{N}$ \\
\hline Mean & 23.30 & 15.20 & 4.46 & 445.78 & 30.5 & 13.81 & 4.61 & 451.32 & 30.58 & 15.97 & 4.63 & 448.92 \\
\hline Standard error & 0.09 & 0.03 & 0.01 & 13.42 & 0.11 & 0.32 & 0.01 & 16.07 & 0.11 & 0.23 & 0.01 & 10.79 \\
\hline Median & 25 & 13.7 & 4.26 & 398.67 & 26.2 & 13.3 & 4.17 & 324.67 & 26.25 & 14.7 & 4.18 & 365.44 \\
\hline Standard deviation & 14.56 & 6.09 & 1.75 & 289.25 & 15.13 & 5.57 & 1.69 & 395.27 & 15.24 & 6.68 & 1.70 & 353.04 \\
\hline Sample variance & 212.01 & 37.15 & 3.09 & 83667 & 229.19 & 31.13 & 2.87 & 156243 & 232.51 & 44.64 & 2.90 & 124641 \\
\hline Range & 122 & 44.2 & 13.30 & 1893 & 204.6 & 30.5 & 18.98 & 2532 & 209.6 & 44.5 & 19.30 & 2532 \\
\hline Minimum & 10 & 5.8 & 0.92 & 33.22 & 15.0 & 4.5 & 2.71 & 32.46 & 10 & 4.5 & 0.92 & 32.46 \\
\hline Maximum & 132 & 50 & 14.23 & 1926 & 219.6 & 35 & 21.69 & 2564 & 219.6 & 50 & 21.69 & 2564.0 \\
\hline
\end{tabular}

\footnotetext{
Note: DBH, diameter at breast height $(1.30 \mathrm{~m})$; H, height; $\mathrm{C}$, crown diameter; $\mathrm{N}$, number of trees per ha.
} 
(and therefore more complex) than plots with lower values. A zero value is possible, while unlikely, if all trees measured in a plot have exactly the same dimension. As a density attribute, the number of trees per ha $(N)$ would be expected to be significant in the characterization of forest structure diversity at the stand level, but at the scale of analysis (plot level) there is no internal variation of this variable. We included the number of trees per ha $(N)$ as an absolute value (no plot MAD could be calculated) in the initial stages of analysis, but found no significance in the models.

$\operatorname{MAD}=\operatorname{median}_{i}\left(\operatorname{abs}\left(X_{i}-\operatorname{median}_{j}\left(X_{j}\right)\right)\right)$

where $X_{i}$ is the attribute (i.e., DBH, height, crown diameter) of the $i$ th element in each plot and $X_{j}$ is the attribute of the $j$ th element of the complete sample.

\section{High spatial resolution imagery}

Imagery acquired by the QuickBird-2 satellite covering the study sites was used. QuickBird-2 collects data in various regions of the electromagnetic spectrum, with three bands in the visible and one in the NIR (with $2.4 \mathrm{~m} \times 2.4 \mathrm{~m}$ pixels); an additional panchromatic band provides data with finer spatial resolution (with $0.68 \mathrm{~m} \times 0.68 \mathrm{~m}$ pixels; Table 2). QuickBird-2, launched 18 October 2001, is a commercial satellite and is unique among other satellites in this class as it has the largest image footprint and most on-board storage capacity.

Processing of imagery involved: atmospheric correction of the multispectral images with the COST model (Chavez, 1996) using water bodies as dark objects and the atmosphere-scattered path radiance $L_{\lambda}^{p}$ estimated with a relative spectral scattering DOS model $\left(\lambda^{-4}\right)$ under very clear atmospheric conditions (Chavez, 1988). Separate orthorectification of the multispectral (MS) and panchromatic (Pan) bands with a digital elevation model derived from a contour vector map 1:10 000 (www.sitcyl.jcyl.es) (Root Mean Square Error of $0.69-0.72 \mathrm{~m}$ for the MS bands and 0.66-0.81 m for the Pan bands); and registration to aerial photography

Table 2. Characteristics of the satellite imagery used in the study.

\begin{tabular}{lll}
\hline \multicolumn{3}{c}{ QuickBird-2 imagery } \\
\hline Spatial resolution & Multispectral & $2.4 \mathrm{~m}$ \\
& Panchromatic & $0.68 \mathrm{~m}$ \\
Bands & Blue & $0.45-0.52 \mu \mathrm{m}$ \\
& Green & $0.52-0.60 \mu \mathrm{m}$ \\
& Red & $0.63-0.69 \mu \mathrm{m}$ \\
& NIR & $0.76-0.90 \mu \mathrm{m}$ \\
& Pan & $0.45-0.90 \mu \mathrm{m}$ \\
& Valsaín & Iruelas \\
Date & 19 May 2004 & 05 August 2005 \\
Sun elevation $\left({ }^{\circ}\right)$ & 58.4 & 72.0 \\
\hline
\end{tabular}

of $0.25 \mathrm{~m}$ pixel size (www.sitcyl.jcyl.es), with the full suite of characteristics in Table 2.

\section{Image metrics: reflectance and texture diversity}

Image texture is a valuable criterion for visual interpretation, contains information about spatial and structural arrangement of objects (Tso and Mather, 2001), and provides context that may improve estimates of forest structural parameters (Wulder et al., 1998). Image texture is a means to interpret the spatial relationships between digital numbers (Haralick et al., 1973) and to understand how the variability in these values can inform on what is being portrayed by the imagery. Single pixel measures often inform on a portion of an object, with additional content offered when considering neighbouring pixels. Texture measures provide information regarding the simplicity or complexity of neighbourhoods of pixels. For characterization of forest structure, high resolution imagery texture provides spatial information about density, distribution, and spatial arrangement of trees (Ouma et al., 2006) and is also related to the three-dimensional organization of tree crowns (St-Onge and Cavayas, 1995; Bruniquel-Pinel and Gastellu-Etchegorry, 1998). Greater variance in digital numbers often implies a more complex forest environment, whereas simple forest structure is associated with less image variance (Cohen et al., 1990). In short, a relationship exists between image spatial structure and the forest structure in the scene (Wulder et al., 1998). One approach for characterizing the spatial inter-relationships between image digital numbers is the grey-level co-occurrence matrix (GLCM) and associated indices that can be used to describe the matrix (Haralick and Bryant, 1976). The GLCM is a tabulation of how often different combinations of pixel grey levels occur in an image (Hall-Beyer, 2007) at a specific distance and orientation. For evaluation of image texture we applied the approach of Haralick (Haralick and Bryant, 1976), a method using statistical measures based on the GLCM values (Caridade et al., 2008) that is also known as a second order approach.

Exploratory research over a range of measurement contexts (i.e., plot, stand) indicated that second order texture metrics "homogeneity", "contrast", and "entropy" appeared as most appropriate of the GLCM texture metrics for distinguishing forest stands of varying structure (differing height, age, number of trees per hectare, and $\mathrm{DBH}$ ) for the Mediterranean pine forests present. Homogeneity and contrast are measures of the amount of local variation in the image (Haralick et al., 1973) and are by definition highly correlated (Equations (2-3)). Entropy is a measure of orderliness (Hall-Beyer, 2007) (Equation (4)) or lack of image structure. 


$$
\begin{aligned}
& \text { Homogeneity }=\sum_{i, j=0}^{N-1} \frac{P_{i, j}}{1+(i-j)^{2}} \\
& \text { Contrast }=\sum_{i, j=0}^{N-1} P_{i, j}(i-j)^{2} \\
& \text { Entropy }=\sum_{i, j=0}^{N-1} P_{i, j}\left(-\ln P_{i, j}\right)
\end{aligned}
$$

where $P_{i, j}$ is the $(i, j)$ th entry of the normalized GLCM matrix, $N$ is the number of rows and columns in the image.

Texture metrics evaluated at three different window sizes were calculated over the panchromatic channel of the QuickBird-2 imagery. For evaluation of texture metrics we aimed to apply window sizes corresponding to the mean dimension of the scene objects (Kayitakire et al., 2006), that is, a distance equivalent to individual crown

Table 3. Texture metrics evaluated in the study sites.

\begin{tabular}{llll}
\hline Window & Metric & Valsaín & Iruelas \\
\hline Small & $\begin{array}{l}\text { Homogeneity } \\
\text { Contrast }\end{array}$ & $7 \times 7$ & $7 \times 7$ \\
Entropy \\
Medium & $\begin{array}{l}\text { Homogeneity } \\
\text { Contrast } \\
\text { Entropy }\end{array}$ & $9 \times 9$ & $13 \times 13$ \\
& $\begin{array}{l}\text { Homogeneity } \\
\text { Contrast } \\
\text { Entropy }\end{array}$ & $13 \times 13$ & $23 \times 23$ \\
& & \\
\hline
\end{tabular}
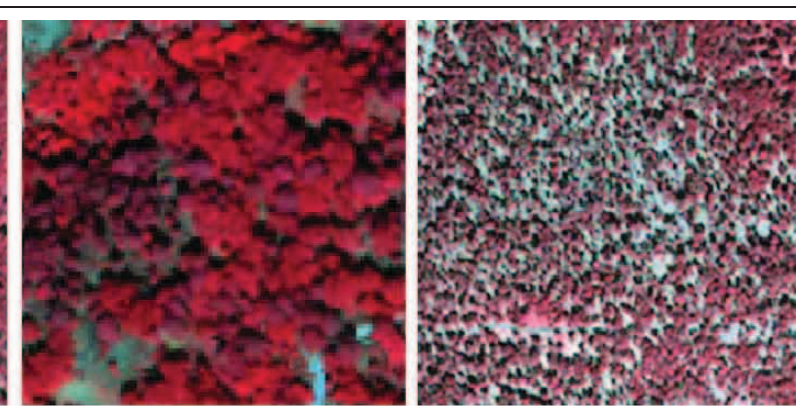

diameters or groups of trees' canopy size, in each of the sites (Table 3). For this purpose we followed the semivariogram approach (Johansen et al., 2007; Nijland et al., 2009) whereby the "range" value of the semivariogram identifies the size of the scene objects and therefore determines the window size to use (Franklin et al., 1996). As expected, the uneven structure in Iruelas indicated a need for larger and different window sizes than in Valsaín, where the species and silvicultural system applied have made the forest stands more homogeneous (Figure 3). These findings are included at this stage of the communication as the window sizes produced are used to guide subsequent analyses.

To quantify the variation of the image metrics at the plot level we used the MAD which, unlike the standard deviation, is resistant to outliers (Chung et al., 2008); half the values are closer to the median than the MAD and half are further away. For each reflectance band (three in the visible and one in the NIR) the MAD of pixel values was calculated for each 0.3 ha circular area (approx. 616 pixels) and the absolute difference with each equivalent global MAD (calculated using all plots at each site) was evaluated. A similar process was followed with co-occurrence texture metrics over the panchromatic image (approx. 6640 pixels per 0.3 ha circular area).

\section{Canonical correlation analysis}

While complex, quantifying structural diversity may be approached through the application of multivariate statistical analysis (McElhinny et al., 2005). The statistical analysis

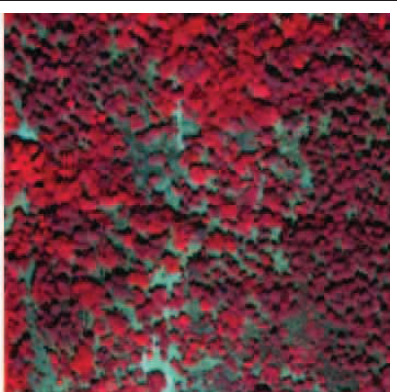

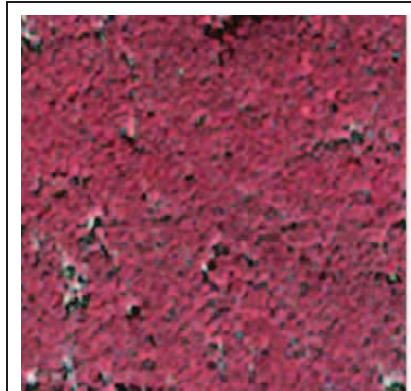
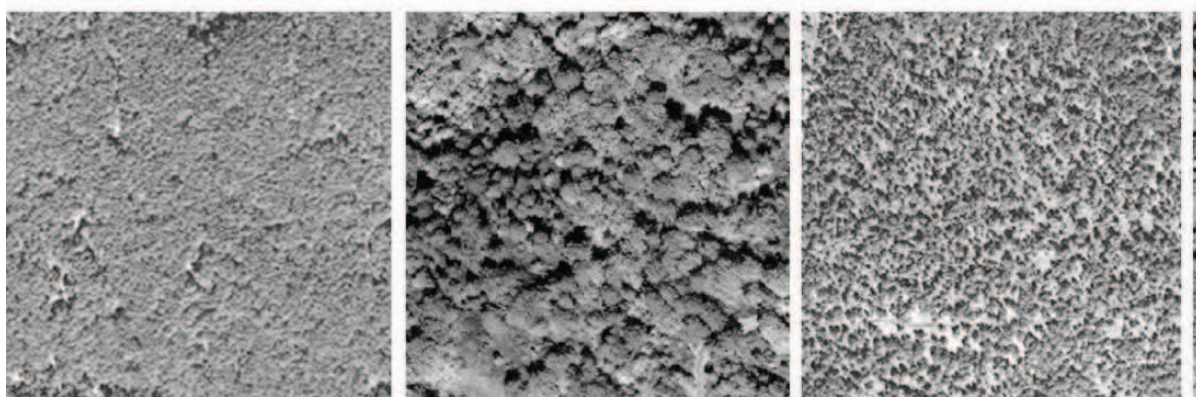

Figure 3. Examples of areas with different forest structure and visual texture (top line: multispectral visualization (Red: NIR, Green: red, Blue: green); bottom line: panchromatic visualization). 
required in this study will demonstrate if there is a relation, and how strong it is, between the forest structural diversity measured at the plot level as captured by the inventory attributes and the spectral diversity measured by the reflectance of the MS satellite-borne high spatial resolution sensor and texture co-occurrence metrics evaluated with various window sizes. We chose the CCA statistical approach as it facilitates the study of interrelationships among sets of multiple dependent and independent variables (Hair et al., 2010). CCA places few restrictions on the data: normality, that was tested with the Jarque-Bera test, and absence of outliers that was checked through the Grubbs test (Grubbs, 1950). The ratio of sample size to number of variables was in our case well over the recommended value of ten. In Table 4 we summarize the variables included in the statistical analysis.

CCA enables generation of two outcomes of interest: the "canonical variates" representing the optimal linear combinations of dependent and independent variables and the "canonical correlation" representing the strength of the relationship between them. All variables are linearly combined by group (dependent and independent) into "variates"; the dependence role is interchangeable and used to facilitate interpretation.

A number of orthogonal (independent) "canonical functions" are derived, maximizing the correlation between linear composites. Each variable partial correlation with the respective canonical function is represented by its coefficient or "canonical weight", which enables understanding of the function composition. However, frequent instability of these coefficients advice the alternative use of "canonical loadings" after a process of variables standardization (Hair et al., 2010). Therefore, canonical loadings measure the simple linear correlation between an original observed variable in the dependent or independent set and the set's canonical variate, intended to indicate the variance that the variable shares with its canonical variate. Variables that are highly correlated with a canonical variate have more in common with the variate and should therefore be given more importance in the variate's interpretation. Additionally, a measure of "redundancy" may be calculated that informs on the amount of variance in a set of input variables (dependent or independent) that is explained by the other canonical variate. To determine which of the canonical functions to interpret, a combined criterion based on the statistical significance, the practical significance of the canonical correlation and the redundancy measures for each variate should be applied (Hair et al., 2010). "Canonical cross-loadings" measure the simple linear correlation between the original observed variables and the opposite set's canonical variate, i.e., they represent the relation between one variable and the linear combination of variables on the other side. These coefficients are useful to determine which independent variables are explicative of the dependent set combination and, in our case, which spectral or textural metrics would better explain the forest structural diversity.

\section{Results}

The CCA yielded two results of interest: the canonical variates, which represented the optimal linear combinations of dependent (forest structural diversity) and independent (image reflectance-texture diversity) variables and the canonical correlation, representing the relationship between variates. We describe and interpret some outcomes of the analysis which were relevant to our study objectives.

\section{Canonical correlations and relative importance of reflectance and texture metrics}

The number of canonical functions CCA yields is limited by the lower number of variables in either the dependent or

Table 4. Dependent and independent variables used as input into the canonical correlation analysis.

\begin{tabular}{ll}
\hline Dependent variables & Independent variables \\
\hline & Reflectance \\
MAD of: & Blue \\
& Green \\
& Red \\
& Near infrared \\
MAD (Median Absolute Deviation) of: & Texture \\
Diameter $\left(\mathrm{D}_{\mathrm{MAD}}\right)$ & MAD of: \\
Height $\left(\mathrm{H}_{\mathrm{MAD}}\right)$ & Homogeneity small window \\
Crown diameter $\left(\mathrm{C}_{\mathrm{MAD}}\right)$ & Homogeneity medium window \\
& Homogeneity large window \\
& Contrast small window \\
& Contrast medium window \\
& Contrast large window \\
& Entropy small window \\
& Entropy medium window \\
\hline
\end{tabular}


independent variate (Hair et al., 2010); in our case the maximum number of functions was three, as this was the number of original dependent variables considered ( $\mathrm{D}_{\mathrm{MAD}}, \mathrm{H}_{\mathrm{MAD}}, \mathrm{C}_{\mathrm{MAD}}$ ). Our interest focused on determining if there is a relation and how strong it is between variates. Therefore, only the strongest relation in each case scenario was retained for further analysis and discussion, even if more than one function was statistically significant (Table 5). The statistical significance was tested with the $\chi^{2}$ test.

In both Valsaín and Iruelas there was a moderate relation between the dependent (forest structural diversity) and the independent (reflectance-texture diversity) variates, with similar values of correlation in both cases $(0.50$ in Valsaín and 0.51 in Iruelas). To test the strength of the relationship between forest structural diversity and the reflectance and texture variables' groups individually, we ran the analysis independently with either set treated as independent. This analysis showed that when including all variables in the independent group there was a stronger relation than including just one type of image variables (reflectance or texture), which demonstrated the information associated with spectral and textural signatures is complementary (Lu et al., 2002; Colombo et al., 2003; Ouma et al., 2006). Although they exhibited a relatively weak relationship, the reflectance variables alone were more related in both sites with structural diversity than the texture variables alone (Table 5).

In a combined scenario, considering all plots from Valsaín and Iruelas together, with "expectation" median values evaluated together, we found a strong relation between variates, with an $R$ of 0.89 (Table 5). This scenario illustrates a more heterogeneous forest where the range of forest parameters is considerably higher than either the individual sites (Table 1). In this case, texture diversity measures were more able to explain forest structural diversity ( $R$ of $0.88 \mathrm{vs.}$ $R$ of 0.63 ). Possibly the limited explanatory power of texture variables in the individual sites was in part due to the limited range of ground variables and consequent limited variation in image texture outcomes.

Table 5. Canonical correlations of the first canonical function in different scenarios (all statistically significant).

\begin{tabular}{lll}
\hline \multirow{2}{*}{ Site } & Independent group & $\begin{array}{l}R \text { (canonical } \\
\text { correlation) }\end{array}$ \\
\hline Valsaín & Diversity (reflectance and texture) & 0.505 \\
& Diversity reflectance & 0.474 \\
\multirow{4}{*}{ Iruelas } & Diversity texture & 0.389 \\
& Diversity (reflectance and texture) & 0.512 \\
& Diversity reflectance & 0.460 \\
Combined & Diversity texture & 0.360 \\
& Diversity (reflectance and texture) & 0.890 \\
& Diversity reflectance & 0.634 \\
& Diversity texture & 0.882 \\
\hline
\end{tabular}

\section{Most significant variables}

Canonical cross loadings were interpreted to assess how the individual independent variables (measures of reflectance and texture diversity) related linearly with the forest structural diversity or dependent variate. This procedure enabled identification of those image metrics most contributing in the characterization of structural diversity for the combined case scenario (Valsaín and Iruelas plots analyzed together).

Contrast and homogeneity evaluated at different window sizes were the variables most strongly correlated with forest structural diversity (Figure 4). This result supported the intuitive notion that visual changes in the image are related with variability of tree sizes on the ground, as this variability produced internal shadowing effects within the stand. As contrast and homogeneity are by definition strongly correlated metrics, similar cross-loading values were expected, and the opposite sign that occurred at medium window sizes remains unexplained. Variations in the reflectance bands were positively correlated with structural diversity, with the three visible bands found more strongly correlated than the NIR band. The character of entropy is variable and not completely clear, being negatively correlated with structural diversity when measured at the small window size (that is, 7 pixels $\times 7$ pixels, or $4.2 \mathrm{~m} \times 4.2 \mathrm{~m}$ ) and weakly correlated when measured at the other window sizes. It should be noted that at the smaller window sizes, single tree crowns may be represented, resulting in texture measures with a high local variance (with noncrown conditions represented in neighboring locations). These findings support the use of larger windows relating stand conditions, rather than individual trees (objects). Varying behaviour of GLCM metrics at different window sizes was previously reported (Moskal, 1999) and detailed examination would be required for complete understanding in local circumstances.

The linear correlation between the original variables ( $\mathrm{D}_{\mathrm{MAD}}, \mathrm{C}_{\mathrm{MAD}}, \mathrm{H}_{\mathrm{MAD}}$ ) and the forest structure diversity variate is measured by the canonical loadings. These coefficients showed diameter variability $\left(\mathrm{D}_{\mathrm{MAD}}\right)$ was the most relevant parameter (loading 0.63 ) in building the forest structure diversity variate, followed by crown diameter variability $\left(\mathrm{C}_{\mathrm{MAD}}\right.$, loading 0.15 ), and leaving height variability $\left(\mathrm{H}_{\mathrm{MAD}}\right.$ loading 0.10$)$ in third position. The importance of diameter variability for characterization of forest structural complexity was an expected result, as diameter is a common variable used for description of forest structure and its variation is frequently used for computation of diversity indices such as Simpson or Shannon (McElhinny et al., 2005).

\section{Validation of the CCA in the combined case scenario}

To ensure that the results of the CCA were not specific to the sample data, the method was validated over a subsample of 500 plots, proportionally and randomly selected from 


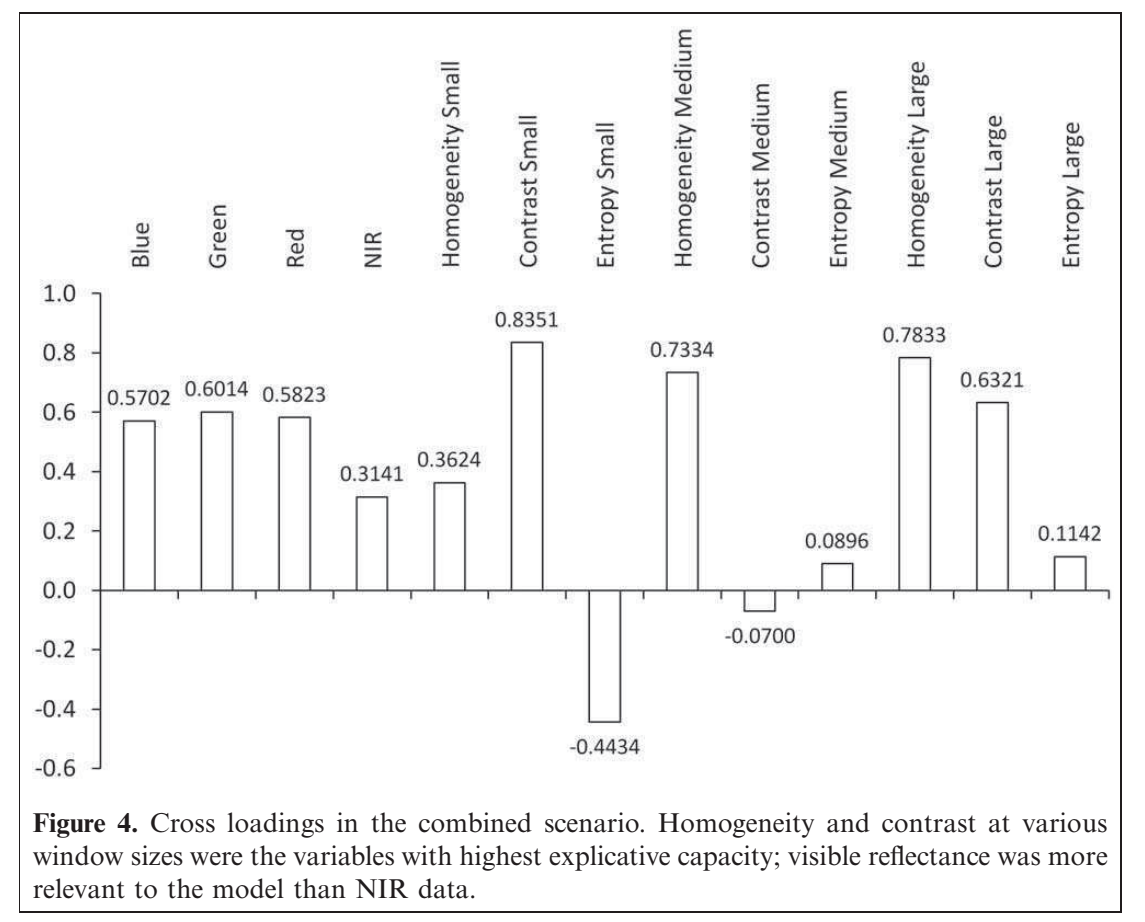

both sites (226 plots from Valsaín and 274 plots from Iruelas). The validity of the CCA was assessed by conducting a sensitivity analysis in which the stability of the redundancy index and the overall canonical correlations was assessed applying the same procedure after removing individual independent variables from the analysis (Hair et al., 2010) (Figure 5). The similarity of the values of the redundancy index and canonical correlation for all tested situations indicated the stability of the CCA results; crossloadings were also found to be relatively stable.

Optical sensors have limited capacity to identify canopy height and differences (Hudak et al., 2002), often relying on the existence of image shadows or the calculation of gap fraction to partially accomplish this task (see Mora et al. (2010) for a summary of height estimation from optical imagery). To test the relevance of $\mathrm{H}_{\mathrm{MAD}}$ in the model, it was removed from the analysis and results were checked: the canonical correlation decreased markedly and the redundancy index was lower than all other situations, demonstrating the significance of $\mathrm{H}_{\mathrm{MAD}}$ contribution to the structural dependent variate in this model. As expected more notable reductions in redundancy index were found when $\mathrm{D}_{\mathrm{MAD}}$ or $\mathrm{C}_{\mathrm{MAD}}$ were removed from the analysis.

\section{Discussion and conclusion}

Forest structural diversity defined in terms of field inventory measures at the plot level has been related to values of reflectance and texture diversity as captured by a fine spatial resolution satellite-borne optical sensor in
Mediterranean pine forests of the Central Range in Spain. Results showed a strong relationship between both sets of diversity features (field derived and image derived) when considered at the plot level and with an appropriate range of variation, indicating the potential of remote sensing and image processing as an approach for characterization of forest structural diversity over wide areas.

Quantifying structural diversity on the ground is difficult and costly, and its importance for biodiversity and production (Lexerod and Leid, 2006) makes exploring remote sensing as an optional means for this purpose. Remote sensing is not seen to fully supplant the need for field measures, but to spatially and temporally augment such measures. The data acquisition regularity offered by satellites and the consistency over space and time enables repetitive estimations and monitoring. In this study we included field measured variables $(\mathrm{DBH}$, height, and crown diameter) in structure diversity characterization for ease of measurement (McElhinny et al., 2005) and, as identified by Río et al. (2003), among the most important aspects of forest structure. Furthermore, the scale of analysis is also an important factor when measuring or characterizing diversity (Lähde et al., 1999). The availability of field data determined the scale of our analysis, enabled by accessibility to high spatial resolution imagery. The detailed plot-level measures available made for a logical informational link between the field and image-based data sources with both of a comparable scale. We worked with circular spatial units of 0.3 ha, analogous to the inventory plots established and measured on the ground. At this scale of analysis (alpha diversity) the 


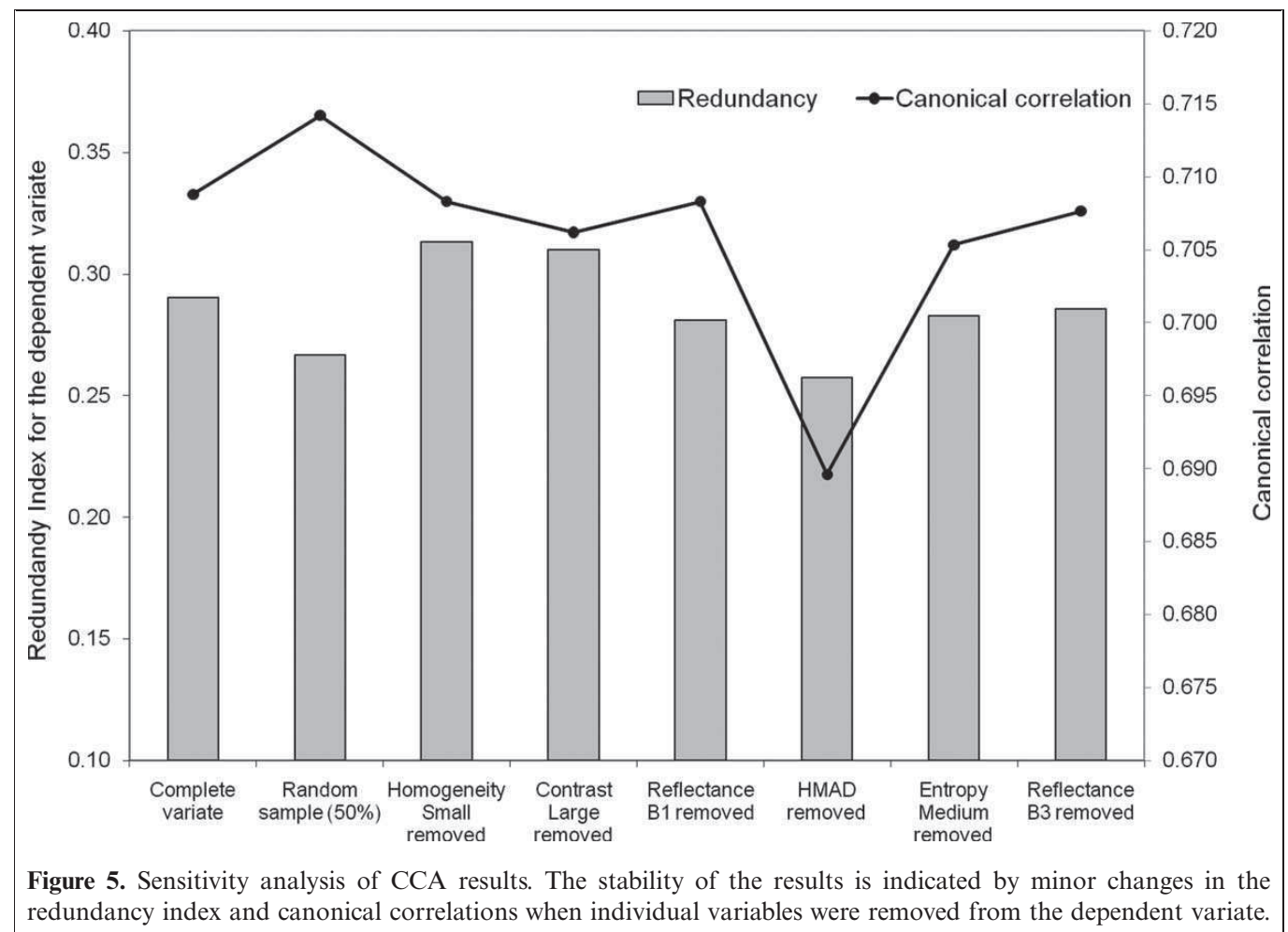

study showed there is potential for characterization of structural diversity from the space. Lamonaca et al. (2008) reached similar conclusions in a study that applied an object oriented approach for characterization of the structure diversity in Mediterranean environments at the stand level. Pasher and King (2010) modelled and mapped forest structural diversity in temperate hardwood forests of Quebec (Canada) with airborne derived data, highlighting the convenience of satellite derived data for mapping of larger areas.

Interestingly, among our findings was the consideration of the scenarios with various crown closure conditions pooled together, that is, the data from open and dense forest sites analyzed jointly. In this case the relation between the variability in image-derived variables and forest structural diversity was stronger (higher canonical correlation) than considering either individual scenario alone. Previous works with remotely sensed data in the study area (Merino et al., 2010; Vázquez de la Cueva, 2008) found significant relations between image and field variables but poor explanatory power of statistical models. Further work is recommended to determine if the limited success relating structural measures with optical sensors' data is due to the limited local variation in structural parameters.

Diameter and basal area are the attributes most frequently used in studies of structural diversity (Solomon and Gove, 1999; Varga et al., 2005; Motz et al., 2010) and forest structure per se (Goodburn and Lorimer, 1998; Rouvinen and Kuuluvainen, 2005; Rubin et al., 2006). We found these to be the attributes indicating variation in forest structure at the plot level that had the highest relevance in the canonical variates in all scenarios. Height showed slight importance in the canonical relations between field-measured and imagedetected diversity but was still relevant to the model, as shown in the sensitivity analysis. Height variation is difficult to detect with optical sensors (Mora et al., 2010), which are better suited for mapping horizontal structure (Hyde et al., 2006). Although shadows and gap fraction are sometimes useful (Shettigara and Sumerling, 1998; Leboeuf et al., 2007), the images we used, captured with high elevation angles ( $>60$ degrees), did not include significant shadows. Including LiDAR measured heights in the modelling process may improve the study results, as fusion of high spatial resolution and LiDAR data is an approach yielding good results (St-Onge et al., 2008; Ke et al., 2010; Chen and Hay, 2011).

In scenarios of relatively low structural diversity, when we considered each of the study sites individually, the variation in reflectance of the visible and NIR was more explicative of the structural diversity than variations in other texture measures evaluated with finer spatial resolution panchromatic data. Similarly, Rocchini et al. (2010) highlighted the relevance of spectral resolution versus spatial resolution for evaluation of species diversity, 
supported by a series of studies in different environments that buttress this idea.

The information associated with spectral and textural signatures is complementary (Lu et al., 2002) in estimation of forest parameters ( $\mathrm{Lu}$ and Batistella, 2005). Wulder et al. (1998) observed an improvement of correlation between LAI and image variables including texture in northern deciduous and mixed wood forest in Canada using aerial imagery. Chubey et al. (2006) studied structural parameters of forests in Alberta, Canada, with Ikonos-2 imagery, obtaining successful results when including reflectance and texture variables. Other studies used textural parameters only (Franklin et al., 2001; Couteron et al., 2005; Kayitakire et al., 2006) for estimation of forest structure, which was shown to be particularly useful in complex structures such as tropical forests ( $\mathrm{Lu}$ and Batistella, 2005). Image texture is influenced by several biophysical parameters including crown diameter, distance between trees, tree positioning, LAI, and tree height. The importance of the window size for evaluation of texture measures has been stressed (Ferro and Warner, 2002; Kayitakire et al., 2006) and the variogram approach is recommended as an appropriate method to guide window size selection (Franklin et al., 1996). We found a common variogram range value in both study sites (open and closed canopy conditions) which is coincident with the median value of crown diameter. The absence of shadows in the imagery allowed the identification of individual trees as dominant textural objects on the ground (Kayitakire et al., 2006). The limited use of texture parameters, previously indicated as due to a lack of software tools (Bruniquel-Pinel and Gastellu-Etchegorry, 1998), is progressively being overcome, but other considerations remain, such as viewing and illumination configurations, spectral domain, and spatial resolution. However, image texture analysis has demonstrated utility for characterizing habitat structure (St-Louis et al., 2006) and identifying areas of high diversity with conservation priority.

Mediterranean forests are notorious for their complex topography (Salvador and Pons, 1998) which often results in high spatial heterogeneity (Neumann and Starlinger, 2001). If field information is contrasted with image data, the accurate spatial location of field plots and a high quality geometric processing (e.g., low RMSE) of the remotely sensed data are particularly important to develop strong empirical models. As demonstrated in this study, high spatial resolution imagery from optical sensors integrated with field measures of forest structure provided a useful approach to investigate and characterize forest structural diversity in Mediterranean pine forests, particularly in Spain where a national high spatial resolution image data base has been initiated, with an annual revisit proposed. Details on the nature of the database and access criteria through Spanish Plan Nacional de Teledetección remain to be determined and communicated.

\section{Acknowledgements}

This work was done under the project "Estructura, dinámica y selvicultura para la conservación y el uso sostenible de los bosques en el Sistema Central" (VA-096-A05) with funding from Consejería de Educación, Junta de Castilla y León, Plan Regional I + D + I. Field data was provided by Consejería de Medio Ambiente y Ordenación Territorial de Castilla y León. Wolfgang Schwanghart is thanked for his help with data analysis.

\section{References}

Box, G.E.P., and Cox, D.R. 1982. The analysis of transformations revisited, rebutted. Journal of the American Statistical Association, Vol. 77, No. 377, pp. 209-210. doi: 10.2307/2287791.

Bruniquel-Pinel, V., and Gastellu-Etchegorry J.P. 1998. Sensitivity of texture of high resolution images of forest to biophysical and acquisition parameters. Remote Sensing of Environment, Vol. 65, No. 1, pp. 61-85. doi: 10.1016/S0034-4257(98)00009-1.

Caridade, C.M.R., Marca, A.R.S., and Mendonca, T. 2008. The use of texture for image classification of black and white air photographs. International Journal of Remote Sensing, Vol. 29, No. 2, pp. 593-607. doi: 10.1080/01431160701281015.

Chavez, P. 1988. An improved dark object subtraction technique for atmospheric scattering correction of multispectral data. Remote Sensing of the Environment, Vol. 24, No. 3, pp. 459-479. doi: 10.1016/00344257(88)90019-3.

Chavez, P.S. 1996. Image-based atmospheric corrections-Revisited and improved. Photogrammetric Engineering and Remote Sensing, Vol. 62, No. 9, pp. 1025-1036.

Chen, G., and Hay, G. 2011. An airborne lidar sampling strategy to model forest canopy height from Quickbird. Remote Sensing of Environment, Vol. 115, No. 6, pp. 1532-1542. doi: 10.1016/j.rse.2011.02.012.

Cho, M.A., Skidmore, A.K., and Sobhan, I. 2009. Mapping beech (Fagus sylvatica L.) forest structure with airborne hyperspectral imagery. International Journal of Applied Earth Observation and Geoinformation, Vol. 11, No. 3, pp. 201-211. doi: 10.1016/j.jag.2009. 01.006 .

Chubey, M.S., Franklin, S.E., and Wulder, M.A. 2006. Object-based Analysis of Ikonos-2 Imagery for Extraction of Forest Inventory Parameters. Journal of Photogrammetry and Remote Sensing, Vol. 72, No. 4, pp. 383-394.

Chung, N., Zhang, X.D., Kreamer, A., Locco, L., Kuan, P-F., Bartz, S. Linsley, P.S., Ferrer, M., and Strulovici, B. 2008. Median Absolute Deviation to Improve Hit Selection for Genome-Scale RNAi Screens. Journal of Biomolecular Screening, Vol. 13, No. 2, pp. 149-158. doi: $10.1177 / 1087057107312035$.

Cohen, W.B., Spies, T.A., and Bradshaw, G.A. 1990. Semivariograms of digital imagery for analysis of conifer canopy structure. Remote Sensing of Environment, Vol. 34, No. 3, pp. 167-178. doi: 10.1016/00344257(90)90066-U.

Cohen, W.B., Spies, T.A., and Fiorella, M. 1995. Estimating the age and structure of forest in a multi-ownership landscape of western Oregon, USA. International Journal of Remote Sensing, Vol. 16, No. 4, pp. 721-746. doi: 10.1080/01431169508954436. 
Cohen, W.B., and Goward, S. 2004. Landsat's role in ecological applications of remote sensing. BioScience, Vol. 54, No. 6, pp. 535-545. doi: 10.1641/0006-3568(2004)054[0535:LRIEAO]2.0.CO;2.

Colombo, R., Bellingeri, D., Fasolini, D., and Marino, C.M. 2003. Retrieval of leaf area index in different vegetation types using high resolution satellite data. Remote Sensing of Environment, Vol. 83, No. 1, pp. 120-131. doi: 10.1016/S0034-4257(03)00094-4.

Coops, N.C., and Catling, P.C. 1997. Predicting the complexity of habitat in forests from airborne videography for wildlife management. International Journal of Remote Sensing, Vol. 18, No. 12, pp. 2677-2682. doi: $10.1080 / 014311697217530$.

Couteron, P., Pelissier, R., Nicolini, E.A., and Paget, D. 2005. Predicting tropical forest stand structure parameters from Fourier transform of very high-resolution remotely sensed canopy images. Journal of Applied Ecology, Vol. 42, No. 6, pp. 1121-1128. doi: 10.1111/j.1365-2664.2005. 01097.x.

Elmqvist, T., Folke, C., Nystrom, M., Peterson, G., Bengtsson, J., Walker B., and Norberg, J., 2003. Response diversity, ecosystem change, and resilience. Frontiers in Ecology and the Environment, Vol. 1, No. 9, pp. 488-494. doi: 10.1890/1540-9295(2003)001[0488:RDECAR] 2.0.CO;2

Falkowski, M.J., Wulder, M.A., White, J.C., and Gillis, M.D. 2009. Supporting large-area, sample-based forest inventories with very high spatial resolution satellite imagery. Progress in Physical Geography, Vol. 33, No. 3, pp. 403-423. doi: 10.1177/03091333093 42643.

Feng, Y., Zengyuan, L., and Tokola, T. 2010. Estimation of stand mean crown diameter from high-spatial-resolution imagery based on a geostatistical method. International Journal of Remote Sensing, Vol. 31, No. 2, pp. 363-378. doi: 10.1080/01431160902887867.

Ferro, C.J.S., and Warner, T.A. 2002. Scale and texture in digital image classification. Photogrammetric Engineering \& Remote Sensing, Vol. 68, No. 1 , pp. $51-63$.

Franklin, S.E., Wulder, M.A., and Lavigne, M.B. 1996. Automated derivation of geographic window sizes for use in remote sensing digital image texture analysis. Computers and Geosciences, Vol. 22, No. 6, pp. 665-673. doi: 10.1016/0098-3004(96)00009-X.

Franklin, S.E., Wulder, M.A., and Gerylo, G.R. 2001. Texture analysis of IKONOS panchromatic data for Douglas-fir forest age class separability in British Columbia. International Journal of Remote Sensing, Vol. 22, No. 13, pp. 2627-2632.

García-López, J.M., and Allué, C. 2011. Modelling phytoclimatic versatility as a large scale indicator of adaptive capacity to climate change in forest ecosystems. Ecological Modelling, Vol. 222, No. 8, pp. 1436-1447. doi: 10.1016/j.ecolmodel.2011.02.001

Gil-Tena, A. Vega-García, C., Brotons, L., Saura, S. 2010. Modelling bird species richness with neural networks for forest landscape management in NE Spain. Forest Systems, Vol. 19 (Special Issue), pp. 113-125.

Goodburn, J.M., and Lorimer, C.G. 1998. Population structure in oldgrowth and managed northern hardwoods: an examination of the balanced diameter distribution concept. Forest Ecology and Management, Vol. 118, No. 1-3, pp. 11-29.

Gougeon, F.A., and Leckie, D.G. 2006. The individual tree crown approach applied to IKONOS images of a coniferous plantation area. Photogrammetric Engineering and Remote Sensing, Vol. 72, No. 11 , pp. $1287-1297$.
Greenberg, J.A., Dobrowski, S.Z., and Ustin, S.L. 2005. Shadow allometry: Estimating tree structural parameters using hyperspatial image analysis. Remote Sensing of Environment, Vol. 97, No. 1, pp. 15-25. doi: 10.1016/ j.rse.2005.02.015.

Grubbs, F.E. 1950. Sample Criteria for testing outlying observations Annals of Mathematical Statistics, Vol. 21, No. 1, pp. 27-58. doi: 10.1214/aoms/1177729885

Hair, J.F., Anderson, R.E., Tatham, R.L., Black, W.C. 2010. Multivariate data analysis. 7th Edition, Prentice Hall. New Jersey, USA.

Hall-Beyer, M. GLCM tutorial home page. 2007. Available from http:// www.fp.ucalgary.ca/mhallbey/tutorial.htm [accessed 13 September 2011].

Haralick, R.M., Shanmugan, K., and Dinstein, I. 1973. Texture features for image classification. IEEE Transactions on Systems, Man and Cybernetics, Vol. 3, No. 6, pp. 610-621. doi: 10.1109/TSMC.1973. 4309314.

Haralick, R.M., and Bryant, W.F., 1976. Documentation of procedures for texturallspatial pattern recognition techniques. Remote Sensing Laboratory, University of Kansas, Lawrence, Kans., RSL Technical Report 278-1

Hirata, Y. 2008. Estimation of stand attributes in Cryptomeria japonica and Chamaecyparis obtusa stands using QuickBird panchromatic data. Journal of Forest Research, Vol. 13, No. 3, pp. 147-154. doi: 10.1007/ s10310-008-0059-7.

Hudak, A.T., Lefsky, M.A., Cohen, W.B., and Berterretche, M. 2002. Integration of lidar and Landsat ETM + data for estimating and mapping forest canopy height. Remote Sensing of Environment, Vol. 82, No. 2-3, pp. 397-416. doi: 10.1016/S0034-4257(02)00056-1.

Hyde, P., Dubayah, R., Walker, W., Blair, B., Hofton, M., and Hunsaker, C. 2006. Mapping forest structure for wildlife habitat analysis using multi-sensor (LiDAR, SAR/InSAR, ETM+, Quickbird) synergy. Remote Sensing of Environment, Vol. 102, No. 1-2, pp. 63-73. doi: 10.1016/j.rse.2006.01.021.

Johansen, K., Coops, N.C., Gergel, S.E., and Stange, Y., 2007. Application of high spatial resolution satellite imagery for riparian and forest ecosystem classification. Remote Sensing of Environment, Vol. 110, No. 1, pp. 29-44. doi: 10.1016/j.rse.2007.02.014.

Kayitakire, F., Hamel, C., and Defourny, P. 2006. Retrieving forest structure variables based on image texture analysis and IKONOS-2 imagery. Remote Sensing of Environment, Vol. 102, No. 3-4, pp. 390-401. doi: 10.1016/j.rse.2006.02.022.

Ke, Y., Quackenbush, L.J., and Im, J. 2010. Synergistic use of QuickBird multispectral imagery and LIDAR for object-based forest species classification. Remote Sensing of Environment, Vol. 114, No. 6, pp. 1141-1154. doi: 10.1016/j.rse.2010.01.002.

Lähde, E., Laiho, O., Norokorpi, Y., and Saska, T. 1999. Stand structure as the basis of diversity index. Forest Ecology and Management, Vol. 115, No. 2-3, pp. 213-220.

Lamonaca, A., Corona, P., and Barbati, A. 2008. Exploring forest structural complexity by multi-scale segmentation of VHR imagery. Remote Sensing of Environment, Vol. 112, No. 6, pp. 2839-2849. doi: 10.1016/j.rse.2008.01.017.

Leboeuf, A., Beaudoin, A., Fournier, R.A., Guindon, L., Luther, J.E., and Lambert, M.C. 2007. A shadow fraction method for mapping biomass of northern boreal black spruce forests using QuickBird imagery. Remote Sensing of Environment, Vol. 110, No. 4, pp. 488-500. doi: 10.1016/j.rse.2006.05.025. 
Lefsky M.A., Hudak A.T., Cohen W.B., Acker S.A., 2005. Patterns of covariance between forest stand and canopy structure in the Pacific Northwest. Remote Sensing of Environment, Vol. 95, pp. 517-531.

Lexerod, N.L., and Eid, T. 2006. An evaluation of different diameter diversity indices based on criteria related to forest management planning. Forest Ecology and Management, Vol. 222, No. 1-3, pp. 17-28. doi: 10.1016/j.foreco.2005.10.046.

Lu D., Mausel P., Brondizio, E., and Moran, E. 2002. Above-Ground Biomass estimation of successional and mature forests using TM images in the Amazon basin. In Symposium on Geospatial Theory, Processing and Applications, July 8-12, Otawa, Canada. ISPRS-SDH-CIG, Canadian Institute of Geomatics, Ottawa, Canada.

Lu, D., and Batistella, M. 2005. Exploring TM image texture and its relationships with biomass estimation in Rondonia, Brazilian Amazon. Acta Amazonica, Vol. 35, No. 2, pp. 249-257. doi: 10.1590/S004459672005000200015 .

Maltamo, M., Packalén, P., Yu, X., Eerikä̈nen, K. Hyyppä, J., and Pitkänen, J. 2005. Identifying and quantifying structural characteristics of heterogeneous boreal forests using laser scanner data. Forest Ecology and Management, Vol. 216, pp. 41-50.

McElhinny, C., Gibbons, Ph., Brack, C., and Bauhus, J. 2005. Forest and Woodland stand structural complexity: its definition and measurement. Forest Ecology and Management, Vol. 218, No. 1-3, pp. 1-24. doi: 10.1016/j.foreco.2005.08.034.

Merino de Miguel, S., Solana Gutiérrez, J., and González Alonso, F. 2010. Análisis de la estructura espacial de las masas de Pinus pinaster Aiton de la Comunidad de Madrid mediante imágenes de alta resolución espacial. Forest Systems, Vol. 19, No. 1, pp. 18-35.

Miura, N., and Jones, S.D., 2010. Characterizing forest ecological structure using pulse types and heights of airborne laser scanning. Remote Sensing of Environment, Vol. 114, No. 5, pp. 1069-1076. doi: 10.1016/j.rse.2009.12.017

Montes, F., Sánchez, M., Río, M., and Cañellas, I. 2004. Using historic management records to characterize the effects of management on the structural diversity of forests. Forest Ecology and Management, Vol. 207, No. 1-2, pp. 279-293.

Mora, B., Wulder, M.A., and White, J.C. 2010. Segment-constrained regression tree estimation of forest stand height from very high spatial resolution panchromatic imagery over a boreal environment. Remote Sensing of Environment, Vol. 114, No. 11, pp. 2474-2484. doi: 10.1016/j. rse.2010.05.022.

Moskal, L.M. 1999. AVI multilayer forest classification using airborne image texture metrics. Calgary, Canada: University of Calgary. $M S C$ Thesis, 147 pp.

Motz, K., Sterba, H., and Pommerening, A. 2010. Sampling measures of tree diversity. Forest Ecology and Management, Vol. 260, No. 11, pp. 1985-1996. doi: 10.1016/j.foreco.2010.08.046.

Neumann, M., and Starlinger, F. 2001. The significance of different indices for stand structure and diversity in forests. Forest Ecology and Management, Vol. 145, No. 1-2, pp. 91-106. doi: 10.1016/S03781127(00)00577-6.

Nijland, W., Addink, E.A., De Jong, S.M., and Van der Meer, F.D., 2009. Optimizing spatial image support for quantitative mapping of natural vegetation. Remote Sensing of Environment, Vol. 113, No. 4 pp. 771-780. doi: 10.1016/j.rse.2008.12.002.
Ouma, Y.O., Ngigi, T.G., and Tateishi, R. 2006. On the optimization and selection of wavelet texture for feature extraction from high resolution satellite imagery with application towards urban tree delineation. International Journal of Remote Sensing, Vol. 27, No. 1, pp. 73-104. doi: $10.1080 / 01431160500295885$

Ozdemir, I. 2008. Estimating stem volume by tree crown area and tree shadow area extracted from pan-sharpened Quickbird imagery in open Crimean juniper forests. International Journal of Remote Sensing, Vol. 29, No. 19 , pp. $5643-5655$.

Ozdemir, I., Norton, D.A., Ozkan, U.Y., Mert, A., and Senturk, O. 2008 Estimation of tree size diversity using object oriented texture analysis and ASTER imagery. Sensors, Vol. 8, pp. 4709-4724. doi: 10.3390/ s8084709.

Pascual, C., García Abril, A., García Montero, L.G., Martín Fernández, S., and Cohen, W.B. 2008. Object-based semi-automatic approach for forest structure characterization using lidar data in heterogeneous Pinus sylvestris stands. Forest Ecology and Management, Vol. 255, No. 11, pp. 3677-3685. doi: 10.1016/j.foreco.2008.02.055.

Pasher, J., and King, D.J. 2010. Multivariate forest structure modeling and mapping using high resolution airborne imagery and topographic information. Remote Sensing of Environment, Vol. 114, No. 8, pp. 1718-1732. doi: 10.1016/j.rse.2010.03.005.

Poage, N.J., and Tappeiner, J.C. 2005. Tree species and size structure of old-growth Douglas-fir forests in central western Oregon. Forest Ecology and Management, Vol. 204, No. 2-3, pp. 329-343. doi: 10.1016 j.foreco.2004.09.012

Pommerineng, A. 2006. Evaluating structural indices by reversing forest structural analysis. Forest Ecology and Management, Vol. 224, No. 3, pp. 266-277. doi: 10.1016/j.foreco.2005.12.039.

$\mathrm{Pu}, \mathrm{R}$., Landry, S., and Yu, Q. 2011. Object-based urban detailed land cover classification with high spatial resolution IKONOS imagery. International Journal of Remote Sensing, Vol. 32, No. 12, pp. 32853308. doi: 10.1080/01431161003745657.

Río, M., Montes, F., Cañellas, I., and Montero, G. 2003. Revisión: Indices de diversidad estructural en masas forestales. Investigaciones Agrarias: Sistemas y Recursos Forestales, Vol. 12, No. 1, pp. 159-176.

Rocchini, D., Balkenhol, N., Carter, G.A., Foody, G.M., Gillespie, T.W. He, K.S., Kark, S., Levin, N., Lucas, K., Luoto, M., Nagendra, H., Oldeland, J., Ricotta, C., Southworth, J., and Neteler, M. 2010 Remotely sensed spectral heterogeneity as a proxy of species diversity: Recent advances and open challenges. Ecological Informatics, Vol. 5, No. 5, pp. 318-329. doi: 10.1016/j.ecoinf.2010.06.001

Rozdilsky, I.D., and Stone, L.S. 2001. Complexity can enhance stability in competitive systems. Ecology Letters, Vol. 4, pp. 397-400.

Rouvinen, S., and Kuuluvainen, T. 2005. Tree diameter distributions in natural and managed old Pinus sylvestris-dominated forests. Forest Ecology and Management, Vol. 208, No. 1-3, pp. 45-61. doi: 10.1016/ j.foreco.2004.11.021

Rubin, B.D., Manion, P.D., and Faber-Langendoen, D. 2006. Diamete distributions and structural sustainability in forests. Forest Ecology and Management, Vol. 222, No. 1-3, pp. 427-438. doi: 10.1016/j.foreco.2005.10.049.

Rydberg, D., and Falck, J., 2000. Urban forestry in Sweden from a silvicultural perspective: a review. Landscape and Urban Planning Vol. 47, No. 1-2, pp. 1-18. doi: 10.1016/S0169-2046(99)00068-7. 
Salvador, R., and Pons, X. 1998. On the applicability of Landsat TM images to Mediterranean forest inventories. Forest Ecology and Management. Vol. 104, pp. 193-208.

Shettigara, V.K., and Sumerling, G.M. 1998. Height Determination of Extended Objects Using Shadows in SPOT Images. Photogrammetric Engineering \& Remote Sensing, Vol. 64, No. 1, pp. 35-44.

Solomon, D.S., and Gove, J.H. 1999. Effects of uneven-age management intensity on structural diversity in two major forest types in New England. Forest Ecology and Management, Vol. 114, No. 2-3, pp. 265-274. doi: 10.1016/S0378-1127(98)00358-2.

Song, C. 2007. Estimating tree crown size with spatial information of high resolution optical remotely sensed imagery. International Journal of Remote Sensing, Vol. 28, No. 15, pp. 3305-3322. doi: 10.1080/0143 1160600993413

Song, C., Dickinson, M.B., Su, L., Zhang, S., and Yaussey, D., 2010. Estimating average tree crown size using spatial information from Ikonos and QuickBird images: across-sensor and across-site comparisons. Remote Sensing of Environment, Vol. 114, No. 5, pp. 1099-1107. doi: $10.1016 /$ j.rse.2009.12.022.

Spies, T.A., and Franklin, J.F. 1991. The structure of natural young, mature, and old-growth Douglas-fir forests in Oregon and Washington. In Wildlife and vegetation of unmanaged Douglas- fir forests. Edited by L.F. Ruggiero, K.B. Aubry, A.B. Carey, and M.H. Huff. USDA Forest Service General Technical Report. PNWGTR- 285. pp. 91-109.

St-Louis, V., Pidgeon, A.M., Radeloff, V.C., Hawbaker, T.J., and Clayton, M.K., 2006. High-resolution image texture as a predictor of bird species richness. Remote Sensing of Environment, Vol. 105, No. 4, pp. 299-312. doi: 10.1016/j.rse.2006.07.003.

St-Onge, B., and Cavayas, F. 1995. Estimating forest stand structure from high resolution imagery using the directional variogram. International Journal of Remote Sensing, Vol. 16, No. 11, pp. 1999-2021. doi: 10.1080/ 01431169508954535

St-Onge, B., Hu, Y., and Vega, C. 2008. Mapping the height and aboveground biomass of a mixed forest using lidar and stereo Ikonos images. International Journal of Remote Sensing, Vol. 29, No. 5, pp. 1277-1294. doi: 10.1080/01431160701736505.
Sullivan, T.P., Sullivan, D.S., and Lindgren, P.M.F. 2001. Stand structure and small mammals in young Lodgepole Pine forest: 10- year results after thinning. Ecological Applications, Vol. 11, No. 4, pp. 1151-1173. doi: 10.1890/1051-0761(2001)011[1151:SSASMI]2.0.CO;2.

Tappeiner, II J.C., Maguire, D.A., and Harrington, T.B. 2007. Silviculture and ecology of Western U.S. forests. Oregon State University Press, Corvallis, Oregon.

Tso, B., and Mather, P. 2001. Classification Methods for Remotely Sensed Data, Taylor \& Francis. New York.

Varga, P., Chen, H.Y.H., and Klinka, K. 2005. Tree-size diversity between single-and mixed-species stands in three forest types in western Canada. Canadian Journal of Remote Sensing, Vol. 35, pp. 593-601.

Vázquez de la Cueva, A. 2008. Structural attributes of three forest types in central Spain and Landsat ETM + information evaluated with redundancy analysis. International Journal of Remote Sensing, Vol. 29, No. 19 , pp. 5657-5676. doi: 10.1080/01431160801891853.

White, J.C., Gómez, C., Wulder, M.A., and Coops, N. 2010. Characterizing temperate forest structural and spectral diversity with Hyperion EO-1 data. Remote Sensing of Environment, Vol. 114, No. 7, pp. 1576-1589. doi: 10.1016/j.rse.2010.02.012.

Wolter, P.T., Townsend, P.A., and Sturtevant, B.R. 2009. Estimation of forest structural parameters using 5 and 10 meter SPOT-5 satellite data. Remote Sensing of Environment, Vol. 113, No. 9, pp. 2019-2036. doi: 10.1016/j.rse.2009.05.009.

Wulder, M.A., LeDrew, E.F., Franklin, S.E., and Lavigne, M.B. 1998. Aerial texture information in the estimation of northern deciduous and mixed wood forest leaf area index (LAI). Remote Sensing of Environment, Vol. 64, No. 1, pp. 64-76. doi: 10.1016/S0034-4257(97) 00169-7.

Wulder, M.A., Hall, R.J., Coops, N.C., and Franklin, S.E. 2004. High spatial resolution remotely sensed data for ecosystem characterization. BioScience, Vol. 54, No. 6, pp. 511-521. doi: 10.1641/0006-3568(2004) 054[0511:HSRRSD]2.0.CO;2. 



\section{CHAPTER V}

Cristina Gómez, Joanne C. White, Michael A. Wulder, Pablo Alejandro (acceptado enero 2014). Historical forest biomass dynamics modelled with Landsat spectral trajectories. ISPRS Journal of Photogrammetry and Sensing.

\section{RESUMEN}

\section{Biomasa forestal estimada mediante modelos de trayectoria espectral Landsat}

Para conocer el papel de los ecosistemas forestales en el balance de carbono a nivel local y global, es necesario estimar la biomasa aérea forestal y su evolución en el tiempo. La evaluación del cambio requiere establecer unos valores de referencia de forma retroactiva. En este estudio se utilizaron trayectorias espectro-temporales, con información intrínseca relacionada con los procesos de sucesión, para modelizar y cartografiar valores recientes e históricos de biomasa aérea en pinares mediterráneos del Sistema Central. Los valores de biomasa generados a partir de dos repeticiones (1990 y 2000) de medidas del inventario forestal nacional (IFN) español se tomaron como referencia y se relacionaron con datos espectrales estáticos y dinámicos medidos por los sensores Thematic Mapper (TM) y Enhanced Thematic Mapper Plus (ETM+) de Landsat en un período de 25 años (19842009). Primero se investigó la relación entre biomasa e índices de vegetación mediante transformaciones wavelet unidimensionales, comprobando la fuerte influencia de la complejidad estructural en estas relaciones. Mediante transformaciones wavelet en dos dimensiones se identificaron trayectorias espectrales tipo para esta zona que se relacionan con características individuales de las parcelas del IFN mediante un algoritmo flexible de máxima similitud. Los índices espectrales de vegetación, las trayectorias espectrales y sus derivadas temporales (asociadas a procesos de sucesión forestal), se incluyen como variables independientes en un proceso de decisión binaria para modelizar, estimar, y cartografiar la biomasa y las reservas de carbono en toda el área considerada. Los resultados indican que las trayectorias tipo de variación de NDVI durante periodos cortos están relacionadas con clases de biomasa forestal. El índice TCA está fuertemente relacionado con la densidad forestal pero sus patrones de cambio tienen poca relación con la dinámica de biomasa en el pasado. Los modelos de biomasa obtenidos se extendieron a todo el área de estudio a través de pequeños segmentos espaciales ( 2.5 ha) definidos mediante homogeneidad espectral. Se cartografiaron los cambios de biomasa durante el periodo 1990-2000 (70\% de precisión al validar con los valores de cambio medidos en parcelas), revelando un incremento del 18\% distribuido irregularmente sobre $814 \mathrm{~km}^{2}$ de 
pinares. La acumulación media de carbono en biomasa aérea en estos pinares mediterráneos fue de $0.65 \mathrm{t} \cdot \mathrm{ha}^{-1} \cdot \mathrm{a}^{-1}$, equivalente a la fijación de $2.38 \mathrm{t} \cdot \mathrm{ha}^{-1} \cdot \mathrm{a}^{-1}$ de dióxido de carbono.

Palabras clave: serie temporal; retrospectivo; biomasa aérea; Landsat; transformación wavelet, dynamic time warping, Inventario Forestal Nacional, España 
Historical forest biomass dynamics modelled with Landsat spectral trajectories

Authors:

Cristina Gómez ${ }^{\mathrm{a}}$, Joanne C. White ${ }^{\mathrm{b}}$, Michael A. Wulder ${ }^{\mathrm{b}}$, Pablo Alejandro ${ }^{\mathrm{c}}$

Affiliations:

${ }^{a}$ Sustainable Forest Management Research Institute, Universidad de Valladolid \& INIA, Palencia, 34004, Spain

${ }^{\mathrm{b}}$ Canadian Forest Service (Pacific Forestry Centre), Natural Resources Canada, Victoria, British Columbia, V8Z 1M5, Canada

c 17 Deveron Park, Huntly, AB54 8UZ, United Kingdom

Corresponding author: Cristina Gómez

E-mail: c.gomez@abdn.ac.uk

Keywords: remote sensing; time series; retrospective; above ground biomass; Landsat; wavelet transform, dynamic time warping, National Forest Inventory, Spain

Submitted to: ISPRS Journal of Photogrammetry and Remote Sensing

Submitted on: August 8, 2013

Revised and returned: January 23, 2014 


\begin{abstract}
Estimation of forest aboveground biomass (AGB) is informative of the role of forest ecosystems in local and global carbon budgets. There is a need to retrospectively estimate biomass in order to establish a historical baseline and enable reporting of change. In this research, we used temporal spectral trajectories to inform on forest successional development status in support of modelling and mapping of historic AGB for Mediterranean pines in central Spain. AGB generated with ground plot data from the Spanish National Forest Inventory (NFI), representing two collection periods (1990 and 2000), are linked with static and dynamic spectral data as captured by Landsat Thematic Mapper (TM) and Enhanced Thematic Mapper Plus (ETM+) sensors over a 25 year period (1984-2009). The importance of forest structural complexity on the relationship between AGB and spectral vegetation indices is revealed by the analysis of wavelet transforms. Two-dimensional (2D) wavelet transforms support the identification of spectral trajectory patterns of forest stands that in turn, are associated with traits of individual NFI plots, using a flexible algorithm sensitive to capturing time series similarity. Single-date spectral indices, temporal trajectories, and temporal derivatives associated with succession are used as input variables to non-parametric decision trees for modelling, estimation, and mapping of AGB and carbon sinks over the entire study area. Results indicate that patterns of change found in Normalized Difference Vegetation Index (NDVI) values are associated and relate well to classes of forest AGB. The Tasseled Cap Angle (TCA) index was found to be strongly related with forest density, although the related patterns of change had little relation with variability in historic AGB. By scaling biomass models through small ( 2.5 ha) spatial objects defined by spectral homogeneity, the AGB dynamics in the period 1990-2000 are mapped (70\% accuracy when validated with plot values of change), revealing an increase of $18 \%$ in AGB irregularly distributed over $814 \mathrm{~km}^{2}$ of pines. The accumulation of $\mathrm{C}$ calculated in $\mathrm{AGB}$ was on average $0.65 \mathrm{t} \mathrm{ha}^{-1} \mathrm{y}^{-1}$, equivalent to a fixation of $2.38 \mathrm{t} \mathrm{ha}^{-1} \mathrm{y}^{-1}$ of carbon dioxide.
\end{abstract}

Keywords: remote sensing; time series; retrospective; above ground biomass; Landsat; wavelet transform, dynamic time warping, National Forest Inventory, Spain 


\section{Introduction}

Aboveground biomass (AGB) is a fundamental element of forest ecosystems. AGB is significant for its carbon storage capacity (Liski et al., 2000; Muukkonen and Heiskanen, 2007), and as a potential source of timber and production of bio-energy (FAO, 2003; Smeets and Faaij, 2007). Biomass amount per surface unit indicates the condition and productivity of a forest (FAO, 2010; Hall et al., 2006) and it is associated with ecological benefits related to biodiversity. Assessing forest AGB and related dynamics with spatially explicit detail is important for sustainable forest management (Herrero and Bravo, 2012; Tan et al., 2007), ecological applications (Barlow and Peres, 2004; Lewis et al., 2004), carbon accounting (Barredo et al., 2012; Houghton, 2005), for providing information in support of carbon markets (Goetz et al., 2009; Wang et al., 2009), and for reporting commitments (Andersson et al., 2009; Kurz and Apps, 2006).

Remote sensing has become the primary data source for large area biomass estimation (Lu, 2006), providing spatial detail to capture ground variability (Wulder et al., 2008), and temporal repetition to account for change (Powell et al., 2010). As summarized by Kangas and Maltamo (2006), national forest inventories (NFI) supply precise information based on plot measurements (e.g. Finland, USA), frequently supported by aerial photography or satellite data (e.g. UK, Canada) that can be scaled and extended to unmeasured areas through direct modelling with passive or active remotely sensed data (Baccini et al., 2004; Blackard et al., 2008). Estimation and monitoring of AGB with remotely sensed data sources can be fast and relatively low cost, providing information for remote and inaccessible areas (Bortolot and Wynne, 2005). While error estimates are ultimately linked to the quality of the reference data (Baccini et al., 2007), improved processing algorithms and techniques for data analysis can enhance the accuracy of AGB estimates from remotely sensed data sources ( $\mathrm{Lu}, 2006)$. The radiometric saturation of optical sensors at high levels of biomass is well known (Gemmell, 1995; Lu, 2005; Turner et al., 1999). Saturation is also a problem for radar instruments (Englhart et al., 2011; Mitchard et al., 2009), with the degree of saturation dependent on wavelength, polarization, and vegetation structure (Lu, 2006). Airborne and spaceborne LiDAR can provide an important alternative source of forest structural information (Duncanson et al., 2010; Kwak et al., 2010; Næsset and Gobakken, 2008), and combinations of data from multiple sensors provide robust options for estimation of forest biomass (Sun et al., 2011; Yu et al., 2010). 
Retrospective estimation of AGB to establish a historical baseline and enable change reporting is feasible with archival data, where the Landsat program provides the longest and most consistent repository of imagery, going back to 1972 (Wulder et al., 2012). The Landsat archive is also the only realistic source of data for mapping at the level of detail required by international treaties (e.g. Kyoto Protocol). Methods to map historical forest attributes may apply date invariant relationships (Healey et al., 2006; Powell et al., 2010) to past data using static measures (i.e. spectral predictors obtained at a given time). The relationship between contemporary spectral and reference data is extended to other dates of interest, relying on a robust process of relative radiometric normalization of imagery, for estimation of change. Incorporation of dynamic variables, that is, predictors combining data captured at various dates, for modelling AGB and its dynamics remains unexplored. In this work we estimate and map historical AGB in central Spain using temporally irregular trajectories of spectral indices from Landsat records, supported with information derived from NFI measurements.

Our goal is to estimate and map historical AGB (at specified dates in time), as well as a decade of change in AGB, by combining the precision of field measures from a network of NFI plots with the wall-to-wall spatial coverage provided by remotely sensed data. We first explore the relationship between live AGB derived from NFI ground plot measurements and vegetation spectral indices derived from Landsat data. Second, we model past AGB with historical spectral data, including single-date data and multi-temporal trajectories, providing a baseline for comparison with more recent estimations. Lastly, we map historical AGB at two dates coincident with NFI rotations (1990 and 2000) and evaluate the distribution of change in view of the uncertainties associated with the process of modelling and mapping.

\subsection{Background}

Estimation of forest biomass with optical remotely sensed data is based on the assumption of a strong statistical relationship between AGB and the spectral response as captured by the sensor ( $\mathrm{Lu}, 2006)$. Providing there are an adequate number of quality ground samples, direct modelling of AGB relies on the choice of a set of appropriate predictor variables and the development of suitable estimation models (Lu et al., 2012). The most frequently attempted model types are regression (González-Alonso et al., 2006; Rahman et al., 2005), imputation (Chirici et al., 2008; Fazakas et al., 1999), neural networks (Foody et al., 2001; 
Jin and Liu, 1997) and decision trees (Blackard et al., 2008; Mutanga et al., 2012). The adequacy of a model depends on data availability, desired precision, transparency, and sitespecific characteristics (Labrecque et al., 2006). Amongst the suite of possible predictor variables of AGB, the calibrated reflectance of visible and near-infrared wavelengths without further processing is sometimes used, although vegetation indices (i.e. combinations of two or more spectral bands) are recommended for the capacity to reduce noise effects associated with canopy shadows (Gemmell, 1999), which can be relevant in sites of complex vegetation structure (Lu et al., 2004).

Empirical relationships between forest $\mathrm{AGB}$ and spectral properties-as captured by optical sensors-have been intensively explored in a broad range of biomes and are site specific (e.g. Foody et al., 2003; Gemmell, 1998). Uncertainties in this empirical relationship may arise from sensor limitations (e.g. viewing angle, radiometric resolution), atmospheric effects (e.g. haze, cloud), vegetation phenology, and topographic characteristics (Gemmell, 1998), but also from intrinsic forest structure and variability (Gemmell, 1995; Lu et al., 2005). In Mediterranean forests, typically characterized by rugged locations and structural heterogeneity (Salvador and Pons, 1998), the relationship between AGB and spectral response has proven difficult to characterize (e.g. Maselli et al., 2005; Vázquez de la Cueva, 2008).

\subsection{Incorporation of temporal information into modelling of forest attributes}

The majority of direct models incorporate data captured at a single point in time, which ideally is as close as possible to the timing of reference data collection on the ground. Multi-seasonal imagery has been shown to improve the accuracy of forest biomass estimation (Gasparri et al., 2010; Lefsky et al., 2001). Furthermore, the benefits of multitemporal data for estimation of successional processes (Song et al., 2002; Song et al., 2007) and forest structure (Gemmell et al., 2001), both of which are intimately linked to AGB, have been acknowledged, with multiple images analyzed independently (Foody et $a l .$, 1996) or linked in a temporal trajectory (Liu et al., 2008).

Open access data policies facilitating the use of image time series (Wulder et al., 2012) have prompted the emergence of new approaches to extract information from spatially coincident multi-date imagery (Table 1). Polynomial characterization of spectral curves (Goodwin et al., 2010) or identification of distinctive trajectory segments (Kennedy et al., 2010) are alternative options to make use of the inherent temporal information of a series 
of calibrated data for interpretation of ecological processes. We explore here an option to directly incorporate temporal information in predictor variables for estimation of AGB. The empirical models linking AGB measurements with Landsat spectral data facilitate mapping of forest biomass and change.

Table 1. Forest studies capitalizing on information from Landsat imagery spectral trajectories.

\begin{tabular}{|c|c|c|c|}
\hline \multirow{2}{*}{ Study } & \multirow{2}{*}{$\begin{array}{l}\text { Ecosystem/ } \\
\text { Location }\end{array}$} & \multicolumn{2}{|l|}{ Goal } \\
\hline & & Approach & Spectral variable \\
\hline \multirow{2}{*}{ Liu et al., 2008} & \multirow{2}{*}{$\begin{array}{l}\text { Coniferous / } \\
\text { Oregon (USA) }\end{array}$} & \multicolumn{2}{|c|}{ Prediction of forest successional stages } \\
\hline & & $\begin{array}{l}\text { Modelling with progressive } \\
\text { multi-date predictors }\end{array}$ & TCB,TCG,TCW \\
\hline \multirow{2}{*}{ Huang et al., 2009} & \multirow{2}{*}{$\begin{array}{l}\text { Various National } \\
\text { Forests / } \\
\text { (USA) }\end{array}$} & \multicolumn{2}{|c|}{$\begin{array}{l}\text { Validation of VCT performance in detection of forest } \\
\text { change dynamics }\end{array}$} \\
\hline & & $\begin{array}{l}\text { Interpretation of IFZ temporal } \\
\text { profiles }\end{array}$ & $\begin{array}{l}\text { IFZ (Red, SWIR1, } \\
\text { SWIR2) }\end{array}$ \\
\hline \multirow{2}{*}{ Goodwin et al., 2010} & \multirow{2}{*}{$\begin{array}{l}\text { Coniferous / } \\
\text { British Columbia } \\
\text { (Canada) }\end{array}$} & \multicolumn{2}{|c|}{ Characterization of mountain pine beetle infestation } \\
\hline & & Polynomial curve fitting model & NDMI \\
\hline \multirow{2}{*}{ Kennedy et al., 2010} & \multirow{2}{*}{$\begin{array}{l}\text { Coniferous and } \\
\text { broadleaved / } \\
\text { Oregon and } \\
\text { Washington (USA) }\end{array}$} & \multicolumn{2}{|c|}{$\begin{array}{l}\text { Description of successional processes: disturbance and } \\
\text { recovery }\end{array}$} \\
\hline & & $\begin{array}{l}\text { Temporal segmentation and } \\
\text { interpretation of segments }\end{array}$ & NDVI, NBR, TCW \\
\hline \multirow[b]{2}{*}{ Powell et al., 2010} & \multirow{2}{*}{$\begin{array}{l}\text { Coniferous and } \\
\text { mixed / } \\
\text { Arizona and } \\
\text { Minnesota (USA) }\end{array}$} & \multicolumn{2}{|l|}{ Assessment of AGB over two decades } \\
\hline & & Trajectory of modelled AGB & $\begin{array}{l}\text { TCA, TCB, TCG, } \\
\text { TCW, DI, } \\
\text { Reflectances }\end{array}$ \\
\hline \multirow[b]{2}{*}{ Gómez et al., 2012} & \multirow{2}{*}{$\begin{array}{l}\text { Mediterranean } \\
\text { pines / } \\
\text { (Spain) }\end{array}$} & \multicolumn{2}{|c|}{ Assessment of 25 years of carbon fluxes } \\
\hline & & $\begin{array}{l}\text { Temporal derivative of spectral } \\
\text { trajectory with interpretation of } \\
\text { state and process }\end{array}$ & TCA \\
\hline \multirow[b]{2}{*}{ Pflugmacher et al., 2012} & \multirow{2}{*}{$\begin{array}{l}\text { Mixed-conifer } \\
\text { forest / } \\
\text { Oregon (USA) }\end{array}$} & \multicolumn{2}{|c|}{$\begin{array}{l}\text { Estimation of current structural parameters (live and } \\
\text { dead biomass) }\end{array}$} \\
\hline & & $\begin{array}{l}\text { Model current parameters with } \\
\text { disturbance and recovery features } \\
\text { derived from spectral trajectories }\end{array}$ & $\begin{array}{l}\text { TCA, } \\
\text { TCB,TCG,TCW }\end{array}$ \\
\hline \multirow[b]{2}{*}{ Zhu et al., 2012} & \multirow{2}{*}{$\begin{array}{l}\text { Evergreen forest / } \\
\text { Georgia and } \\
\text { California (USA) }\end{array}$} & \multicolumn{2}{|l|}{ Monitoring of forest disturbance } \\
\hline & & $\begin{array}{l}\text { Dense time series models } \\
\text { phenology with trigonometric } \\
\text { functions for detection of change }\end{array}$ & DI \\
\hline
\end{tabular}

DI: Disturbance Index; IFZ: Integrated Forest Z-score; NDMI: Normalized Difference Moisture Index; NDVI: Normalized Difference Vegetation Index; TCA: Tasseled Cap Angle; TCB: Tasseled Cap Brightness; TCG: Tasseled Cap Greenness; TCW: Tasseled Cap Wetness. 


\subsection{Wavelet transforms in remote sensing and forestry applications}

Wavelet transforms have been used in the remote sensing community for image blending (Garguet-Duport et al., 1996; Zhou et al., 1998), for detection of haze (Du et al., 2002), spectral unmixing of hyperspectral data ( $\mathrm{Li}, 2004)$, post-classification change detection (Raja, 2013), and feature extraction (Fukuda and Hirosawa, 1999; Niedermeier et al., 2000; Simhadri et al., 1998). In relation to vegetation dynamics, Sakamoto et al. (2005) developed a method for detection of crop phenology incorporating wavelet filters. Percival et al. (2004) proposed the usefulness of the multi-resolution analysis (MRA) applied to vegetation time series, with which Martínez and Gilabert (2009) identified seasonal and long term trend changes of various land covers in Spain. Freitas and Shimabukuro (2008) applied MRA to spectral fractions of MODIS bands for analysis of land cover change in Brazil, identifying the location and time of disturbance events.

As a tool for analysis of data, wavelet transform techniques facilitate the characterization of non-stationary processes (Meyers et al., 1993), that is, processes of change dependent on the scale of variation. The most distinctive property of wavelet transforms is the capacity to provide local information of the target series $\mathrm{F}(\mathrm{x})$ and at a range of selected scales (Lindsay et al., 1996). This property derives directly from the wavelet definition as a function that oscillates around zero, and that is localized in a finite width interval (Meyers et al., 1993). Basically, a wavelet transform decomposes the original series $\mathrm{F}(\mathrm{x})$ into a set of functions by convolving $\mathrm{F}(\mathrm{x})$ with a family of wavelets, which are derived by scaling and translation of a mother or basis function $\mathrm{G}(\mathrm{x})$. As result of the wavelet transform a number of functions are produced, one approximation $\left(\mathrm{A}_{\mathrm{i}}\right)$ and one detail $\left(\mathrm{D}_{\mathrm{i}}\right)$ function per scale or level. Another interesting property of the wavelet transform is that the original series can always be reconstructed from its decomposed elements: at any level of decomposition (i) the original series $F(x)$ equals that level approximation $A_{i}$ plus the sum of all lower level details $\left(\sum \mathrm{D}_{\mathrm{j}}\right)(\mathrm{j}=1 \ldots \mathrm{i}-1)$. For the sake of interpretation, approximation functions inform trends of change whilst detail functions account for high frequency related with noise (Percival et al., 2004) and are associated with changes in averages at each given scale. A measure of variance or energy associated with each function helps identify which are the most relevant levels of the wavelet transform decomposition (Lindsay et al., 1996). Wavelet transforms are used in this work with a double purpose: exploratory analysis of the relationship between spectral indices and plot measured AGB, and smoothing of a system of data for derivation of dynamic spectral variables. 


\section{Methods}

\subsection{Overview}

The relationship between AGB and spectral properties at the plot level was explored in a forest ecosystem of Mediterranean pines. Vegetation indices suitable for modelling AGB were identified. Dynamic spectral variables associated with forest successional development were defined through wavelet transformations of a data system formed by a set of spatially coincident field measures and corresponding calibrated spectral data captured over 25 years. The domain of the dynamic variables was identified as a number of modelled trajectories. To test the significance of the dynamic spectral variables in predicting $\mathrm{AGB}$, a binary rule-based approach was applied to ground plots characterized by dynamic, as well as static variables, in order to identify the most relevant predictors. Cross-validation was used to determine the best binary model for AGB in 1990 and 2000; the best binary models were then applied to small spectrally homogenous ground units for mapping AGB and carbon dynamics over the entire study area. The resulting map of AGB change was validated with plot values of biomass change. Figure 1 provides an overview of the main methods applied in this work. 


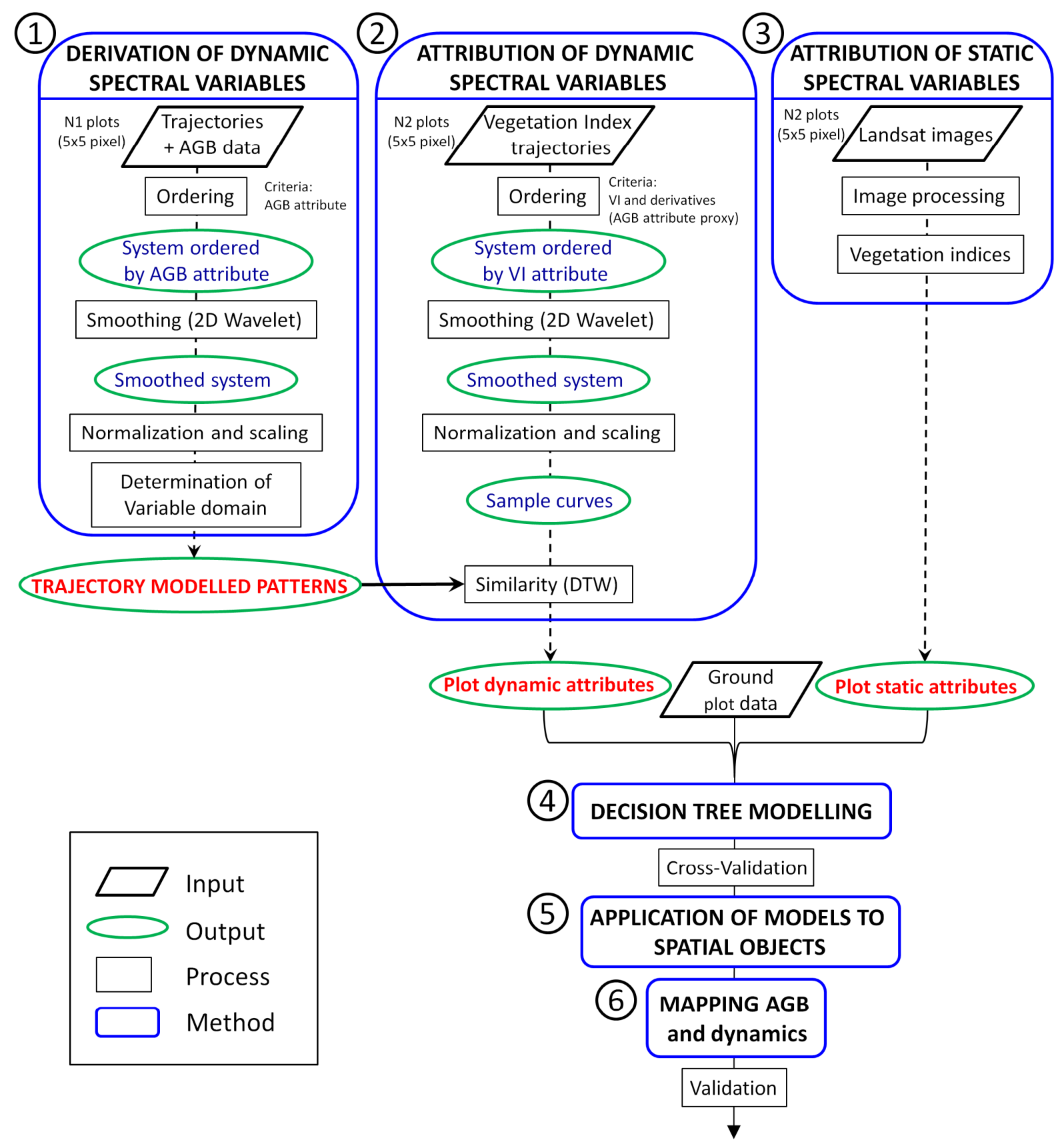

Figure 1. Schematic representation of main methods followed in this study. Dynamic spectral variables are defined with a flow process based on 2D wavelet transforms, and the domain of each variable is identified as a number of modelled trajectories. Sample plots of unknown AGB are attributed dynamic variables by maximum similarity to trajectory models. Statistical models of AGB at the plot level are derived with a binary-rule approach based on dynamic and static spectral variables. These models are applied to the entire area to map estimated AGB dynamics between 1990 and 2000. 


\subsection{Study area}

The study area is centred at latitude $40^{\circ} 37^{\prime} 56^{\prime \prime} \mathrm{N}$ and longitude $-4^{\circ} 6^{\prime} 47^{\prime}$ ' $\mathrm{E}$, in the Central Range of Spain, and occupies part of the Ávila, Segovia, Madrid, Guadalajara and Toledo provinces (Figure 2). It is a pine ecosystem with dominant tree species Pinus sylvestris L., Pinus pinaster Ait., and Pinus nigra Arn. Forests extend to elevations of 2000 m, beyond which shrubs (Cytisus sp., Genista sp., Erica sp., Echinospartum sp.) are the prevalent vegetation (Rivas-Martínez, 1963). Some of these Mediterranean pines have traditionally been managed for production of resin and timber, recreation, and protection, with the last two objectives having increasing importance. A range of structural conditions (e.g. monospecific and even aged, multi-species, multi-layer) have resulted from the various management practices that have been applied, including the non-management option (e.g. multi-aged, multi-story). Stand age classes are typically defined as 20-year intervals for the species in the entire area (Serrada, 2008). Silvicultural practices include pruning and thinning, with timber extraction implemented over time by progressive cuts of low intensity.

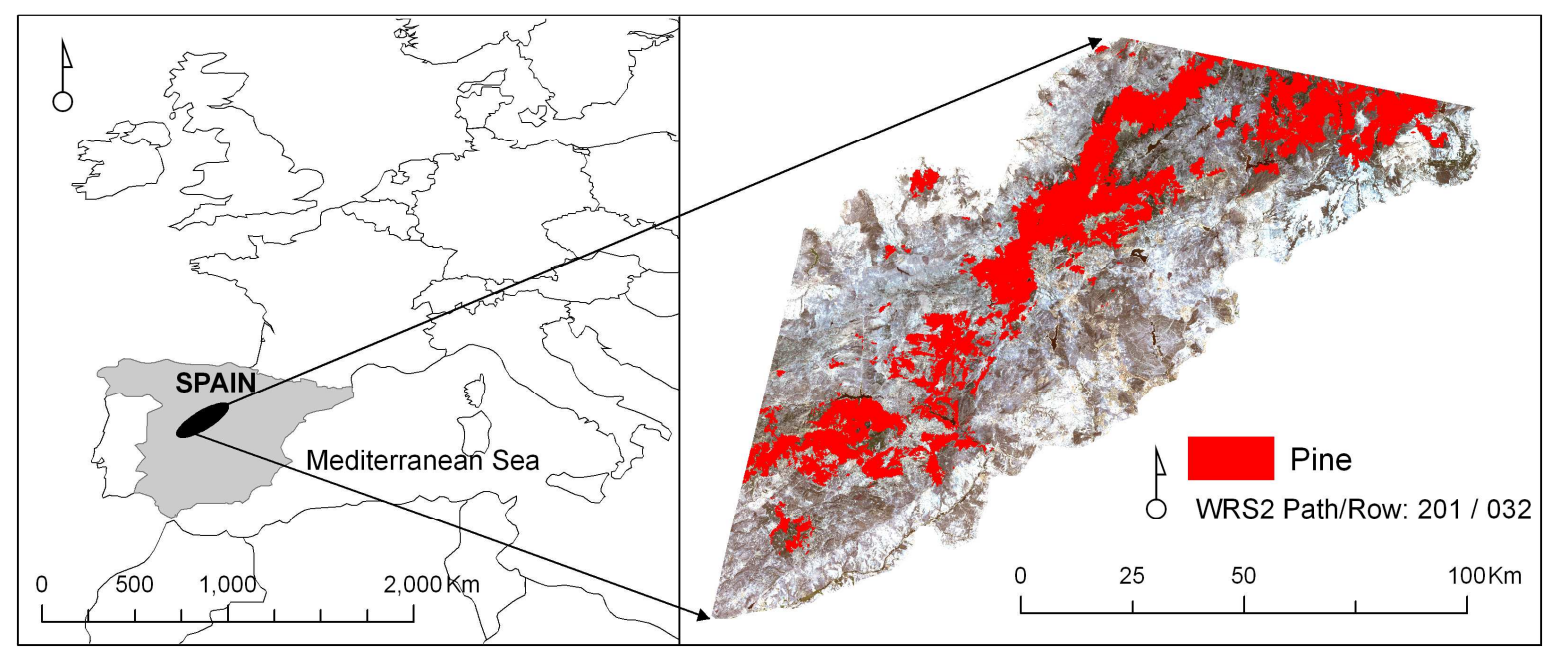

Figure 2. Location of the study area in the Central Range of Spain. It is a Mediterranean ecosystem that has been permanently covered with pine forests during period 1984-2009. 


\subsection{Ground plot data and derived ground plot attributes}

Two rounds of the Spanish National Forest Inventory data (NFI2 ca. 1990 and NFI3 ca. 2000) (Bravo et al., 2002), including per tree measures of diameter at breast height (D), total height $(\mathrm{H})$, and per plot number of trees $(\mathrm{N})$, were used for calculation of biomass in 605 plots spread over an area permanently forested with pines over the period 1984-2009 (Gómez et al., 2012). In this area NFI plots were de facto measured during the 1992-1994 and 2000-2004 campaigns of the NFI2 and NFI3 respectively. Live AGB was calculated with the species specific allometric equations of Montero et al. (2005) and Ruiz-Peinado et al. (2011) for all trees with $\mathrm{D} \geq 7.5 \mathrm{~cm}$. These equations can determine the dry biomass fraction of stem, roots, and branches of various dimensions; however, we did not consider the root portion in our analysis, and focused on the AGB. Absolute and relative change of AGB between the rounds of NFI was calculated (Table 2). NFI2 intra- plot structural complexity was evaluated as in Gómez et al. (2011a) calculating the median absolute deviation $(\mathrm{MAD})$ of measured $\mathrm{D}\left(\mathrm{D}_{\mathrm{MAD}}\right)$ and $\mathrm{H}\left(\mathrm{H}_{\mathrm{MAD}}\right)$ in each plot: increasing values of the MAD indicate higher structural complexity, and a zero MAD value is possible but unlikely to occur if all trees in a plot have exactly the same dimension. Thirty two plots subject to complete resource extraction between the two NFI rounds were disqualified in support of our assumption of near to natural successional conditions, leaving 573 plots for further analysis.

Table 2. Statistics of the attributes related to biomass $\left(\mathrm{t} \mathrm{ha}^{-1}\right)$ and structural complexity evaluated at NFI plots.

\begin{tabular}{|c|c|c|c|c|c|c|}
\hline $\begin{array}{l}\text { Attribute } \\
\text { type }\end{array}$ & $\begin{array}{c}\text { Plot } \\
\text { Attribute }\end{array}$ & Description & Mean & $\begin{array}{l}\text { Std. } \\
\text { dev. }\end{array}$ & Min. & Max. \\
\hline \multirow{5}{*}{ Biomass } & $\mathrm{AGB}_{1990}$ & Above ground biomass NFI2 (1990) & 93.29 & 67.09 & 1.45 & 352.08 \\
\hline & $\mathrm{AGB}_{2000}$ & Above ground biomass NFI3 (2000) & 109.36 & 68.99 & 0 & 398.90 \\
\hline & $\triangle \mathrm{AGB}$ & $\begin{array}{l}\text { Increment of AGB between NFI2 and } \\
\text { NFI3 }\end{array}$ & 14.80 & 50.07 & -236.86 & 242.38 \\
\hline & $\operatorname{Rel}_{1990}$ & Increment of AGB relative to $\mathrm{AGB}_{1990}$ & 0.79 & 2.55 & -1 & 28.41 \\
\hline & $\operatorname{Rel}_{2000}$ & Increment of $A G B$ relative to $A_{G B} 2000$ & -0.03 & 1.33 & -17.00 & 0.96 \\
\hline \multirow{2}{*}{$\begin{array}{l}\text { Structural } \\
\text { complexity }\end{array}$} & $\mathrm{D}_{\mathrm{MAD}}$ & Median absolute deviation of D (1990) & 4.59 & 3.93 & 0 & 8.00 \\
\hline & $\mathrm{H}_{\mathrm{MAD}}$ & Median absolute deviation of $\mathrm{H}$ (1990) & 1.81 & 1.18 & 0 & 24.35 \\
\hline
\end{tabular}




\subsection{Landsat data and processing}

Eight Landsat TM and ETM+ images (path/row: 201/32) spanning 25 years (1984-2009) (Table 3) were processed following standard procedures that include atmospheric correction of a reference image (date 2000) with the COST method (Chávez, 1988), relative radiometric normalization of the whole series with IR-MAD (Canty et al., 2004), ortho-correction with a $30 \mathrm{~m}$ digital elevation model, and geometric co-registration (RMSE $<0.5$ pixel), following a processing flow recommended for detection of vegetation dynamics (Vicente-Serrano et al., 2008). A set of near anniversary images at an advanced date in the growing season was selected to minimize phenological fluctuations. Spectral vegetation indices related with forest biomass and structure such as the Normalized Difference Vegetation Index (NDVI) (Dong et al., 2003; Piao et al., 2005), the Tasseled Cap Angle (TCA) (Gómez et al., 2012; Powell et al., 2010; Pflugmacher et al., 2012) and the Tasseled Cap Distance (TCD) (Duane et al., 2010; Powell et al., 2010) were derived from normalized Landsat reflectances. The temporal trajectory, namely the sequence of spectral values obtained from consecutive images of these spectral indices at averaged $5 \times 5$ pixel windows centred at the 573 NFI plots were identified and saved for analysis.

Table 3. Landsat imagery used in the study. Reference image for relative radiometric normalization (22/08/2000) is highlighted.

\begin{tabular}{ccc}
\hline $\begin{array}{c}\text { Landsat / } \\
\text { Sensor }\end{array}$ & dd/mm/yyyy & $\begin{array}{c}\text { Sun elev. } \\
(\mathbf{o})\end{array}$ \\
\hline 5 / TM & $18 / 08 / 1984$ & 52.89 \\
\hline $5 / \mathrm{TM}$ & $11 / 08 / 1987$ & 54.11 \\
\hline 4 / TM & $11 / 08 / 1990$ & 54.38 \\
\hline 4 / TM & $14 / 08 / 1991$ & 51.68 \\
\hline 7 / ETM+ & $22 / 08 / 2000$ & 54.87 \\
\hline 5 / TM & $07 / 08 / 2003$ & 56.50 \\
\hline 5 / TM & $25 / 08 / 2004$ & 53.15 \\
\hline 5 / TM & $23 / 08 / 2009$ & 54.48 \\
\hline
\end{tabular}




\subsection{Relationships between ground plot estimates of AGB and spectral vegetation indices}

To explore the relationship between plot AGB and vegetation spectral indices (NDVI, TCA, and TCD), temporal spectral trajectories were compiled into a block of trajectories

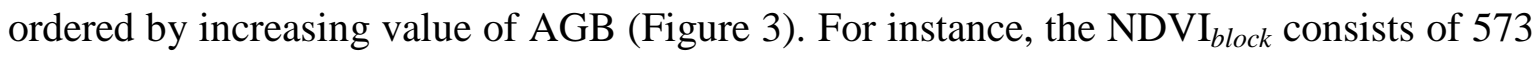
NDVI trajectories (one per 5x5 pixel window-plot), and similarly the $\mathrm{TCA}_{\text {block }}$ and the $\mathrm{TCD}_{\text {block }}$ consist of $573 \mathrm{TCA}$ and 573 TCD trajectories respectively. Each data system provides information that can be interpreted in the temporal or the biomass directions. Examined in the AGB direction, the spectral series represent at each date (1984 to 2009) a function of increasing AGB. At dates corresponding with the NFI2 (1990) and the NFI3 (2000), the values of the biomass function are known (calculated from field measures).

The spectral blocks of original trajectories (before wavelet smoothing) are characterized by high variability in the temporal and biomass directions, derived from sensor and environmental factors. Smoothing the system of spectral trajectories with a onedimensional wavelet transform in the biomass direction reveals the essential underlying relationship AGB-spectral index. We run a discrete wavelet transformation through a family of Meyer wavelets, specifically adapted for sampled series (Daubechies, 1992; Lindsay et al., 1996) followed by multi-resolution analysis for interpretation. The multilevel wavelet transformation smoothes the spectral system by isolating high frequency noise from the lower frequency basic signal (Figure 3). The level of decomposition necessary to isolate base information is related to the number and frequency of samples, and it is linked to the family of wavelets used. We run an eight level decomposition and found level six, with highest measure of variance, the most useful for description and interpretation. Running the wavelet transform simultaneously over the complete spectral block (1984-2009) rather than a single date function provides information of local (AGB) and temporal discontinuities, irregularities or exceptions, as well as an easy means to visually interpret information (Freitas and Shimabukuro, 2008). 


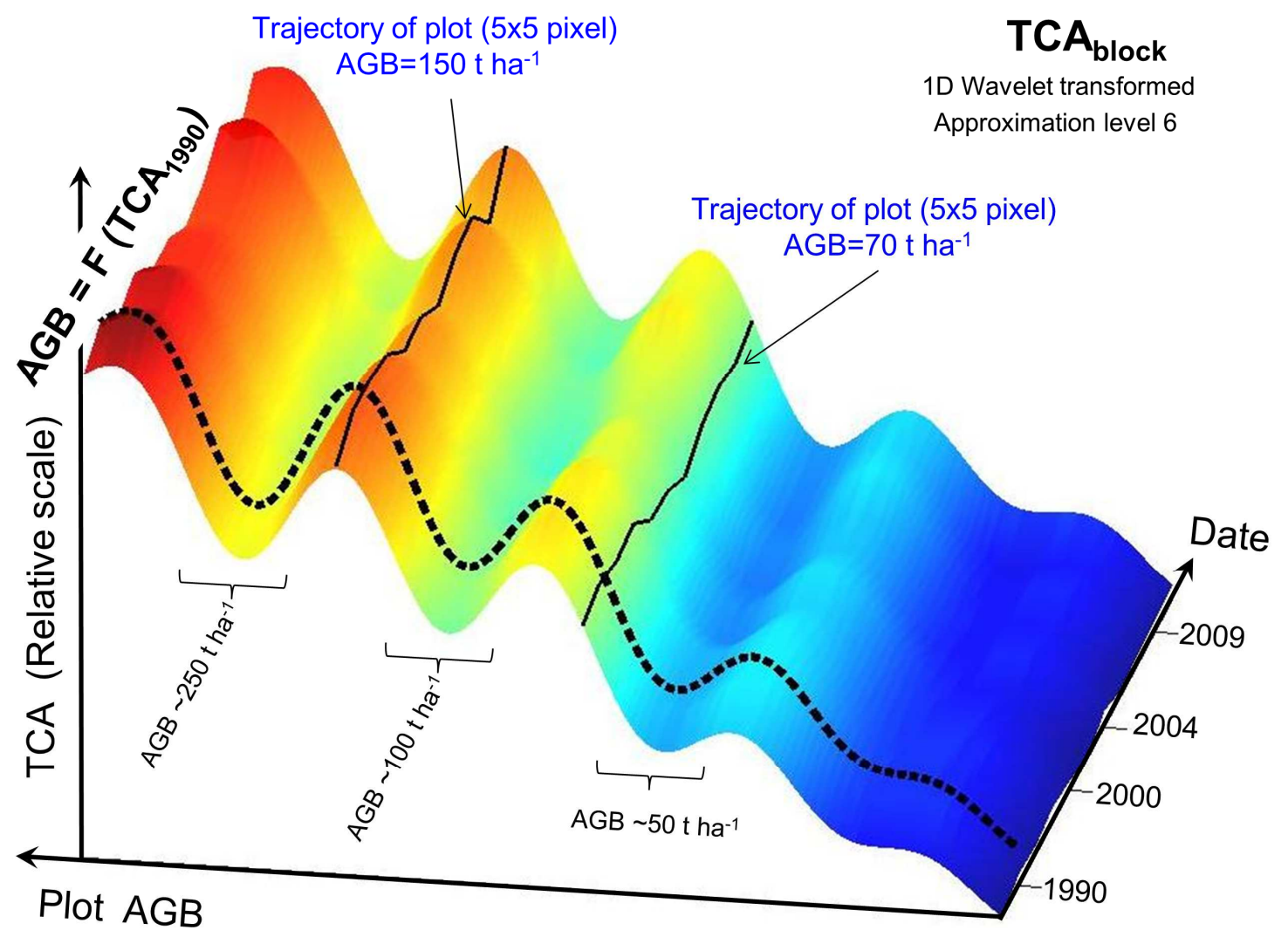

Figure 3. TCA $A_{\text {block }}$ for exploration of the relationship between the spectral index and plot AGB. The level 6 approximation of the smoothed system is represented. A positive relation AGB $=F$ (TCA) is evident although broken at intervals by the influence of endogenous (structure) and exogenous (topography, sensor) factors, conferring the system its wavy aspect.

The influence of local structural complexity on the relationship AGB-spectral index was explored with blocks of spectral trajectories previously modified by standardized values of MAD (plot $\mathrm{D}_{\mathrm{MAD}}$ and $\mathrm{H}_{\mathrm{MAD}}$ ). Constant structural complexity over the period 1984-2009 was assumed for each plot; therefore only one value of $\mathrm{D}_{\mathrm{MAD}}$ and $\mathrm{H}_{\mathrm{MAD}}$ was calculated for each plot (with NFI2 data) and applied to the entire trajectory. The blocks' sampling interval is neither regular in the temporal nor in the biomass direction, and it enables inference of qualitative information but has limited capacity to infer quantitative relations. For this reason, and with the aim to identify AGB categories as are routinely used in regional forest management, that could be unequivocally related with vegetation indices, we undertook a second exploratory analysis that included a sub-sample of 182 plots regularly distributed every $\sim 1.7 \mathrm{tha}^{-1}$ over the range $1-310 \mathrm{tha}^{-1}$. 
In the following sections we describe the process followed for modelling and mapping historical AGB and AGB dynamics during period 1990-2000. Figure 1 provides a summary of all stages to aid the reader in following the methods presented.

\subsection{Derivation of dynamic spectral variables and trajectory models}

The temporal series of spectral values depict rich and complex information that typically require specifically developed methods to expose. In order to derive an assortment of dynamic variables, each relating inherent temporal dimensionality, original trajectories and temporal derivatives (Gómez et al., 2011b) of a set of plots measured on the ground were considered $(\mathrm{N} 1=573)$. The sparse and irregular character of the series of spectral data available, with 8 samples in a 25 year interval (Table 3) required regularization by linear interpolation for completeness and easiness of interpretation. The state (original trajectory) and process (temporal derivative trajectory) of $\mathrm{NDVI}_{\text {block }}$ (573 NDVI trajectories) and $\mathrm{TCA}_{\text {block }}$ (573 TCA trajectories) were independently organized (ordered) by a biomass attribute $\left(\mathrm{AGB}_{1990}, \mathrm{AGB}_{2000}, \Delta \mathrm{AGB}, \mathrm{Rel}_{1990}\right.$, or $\left.\mathrm{Rel}_{2000}\right)$ and subject to a $2 \mathrm{D}$ wavelet smoothing filter. In this way, 16 ordered and smoothed data systems (M1 to M16) were considered (Table 4) and identified as dynamic variables (Figure 1, box 1). For instance, M11-M16 describe the successional path of these forests, while M1-M10 describe the changing pace, as represented by NDVI and TCA values over time, always relative to this particular area. The wavelet transform scale was adjusted in each direction, with six levels in the biomass direction and two levels in the temporal direction. For each system (Table 4) the domain of a dynamic variable is defined by semi-automatic identification of six to eight distinctive curve patterns (Figure 4, bottom). The independence of the smoothed systems and associated dynamic variables is assured by the individuality of the ordering criteria (Figure 4, top).

The dynamic variables can be grouped as state or process variables (Table 4). State variables are made up by the temporal spectral trajectory, while process variables are associated with the temporal derivatives of those trajectories (Gómez et al., 2011b). Ideally, if endogenous factors (e.g. structural complexity) and exogenous factors (e.g. topography, sensor limitations) were controlled or suppressed, state variables could describe the evolution of forest biophysical parameters related with spectral indices, and process variables would represent the rate at which those processes of change occurred. In 
reality, only approximations can be interpreted, as no single state or process variable is capable of completely explaining the biophysical development of forests.

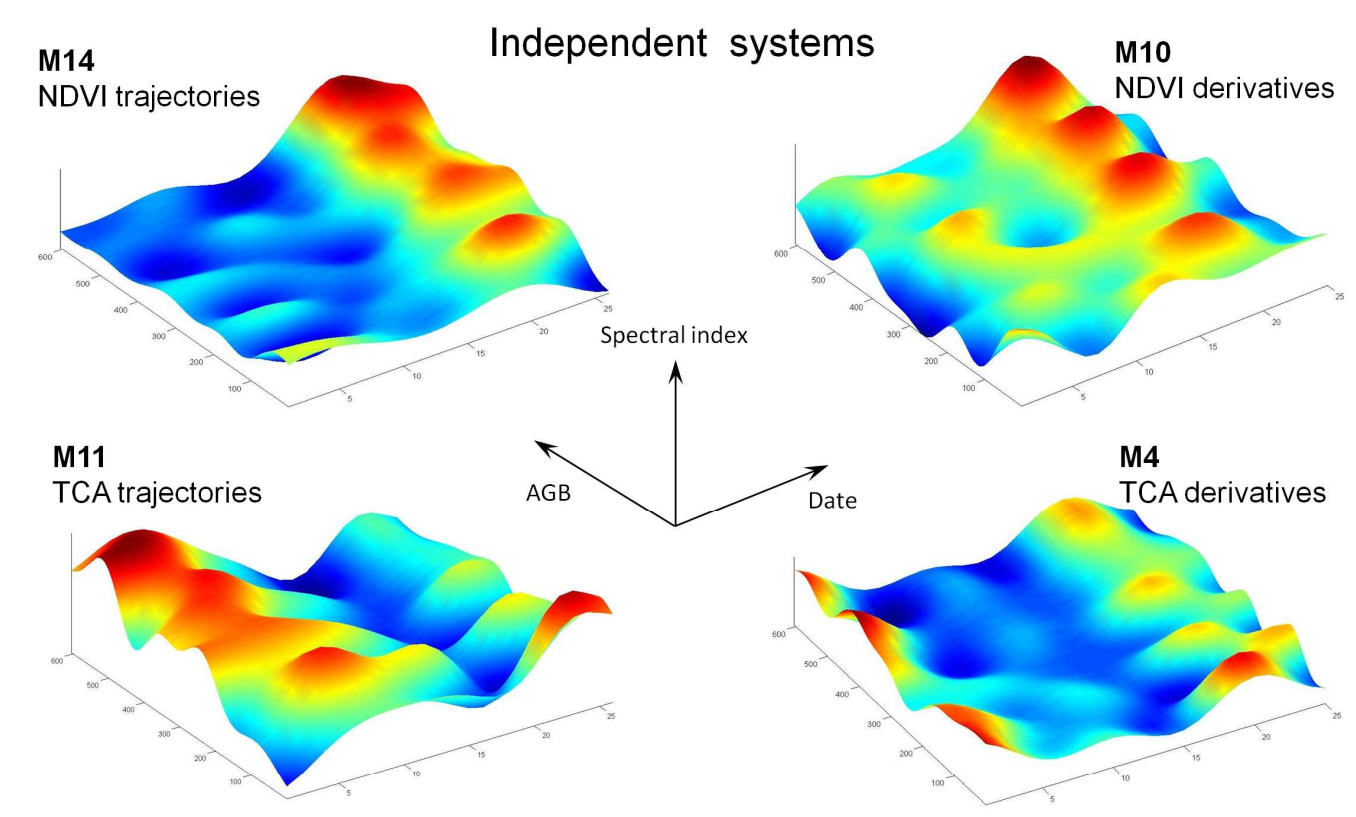

Modelled trajectories: M10 scaled curves

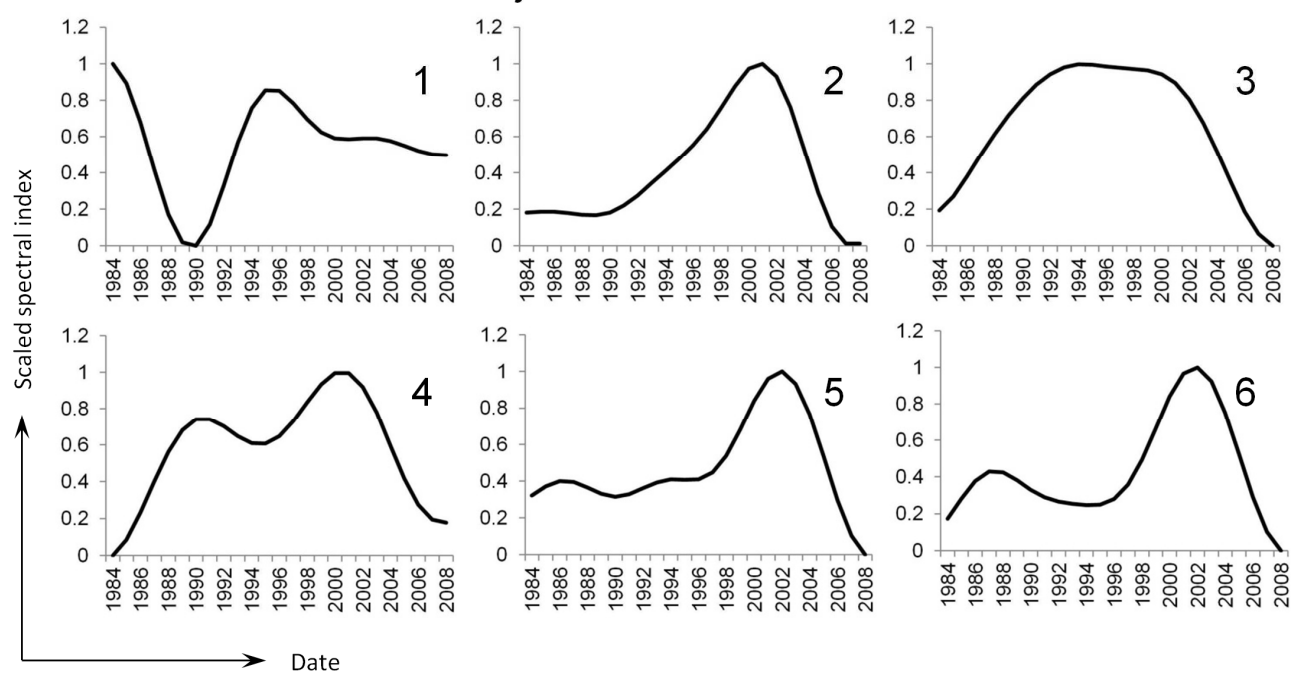

Figure 4. Illustration of stages in the derivation of dynamic spectral variables. Top: examples of independent and smoothed (2D wavelet) ordered data systems: M14 (NDVI

state trajectories ordered by $\mathrm{AGB}_{1990}$ ); M10 (NDVI process trajectories ordered by $\mathrm{AGB}_{2000}$ ); M11 (TCA state trajectories ordered by AGB 1990 ); M4 (TCA process trajectories ordered by $\left.\mathrm{AGB}_{1990}\right)$. Bottom: examples of modelled NDVI process patterns obtained from the data system M10 (NDVI process trajectories ordered by $\mathrm{AGB}_{2000}$ ). 
As an example, M5 (Table 4) is a process variable originated by the system of TCA derivative trajectories ordered by $\mathrm{AGB}_{2000}$ and smoothed in two directions (time and biomass). M5 domain consists of 8 patterns for period 1984-2009: in this area the TCA rate of change at the plot level follows one of 8 patterns, each one expected to be related to a different amount of AGB. To enable later comparison, model curves were normalized and scaled between zero and one.

The effectiveness of spectral trajectories as predictor variables is likely to be related to duration and starting position, which in turn might be limited by data availability. Acknowledging the importance of these features we tested the performance of two versions of each variable. Hence, in addition to the complete 25-year (1984-2009) spectral trajectory available, a 15-year (1990-2004) version, spanning the time lapse between NFI2 and NFI3 measurements, was considered. The initial point of the 15 -year variables is coincident with NFI2 ground measurements.

\subsection{Attribution of dynamic spectral variables to unmeasured locations}

Intending to recognize the nature of the spectral trajectories with highest capacity to describe AGB, dynamic variables related with successional processes have been created in a process with controlled AGB parameters. The predictive capacity of these variables has to be tested over locations of unknown AGB. In order to assign values of each dynamic variable domain to any ground location of unmeasured AGB, its corresponding temporal spectral trajectory is included into a system of spectral trajectories. The system needs to be subject to mathematical transformations similar to the models: ordering and $2 \mathrm{D}$ wavelet smoothing (Figure 1, box 2). In this case, as AGB parameters are unknown, spectral indices (NDVI, TCA) and derivative values $\left(\mathrm{PI}_{\mathrm{TCA}}, \mathrm{PI}_{\mathrm{NDVI}}\right)$ are employed as ordering features, as proxies to biomass and biomass changing properties (Table 4). We attempted a series of a priori reasonable proxies and created 14 spectral systems with spectral trajectories linked to ground plots. The process of attribution was based on identification of most similar pattern; with this purpose each system of curves was compared with the model counterparts. Since optimal proxies are not identified in advance, a priori various pairings are feasible: for instance system A1 curves (ordered by $\mathrm{PI}_{\mathrm{TCA}-1990}$ - the value of TCA derivative at date 1990) were compared with models in M1 to M5 (five comparisons), system N11 curves (ordered by NDVI 1990 ) were compared with models in M14 to M16 (three comparisons) and so on (Table 4). Fifty-eight combinations (18 state 
and 40 process) were possible. The number of spectral trajectories (N2) necessary to develop a suitable system is not fixed, but should be enough to be fitted for the wavelet transform parameters. For the sake of verification, the same set of ground plots previously used to build the curve models (AGB known case) are now attributed (AGB unknown case).

Table 4. Dynamic variables derived by transformation of spectral trajectories with a 2D wavelet smoothing of an ordered system. Fifty-eight combinations resulted from pairing sample systems (AGB unknown case) and model systems (AGB known case).

\begin{tabular}{|c|c|c|c|c|c|}
\hline \multirow[b]{2}{*}{$\begin{array}{l}\text { Group of } \\
\text { dynamic } \\
\text { variables }\end{array}$} & \multirow[b]{2}{*}{$\begin{array}{c}\text { Spectral } \\
\text { index }\end{array}$} & \multicolumn{2}{|c|}{ VARIABLE CONSTRUCTION } & \multicolumn{2}{|c|}{ ATTRIBUTION } \\
\hline & & $\begin{array}{c}\text { Model } \\
\text { ordering } \\
\text { attribute }\end{array}$ & $\begin{array}{c}\text { Variable } \\
\text { identifier } \\
\text { (\# domain } \\
\text { patterns) } \\
\end{array}$ & $\begin{array}{c}\text { Independent } \\
\text { ordering attribute } \\
\text { (biomass feature } \\
\text { proxy) } \\
\end{array}$ & $\begin{array}{c}\text { System } \\
\text { identifier }\end{array}$ \\
\hline \multirow{6}{*}{$\begin{array}{c}\text { State } \\
\text { (Trajectory } \\
\text { 1984-2009) }\end{array}$} & \multirow{3}{*}{ TCA } & $\mathrm{AGB}_{1990}$ & M11 (6) & $\mathrm{TCA}_{1990}$ & A11 \\
\hline & & $\mathrm{AGB}_{2000}$ & M12 (8) & $\mathrm{TCA}_{1984}$ & A12 \\
\hline & & $\triangle \mathrm{AGB}$ & M13 (8) & $\mathrm{TCA}_{2004}$ & $\mathrm{~A} 13$ \\
\hline & \multirow{3}{*}{ NDVI } & $\mathrm{AGB}_{1990}$ & M14 (7) & $\mathrm{NDVI}_{1990}$ & N11 \\
\hline & & $\mathrm{AGB}_{2000}$ & M15 (7) & $\mathrm{NDVI}_{1984}$ & $\mathrm{~N} 12$ \\
\hline & & $\Delta \mathrm{AGB}$ & M16 (7) & $\mathrm{NDVI}_{2004}$ & N13 \\
\hline \multirow{10}{*}{$\begin{array}{c}\text { Process } \\
\text { (Derivative } \\
\text { 1984-2009) }\end{array}$} & \multirow{5}{*}{ TCA } & $\Delta \mathrm{AGB}$ & M1 (7) & $\mathrm{PI}_{\mathrm{TCA}-1990}$ & A1 \\
\hline & & $\operatorname{Rel}_{1990}$ & M2 (7) & mean $\mathrm{PI}_{\mathrm{TCA}-1990-2004}$ & A2 \\
\hline & & $\operatorname{Rel}_{2000}$ & M3 (7) & $\mathrm{PI}_{\mathrm{TCA}-1995}$ & A3 \\
\hline & & $\mathrm{AGB}_{1990}$ & M4 (8) & $\mathrm{PI}_{\mathrm{TCA}-2004}$ & A4 \\
\hline & & $\mathrm{AGB}_{2000}$ & M5 (8) & & \\
\hline & \multirow{5}{*}{ NDVI } & $\Delta \mathrm{AGB}$ & M6 (7) & $\mathrm{PI}_{\mathrm{NDVI}-1990}$ & N1 \\
\hline & & $\operatorname{Rel}_{1990}$ & M7 (8) & mean $\mathrm{PI}_{\mathrm{NDVI}-1990-2004}$ & $\mathrm{~N} 2$ \\
\hline & & $\mathrm{Rel}_{2000}$ & M8 (8) & $\mathrm{PI}_{\mathrm{NDVI}-1995}$ & $\mathrm{~N} 3$ \\
\hline & & $\mathrm{AGB}_{1990}$ & M9 (8) & $\mathrm{PI}_{\mathrm{NDVI}-2004}$ & $\mathrm{~N} 4$ \\
\hline & & $\mathrm{AGB}_{2000}$ & M10 (7) & & \\
\hline
\end{tabular}

Trajectories are compared with the model curves of coupled systems, which are uniquely identified with a categorical value, and the most similar pattern is assumed and adopted at each plot. For example the 573 curves in system A1 are compared to seven model patterns in M1, each one acquiring the value of the most similar M1 pattern. Similarity was evaluated with the Dynamic Time Warping (DTW) (Giorgino, 2009), a flexible algorithm for alignment of vectors (e.g. time series). DTW compares and evaluates the difference between series of values, and it is more sensitive than the Euclidean distance to distortion in the time axis (Ratanamahatana and Keogh, 2005) allowing certain stretch or compression defined by user criteria, such as delays in a curve maxima or minima. At the 
end of the attribution process each plot is characterized with 58 curve patterns, some of which might be relevant to describe its AGB, as linked to a particular successional path.

\subsection{Decision trees for modelling historical $A G B$}

With ground plots characterized by dynamic variables, we can test the ability of these variables to predict AGB by statistical modelling. Decision trees (Breiman et al., 1984), also known as CART, identify relationships between a single continuous response variable (AGB) and multiple explanatory variables of either continuous and/or discrete character, in our case a collection of static (NDVI and TCA at various dates) and dynamic variables (Table 5). A binary recursive partitioning process based on combinations of variables (rules) that best distinguish the variation of AGB enables identification of relevant independent predictors. This nonparametric method for categorization of samples into increasingly homogeneous groups (nodes) does not make assumptions regarding the distribution of the input data and is robust to errors in the input. Decision trees have been widely used for predicting complex, nonlinear relationships between forest attributes and remotely sensed images (e.g. Saatchi et al., 2007).

Each plot was characterized with the biomass attributes (Table 2), the spectral indices at various dates (Figure 1, box 3), and its most similar patterns of dynamic variables in the 25-year and 15-year versions (Table 5). These sets of data were input for the CART analysis in Matlab® (Figure 1, box 4). Samples were split into calibration (50\%) and validation (50\%) sets, assuring both sets covered the entire range of AGB ( 1 to $350 \mathrm{tha}^{-1}$ ). To fit the model, a cross-validation process with ten iterations was performed and to avoid over-fitting, we considered the establishment of a minimum number of cases in terminal nodes and pruning with the 1 standard error rule (Breiman et al., 1984).

Table 5. Input variables to decision trees for modelling historical AGB in pines of central Spain.

\begin{tabular}{lll}
\hline Character & Nature & Variables \\
\hline \multirow{3}{*}{ Static } & \multirow{2}{*}{ Spectral indices } & TCA 1984, 1990, 2000, 2004, 2009 \\
& & NDVI 1984, 1990, 2000, 2004, 2009 \\
& TCD 1984, 1990, 2000, 2004, 2009 \\
\hline \multirow{3}{*}{ Dynamic } & State patterns (18) & $\begin{array}{l}\text { TCA related trajectory 1984-2009 } \\
\text { NDVI related trajectory 1984-2009 }\end{array}$ \\
\cline { 2 - 3 } & \multirow{2}{*}{ Process patterns (40) } & $\begin{array}{l}\mathrm{PI}_{\mathrm{TCA}} \text { related trajectory 1984-2009 } \\
\mathrm{PI}_{\mathrm{NDV}} \text { related trajectory 1984-2009 }\end{array}$ \\
\hline
\end{tabular}




\subsection{Mapping historical AGB dynamics and validation}

To map and assess the biomass and carbon content over the entire area, AGB models derived at the plot level ( $5 \times 5$ pixel window) were applied to spatial units defined on the Landsat image as small multi-pixel objects, within which the spectral trajectory is the average of the component pixels (Figure 1, box 5). As we aim to derive AGB maps for years 1990 and 2000, contemporaneous images were individually segmented with Definiens Cognition Network Technology® (Baatz and Schäpe, 2000; Definiens, 2005) (scale parameter 1.5; color-shape 0.9-0.1; smoothness 0.5 ; homogeneity based on Landsat bands 3,4 , and 5) into objects of 3.1 ha and 2.5 ha on average, in the same scale range of the $5 \times 5$ pixels window used for modelling. Objects were characterized with static and dynamic predictors and classified following the best decision tree model rules. Through this process each spatial object acquired an AGB $\left(\mathrm{t} \mathrm{ha}^{-1}\right)$ value and its related standard deviation as a measure of uncertainty.

Among other advantages, pixel-based mapping facilitates comparisons and evaluation of change with direct algebraic calculations, and it offers the option to define aggregation units for particular applications. Pixel-based maps were derived from the object maps initially produced: each pixel was assigned the AGB $\left(\mathrm{t} \mathrm{ha}^{-1}\right)$ and uncertainty $\left(\mathrm{E}_{1990}, \mathrm{E}_{2000}\right)$ values of the object it belongs to, and from these maps the AGB change ( $\triangle \mathrm{AGB}$ ) map was derived (Figure 1, box 6). The $\triangle \mathrm{AGB}$ map consists of three layers: a main map evaluated by differences in pixel nominal values and two other layers depicting scenarios of maximum added uncertainty (eq. 1).

$\Delta \mathrm{AGB}=\left(\mathrm{AGB}_{2000}-\mathrm{AGB}_{1990}\right) \pm\left(\mathrm{E}_{1990}+\mathrm{E}_{2000}\right)$ eq. 1

Detailed maps of carbon stock and carbon flux due to biomass change over the period 1990-2000 can then be derived from the biomass maps using a 0.5 multiplier of AGB to carbon (Kollmann, 1959; Penman et al., 2003). As a standard, this biomass to carbon relation is widely used (e.g. Krankina et al., 2004; Houghton et al., 2007) and enables comparison and reporting of regional and global carbon stocks (e.g. Keith et al., 2009; Houghton, 2005).

In order to validate the raster map of change, it was cross checked with the original values of plot $\triangle \mathrm{AGB}$ distributed into six categories. To identify sources of confusion we used an 
error matrix with an expanded diagonal, deemed adequate for this continuum classification established with artificial hard class breaks (Congalton and Green, 2009) (Table 7).

\section{Results}

\subsection{Ground plot attributes derived from NFI measures}

There were more eligible trees ( $D>7.5 \mathrm{~cm}$ ) for measurement in the NFI3 (ca. 2000) than in the previous rotation of the inventory in this area (NFI2, $c a$. 1990). Increments are particularly marked for the larger diameter classes, resulting in an expected increase in AGB during the period 1990-2000. However, the distribution of AGB ( $\left.\mathrm{t} \mathrm{ha}^{-1}\right)$, as derived from field measures in NFI plots (Figure 5) is similar at both dates, unimodal and positively skewed, with a majority of plots around $50 \mathrm{tha}^{-1}$ and median values of 59 and 77 $\mathrm{t} \mathrm{ha}^{-1}$ in NFI2 and NFI3 respectively. The indicators of structural complexity are distributed over very different scales, with a potentially more relevant $\mathrm{D}_{\mathrm{MAD}}$ ranging from 0 to 24 while $\mathrm{H}_{\mathrm{MAD}}$ ranges between 0 and 8 . We show in Figure 5 the distributions of standardized values of $D_{M A D}$ and $H_{M A D}$.
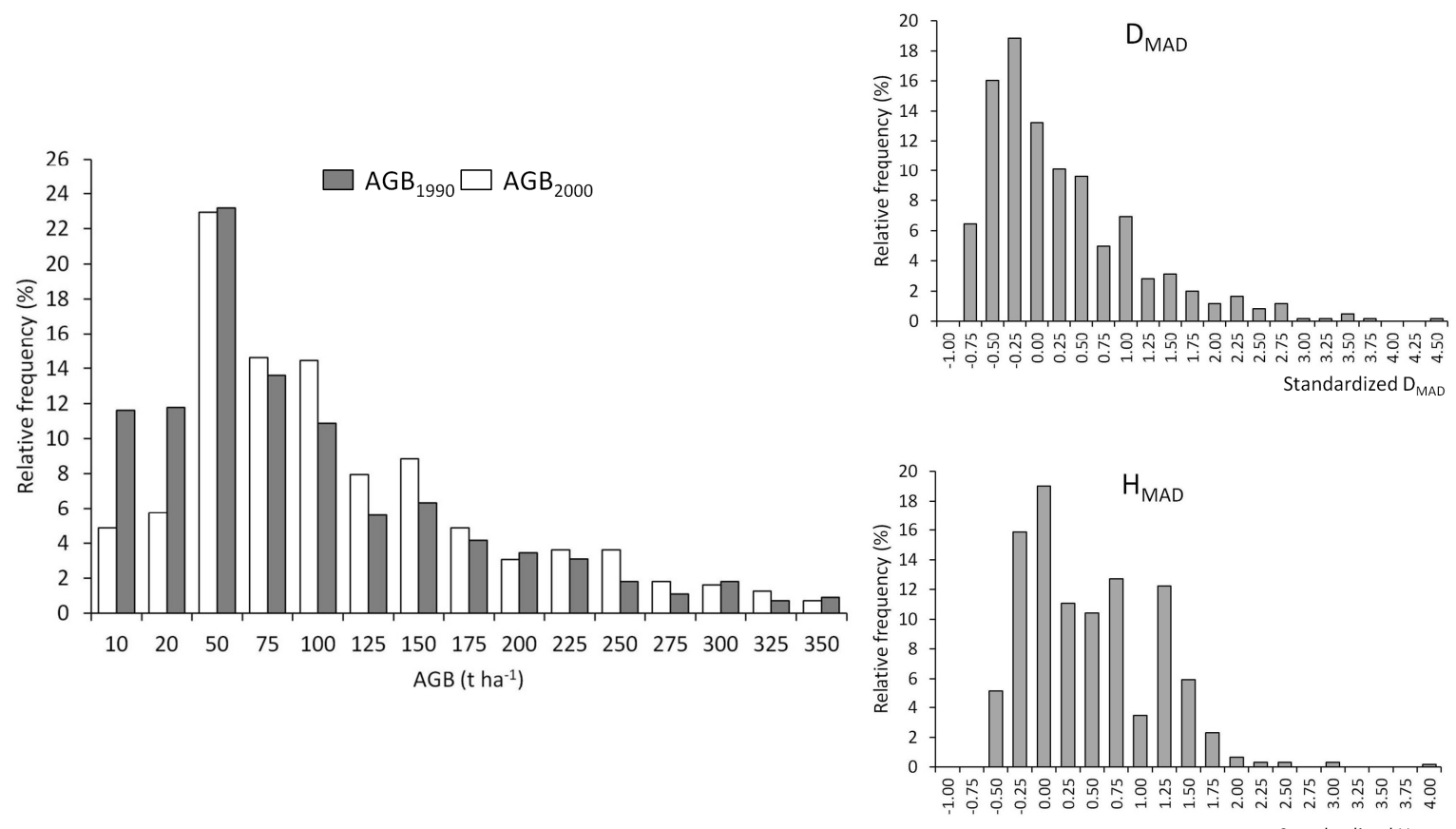

Standardized $\mathrm{H}_{\text {MAD }}$

Figure 5. Distribution of AGB at two rounds of NFI (ca. 1990 and ca. 2000) and standardized structural diversity indicators $\left(\mathrm{D}_{\mathrm{MAD}}\right.$ and $\left.\mathrm{H}_{\mathrm{MAD}}\right)$ in 1990. 


\subsection{Relationship between ground plot estimates of $A G B$ and spectral vegetation indices}

Our exploration of the relationship between vegetation spectral indices and AGB through wavelet transformations revealed an underlying strong connection, influenced by forest structural complexity (expressed by the diversity of ground plot measured diameters and heights) and affected by exogenous factors. Level six of the Meyer based discrete wavelet transform decomposition had the highest variance: it contributes the most to the overall variability in the original series and therefore has the highest explanatory power. After the first quartile of increasing AGB, NDVI and TCA approximation functions follow an almost coincident trend (Figure 6, left). The relationship of TCD with AGB is strongly influenced by forest structure, in particular by local diversity of diameter and height (Figure 6, right) and it is not constant over time as was observed in the $\mathrm{TCD}_{\text {block. At higher }}$ levels of wavelet transform decomposition (level 7 and 8) curves flatten on the end corresponding with the plots with the largest amount of biomass, pointing to radiometric saturation at high levels of biomass. We interpret the strong wavy effect observed in all curves, quasi coincident when corrected by structure, as an influence of forest cover and/or variation in terrain features (i.e. elevation, slope, and orientation).
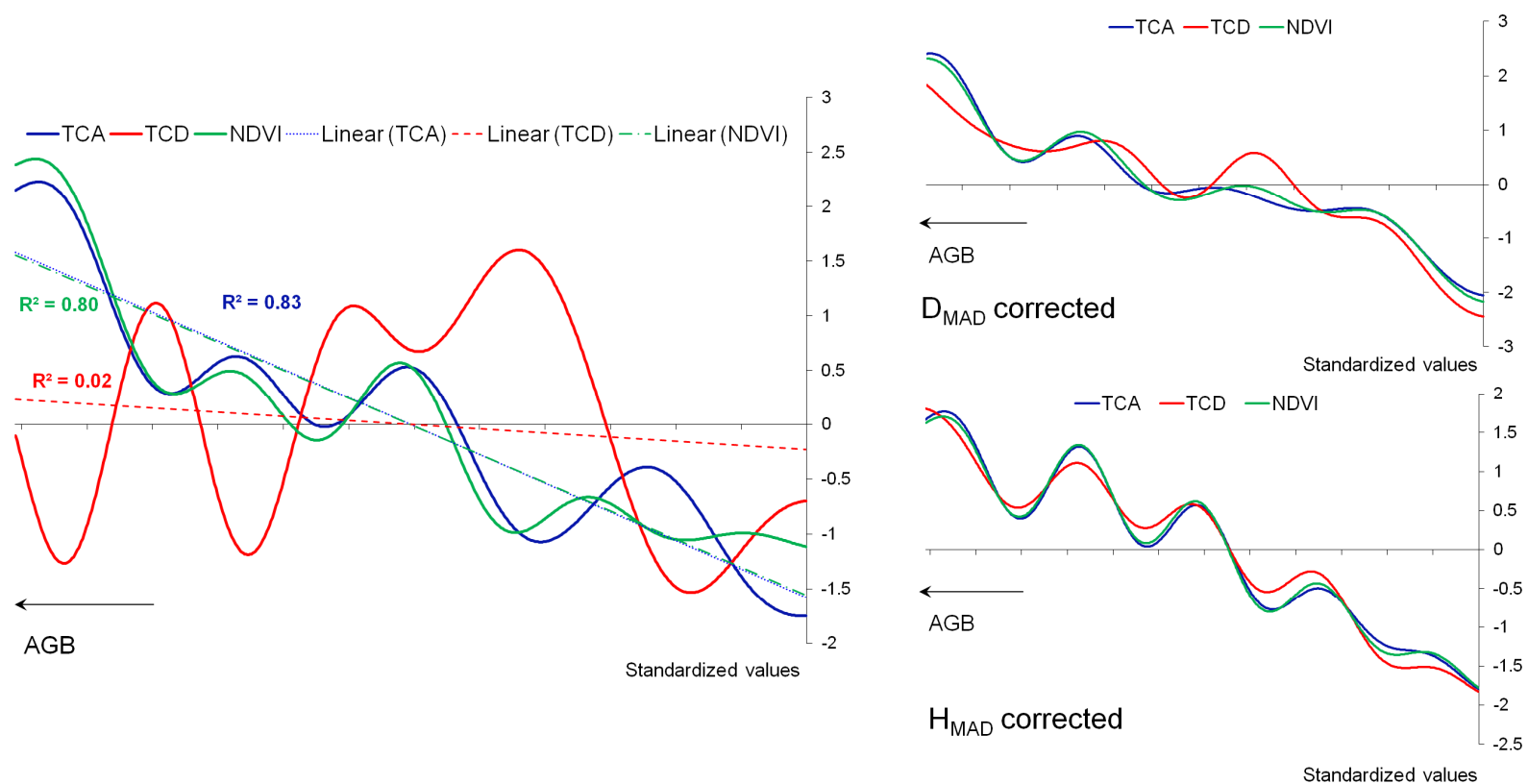

Figure 6. Approximation 6 of the Discrete Wavelet Transformation (DWT) decomposition of vegetation spectral indices (NDVI, TCA, TCD) as a function of AGB. Left: NDVI and TCA follow a similar non-linear trend with increasing AGB, whilst TCD evidences a different type of relationship. Right: same as left but spectral indices are corrected with structural diversity factors ( $D_{M A D}$ and $\mathrm{H}_{\mathrm{MAD}}$ ) to show their weight on the relationship. 
When analysing the sub-sample of 182 plots regularly distributed every $\sim 1.7 \mathrm{t} \mathrm{ha}^{-1}$ over the range 1-310 $\mathrm{t} \mathrm{ha}^{-1}$, the detail function of level five revealed some sections with maximal variation found at regular intervals, suggesting categories equivalent to $\sim 50 \mathrm{t} \mathrm{ha}^{-1}$. Only the $\mathrm{NDVI}_{\text {block }}$ showed an apparent stability of these groups over time.

\subsection{Decision trees for modelling historical AGB}

In building the decision trees for modelling AGB, different combinations of predictor variables were tested (Table 6) and the relevance of each group of variables was evaluated. All fitted models were statistically significant $(p$-value $<0.001)$ but exhibited variable levels of correlation between AGB and the spectral predictors (Table 6). Models were applied to the independent set of data for validation and their performance was assessed with the Root Mean Square Error (RMSE), the correlation coefficient $\left(\mathrm{R}^{2}\right)$, percentage average error (ME), and bias.

Table 6. Summary of modelling results when including different sets of variables. NDVI process patterns are best predictors. The entire 25 -year pattern variables yield more accurate and precise results than the 15-year pattern variables, but a combination of both yields best results.

\begin{tabular}{|c|c|c|c|c|c|c|}
\hline & \multicolumn{3}{|c|}{ Fitting } & \multicolumn{2}{|c|}{ Validation } & \multirow[b]{2}{*}{ Bias } \\
\hline & Variable & $\mathbf{R}$ & $\overline{\mathbf{R}^{2}}$ & RMSE $\left(\mathrm{t} \mathrm{ha}^{-1}\right)$ & \% Mean error & \\
\hline \multirow{7}{*}{$\mathrm{AGB}_{1990}$} & All & 0.95 & 0.90 & 32.2 & 0.34 & 0.99 \\
\hline & 25 -year pattern & 0.84 & 0.68 & 58.7 & 0.62 & 1.02 \\
\hline & 15 -year pattern & 0.76 & 0.54 & 70.9 & 0.74 & 1.01 \\
\hline & NDVI pattern & 0.94 & 0.89 & 32.2 & 0.36 & 0.99 \\
\hline & TCA pattern & 0.29 & - & - & - & - \\
\hline & State trajectory & 0.22 & - & - & - & - \\
\hline & Static indices & 0.18 & - & - & - & - \\
\hline \multirow{7}{*}{$\mathrm{AGB}_{2000}$} & All & 0.73 & 0.53 & 71.6 & 0.65 & 0.96 \\
\hline & 25-year pattern & 0.65 & 0.40 & 79.1 & 0.72 & 0.93 \\
\hline & 15-year pattern & 0.58 & 0.26 & 87.9 & 0.80 & 0.95 \\
\hline & NDVI pattern & 0.65 & 0.41 & 78.0 & 0.71 & 0.92 \\
\hline & TCA pattern & 0.18 & - & - & - & - \\
\hline & State trajectory & 0.22 & - & - & - & - \\
\hline & Static indices & 0.17 & - & - & - & - \\
\hline
\end{tabular}

Trees yielding better results (higher $\mathrm{R}^{2}$, and lower RMSE, ME, and bias) include decision rules based on process and state patterns. Moreover, the best fitted tree $(\mathrm{R}=0.95)$ combines 25- and 15-year NDVI process variables (Figure 7). When validated, this model shows high $\mathrm{R}^{2}$ and a small bias towards under-predictions; with a RMSE of $32 \mathrm{t} \mathrm{ha}^{-1}$ it produces errors of $34 \%$ on average. Modelling options that include either 25- or 15-year patterns are 
not optimal; however, the model based on the entire 25-year trajectory patterns yields better results. Static indices alone or together with state trajectories did not model biomass satisfactorily, they produced low correlations. Interestingly we found NDVI process patterns more relevant than the analogous TCA patterns in describing historical AGB, despite a similar relationship of either static index with biomass.

Decision trees modelling $\mathrm{AGB}_{1990}$ have a common feature, a first split of plots with AGB > $100 \mathrm{t} \mathrm{ha}^{-1}$ (31\% of the sample) into one branch and plots with AGB $<100 \mathrm{t} \mathrm{ha}^{-1}$ (69\% of the sample) into the other branch (Figure 7). Unless restricted by selective inclusion of predictors, the initial split is determined by a rule based on an NDVI process pattern: in other words, the rate of stand development is the most relevant factor for identifying plots with large amounts of AGB (which are presumably more mature) from low AGB (and frequently younger) plots. The criteria for further splitting the group of plots with more than $100 \mathrm{t} \mathrm{ha}^{-1}$ of biomass include process patterns associated with relative $\left(\triangle \mathrm{AGB} / \mathrm{AGB}_{2000}\right)$ and absolute change $(\triangle \mathrm{AGB})$ of $\mathrm{AGB}$. The group of low AGB plots (i.e. $<100 \mathrm{t} \mathrm{ha}^{-1}$ ) is further categorized by patterns associated with $\mathrm{AGB}_{1990}$ and $\mathrm{AGB}_{2000}$ ) (Table 4). Just one static index, the $\mathrm{TCA}_{1990}$, was present in an accurate classification of the ground plot biomass. Five out of the six terminal nodes in the best fitting tree are defined by 25-year patterns, highlighting the convenience of longer term information. In only one case was a TCA pattern of change used to split the largest branch in the decision tree.

For interpretation of the dynamic predictors and to associate them with ecological change and forest succession, their relative value acquired by normalization and scaling requires consideration. For instance, the plots with the larger values of AGB in 1990 are related with a pattern characterized by a constant and relatively low speed of NDVI variation, positive over most of the period 1990-2004, (it appears constant and close to maximum in the scaled curve (model 3 in Figure 4, bottom)). This is in agreement with expectation from a relatively mature and healthy closed canopy stand. Other patterns of this predictor that identify plots with relatively low AGB represent a varying speed of change, with minimum and maximum at specific locations: for instance the plots with the lowest AGB are characterized by a pattern that goes from an absolute minimum speed of NDVI variation ( $\mathrm{PI}_{\mathrm{NDVI}}$ ) in 1990 to an absolute maximum $\mathrm{PI}_{\mathrm{NDVI}}$ after only a few years, followed by stabilization probably associated with the closing of the canopy. 
We assessed the capacity of individual dynamic predictors for classifying AGB and found that patterns derived from spectral systems ordered by AGB are the most powerful. Patterns based on $\mathrm{AGB}_{1990}$ and defining eight groups of biomass classified correctly $31 \%$ of the plots, with $51 \%$ within \pm 1 group (and $70 \%$ within \pm 2 groups).

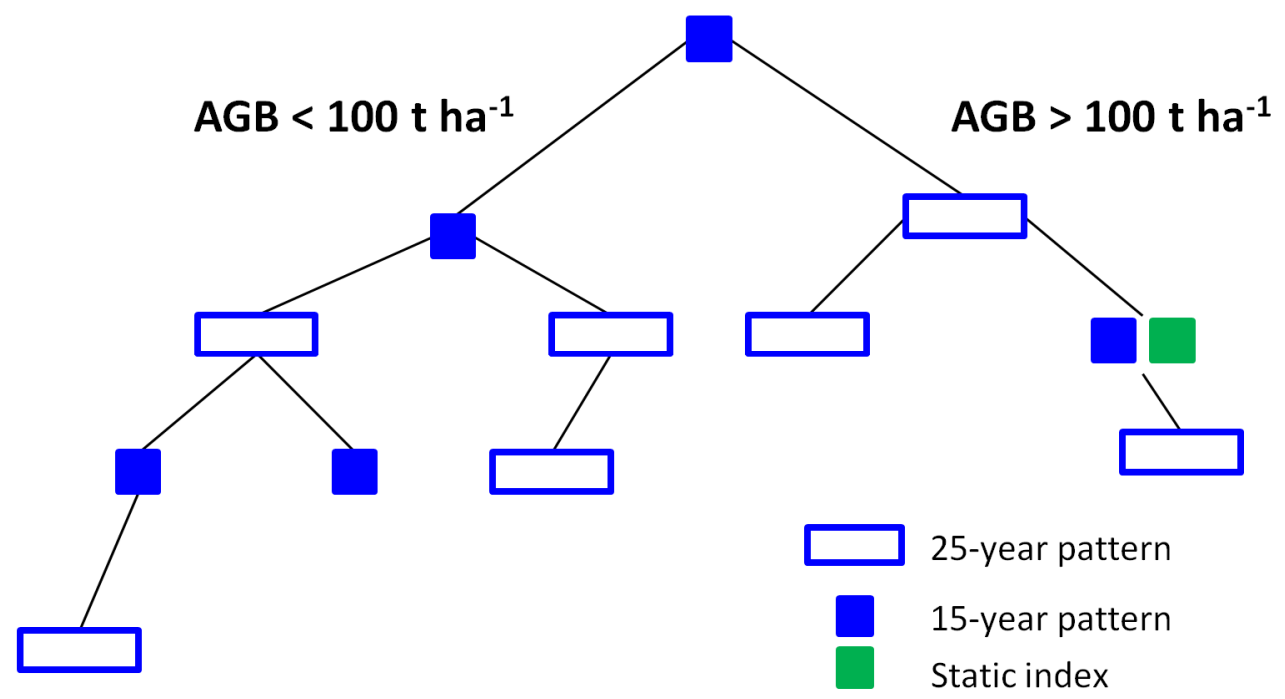

Figure 7. Schematic representation of an optimal decision tree for classification of AGB1990. The tree combines decision rules based on 25- and 15-year patterns. A main division splits the sample into ground plots with AGB $>100 \mathrm{tha}^{-1}$ and AGB $<100 \mathrm{tha}^{-1}$.

With a similar procedure we classified plots according to their biomass at a date corresponding with the NFI3 ( $c a$. 2000). In this case the biophysical attribute is modelled with the history of spectral indices and a collection of past and prospective changing patterns, testing a different temporal configuration (Figure 9). Results of modelling $\mathrm{AGB}_{2000}$ are more restricted, with statistically significant (p-value $<0.001$ ) best fitting trees having a correlation with the sample of $\mathrm{R}=0.73$. Models show a general tendency to underestimate $\mathrm{AGB}$, and have limited predictive power $\left(\mathrm{R}^{2}=0.53\right)$. With high $\mathrm{ME}(70 \%)$ these models are limited for estimation of biomass in the area. Still, the variables related with changing processes have stronger predictive power than those related with state, which reinforces the importance of the rate of change to model development. Attempts to model absolute $(\triangle \mathrm{AGB})$ and relative $\left(\operatorname{Rel}_{1990}, \mathrm{Rel}_{2000}\right)$ change of biomass were unsuccessful, with no direct relation between these variables and the estimators considered. 


\subsection{Mapping historical AGB dynamics and validation}

In the process of mapping $\mathrm{AGB}_{1990}, 26,406$ objects resulted from segmentation of the contemporaneous Landsat image, $40.4 \%$ of which $(10,693)$ was classified by the decision tree branch of larger AGB values (> $100 \mathrm{t} \mathrm{ha}^{-1}$ ). Ninety-five percent of objects achieved terminal nodes of the decision tree, indicating consistency in the up-scaling from plot-level model to object-level classification: all combinations of the relevant spectral trajectories characterizing AGB at the plot level correspond with combinations of averaged spectral trajectories of spatial objects with the same AGB $\left(\mathrm{t} \mathrm{ha}^{-1}\right)$.

The biomass allocated in the aboveground fraction of trees in year 1990 was on average $77.6 \mathrm{t} \mathrm{ha}^{-1}$ (total in the area amounts $6295 \times 10^{3} \mathrm{t}$ ), and it was estimated to be $91.5 \mathrm{t} \mathrm{ha}^{-1}$ $\left(7415 \times 10^{3} \mathrm{t}\right)$ ten years later $(2000)$. The difference of calculated AGB represents an increment of $1.3 \mathrm{t} \mathrm{ha}^{-1} \mathrm{y}^{-1}$ on average and the total increase in the area is equivalent to 560 $\times 10^{3} \mathrm{t}$ of $\mathrm{C}$. Considering individual objects imprecision, global values of $\mathrm{AGB}_{1990}$ and $\mathrm{AGB}_{2000}$ range between 5.5 and $7.1 \times 10^{6} \mathrm{t}$ and between 3.4 and $11.3 \times 10^{6} \mathrm{t}$ respectively, and as expected from the modelling results, the later date contributes notably more to the uncertainty of estimated change. By means of the multilayer raster maps we evaluated total change in the case scenarios of additive uncertainties derived from modelling and mapping, obtaining values of $2.9 \mathrm{t} \mathrm{ha}^{-1} \mathrm{y}^{-1}$ loss and $8.5 \mathrm{t} \mathrm{ha}^{-1} \mathrm{y}^{-1}$ gain on average. A detail of the multilayer maps of biomass change in Figure 8 shows the spatial distribution and variability that exists, information of crucial value for management. 


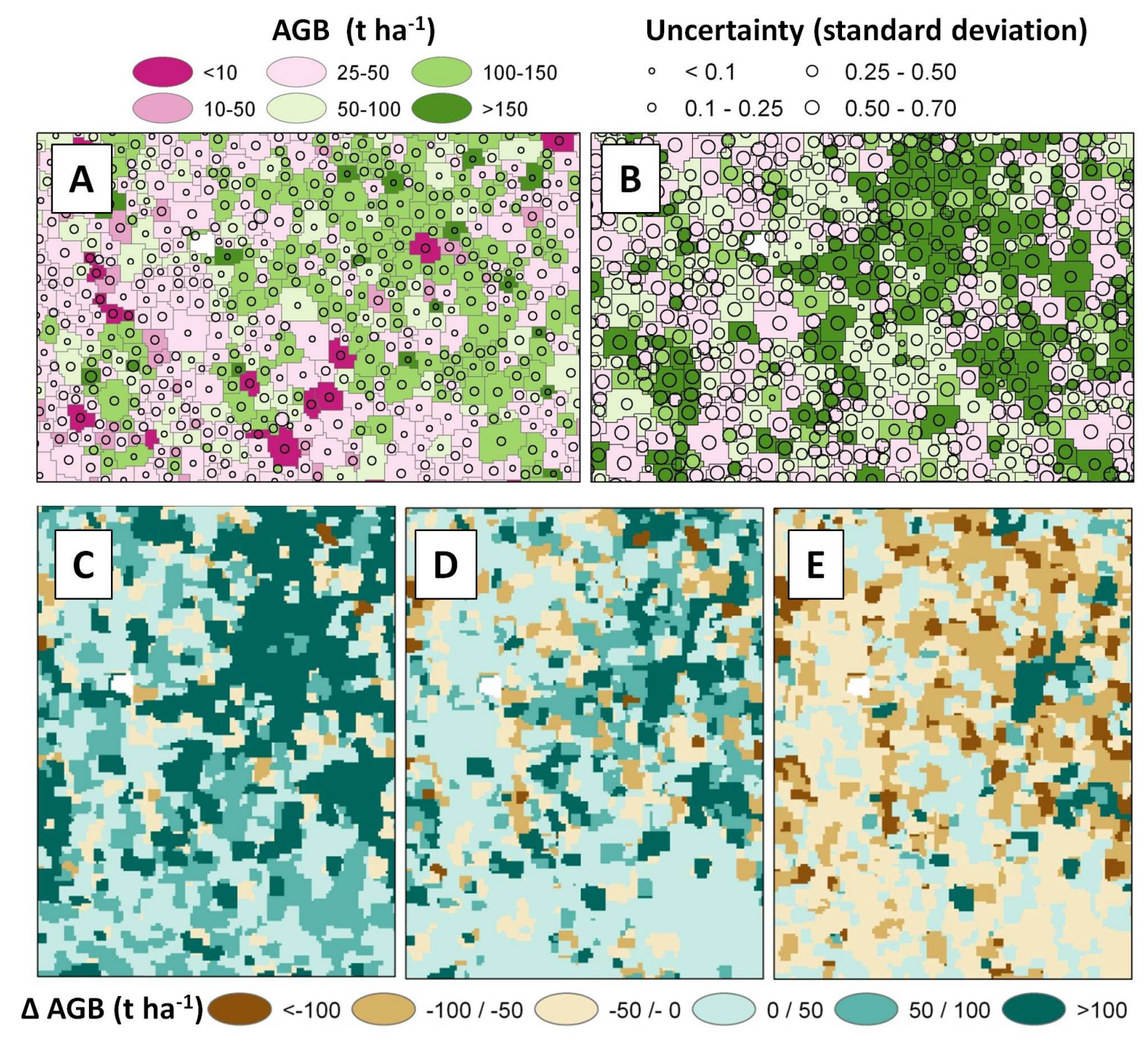

Figure 8. Top: detail of the object based biomass maps in 1990 (A) and 2000 (B). Bottom: detail of multilayer $\triangle \mathrm{AGB}$ maps showing spatial distribution and variability of change. (C) optimistic result derived from uncertainty; (D) nominal change; (E) pessimistic result derived from uncertainty.

Validating the raster map of change by cross checking with the original values of plot $\triangle \mathrm{AGB}$ distributed into six categories, low producer's (21-27\%) and user's (16-23\%) errors are recorded in intermediate categories (Table 7). However, the distribution of values in the matrix point to a slight tendency to overestimate incremental biomass. Overall, $70 \%$ of checked points were classified into the correct category of AGB change. 
Table 7. Accuracy matrix of the raster map of biomass change categories.

\begin{tabular}{|c|c|c|c|c|c|c|c|}
\hline & $<-100$ & $\begin{array}{l}\text { Plot ch } \\
-100 /- \\
50\end{array}$ & ge $(\mathrm{t} \mathrm{h}$ & ) (refer & nce) & $>100$ & $\begin{array}{l}\text { User's } \\
\text { metrics }\end{array}$ \\
\hline$<-100$ & 0 & 0 & 2 & 1 & 0 & 0 & 0 \\
\hline$-100 /-50$ & 3 & 1 & 10 & 33 & 8 & 0 & 0.25 \\
\hline$-50 / 0$ & 3 & 2 & 11 & 28 & 9 & 0 & 0.77 \\
\hline $0-50$ & 14 & 15 & 50 & 143 & 53 & 17 & 0.84 \\
\hline $50 / 100$ & 3 & 7 & 16 & 61 & 8 & 5 & 0.74 \\
\hline$>100$ & 2 & 3 & 8 & 26 & 8 & 1 & 0.19 \\
\hline $\begin{array}{l}\text { Producer's } \\
\text { metrics }\end{array}$ & 0.12 & 0.11 & 0.73 & 0.79 & 0.80 & 0.26 & 0.70 \\
\hline
\end{tabular}

\section{Discussion}

Historical forest aboveground biomass was modelled, evaluated, and mapped in Mediterranean pines of Spain combining a set of NFI plots representative of the forest conditions present and spectral data captured by Landsat sensors over a period of 25 years (1984-2009). As a baseline for comparison with more recent estimates, an assessment of past AGB with spatial detail is of value to support monitoring and reporting commitments. In this area, characterized by absence of major perturbations and moderate human intervention during succession stages, dynamic variables of change (i.e. predictors combining data captured at various dates), showed higher predictive capacity than static variables to explain the variability of AGB retrospectively.

Spectral response is related to forest structure (Cohen et al., 1995) and develops progressively with successional state (Peterson and Nilson, 1993). Under equal environmental conditions and absent disturbance, forest stands develop similarly and are expected to show similar temporal spectral trajectories, although slight deviations from a pattern may exist. However, although forest attributes have been modelled accurately with spectral variables, forest change remains elusive for direct modelling: spectral differences alone have demonstrated inadequate for the purpose (Healey et al., 2006), and trends of spectral trajectories do not necessarily have a direct relation with the increase or decrease of biomass (Campbell et al., 2012).

Our previous attempts to model biomass in the Central Range of Spain with single date optical data were limited, characterized by moderate fitting correlation $(\mathrm{R}=0.7)$ and $\mathrm{ME}$ of 0.78 (Gómez, 2006). Also in the same area, Vázquez de la Cueva (2008) found structural 28 
parameters (canopy crown closure, stand height, stem density, and basal area) insufficiently explained by the multispectral predictors selected to derive empirical models; however, the Tasseled Cap Wetness had a stronger relation with forest density than NDVI or other TM/ETM+ bands. Interestingly, in this work we have found TCA significant as static variable, while patterns associated with NDVI were relevant as process variables. The TCD, more related to age and associated structural complexity than other Tasseled Cap-related indices in coniferous forests of Oregon, USA (Duane et al., 2010) was also found linked to forest complexity in these Mediterranean pines, despite a low correlation between AGB and parameters of structural complexity (Pearson's R of 0.22, 0.24, with $\mathrm{D}_{\mathrm{MAD}}$ and $\mathrm{H}_{\mathrm{MAD}}$ respectively). In view of local difficulties to directly model forest attributes, we applied mathematical transformations based on $2 \mathrm{D}$ wavelet algorithms to a data-system created with information from two rounds of field measures and eight repetitions of calibrated spectral data, filtering fundamental relations from environmental and endogenous noise. Dynamic variables (i.e. variables with an inherent temporal component) associated with patterns of change, including rate and shape, characterized ground plots, and together with static variables served to model AGB and calculate AGB dynamics. This approach significantly improved previous results, but no single predictor was able to accurately classify biomass.

Frequency and regularity of measurements can be critical in providing an accurate understanding of ecological processes. Gaps in a series of measures and irregular data frequencies leave intervals of uncertainty in explaining continuous processes that might be notable in ecosystems prone to rapid changes related to disturbance (Jin and Sader, 2005). Successional patterns are more predictable in undisturbed forests than in areas with unexpected perturbations (Schroeder et al., 2007; Vogelmann et al., 2009) and the rate of spectral variation is typically greater in immature stands when compared to more mature stands in similar environments. Wavelet transform analysis is particularly suited to detect anomalies in series of data (Mallat and Hwang, 1992) and does not require periodic sampling (Daubechies et al., 1999), conferring this approach versatility for analysis of data in a wide range of environments. The limited number of seasonally appropriate, cloud-free images available at the time of this study is not necessarily indicative of the full Landsat archive, which the USGS is currently consolidating with unique images held by International Cooperators (Loveland and Dwyer, 2012). As of writing, the European Space Agency has yet to provide Landsat data through the free and open access model 
demonstrated by the USGS. Reportedly there are plans to share these European images with the USGS, which when implemented, will improve the density of images available over Europe.

The temporal configuration (i.e. the duration, starting point, and position relative to the target date) of the dynamic variables (Figure 9) presumably affects the capacity to predict structural and successional forest attributes, as suggest different results in modelling AGB in 1990 and 2000. $\mathrm{AGB}_{1990}$ corresponds with the initial stages of a trajectory to resemble one of a series of temporal patterns, with possible deviations or delays of key features. Deviation of forest stands from standard expectations of development is often related to site index differences, canopy cover and density, or species characteristics, factors requiring attention when deriving, applying, and interpreting model results. Alternatively, $\mathrm{AGB}_{2000}$ corresponds with an intermediate position of the available spectral trajectories, with which processes are not aligned. The duration of spectral trajectory necessary to identify significant temporal patterns in AGB is presumably variable and site dependent. Liu et al. (2008) demonstrated that a series of images covering a longer period predicts forest age more accurately, but in some cases a shorter time series of imagery may suffice. In this work a combination of 25-year and 15-year trajectories was the best option for estimating retrospective AGB. Longer-term patterns may potentially explain the variability of AGB more precisely, but they may also introduce irregularities outside the time lapse between data used for calibration of the trajectory models; on the other hand, shorter-term patterns are more explicit and less prone to variations out of the reference period. Further work is necessary to clarify the distinctive effect that duration and relative location of spectral trajectories produce when employed as dynamic variables. Another set of ground plot measures (NFI4 ca. 2010) in this area is expected to be released shortly, with available spectral data completing the temporal series to that date and beyond (Figure 9). Hence the duration, starting point, and temporal character (retrospective, prospective or inclusive) of the trajectory will be available for further exploration. 


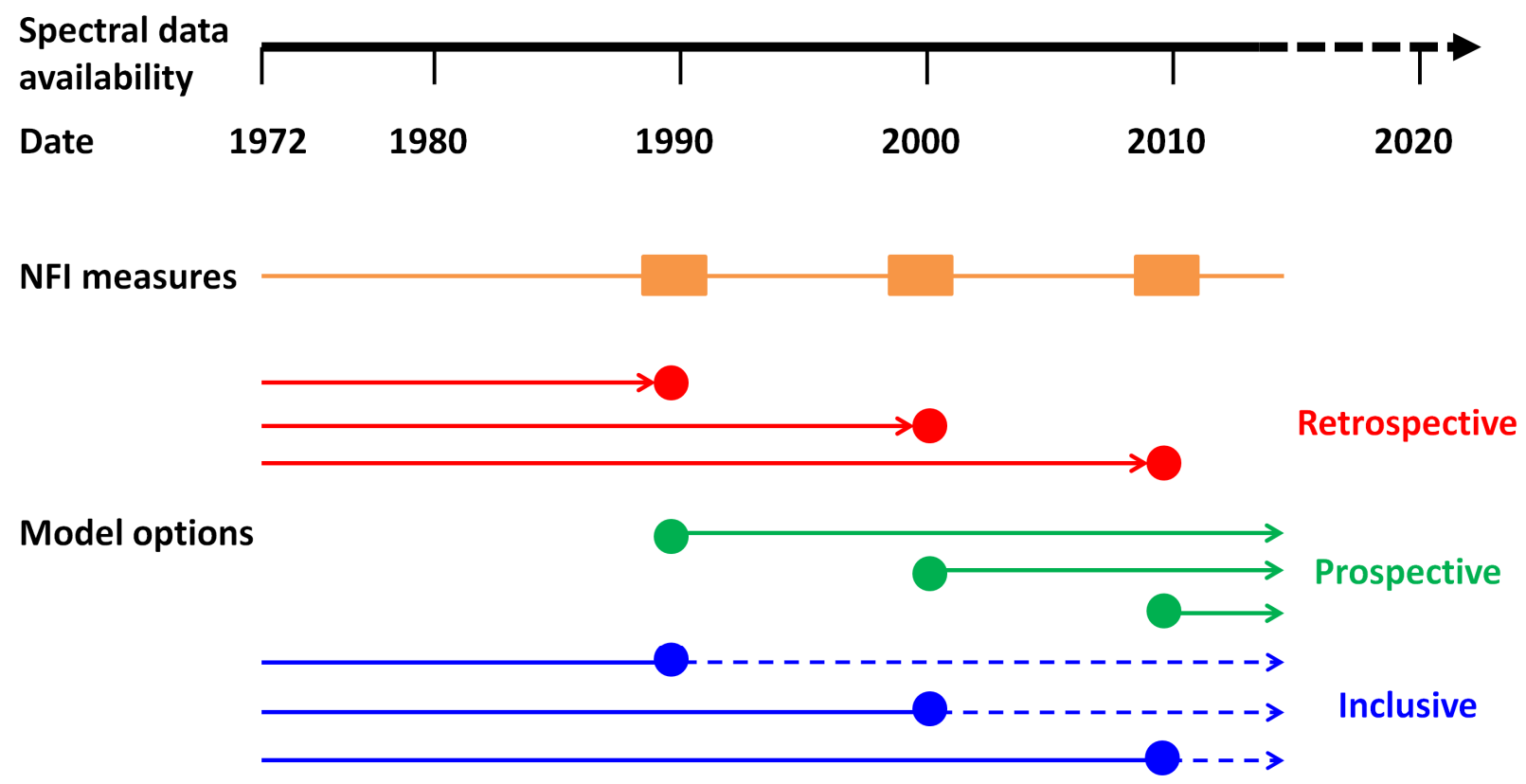

Figure 9. Schematic of options to investigate temporal configurations of dynamic predictor variables. Circles indicate dates to model; arrows indicate the end point of spectral trajectories. Retrospective case: the trajectory interval is prior to the modelled date; prospective case: the trajectory interval is posterior to the modelled date; inclusive: previous and subsequent intervals of spectral trajectories are used to model and intermediate date attributes.

We chose Dynamic Time Warping (DTW) as a measure of series similarity for its documented optimal performance in fields like speech pattern recognition (Velichko and Zagoruyko, 1970) or clustering of gene expression profiles (Aach and Church, 2001), but the superiority of this measure over others in identification of patterns of forest spectral trajectories has not been widely demonstrated. Both the robustness of the DTW measure and the automation of pattern identification require further investigation.

The uncertainty reported in the final maps possibly originates from imprecision in modelling, but could also have originated at various stages of the overall approach, including location of plots, field measures, allometric equations, image capture, and image processing (Lu et al., 2012). To minimize the impact of these factors, a representative sample acquired to consistent specifications, such as NFI plots, is recommended for modelling (Duane et al., 2010), and necessary to obtain a comprehensive domain of trajectory patterns for accurate identification by the similarity algorithm. We identified confusion in the final map of change with an inclusive approach of all error sources, but 
from plot based model to final maps, some aspects could be subject to individual testing, such as the equivalence of pixel and object trajectory or the vector to raster transformation.

Estimates of AGB dynamics between 1990 and 2000 obtained in the current study are in agreement with complementary regional studies. For instance, pines in the Central Range were found to be more dense and mature in year 2000 than during the previous decade, and - as could be expected - accounted a net increment of biomass and carbon stock. Analyzing inputs and outputs recorded by NFI measures, Herrero and Bravo (2012) corroborated a net carbon sinking character between NFI2 and NFI3 rotations, with AGB allocated in pines of $85 \mathrm{t} \mathrm{ha}^{-1}$, while Montero et al. (2004) estimated an annual increment of $0.9 \mathrm{t} \mathrm{ha}^{-1}$ of pine biomass between 1993 and 2003. Gómez et al. (2012) reported a maximum rate of $\mathrm{C}$ stocking in this area for year 2000 with a later change of trend towards C loss during the 2000-2010 decade that forthcoming NFI4 measures may help corroborate.

Information provided by Landsat spectral trajectories has been linked to field measurements, which has proven useful for improving the estimation of current biomass and other structural attributes, particularly in ecosystems with stand replacing disturbances (Pflugmacher et al., 2012). Furthermore, spectral trajectories have demonstrated utility for characterizing mountain pine beetle infestations (Goodwin et al., 2010) and for continuous monitoring of forest disturbance (Zhu et al., 2012). In this study, we have found that the identification of temporal patterns in the trajectory of vegetation indices (i.e. dynamic variables) provides useful information to model and explain historical biomass variability.

\section{Conclusion}

Remote sensing technology supports and enhances the value of national forest inventories for the assessment of biomass and carbon balance, and the Landsat archive in particular is a unique source of spectro-temporal data for modelling and mapping forest attributes. Mathematical transformations of original data are necessary to unveil underlying relations in complex environments, and to derive dynamic variables with explanatory capacity of past and present biophysical conditions. Dynamic process features such as pattern and rate of change were more relevant than static variables in the retrospective estimation of AGB in the Mediterranean pines of central Spain. Pines in these forests were found to have 
accrued biomass over the decadal monitoring period, representing a net carbon sink. The approach presented herein allows for the retrospective estimation and mapping of AGB in order to establish a historical baseline and enable change reporting.

\section{Acknowledgements:}

National Forest Inventory data are available online, provided by Ministerio de Agricultura, Alimentación y Medio Ambiente (España). Landsat images are available online, provided by the USGS.

\section{References}

Aach, J., Church, G.M., 2001. Aligning gene expression time series with time warping algorithms. Bioinformatics, 17(6), 495-508.

Andersson, K., Evans, T.P., Richards, K.R., 2009. National forest carbon inventories: policy needs and assessment capacity. Climatic Change, 93, 69-101.

Baatz M., Schäpe, M., 2000. Multiresolution segmentation - an optimization approach for high quality multi-scale image segmentation. In: Strobl, J., Blaschke, T.,Griesebner, G. (Eds.), Angewandte Geographische Informations-Verarbeitung XII. Wichmann Verlag,Karlsruhe, pp. 12-23.

Baccini, A., Friedl, M.A., Woodcock, C.E., Warbington, R., 2004. Forest biomass estimation over regional scales using multisource data. Geophysical Research Letters, 31, L10501, doi:10.1029/2004GL019782.

Baccini, A., Friedl, M.A., Woodcock, C.E., Zhu, Z., 2007. Scaling field data to calibrate and validate moderate spatial resolution remote sensing models. Photogrammetric Engineering and Remote Sensing, 73, 945-954.

Barlow, J., Peres, C.A., 2004. Ecological responses to El Niño-induced surface fires in central Brazilian Amazonia: management implications for flammable tropical forests. Philosophical Transactions of the Royal Society, 359, 367-380.

Barredo, J.I., San-Miguel-Ayanz, J., Caudullo, G., Busetto, L., 2012. A European map of living forest biomass and carbon stock. EUR 25730 EN. Luxemburg: Publications Office of the European Union. JRC77439. DOI: 10.2788/780.

Blackard, J.A., Finco, M.V., Helmer, E.H., Holden, G.R., Hoppus, M.L., Jacobs, D.M., Lister, A.J., Moisen, G.G., Nelson, M.D., Riemann, R., Ruefenacht, B., Slajanu, D., Weyermann, D.L., Winterberger, K.C., Brandeis, T.J., Czaplewski, R.L., McRoberts, R.E., Patterson, P.L., Tymcio, R.P., 2008. Mapping US forest biomass using nationwide forest inventory data and moderate resolution information. Remote Sensing of Environment, 112, 1658-1677. 
Bortolot, Z.J., Wynne, R.H., 2005. Estimating forest biomass using small footprint LiDAR data: an individual tree-based approach that incorporates training data. IPRS Journal of Photogrammetry and Remote Sensing, 59, 342-360.

Bravo, F., Río, M., Pando, V., San Martín, R., Montero, G., Ordoñez, C., Cañellas, I., 2000. El diseño de las parcelas del inventario forestal nacional y la estimación de variables dasómetricas. In El Inventario Forestal Nacional, Elemento Clave para la Gestión Forestal Sostenible; Bravo, F., Rio, M., Peso, C. (Eds.), Fundación General de la Universidad de Valladolid: Valladolid, Spain, pp. 19-35.

Breiman, L., Friedman, J.H., Olshen, R.A., Stone, C.J., Classification and Regression Trees; Chapman and Hall/CRC: Boca Raton, FL, USA, 1984; pp. 358.

Campbell, J.L., Kennedy, R.E., Cohen, W.B., Miller, R.F., 2012. Assessing the carbon consequences of western juniper (Juniperus occidentalis) encroachment across Oregon, USA, Rangeland Ecology Management, 5, 223-231.

Canty, M.J., Nielsen, A.A., Schmidt, M., 2004. Automatic radiometric normalization of multitemporal satellite imagery. Remote Sensing of Environment, 91, 441-451.

Cohen, W.B., Spies, T., Fiorella, M., 1995. Estimating the age and structure of forests in a multi-ownership landscape of western Oregon, U.S.A. International Journal of Remote Sensing, 16(4), 721-746.

Congalton, R.G., Green, K., 2009. Assessing the accuracy of remotely sensed data, principles and practices. Second edition. Boca Raton, FL. CRC Press, 177 pp.

Chávez, P., 1988. An improved dark object subtraction technique for atmospheric scattering correction of multispectral data. Remote Sensing of the Environment, 24, 459479.

Chirici, G., Barbati, A., Corona, P., Marchetti, M., Travaglini, D., Maselli, F., Bertini, R., 2008. Non-parametric and parametric methods using satellite images for estimating growing stock volume in alpine and Mediterranean forest ecosystems. Remote Sensing of Environment, 112, 2686-2700.

Daubechies, I., 1992. Ten lectures on wavelets. Society for Industrial and Applied Mathematics, $357 \mathrm{pp}$.

Daubechies, I., Guskov, I., Schröder, P., Sweldens, W. 1999. Wavelets on Irregular Point Sets, Philosophical Transactions of the Royal Society A: Mathematical Physical and Engineering Sciences, 357 (1760), 2397-2413.

Definiens. 2005, Definiens eCognition Version 5 Object Oriented Image Analysis User 5 Guide, Definiens, AG, Munich, Germany.

Dong, J., Kaufman, R.K., Myneni, R.B., Tucker, C.J., Kauppi, P.E., Liski, J., Buermann, W., Alexeyev, V., Hughes, M.K., 2003. Remote sensing estimates of boreal and temperate 34 
forest woody biomass: carbon pools, sources, and sinks. Remote Sensing of Environment, 84, 393-410.

Du, Y., Guindon, B., Cihlar, J., 2002. Haze detection and removal in high resolution satellite image with wavelet analysis, IEEE Transactions on Geosciences and Remote Sensing, 40(1), 210-217.

Duane, M.V., Cohen, W.B., Campbell, J.L., Hudiburg, T., Turner, D.P., Weyermann, D.L., 2010, Implications of alternative field-sampling designs on Landsat-based mapping of stand age and carbon stocks in Oregon forests. Forest Science, 56, 405-416.

Duncanson, L.I., Neimann, K.O., Wulder, M.A., 2010. Integration of GLAS and Landsat TM data for aboveground biomass estimation. Canadian Journal of Remote Sensing, 36 (2), 129-141.

Englhart, S., Keuck, V., Siegert, F. 2011. Aboveground biomass retrieval in tropical forests-The potential of combined X- and L-band SAR data use. Remote Sensing of Environment, 115, 1260-1271.

FAO, 2003. State of the World's forests. Rome, Italy. Available at http://www.fao.org/docrep/005/y7581e/y7581e00.htm (Accessed 8 August, 2013)

FAO, 2010. Global Forest Resources Assessment. Rome, Italy. Available at www.fao.org/forestry/fra/fra2010/en/ (Accessed 8 August, 2013)

Fazakas Z., Nilsson M., Olsson H., 1999. Regional forest biomass and wood volume estimation using satellite data and ancillary data. Agricultural and Forest Meteorology, 9899, 417-425.

Foody, G.M., Cutler, M.E., McMorrow, J., Pelz, D., Tangki, H., Boyd, D.S., Douglas, I., 2001. Mapping the biomass of Bornean tropical rain forest from remotely sensed data. Global Ecology and Biogeography, 10, 379-387.

Foody, G.M., Palubinskas, G., Lucas, R.M., Curran, P.J., Honzak, M., 1996. Identifying terrestrial carbon sinks: classification of successional stages in regenerating tropical forest from Landsat TM data. Remote Sensing of Environment, 55, 205-216.

Foody, G.M., Boyd, D.S., Cutler, M.E.J., 2003. Predictive relations of tropical forest biomass from Landsat TM data and their transferability between regions. Remote Sensing of Environment, 85, 463-474.

Freitas, R.M., Shimabukuro, Y.E., 2008. Combining wavelets and linear spectral mixture model for MODIS satellite sensor time-series analysis. Journal of Computational Interdisciplinary Sciences, 1(1), 51-56.

Fukuda, S., Hirosawa, H., 1999. A wavelet-based texture feature set applied to classification of multifrequency polarimetric SAR images, IEEE Transactions on Geoscience and Remote Sensing, 37(5), 2282-2286. 
Garguet-Duport, B., Girel, J., Chassery, J.M., Pautou, G., 1996. The use of multiresolution analysis and wavelets transform for merging of SPOT panchromatic and multispectral image data. Photogrammetric Engineering and Remote Sensing, 62(9), 1057-1066.

Gasparri, N.I., Parmuchi, M.G., Bono, J., Karszenbaum, H., Montenegro, C.L., 2010. Assessing multi-temporal Landsat 7 ETM+ images for estimating above-ground biomass in subtropical dry forests of Argentina. Journal of Arid Environments, 74, 1262-1270.

Giorgino, T., 2009. Computing and visualizing Dynamic Time Warping alignments in R: the dtw package. Journal of Statistical Software, 31(7), 1-24.

Gemmell, F. 1995. Effects of forest cover, terrain, and scale on timber volume estimation with Thematic Mapper data in a rocky mountain site. Remote Sensing of Environment, 51, 291-305.

Gemmell, F., 1998. An investigation of terrain effects on the inversion of a forest reflectance model. Remote Sensing of Environment, 65, 155-169.

Gemmell, F., 1999. Estimating conifer forest cover with Thematic Mapper data using reflectance model inversion and two spectral indices in a site with variable background characteristics. Remote Sensing of Environment, 69, 105-121.

Gemmell, F., Varjo, J., Strandstrom, M., 2001. Estimating forest cover in a boreal forest test site using thematic mapper data from two dates. Remote Sensing of Environment, 77, 197-211.

Goetz, S.T., Baccini, A., Laporte, N.T., Johns, T., Walker, W., Kellndorfer, J., Houghton, R.A., Sun, M., 2009. Mapping and monitoring carbon stocks with satellite observations: a comparison of methods. Carbon Balance and Management, 4(2), http://dx.doi.org/10.1186/1750-0680-4-2.

Gómez, C. 2006. Estimación de volumen de P. sylvestris L. mediante imágenes Landsat y QuickBird en el Sistema Central español. DEA dissertation. Universidad de Valladolid, Spain, 32 pp.

Gómez, C., Wulder, M.A., Montes, F., Delgado J.A., 2011a. Forest structural diversity characterization in Mediterranean pines of central Spain with QuickBird-2 imagery and canonical correlation analysis. Canadian Journal of Remote Sensing, 37(6), 628-642.

Gómez, C., White, J.C., Wulder, M.A., 2011b. Characterizing the state and processes of change in a dynamic forest environment using hierarchical spatio-temporal segmentation. Remote Sensing of Environment, 115, 1665-1679.

Gómez, C., Wulder, M.A., White, J.C., Montes, F., Delgado J.A., 2012. Characterizing 25 years of change in the area, distribution, and carbon stock of Mediterranean pines in Central Spain. International Journal of Remote Sensing, 33(17), 5546-5573. 
González-Alonso, F., Merino de Miguel, S., Roldán-Zamarrón, A., García-Gigorro, S., Cuevas, J.M., 2006. Forest biomass estimation through NDVI composites. The role of remote sensed data to assess Spanish forests as carbon sinks. International Journal of Remote Sensing, 27, 5409-5415.

Goodwin, N.R., Magnussen, S., Coops, N.C., Wulder, M.A., 2010. Curve fitting of time series Landsat imagery for characterising a mountain pine beetle infestation disturbance. International Journal of Remote Sensing, 31(12) 3263-3271.

Healey, S.P., Yang, Z., Cohen, W.B., Pierce, D.J., 2006. Application of two regressionbased methods to estimate the effects of partial harvest on forest structure using Landsat data. Remote Sensing of Environment, 101, 115-126.

Herrero, C., Bravo, F., 2012. Can we get an operational indicator of forest carbon sequestration? A case study from two forest regions in Spain. Ecological Indicators, 17, $120-126$

Houghton, R.A., 2005. Aboveground forest biomass and the global carbon balance. Global Change Biology, 11, 945-958.

Houghton, R.A., Butman, D., Bunn, A.G., Krankina, O.N., Schlesinger, P., Stone, T.A. 2007. Mapping Russian forest biomass with data from satellites and forest inventories. Environmental Research Letters, 2045032 (7pp)

Huang, Ch., Goward, S.N., Schleeweis, K., Thomas, N., Masek, J.G., Zhu, Z. 2009. Dynamics of national forests assessed using the Landsat record: Case studies in eastern United States. Remote Sensing of Environmen, 113, 1430-1442.

Jin, Y.Q., Liu, C., 1997. Biomass retrieval from high-dimensional active/passive remote sensing data by using artificial neural networks. International Journal of Remote Sensing, 18(4), 971-979.

Jin, S., Sader, S.A., 2005. Comparison of time series tasseled cap wetness and the normalized difference moisture index in detecting forest disturbances. Remote Sensing of Environment, 94, 364-372.

Kangas, A., Maltamo, M., 2006. Managing Forest Ecosystems: Forest Inventory: Methodology and Applications. Springer. Dordrecht, Netherlands.

Keith, H., Mackey, B.G., Lindenmayer, D.B. 2009. Re-evaluation of forest biomass carbon stocks and lessons from the world's most carbon-dense forests. Proceedings of the National Academy of Sciences of the United States, 106(28), 11635-11640.

Kennedy, R., Yang, Z., Cohen, W.B., 2010. Detecting trends in forest disturbance and recovery using yearly Landsat time series: 1. LandTrendr - Temporal segmentation algorithms. Remote Sensing of Environment, 114, 2897-2910. 
Kollmann, F., 1959. Tecnología de la madera y sus aplicaciones. Translation of second edition. In: German of 'Tecnologie des Holzes und der Holzwerkstoffe: mit 1194 Abbildungen im Text und 6 Tafeln'. Springer, Berlín, Germany.

Krankina, O.N., Harmon, M.E., Cohen, W.B., Oetter, D.R., Zyrina, O., Duane, M.V. 2004. Carbon stores, sinks, and sources in forests of Northwestern Russia: can we reconcile forest inventories with remote sensing results?. Climatic Change, 67, 257-272.

Kurz, W.A., Apps, M.J., 2006. Developing Canada's national forest carbon monitoring, accounting and reporting system to meet the reporting requirements of the Kyoto Protocol, Mitigation and Adaptation Strategies for Global Change, 11, 33-43

Kwak, D.A., Lee, W.K., Cho, H.K., Lee, S.H., Son, Y., Kafatos, M., Kim, S.R., 2010. Estimating stem volume and biomass of Pinus koraiensis using LiDAR data. Journal of Plant Research, 123, 421-432.

Labrecque, S., Fournier, R.A., Luther, J.E., Piercey, D., 2006. A comparison of four methods to map biomass from Landsat-TM and inventory data in western Newfoundland. Forest Ecology and Management, 226, 129-144.

Lefsky, M., Cohen, W.B., Spies, T.A., 2001. An evaluation of alternate remote sensing products for forest inventory, monitoring, and mapping of Douglas-fir forests in western Oregon. Canadian Journal of Forest Research 31, 78-87.

Lewis, S.L., Phillips, O.L., Baker, T.R., Lloyds, J., Malhi, Y., Almeida, S., Higuchi, N., Laurance, W.F., Neill, D.A., Silva, J.N.M., Terborgh, J., Torres Lezama, A., Vásquez Martínez, R., Brown, S., Chave, J., Kuebler, C., Nuñez Vargas, P., Vinceti, B., 2004. Concerted changes in tropical forest structure and dynamics: evidence from 50 South American long-term plots. Philosophical Transactions of the Royal Society B, 359, 421436.

Li, J., 2004. Wavelet-Based Feature Extraction for Improved Endmember Abundance Estimation in Linear Unmixing of Hyperspectral Signals. IEEE Transactions on Geoscience and Remote Sensing, 42(3), 644-649.

Lindsay, R.W., Percival, D.B., Rothrock, D.A., 1996. The discrete wavelet transform and the scale analysis of the surface properties of sea ice. IEEE Transactions on Geoscience and Remote Sensing, 34(3), 771-787.

Liski, J., Karjalainen, T., Pussinen, A., Nabuurs, G.J., Kauppi, P., 2000. Trees as carbon sinks and sources in the European Union. Environmental Science and Policy, 3, 91-97.

Liu, W., Song, C., Schroeder, T.A., Cohen, W.B., 2008. Predicting forest successional stages using multitemporal Landsat imagery with forest inventory and analysis data. International Journal of Remote Sensing, 29(13) 3855-3872. 
Lu, D., Mause, P., Brondizios, E., Moran, E., 2004. Change detection techniques. International Journal of Remote Sensing, 25, 2365-2407.

Lu, D., 2005. Aboveground biomass estimation using Landsat TM data in the Brazilian Amazon. International Journal of Remote Sensing, 26(12) 2509-2525.

Lu, D., Batistella, M., Moran, E., 2005. Satellite estimation of aboveground biomass and impacts of forest stand structure. Photogrammetric Engineering and Remote Sensing, 71(8), 967-974.

Lu, D., 2006. The potential and challenge of remote sensing-based biomass estimation. International Journal of Remote Sensing, 27, 1297-1328.

Lu, D., Chen, Q., Wang, G., Moran, E., Batistella, M., Zhang, M., Laurin, G.V., Saah, D., 2012. Aboveground Forest Biomass Estimation with Landsat and LiDAR Data and Uncertainty Analysis of the Estimates. International Journal of Forestry Research vol 2012, Article ID 436537, 16 pages, doi:10.1155/2012/436537

Mallat, S., Hwang, W.L., 1992. Singularity detection and processing with wavelets. IEEE Transactions on Information Theory, 38(2), 617-643.

Maselli, F., Chirici, G., Bottai, L., Corona, P., Marchetti, M., 2005. Estimation of Mediterranean forest attributes by the application of k-NN procedures to multitemporal Landsat ETM+ images. International Journal of Remote Sensing, 26(17), 3781-3796.

Martínez, B., Gilabert, M.A., 2009. Vegetation dynamics from NDVI time series analysis using the wavelet transform. Remote Sensing of the Environment, 113, 1823-1842.

Meyers, S.D., Kelly, B.G., O’Brien, J.J., 1993. An introduction to wavelet analysis in oceanography and meteorology: with application to the dispersion of Yanai waves. American Meteorological Society, 121, 2858-2866.

Mitchard, E. T. A., Saatchi, S. S., Woodhouse, I. H., Nangendo, G., Ribeiro, N. S., Williams, M., Ryan, M., Lewis, S.L., Feldpausch, T.R., Meir, P. 2009. Using satellite radar backscatter to predict above-ground woody biomass: A consistent relationship across four different African landscapes. Geophysical Research Letters, 36, L23401, doi:10.1029/2009GL040692

Montero, G. Muñoz, M., Donés, J., Rojo, A., 2004. Fijación de CO2 por Pinus sylvestris L. y Quercus pyrenaica Willd. en los montes "Pinar de Valsaín” y "Matas de Valsaín". Sistemas y Recursos Forestales, 13(2), 399-415.

Montero, G., Ruiz-Peinado, R., Muñoz, M., 2005. Producción de biomasa y fijación de $\mathrm{CO} 2$ por parte de los bosques españoles. Monografías INIA: Serie Forestal $n^{\circ} 13$, Madrid, $270 \mathrm{pp}$. 
Mutanga, O., Adam, E., Cho, M.Z., 2012. High density biomass estimation for wetland vegetation using WorldView-2 imagery and random forest regression algorithm. International Journal of Applied Earth Observation and Geoinformation 18, 399-406.

Muukkonen, P., Heiskanen J., 2007. Biomass estimation over a large area based on standwise forest inventory data and ASTER and MODIS satellite data: a possibility to verify carbon inventories. Remote Sensing of Environment, 107, 617-624.

Næsset, E., Gobakken, T., 2008. Estimation of above- and below-ground biomass across regions of the boreal forest zone using airborne laser. Remote Sensing of Environment, 112, 3079-3090.

Niedermeier, A., Romaneeben, E., Lehner, S., 2000. Detection of coastlines in SAR images using wavelet methods, IEEE Transactions on Geoscience and Remote Sensing, 38(5) 2270-2281.

Penman, J., Gytarsky, M., Hiraishi, T., Krug, T., Kruger, D., Pipatti, R., Buendia, L., Miwa, K., Ngara, T., Tanabe, K., Wagner, F., 2003. Good Practice Guidance for Land Use, Land-Use Change and Forestry. Intergovernmental Panel on Climate Change (IPCC), Hayama, Japan.

Percival, D.B., Wang, M., Overland, J.E., 2004. An introduction to wavelet analysis with applications to vegetation time series. Community Ecology, 5(1), 19-30.

Peterson, U., Nilson, T., 1993. Successional reflectance trajectories in northern temperate forests. International Journal of Remote Sensing, 14, 609-613.

Piao, Sh., Fang, J., Zhu, B., Tan, K., 2005. Forest biomass carbon stocks in China over the past 2 decades: Estimation based on integrated inventory and satellite data. Journal of Geophysical Research, 110, G01006, doi:10.1029/2005JG000014

Pflugmacher, D., Cohen, W.B., Kennedy, R.E., 2012. Using Landsat-derived disturbance history (1972-2010) to predict current forest structure. Remote Sensing of Environment, $122,146-165$.

Powell, S.L., Cohen, W.B., Healey, S.P., Kennedy, R.E., Moisen, G.G, Pierce, K.B., Ohmann, J.L., 2010. Quantification of live aboveground biomass dynamics with Landsat time-series and field inventory data: A comparison of empirical modeling approaches. Remote Sensing of Environment, 114, 1053-1068.

Rahman, M.M., Csaplovics, E., Koch, B., 2005. An efficient regression strategy for extracting forest biomass information from satellite sensor data. International Journal of Remote Sensing, 26 (7), 1511-1519.

Raja, R.A.A., Anand, V., Kumar, A.S., Maithani, S., Kumar, V.A., 2013. Wavelet Based Post Classification Change Detection Technique for Urban Growth Monitoring. Journal of Indian Society Remote Sensing, 41(1), 35-43. 
Ratanamahatana, Ch.A., Keogh, E., 2005. Three myths about Dynamic Time Warping data mining. SIAM International Conference on Data Mining (SDM), Newport Beach, California, April 21-23.

Rivas-Martínez, S., 1963. Estudio de la vegetación y flora de la Sierra de Guadarrama y Gredos. Anales del Instituto Botánico A.J. Cavanilles, 21, 5-325.

Ruiz-Peinado R., Río M., Montero G., 2011. New models for estimating the carbon sink capacity of Spanish softwood species. Forest Systems, 20 (1), 176-188.

Saatchi, S.S., Houghton, R.A., Dos Santos Alvala, R.C., Soares, J.V., Yu, Y., 2007. Distribution of aboveground live biomass in the Amazon basin. Global Change Biology, $13,816-837$.

Salvador, R., Pons, X., 1998. On the applicability of Landsat TM images to Mediterranean forest inventories. Forest Ecology and Management, 104, 193-208.

Sakamoto, T., Yokozawa, M., Toritani, H., Shibayama, M., Ishitsuka, N., Ohno, H., 2005. A phenology detection method using time-series MODIS data. Remote Sensing of Environment, 96, 366-374.

Schroeder, T.A., Cohen, W.B., Yang, Z., 2007. Patterns of forest regrowth following clearcutting in western Oregon as determined from a Landsat time-series. Forest Ecology and Management, 243, 259-273.

Serrada, R. 2008. Apuntes de selvicultura. Servicio de publicaciones. EUIT Forestal. Madrid.

Simhadri, K.K., Iyengar, S.S., Holyer, R.J., Lybanon, M., Zachary, J.M., 1998. Waveletbased feature extraction from oceanographic images. IEEE Transactions on Geoscience and Remote Sensing, 36(3), 767-778.

Smeets, E.M.W., Faaij, A.P.C., 2007. Bioenergy potentials from forestry in 2050. Climatic Change, 81(3), 353-390.

Song, C., Woodcock, C.E., Li, X., 2002. The spectral/temporal manifestation of forest succession in optical imagery: the potential of multitemporal imagery. Remote Sensing of Environment, 82, 285-302.

Song, C., Schroeder, T.A., Cohen, W.B., 2007. Predicting temperate conifer forest successional stage distributions with multitemporal Landsat Thematic Mapper imagery. Remote Sensing of Environment, 106, 228-237.

Sun, G., Ranson, K.J., Guo, Z., Zhang, Z., Montesano, P., Kimes, D., 2011. Forest biomass mapping from lidar and radar synergies. Remote Sensing of Environment, 115, 2906-2916. 
Tan, K., Piao, S., Peng, C., Fang, J., 2007. Satellite-based estimation of biomass carbon stocks for northeast China's forests between 1982 and 1999. Forest Ecology and Management, 240, 114-121.

Turner, D.P., Cohen, W.B., Kennedy, R.E., Fassnacht, K.S., Briggs, J.M., 1999. Relationship between leaf area index and Landsat TM spectral vegetation indices across three temperate zone sites. Remote Sensing of Environment, 70, 52-68.

Vázquez de la Cueva, A., 2008. Structural attributes of three forest types in central Spain and Landsat ETM+ information evaluated with redundancy analysis. International Journal of Remote Sensing, 29 (19), 5657-5676.

Velichko, V.M., Zagoruyko, N.G., 1970. Automatic recognition of 200 words. International Journal of Man-Machine Studies, 2, 223-234.

Vicente-Serrano, S.M., Perez-Cabello, F., Lasanta, T., 2008. Assessment of radiometric correction techniques in analyzing vegetation variability and change using time series of Landsat images. Remote Sensing of Environment, 112, 3916-3934.

Wang, G., Oyana, T., Zhang, M., Adu-Prah, S., Zeng, S., Lin, H., Se, J., 2009. Mapping and spatial uncertainty analysis of forest vegetation carbon by combining national forest inventory data and satellite images. Forest Ecology and Management, 258, 1275-1283.

Wulder, M.A., White, J.C., Fournier, R.A., Luther, J.E., Magnussen, S., 2008. Spatially explicit large area biomass estimation: three approaches using forest inventory and remotely sensed imagery and GIS. Sensors, 8, 529-560.

Wulder, M. A., Masek, J. G., Cohen, W. B., Loveland, T. R., Woodcock, C. E., 2012. Opening the archive: How free data has enabled the science and monitoring promise of Landsat. Remote Sensing of Environment, 122, 2-10.

Yu, Y., Saatchi, S., Heath, L.S., LaPoint, E., Myneni, R., Knyazikhin, Y., 2010. Regional distribution of forest height and biomass from multisensor data fusion, Journal of Geophysical Research, 115, G00E12, doi:10.1029/2009JG000995.

Zhou, J., Civco, D.L., Silander, J.A., 1998. A wavelet transform method to merge Landsat TM and SPOT panchromatic data. International Journal of Remote Sensing, 19(4), 743757.

Zhu, Z., Woodcock, C.E., Olofsson, P., 2012. Continuous monitoring of forest disturbance using all available Landsat images. Remote Sensing of Environment, 122, 75-91. 